Aus dem Institut für Tierzucht und Haustiergenetik der Georg-August-Universität Göttingen

\title{
Untersuchungen über die Eignung biochemischer und molekulargenetischer Marker für eine Identifizierung von verschiedenen Störarten und deren Hybriden
}

\author{
Dissertation \\ zur Erlangung des Doktorgrades \\ der Fakultät für Agrarwissenschaften \\ der Georg-August-Universität Göttingen
}

vorgelegt von

Ingo Manfred Jenneckens

geboren in Helmarshausen

Göttingen, im Juli 1999

Die Untersuchungen wurden mit dankenswerter Unterstützung der Deutschen Forschungsgemeinschaft durchgeführt 
D7

Referentin: Prof. Dr. G. Hörstgen-Schwark

Korreferent: Prof. Dr. Dr. B. Brenig

Tag der mündlichen Prüfung: 08. Juli 1999 
Meiner Antje und Familie 



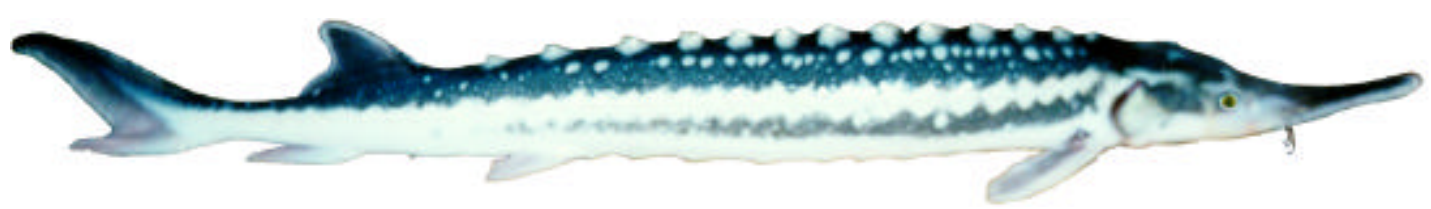

WHEREVER THEY OCCUR IN THE WILD, IN NORTH AMERICA, EUROPE AND ASIA, THESE FISHES ARE IN TROUBLE 



\section{Inhaltsverzeichnis}

Abbildungsverzeichnis

Tabellenverzeichnis

IX

Abkürzungsverzeichnis

XII

1

Einleitung

2.1 Die Arten innerhalb der Ordnung Acipenseriformes

2.3 Überblick über die Zytogenetik der Acipenseriformes

2.3.1 Karyotypen, DNA-Gehalt und Ploidielevel der Acipenseriformes

2.3.2 Ploidisierungsereignisse in der Evolution der Acipenseriformes

2.4 Aquakulturelle Bedeutung der Acipenseriformes

2.5 Methoden zur Spezieserkennung und Populationsdifferenzierung

2.5.1 Identifizierung von Störkaviar

2.5.2 Identifizierung von Individuen

2.5.3 Identifizierung und Charakterisierung von Populationen

$\begin{array}{lll}\text { 3.1.3 Puffer und Stammlösungen } & 24\end{array}$

3.1.4 Chemikalien, Enzyme, Verbrauchsmaterial und Geräte 25

$\begin{array}{lll}3.1 .4 .1 & \text { Chemikalien } & 25\end{array}$

$\begin{array}{lll}3.1 .4 .2 & \text { Enzyme } & 27\end{array}$

$\begin{array}{lll}\text { 3.1.4.3 Verbrauchsmaterial } & 28\end{array}$

$\begin{array}{lll}\text { 3.1.4.4 Geräte } 28 & 28\end{array}$ 
3.2 Methoden 29

$\begin{array}{lll}\text { 3.2.1 Sterilisationstechniken } & 29\end{array}$

$\begin{array}{lll}\text { 3.2.2 } & 30\end{array}$

3.2.3 Biochemische Untersuchungsmethoden 31

3.2.3.1 Verwendete Trennmedien und Probenapplikation 31

3.2.3.1.1 Agarosegele 31

3.2.3.1.2 Stärkegele 32

3.2.3.1.3 Native Polyacrylamidgele 32

3.2.3.2 Untersuchte Allozymsysteme und Plasmaproteine 33

3.2.3.2.1 Adenosindeaminase (ADA, E.C. 3.5.4.4) 34

3.2.3.2.2 Adenylatkinase (AK, E.C. 2.7.4.3) 34

3.2.3.2.3 Albumine (ALB) und Transferrine (TF) 35

3.2.3.2.4 Alkalische Phosphatase (AKP, E.C. 3.1.3.1) 36

3.2.3.2.5 Carboanhydrase (CA, E.C. 4.2.1.1) 37

3.2.3.2.6 Diaphorase (DIA, E.C. 1.6.9.1) 37

3.2.3.2.7 Esterase-D (EST-D, E.C. 3.1.1.1) 38

3.2.3.2.8 $\alpha$-Glycerophosphatdehydrogenase ( $\alpha$-GPDH, E.C. 1.1.1.8) 38

3.2.3.2.9 Glucosephosphatisomerase (GPI, E.C. 5.3.1.9) 39

3.2.3.2.10 Laktatdehydrogenase (LDH, E.C. 1.1.1.27) 40

3.2.3.2.11 Phosphoglucomutase (PGM, E.C. 2.7.5.1) 41

3.2.3.2.12 6-Phosphogluconat-Dehydrogenase (6PGD, E.C. 1.1.1.43) 41

3.2.4 Molekularbiologische Methoden 42

3.2.4.1 Isolierung von Nukleinsäuren $\quad 42$

3.2.4.1.1 Isolierung von DNA aus Blut durch Aussalzung 42

3.2.4.1.2 Freisetzung von DNA aus Blut mittels Chelex ${ }^{\circledR} 100$

3.2.4.1.3 Isolierung von DNA aus Kaviar 44

3.2.4.1.4 Isolierung von DNA-Fragmenten aus Agarosegelen 45

3.2.4.2 Reinigung und Fällung von Nukleinsäuren 47

$\begin{array}{lll}\text { 3.2.4.2.1 Reinigung mittels Anionenaustauschchromatographie } & 47\end{array}$

3.2.4.2.2 DNA-Fällung mittels Natriumacetat und Ethanol 48

$\begin{array}{lll}\text { 3.2.4.3 Konzentrationsbestimmung von DNA } & 48\end{array}$ 
3.2.4.4 Elektrophoretische Trennung von DNA 49

3.2.4.4.1 Agarose-Gelelektrophorese 50

3.2.4.4.2 Native Polyacrylamid-Gelelektrophorese 50

3.2.4.4.3 Denaturierende Polyacrylamid-Gelelektrophorese 52

3.2.4.4.4 Elektrophorese im viskosen Polymer 54

3.2.4.5 Detektion von DNA nach der gelelektrophoretischen Auftrennung 55

3.2.4.5.1 Detektion im Agarosegel 55

3.2.4.5.2 Detektion im Polyacrylamidgel durch Silberfärbung 55

3.2.4.5.3 Detektion im Polyacrylamidgel durch Fluoreszenzmarkierung 56

3.2.4.5.4 Detektion im Polymer durch Fluoreszenzmarkierung 57

3.2.4.6 Anwendungsbereiche der Polymerase Kettenreaktion (PCR) 57

3.2.4.6.1 Amplifikation von Mikrosatelliten-Loci 58

3.2.4.6.2 Random Amplified Polymorphic DNA (RAPD) 60

3.2.4.6.3 Short Interspersed Elements-PCR (SINE-PCR) 63

3.2.4.6.4 Inter-Simple Sequence Repeat PCR (Inter-SSR PCR) 63

3.2.4.6.5 Amplified Fragment Length Polymorphism (AFLP) 65

3.2.4.6.6 Amplifikation des mitochondrialen Cytochrom b 67

$\begin{array}{lll}\text { 3.2.4.7 Sequenzierung } & 68\end{array}$

3.2.5 Dokumentation der Untersuchungsergebnisse 69

3.2.6 Berechnungen und statistische Auswertungen 69

3.2.6.1 Auswertung der Mikrosatelliten-Daten 69

$\begin{array}{lll}\text { 3.2.6.2 Auswertung der AFLP-Daten } & 70\end{array}$

$\begin{array}{lll}\text { 3.2.6.3 Phylogenetische Analysen der mt Cyt b-Daten } & 71\end{array}$

$4 \quad$ Ergebnisse $\quad 72$

4.1 Ergebnisse der biochemischen Untersuchungen 72

$\begin{array}{lll}\text { 4.1.1 } & \text { Alkalische Phosphatase (AK) }\end{array}$

$\begin{array}{lll}\text { 4.1.2 Albumine (ALB) } & 74\end{array}$

$\begin{array}{lll}\text { 4.1.3 Esterase D (EST-D) } & 76\end{array}$

$\begin{array}{lll}\text { 4.1.4 Glucosephosphatisomerase (GPI) } & 77\end{array}$

$\begin{array}{lll}\text { 4.1.5 Phosphoglucomutase (PGM) } & 78\end{array}$ 
$\begin{array}{lll}4.2 & \text { Ergebnisse der molekulargenetischen Untersuchungen } & 79\end{array}$

4.2.1 Ergebnisse der Mikrosatelliten-Analyse 80

4.2.1.1 Mikrosatelliten-Locus LS-19 83

4.2.1.2 Mikrosatelliten-Locus LS-34 85

4.2.1.3 Mikrosatelliten-Locus LS-39 86

4.2.1.4 Mikrosatelliten-Locus LS-54 88

4.2.1.5 Mikrosatelliten-Locus LS-68 90

4.2.1.6 Test der Stichproben auf Hardy-Weinberg-Gleichgewicht 93

4.2.1.7 Auswahl von potentiell unverwandten Individuen innerhalb

$\begin{array}{ll}\text { der Spezies } & 94\end{array}$

4.2.2 Ergebnisse der RAPD 94

4.2.2.1 Ergebnisse der Oligonukleotide des Operon Kit H 95

4.2.2.3 Wiederholbarkeit generierter Fragmentmuster 98

$\begin{array}{lll}\text { 4.2.3 } & \text { Ergebnisse der SINE-PCR }\end{array}$

$\begin{array}{lll}\text { 4.2.4 Ergebnisse der Inter-SSR PCR } & 100\end{array}$

$\begin{array}{lll}\text { 4.2.5 } & \text { Ergebnisse des AFLP } & 103\end{array}$

4.2.5.1 Auswertung der generierten Fragmentmuster 103

4.2.5.2 Berechnung des genetischen Distanzmaßes $\mathrm{D}_{\mathrm{A}}$ und

4.2.6 Ergebnisse des mitochondrialen Cytochrom b (mt Cyt b) 109

$\begin{array}{lll}\text { 4.2.6.1 Untersuchung eines partiellen mt Cyt b-Fragments im SSCP } & 109\end{array}$

$\begin{array}{lll}\text { 4.2.6.2 Sequenzierungsergebnisse des mt Cyt b } & 110\end{array}$

4.2.6.3 Konstruktion phylogenetischer Stammbäume anhand des mt Cyt b 115

$5 \quad$ Diskussion

5.1 Die Eignung verschiedener Marker für eine Identifizierung der $\begin{array}{ll}\text { Störarten } & 119\end{array}$

$\begin{array}{lll}\text { 5.1.1 Biochemische Marker } & 119\end{array}$

$\begin{array}{ll}\text { 5.1.2 Molekularbiologische Marker } & 122\end{array}$

$\begin{array}{lll}\text { 5.1.2.1 Mikrosatelliten-Loci } & 122\end{array}$ 
5.1.2.2 RAPD

5.1.2.3 SINE-PCR

5.1.2.4 Inter-SSR PCR

5.1.2.5 AFLP

5.1.2.6 Mitochondriales Cytochrom b

5.3 Molekulare Phylogenese der Acipenseriformes

5.3.1 Dendrogramme auf der Basis der AFLP-Daten

5.3.2 Dendrogramme auf der Basis der Sequenzinformationen des

$$
\text { mt Cyt b }
$$

5.4 Schlussbetrachtung und Ausblick für die Entwicklung von artcharakteristischen Markern bei Acipenseriformes 


\section{Abbildungsverzeichnis}

Abb. 1 Kladogramm über die phylogenetischen Beziehungen innerhalb der

Actinopterygii

Abb. 2 Gegenüberstellung der phylogenetischen Kladogramme hinsichtlich

der konträren Ansichten über die Beziehung der Gattungen

rezenter Störe

Abb. 3 Gegenüberstellung der anhand verschiedener Unter-

suchungsmethoden vermuteten verwandtschaftlichen Beziehungen der Arten innerhalb der Familie Acipenserinae

Abb. 4 Entwicklung der Störproduktion und deren Wertschöpfung in der Aquakultur

Abb. 5 Pherogramm der beobachteten Phänotypen an der AK

Abb. 6 Beispiele verschiedener Phänotypen in dem System ALB

Abb. 7 Beispiele verschiedener Phänotypen am Locus EST-D

Abb. 8 Pherogramm der GPI von Individuen der verschiedenen Spezies

Abb. 9 Pherogramm der PGM von Individuen der verschiedenen Spezies

Abb. 10 Beispiele für die Ableitung der Allelverteilung für zwei Individuen von A. gueldenstaedtii an dem Mikrosatelliten-Locus LS-39

Abb. 11 Elektropherogramm eines A. gueldenstaedtii mit vier Allelen am Mikrosatelliten-Locus LS-19

Abb. 12 Beispiel für ein detektiertes Nullallel eines A. baerii-Individuums an dem Mikrosatelliten-Locus LS-19

Abb. 13 Beispiel für ein heterozygotes Individuum der Spezies A. ruthenus 86 an dem Mikrosatelliten-Locus LS-34 
Abb. 14 Vergleich der Amplifikationsprodukte des Mikrosatelliten-Locus LS-39 von drei verschiedenen Kaviarsorten

Abb. 15 Nicht quantifizierbares Peakmuster am Mikrosatelliten-Locus LS-68 bei einem Individuum der Spezies A. baerii

Abb. 16 Im Agarosegel visualisierte Amplifikationsprodukte des RADPPrimers OPH-06 in dessen Voruntersuchung an je drei unverwandten Individuen der fünf Spezies

Abb. 17 Darstellung der mit dem Primer OPH-06 generierten 96 Fragmentmuster bei sieben zusätzlich untersuchten Individuen der Art A. gueldenstaedtii

Abb. 18 Darstellung der in der Voruntersuchung mit dem Primer Long-5 generierten Fragmentmuster

Abb. 19 Darstellung der mit Primer Long-5 generierten Fragmentmuster an 98 zehn Hybriden der Kreuzung H. huso x A. ruthenus

Abb. 20 Beispiel zur Wiederholbarkeit der individuellen Fragmentmuster 99 der Primer OPH-06, Long-5 und Long 11 an einem Individuum der Spezies A. ruthenus

Abb. 21 Generierte Amplifikationsprodukte bei Individuen der fünf Spezies 100 in der SINE-PCR

Abb. 22 Darstellung der generierten Amplifikationsprodukte des Primers 101 ISSR2 im silbergefärbten Polyacrylamidgel

Abb. 23 Erzeugte Fragmentmuster bei Verwendung des Primers ISSR4 102

Abb. 24 Image des LiCor der im AFLP generierten Fragmentmuster für je 104 fünf Individuen der untersuchten Spezies

Abb. 25 Phylogenetische Stammbäume auf der Basis der AFLP-Daten 107 unter der Annahme von Di- bzw. Tetraploidie bei den Spezies 
Abb. 26 Phylogenetische Stammbäume auf der Basis der AFLP-Daten 108 unter der Annahme von Tetra- bzw. Octaploidie bei den Spezies

Abb. 27 Darstellung der inter- und intraspezifisch detektierten Haplotypen eines 370 bp grossen Fragments im SSCP nach der Silberfärbung

Abb. 28 Aus der Nukleotidsequenz deduzierte Aminosäuresequenz des mt Cyt b von A.baerii

Abb. 29 Phylogenetischer Konsensstammbaum verschiedener Acipenseriformes auf der Basis der Aminosäuresequenzen des mt Cyt b nach dem Bootstrap-Test

Abb. 30 Phylogenetischer Konsensstammbaum verschiedener Acipenseriformes auf der Basis stiller Nukleotidsubstitutionen im mt Cyt b nach dem Bootstrap-Test

Abb. 31 Charakteristika von LS-19 dargestellt an einem heterozygoten Individuum der Spezies A. stellatus

Abb. 32 Vergleich der in dieser Arbeit ermittelten Nukleotid- und 138 deduzierten Aminosäuresequenz von $P$. spathula mit dem 3'-Terminus der in der EMBL-Datenbank erhältlichen Sequenz AF006183 dieser Spezies

Abb. A-1 Vergleich der für das mitochondriale Cytochrom b kodierenden Nukleotidsequenzen verschiedener Acipenseriformes

Abb. A-2 Vergleich der aus der Nukleotidsequenzen deduzierten 184 Aminosäuresequenzen der untersuchten Acipenseriformes 


\section{Tabellenverzeichnis}

Tab. 1 Überblick über die direkt nachgewiesene bzw. abgeleitete Zugehörigkeit bisher untersuchter Störarten zu den bislang bekannten chromosomalen Gruppen

Tab. 2 Herkunft und Probenumfang der Störarten und -hybriden

Tab. 3 Überblick über die verwendeten Primer zur Amplifikation der 59 acipenseriden Mikrosatelliten-Loci, deren Wiederholungsmotiv nach MAY et al. (1997), die Fluoreszensmarkierung der Vorwärtsprimer sowie der $\mathrm{MgCh}_{2}$-Konzentration in dem PCRAnsatz

Tab. 4 Nukleotidsequenz der in der RAPD verwendeten Primer

Tab. 5 Im Rahmen des AFLP verwendete Oligonukleotide

Tab. 6: Verwendete Primer für die Amplifikation des vollständigen bzw. partiellen mitochondrialen Cytochrom b (mt Cyt b) und deren Annealingpositionen (Pos.)

Tab. 7 Die Phänotypfrequenzen der fünf Störspezies an dem Locus AK

Tab. 8 Gegenüberstellung der AK-Phänotypfrequenzen zwischen den 74 verschiedenen Herkünften der Spezies A. baerii

Tab. 9 Phänotypfrequenzen der untersuchten Spezies an dem 75 Plasmaprotein ALB

Tab. 10 Phänotypfrequenzen der fünf Acipenserinae an dem EST-D76 Locus

Tab. 11 Phänotypfrequenzen der fünf Störarten am GPI-Locus 
Tab. 12 Phänotypfrequenzen der untersuchten Störspezies an dem PGM79 Locus

Tab. 13 Übersicht über den Amplifikationserfolg und die Auswertbarkeit 81 der neun untersuchten Mikrosatelliten-Loci

Tab. 14 Beobachtete Allele und berechnete Allelfrequenzen an dem Locus 84 LS-19

Tab. 15 Beobachtete Allele und berechnete Allelfrequenzen an dem Locus 85 LS-34

Tab. 16 Beobachtete Allele und berechnete Allelfrequenzen an dem Locus LS-39

Tab. 17 Beobachtete Allele und berechnete Allelfrequenzen an dem Locus 89 LS-54

Tab. 18 Beobachtete Allele der fünf Spezies an dem Mikrosatelliten-Locus 91 LS-68

Tab. 19 Test der Spezies und Herkünfte innerhalb der Spezies auf Hardy93 Weinberg-Gleichgewicht

Tab. 20 Eckdaten der ausgewerteten AFLP-Fragmente innerhalb der fünf untersuchten Spezies

Tab. 21 Mittlere Ähnlichkeitindices und deren Standardabweichungen 105 zwischen Individuen innerhalb einer Spezies

Tab. 22 Durchschnittliche genetische $D_{A}$-Distanzen zwischen den fünf 106 Spezies 
Tab. 23 Übersicht über die durchschnittliche Basenfrequenz im mt Cyt b sowie deren Frequenzen an den drei Nukleotidpositionen der Codons über alle Individuen und Spezies der betrachteten Acipenseriformes

Tab. 24 Vergleich der Aminosäuren an den variablen Positionen im mt Cyt $\mathrm{b}$ verschiedener Acipenseriformes

Tab. 25 Phänotypfrequenzen der fünf Störspezies an dem System PGM bei Postulierung der duplizierten Loci PGM-1 und PGM-2

Tab. 26 Auswirkungen des Ploidiestatus und der Anzahl an beobachteten 143 rezessiven Genotypen (Q) von zehn untersuchten Individuen auf die Berechnung der rezessiven Allelfrequenz (q) an einem Locus (x) 


\section{Abkürzungsverzeichnis}

$\alpha$-GPDH $\quad \alpha$-Glycerophosphatdehydrogenase

1D-PAGE Eindimensionale Polyacrylamid-Gelelektrophorese

6PGD 6-Phosphogluconat-Dehydrogenase

A

Adenin

A.

Acipenser

ADA

Adenosindeaminase

ADP

Adenosindiphosphat

AFLP

Amplifizierter Fragmentlängenpolymorphimus

AK

Adenylatkinase

AKP

Alkalische Phosphatase

ALB

Albumine

AT

DNA-Hybridisierungstemperatur

ATP

Adenosintriphosphat

bp

Basenpaare

BSA

Bovines Serumalbumin

C

Cytosin

CA

Carboanhydrase

cDNA

komplementäre Desoxyribonukleinsäure

CTAB

Cetyltrimethylammoniumbromid

D-loop

Mitochondriale displacement-Loop (Kontrollregion)

$\mathrm{D}_{\mathrm{A}}$

Genetisches Distanzmaß nach NEI et al. (1983)

dATP

Desoxyadenin-5'-Triphosphat

DCIP

Dichlorophenol-Indophenol

$\mathrm{dCTP}$

Desoxycytosin-5'-Triphosphat

$\mathrm{ddH}_{2} \mathrm{O}$

doppelt destilliertes Wasser

ddNTP

Didesoxynucleotid-5', 3'-Triphosphate

dGTP

Desoxyguanin-5'-Triphosphat

DIA

Diaphorase

DNA

Desoxyribonukleinsäure

dNTP

Desoxynucleotid-5'-Triphosphate 


\begin{tabular}{|c|c|}
\hline DTT & Dithiothreitol \\
\hline dTTP & Desoxythymin-5'-Triphosphat \\
\hline E.C. & Enzymklassifizierungsnummer \\
\hline EDTA & Ethylendinitrilotetraessigsäure \\
\hline EST-D & Esterase-D \\
\hline ff. & folgende \\
\hline g & Erdbeschleunigung $\left(9,81 \mathrm{~m} / \mathrm{s}^{2}\right)$, Gramm \\
\hline G & Guanin \\
\hline GPI & Glucosephosphatisomerase \\
\hline$H$. & Huso \\
\hline HPLC & Hochdruckflüssigchromatographie \\
\hline HWG & Hardy-Weinberg-Gleichgewicht \\
\hline $\mathrm{IE}$ & Internationale Einheit(en) \\
\hline IEF & Isoelektrische Fokussierung \\
\hline Ig & Immunglobulin \\
\hline Inter-SSR & Zwischen Mikrosatelliten \\
\hline IRD & Infrared \\
\hline $\mathrm{kb}$ & Kilobasenpaare \\
\hline LDH & Laktatdehydrogenase \\
\hline mer & Nukleotidanzahl eines Primers \\
\hline Mio. & Millionen \\
\hline $\mathrm{mt}$ & mitochondrial \\
\hline mt Cyt b & mitochondriales Cytochrom b \\
\hline MTT & Thiazolylblau \\
\hline n.s. & nicht signifikant \\
\hline NAD & $\beta$-Nicotinamid-Adenindinucleotid \\
\hline $\mathrm{NADH}$ & $\beta$-Nicotinamid-Adenindinucleotid, reduziert \\
\hline NADP & $\beta$-Nicotinamid-Adenindinucleotidphosphat \\
\hline NOR & Nucleus-Organisator \\
\hline OD & Optische Dichte \\
\hline $\mathrm{p}$ & Irrtumswahrscheinlichkeit \\
\hline$P$. & Polyodon, Psephurus, Polypterus \\
\hline
\end{tabular}


PCR Polymerase Kettenreaktion

PGM

$\mathrm{pH}$

PMS

Pos.

RAPD

RFLP

RNA

rRNA

$S$.

SDS

SINE

SSCP

$\mathrm{T}$

$T a q$

TBE

TEMED

$\mathrm{TF}$

Tris

tRNA $^{\mathrm{Glu}}$

tRNA $^{\text {Lys }}$

TSR

UPGMA

UPM

UV

$\mathrm{v} / \mathrm{v}$

Vol

$\mathrm{w} / \mathrm{v}$
Phosphoglucomutase

Negativer dekadischer Logarithmus der Protonenkonzentration

Phenazinmethosulfat

Position

Zufällig amplifizierte polymorphe DNA

Restriktionsfragment-Längenpolymorphismus

Ribonukleinsäure

Ribosomale Ribonukleinsäure

Scaphirhynchus

Natrium-Dodecylsulphat

Kurze repetitive DNA-Sequenzen im Genom

Einzelstrang-Konformationspolymorphismus

Thymin

Thermus aquaticus

Tris-Borat-EDTA

$\mathrm{N}, \mathrm{N}, \mathrm{N}$ ',N'-Tetramethylethylendiamin

Transferrin

Tris-(hydroxymethyl)aminomethan

Transfer-Ribonukleinsäure der Aminosäure Glutamin

Transfer-Ribonukleinsäure der Aminosäure Lysin

„Template suppression reagent“

„Unweighted pair group method with arithmetic mean“

Umdrehungen pro Minute

Ultraviolett

Volumen pro Volumen

Volumen

Gewicht pro Volumen 


\section{$1 \quad$ Einleitung}

Die Ordnung der Acipenseriformes aus der Überklasse der Pisces umfasst nach heutigem Kenntnisstand 27 verschiedene existente Arten. Ein Großteil dieser Arten ist in seinen natürlichen Beständen gefährdet, einige sind sogar vom Aussterben bedroht. Die Ursachen hierfür sind mannigfaltig. Bei den drei Arten Acipenser stellatus, Acipenser gueldenstaedtii und Huso huso liegt der Hauptgrund in einer massiven Überfischung der Populationen, da sie die Hauptlieferanten von Stör-Kaviar sind. Zudem wurden durch wasserbauliche Maßnahmen Laichplätze vernichtet oder der Zugang zu diesen verhindert. Ein weiteres Problem stellt die Wasserverschmutzung dar, die einen negativen Einfluss auf die Fertilität adulter und auf die Schlupf- und Überlebensrate juveniler Tiere besitzt. Künstliche Besatzmaßnahmen finden daher zur Stützung der natürlichen Populationen statt.

Verschiedene Störarten haben sich ausserdem als eine interessante Alternative zu den konventionell in der Aquakultur gehaltenen Fischspezies erwiesen. Das ökonomisch wertvollste Erzeugnis der meisten Acipenseriformes stellt hierbei der Rogen für die Kaviarproduktion dar. Mit Störfleisch sind ebenfalls hohe Markterlöse erzielbar.

Neben künstlich erstellten Artkreuzungen kommen in der Natur Arthybridisierungen zwischen verschiedenen Störspezies bei der gemeinsamen Nutzung von Laichplätzen vor. Hier stellt sich häufig das Problem, dass einige Arthybriden morphologisch nicht von einer oder beiden Elternarten unterschieden werden können. Die Tatsache, dass bestimmte Arthybriden reproduktionsfähig und somit weitere Hybridisierungen bzw. Rückkreuzungen möglich sind, kommt erschwerend hinzu.

Auf diesem gesamten Hintergrund ist eine zweifelsfreie Erkennung von Störindividuen eine Grundvoraussetzung sowohl für Zucht- als auch für Besatzmaßnahmen. Einen Beitrag hierzu soll diese Arbeit liefern. Ihr Ziel ist die Identifizierung von Stören unter Verwendung biochemischer und molekulargenetischer Marker. Als Untersuchungsmaterial standen Blutproben von Tieren verschiedener Eurasischer Arten und Arthybriden zur Verfügung. Unter dem Aspekt zum Teil kontroverser Diskussionen in der Literatur bezüglich der phylogenetischen Einordnung der Arten sowie der Uneinigkeit über den Ploidiestatus werden zudem mögliche Lösungsansätze zu diesen Problematiken aufgezeigt. 


\section{$2 \quad$ Literaturübersicht}

\subsection{Die Arten innerhalb der Ordnung Acipenseriformes}

Nach heutigem Kenntnisstand enthält die Ordnung der Acipenseriformes 27 rezente Arten, die sechs verschiedenen Gattungen angehören (BIRSTEIN 1993, BEMIS \& KYNARD 1997, BIRSTEIN \& Bemis 1997, BIRSTEIN \& DESAlle 1998). Sämtliche Spezies sind dabei nur auf der Nordhalbkugel der Erde vertreten (ROCHARD et al. 1990, BEMIS \& KYNARD 1997). In der Literatur auftauchende Fragen wie "How many valid species of Acipenser should we recognize" (BEMIS et al. 1997a) und "How many species are there within the genus Acipenser" (BIRSTEIN \& BEMIS 1997) zeigen aber, dass letztendlich keine endgültige Klarheit über die exakte Anzahl an Spezies - dies gilt insbesondere innerhalb der Gattung Acipenser - besteht. Letztere Autoren äußern sogar die Befürchtung, dass aufgrund der in Europa und Asien bestehenden Überfischung und Habitatzerstörung bislang unbekannte Störarten vor deren Entdeckung bzw. Charakterisierung eliminiert sein könnten. Des Weiteren waren sie der Ansicht, dass die Konfusion über die Anzahl innerhalb eines Refugiums lebender Spezies zum einen in der häufig vorkommenden morphologischen und metristischen Ähnlichkeit bestimmter Störspezies, welche insbesonders für die Juvenilphase gilt, begründet liegen kann. Zum anderen erschwert eine zum Teil nicht unerhebliche individuelle morphologische Variation innerhalb einer Art zusätzlich deren Charakterisierung (BEMIS et al. 1997a, BIRSTEIN et al. 1997b). So existieren bis heute kontroverse Ansichten darüber, ob Acipenser persicus eine eigenständige Art ist (VLASENKO et al. 1989a, BIRSTEIN \& DESALLE 1998) oder als eine Subspezies von A. gueldenstaedtii betrachtet werden sollte (ROCHARD et al. 1990). Ein weiteres Problem stellt die natürlich vorkommende Hybridisierung zwischen Arten dar (Übersicht bei BIRSTEIN et al. 1997b). Oftmals können Arthybriden dabei nicht von deren Elternarten unterschieden werden (BIRSTEIN \& BEMIS 1997).

Neben der Ungewissheit über die exakte Anzahl an Spezies innerhalb der Gattung der Acipenser stellte sich die Frage, welche wissenschaftlichen Namen für einige der Arten verwendet werden sollten (BIRSTEIN \& BEMIS 1997). Zudem wurden in der Literatur für die meisten Störarten mehrere Synonyme benutzt (Übersicht bei HOCHLEITHNER 1996), 
welche zu Verwirrungen führten. So erkannten z.B. ROCHARD et al. (1990) insgesamt 17 verschiedene Arten innerhalb Acipenser an. A. persicus sprachen sie dabei explizit den Artstatus ab, führten dafür aber A. sinensis und A. kikuchii als unterschiedliche Spezies auf. Beide Namen sind aber Synonyme für ein und dieselbe Art (Übersicht bei HOCHLEITHNER 1996). Darüber hinaus waren unterschiedliche Schreibweisen bezüglich einiger Artnamen in verschiedenen Quellen zu finden. Die im Rahmen dieser Arbeit verwendeten Namen basieren auf den von BEMIS et al. (1997b) für die Spezies in dem Journal Environmental Biology of Fishes 1997, Ausgabe 48 standardisierten Bezeichnungen.

Trotz der aufgeführten Problematiken sollen die auf Basis molekulargenetischer Untersuchungen definierten Arten der Acipenseriformes (BIRSTEIN et al. 1997a, BIRSTEIN \& DESALLE 1998) an dieser Stelle in alphabetischer Reihenfolge aufgeführt werden. BIRSTEIN \& BEMIS (1997) kamen zu dem Schluss, dass nur die Spezies A. baerii und A. oxyrinchus aufgrund eingehender morphologischer bzw. genetischer Untersuchungen valide Subspezies enthielten. In der Literatur wurden auch für andere Arten verschiedene Subspezies und zum Teil auch Populationen beschrieben, welche aber BIRSTEIN \& BEMIS (1997) als nicht gesichert ansahen. Daher werden diese hier nicht aufgeführt.

- $\quad$ Acipenser baerii Brandt, 1869

Drei anerkannte Unterarten sind beschrieben: $A$. b. baerii, $A$. b. baicalensis

und A. b. stenorhynchus (SOKOLOV \& VASIL'EV 1989a, RUBAN 1996, 1997).

- Acipenser brevirostrum Le Sueur, 1818

- $\quad$ Acipenser dabryanus Duméril, 1868

- Acipenser fulvescens Rafinesque, 1817

- $\quad$ Acipenser gueldenstaedtii Brandt, 1833

- Acipenser medirostris Ayres, 1854

- $\quad$ Acipenser mikadoi Hilgendorf, 1892

- $\quad$ Acipenser naccarii Bonaparte, 1836

- $\quad$ Acipenser nudiventris Lovetzky, 1828 
- Acipenser oxyrinchus Mitchill, 1815

Anhand molekularbiologischer Untersuchungen wurde das Vorhandensein der beiden Subspezies A. o. oxyrinchus und A. o. desotoi bestätigt (ONG et al. 1996, WIRGIN et al. 1997, BIRSTEIN \& DESALLE 1998).

- $\quad$ Acipenser persicus Borodin, 1897

- Acipenser ruthenus Linnaeus, 1758

- $\quad$ Acipenser schrenckii Brandt, 1869

- $\quad$ Acipenser sinensis Gray, 1834

- Acipenser stellatus Pallas, 1771

- $\quad$ Acipenser sturio Linnaeus, 1758

- Acipenser transmontanus Richardson, 1836

- Huso dauricus Georgi, 1775

- Huso huso Linnaeus, 1758

- Polyodon spathula Walbaum, 1792

- $\quad$ Psephurus gladius Martens, 1862

- $\quad$ Pseudoscaphirhynchus fedtshenkoi Kessler, 1872

- Pseudoscaphirhynchus hermanni Severtzoff in Kessler, 1877

- Pseudoscaphirhynchus kaufmanni Bogdanow, 1874

- Scaphirhynchus albus Forbes \& Richardson, 1905

- Scaphirhynchus platorynchus Rafinisque, 1820

- $\quad$ Scaphirhynchus suttkusi Williams \& Clemmer, 1991

Morphologische Bestimmungsschlüssel der Spezies sind z.B. bei SOKOLOV \& BERDicheVsKiI (1989a, b), SOKOLOV (1989), ARTYUKHIN (1995), DEBus (1995) und HOCHLEITHNER (1996) zu finden.

Angaben über das Vorkommen und die Verbreitung der verschiedenen Störarten können bei BIRSTEIN (1993), HOCHLEITHNER (1996) und BIRSTEIN et al. (1997b) nachgelesen werden. 


\subsection{Die Phylogenie und Systematik der Acipenseriformes}

Im Laufe der letzten 20 Jahre hat sich die Systematik der Pisces zunehmend gewandelt, sowohl im Hinblick auf die verwandtschaftlichen Beziehungen der Großgruppen wie innerhalb der Ordnung und Familien (FIEDLER 1991). Basierend auf morphologischen Untersuchungen nimmt innerhalb der Unterklasse der Actinopterygii die Familie der Polypteridae eine phylogenetisch basal gelegene Stellung ein (PATTERSON 1982). Dies bestätigte sich auch durch eine Untersuchung an Teilsequenzen der 28S rRNA (LE et al. 1993). Die in der Verwandtschaft nachfolgende Ordnung der Acipenseriformes stellt eine monophyletische Schwestergruppe zu den Neopterygii dar (BEMIS et al. 1997a, siehe Abb. 1).

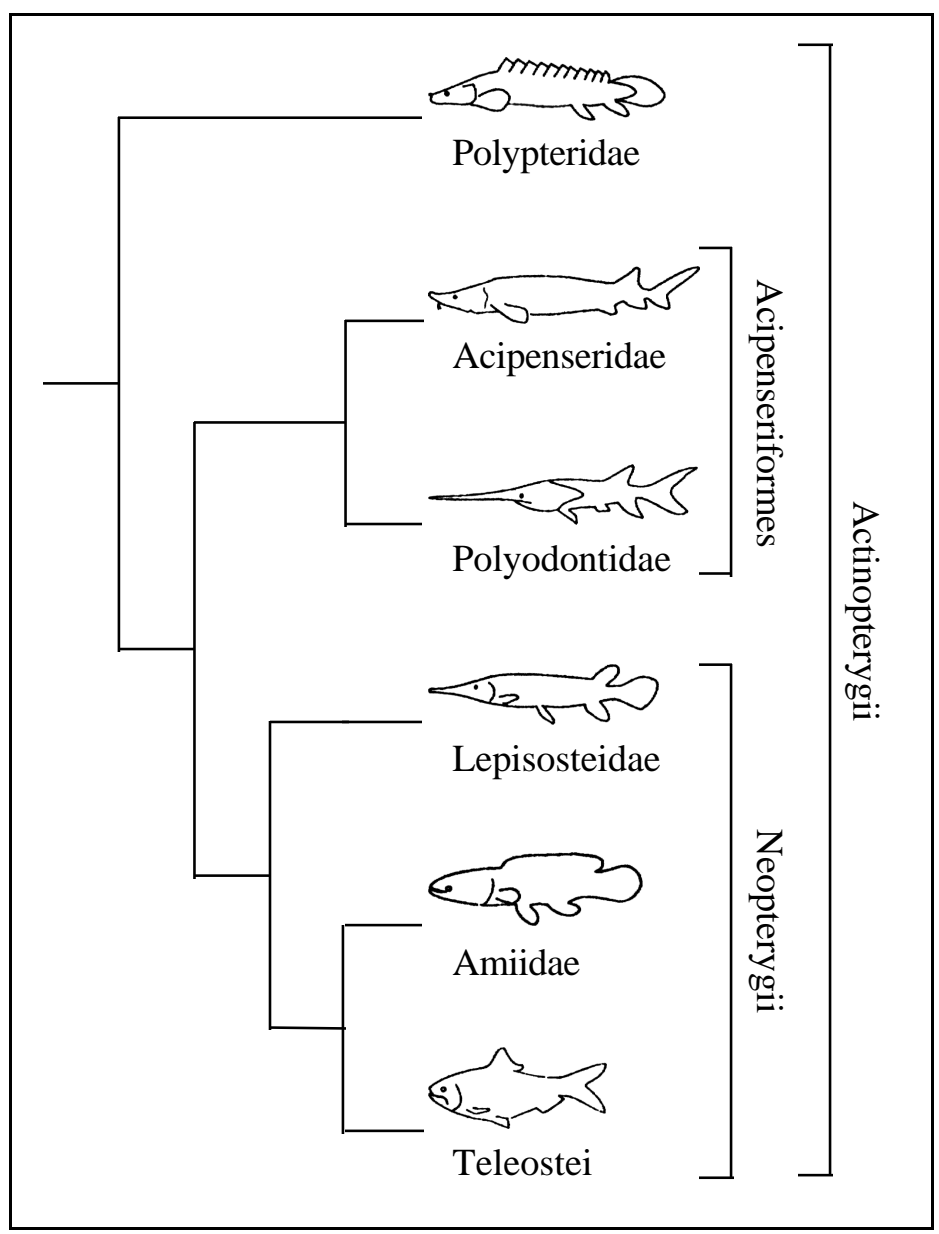

Abb. 1 Kladogramm über die phylogenetischen Beziehungen innerhalb der Actinopterygii (aus BEMIS et al. 1997a) 
Die evolutionäre Entstehung der Acipenseriformes wurde auf 200-225 Mio. Jahre und somit in das Erdzeitalter Jura zurückdatiert (KEDROVA et al. 1980, GRANDE \& BEMIS 1991, CANTATORE et al. 1994, BEMIS et al. 1997a). Aufgrund der zur Verfügung stehenden phylogenetischen und biogeographischen Hinweise hielten BEMIS \& KYNARD (1997) Westeuropa als Ursprung für die Entstehung der Acipenseriformes im Erdzeitalter Trias für plausibel. Ihrer Ansicht nach fand die frühe Diversifikation dieser Ordnung in Asien statt. Dagegen sind BIRSTEIN \& DeSALlE (1998) der Meinung, dass die Acipenseriformes in dem Tethysmeer in der Region des heutigen Zentralasiens ihren Ursprung fanden und sich während des Juras von dort ausgebreitet haben. BEMIS \& KYNARD (1997) waren versucht, die heutige Diversität der Acipenseridae mit der pontokaspischen Region in Verbindung zu bringen. Dagegen schlossen CHOUDHURY \& DicK (1998) diese Region als Zentrum für die Entstehung des Genus Acipenser aus, da die ältesten fossilen Funde in Nordamerika und Westasien lagen. Es schien dabei unwahrscheinlich zu sein, dass die Acipenseridae einen jüngeren marinen Ursprung hatten (MCDOWALl 1993). BEMIS \& KYNARD (1997) erweiterten diese Aussage sogar auf die gesamte Ordnung. Es wird angenommen, dass die ursprüngliche Lebensweise des Ahnen der Acipenseriformes potamodrom oder anadrom gewesen sein könnte (BEMIS \& KYNARD 1997). Fossile Funde der Acipenseridae deuteten an, dass die Gewöhnung dieser Familie an Fluss- und Brackwasser bereits lange ausgeprägt war (CHOUDHURY \& DICK 1998).

In der Literatur bestand Einigkeit darüber, dass die rezenten Störarten innerhalb der Ordnung Acipenseriformes den zwei Familien Polyodontidae und Acipenseridae angehören (z.B. FIEDLER 1991, GRANDE \& BEMIS, 1991, BEMIS et al. 1997a). Es wurde angenommen, dass diese beiden Familien vor 135-200 Mio. Jahren divergierten (Übersicht bei BIRSTEIN \& DeSALle 1998). Die Familie der Polyodontidae besteht aus den beiden Gattungen Polyodon sowie Psephurus, welche mit $P$. spathula und P. gladius jeweils eine Spezies enthalten. Die Familie der Acipenseridae setzte sich nach bisherigen Kenntnissen aus 25 weltweit vorkommenden Arten zusammen, welche sich auf die vier Gattungen Acipenser, Huso, Scaphirhynchus und Pseudoscaphirhynchus verteilen (BIRSTEIN 1993, BEMIS \& KYNARD 1997, BIRSTEIN \& BEMIS 1997, BIRSTEIN \& DESALLE 1998). Hinsichtlich der Phylogenese und somit der Verwandtschaft innerhalb der 
Acipenseridae existierten aber unterschiedliche Auffassungen, die sich in differierenden taxonomischen Einordnungen widerspiegelten (FIEDLER 1991, MAYDEN \& KUHAJDA 1996, BEMIS et al. 1997a, FINDEIS 1997). Auf der Basis klassischer morphologischer und morphometrischer Untersuchungen erfolgte eine Einteilung der Acipenseridae in die Unterfamilien Acipenserinae (zwei Gattungen: Acipenser und Huso) sowie Scaphirhynchinae mit den beiden Gattungen Scaphirhynchus und Pseudoscaphirhynchus (FIEDLER 1991, MAYDEN \& KUHAJDA 1996). Phylogenetische Studien unter Verwendung verschiedener osteologischer Charakteristika kamen hingegen zu dem Schluss, dass innerhalb der Familie der Acipenseridae die beiden Unterfamilien Husinae (eine Gattung: Huso) und Acipenserinae (drei Gattungen: Acipenser, Scaphirhynchus und Pseudoscaphirhynchus) auftreten (BEMIS et al. 1997a, FINDEIS 1997). Die kontroversen Ansichten hinsichtlich der phylogenetischen Entwicklung innerhalb der Acipenseriformes sind in Abb. 2 dagestellt.

a

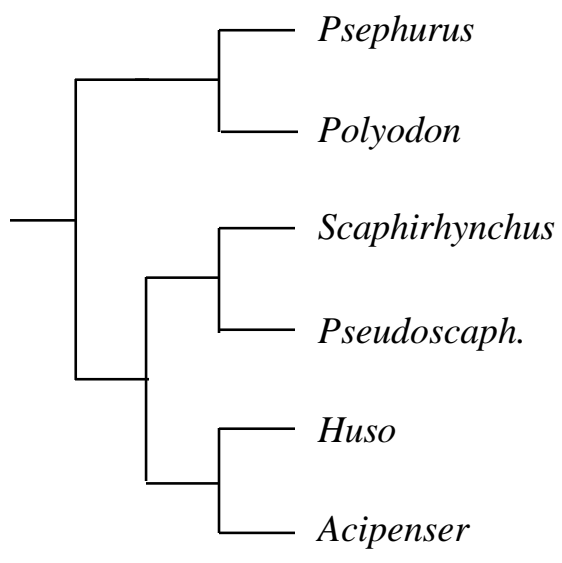

b

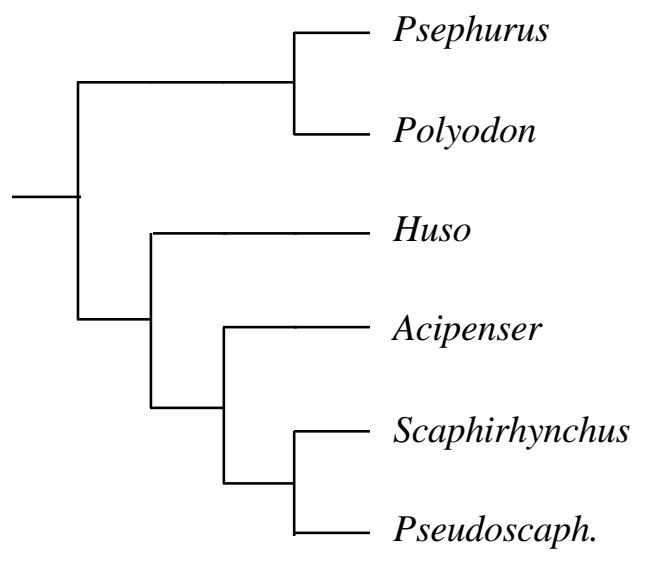

Abb. 2 Gegenüberstellung der phylogenetischen Kladogramme hinsichtlich der konträren Ansichten über die Beziehung der Gattungen rezenter Störe a, Klassisches Kladogramm in Anlehnung an FIEDLER (1991) und MAYDEN \& KUHAJDA (1996); b, Kladogramm aufgrund osteologischer Befunde (BEMIS et al. 1997a, FINDEIS 1997)

Widersprüchliche Angaben waren hinsichtlich der Verwandtschaft der Gattungen Scaphirhynchus und Pseudoscaphirhynchus zu finden. Während die meisten Autoren 
beide Arten als monophyletische Gruppe betrachten (FIEDLER 1991, MAYDEN \& KUHAJDA 1996, BEMIS et al. 1997a), waren BIRSTEIN et al. (1997a) anhand molekulargenetischer Vergleiche innerhalb der Acipenseriformes nicht dieser Auffassung.

BEMIS et al. (1997a) und FINDEIS (1997) zweifelten die klassische taxonomische Nomenklatur aufgrund ihrer osteologischen Befunde an. Dieses stellt sich auf der Grundlage lebender Störarten für die umstrittene Nomenklatur innerhalb der Familie Acipenseridae wie folgt dar:

\section{Klassische Nomenklatur}

Familie Acipenseridae

Unterfamilie Acipenserinae

Gattung Acipenser

Gattung Huso

Unterfamilie Scaphirhynchinae

Gattung Scaphirhynchus

Gattung Pseudoscaphirhynchus

\section{Nomenklatur in Anlehnung an}

BEMIS et al. (1997a), FINDEIS (1997)

\author{
Familie Acipenseridae \\ Unterfamilie Husinae \\ Gattung Huso \\ Unterfamilie Acipenserinae \\ Tribus Acipenserini \\ Gattung Acipenser \\ Tribus Scaphirhynchini \\ Gattung Scaphirhynchus \\ Gattung Pseudoscaphirhynchus
}

BIRSTEIN et al. (1997b) wiesen darauf hin, dass die klassische Systematik nur auf einer geringen Anzahl an untersuchten Exemplaren basierte und somit Fehlinterpretationen hinsichtlich der taxonomischen Stellung einiger Arten möglich sein könnten.

Mit 17 lebenden Arten ist Acipenser die artenreichste Gattung der Acipenseriformes und nach der Auffassung von BEMIS et al. (1997a) zugleich das am meisten trügerische und problematische Taxon innerhalb dieser Ordnung. So fand z.B. FINDEIS (1997) in einer Studie an sieben verschiedenen Arten der Gattung Acipenser keine osteologische Synapomorphien und stellte daher Monophylie von diesem Genus in Frage. Es wurde sogar die Vermutung geäußert, dass die Gattung Acipenser paraphyletisch sein könnte 
(BEMIS et al. 1997a), d.h. dass dieses Taxon nicht alle Nachkommen des gemeinsamen Ahnen enthält.

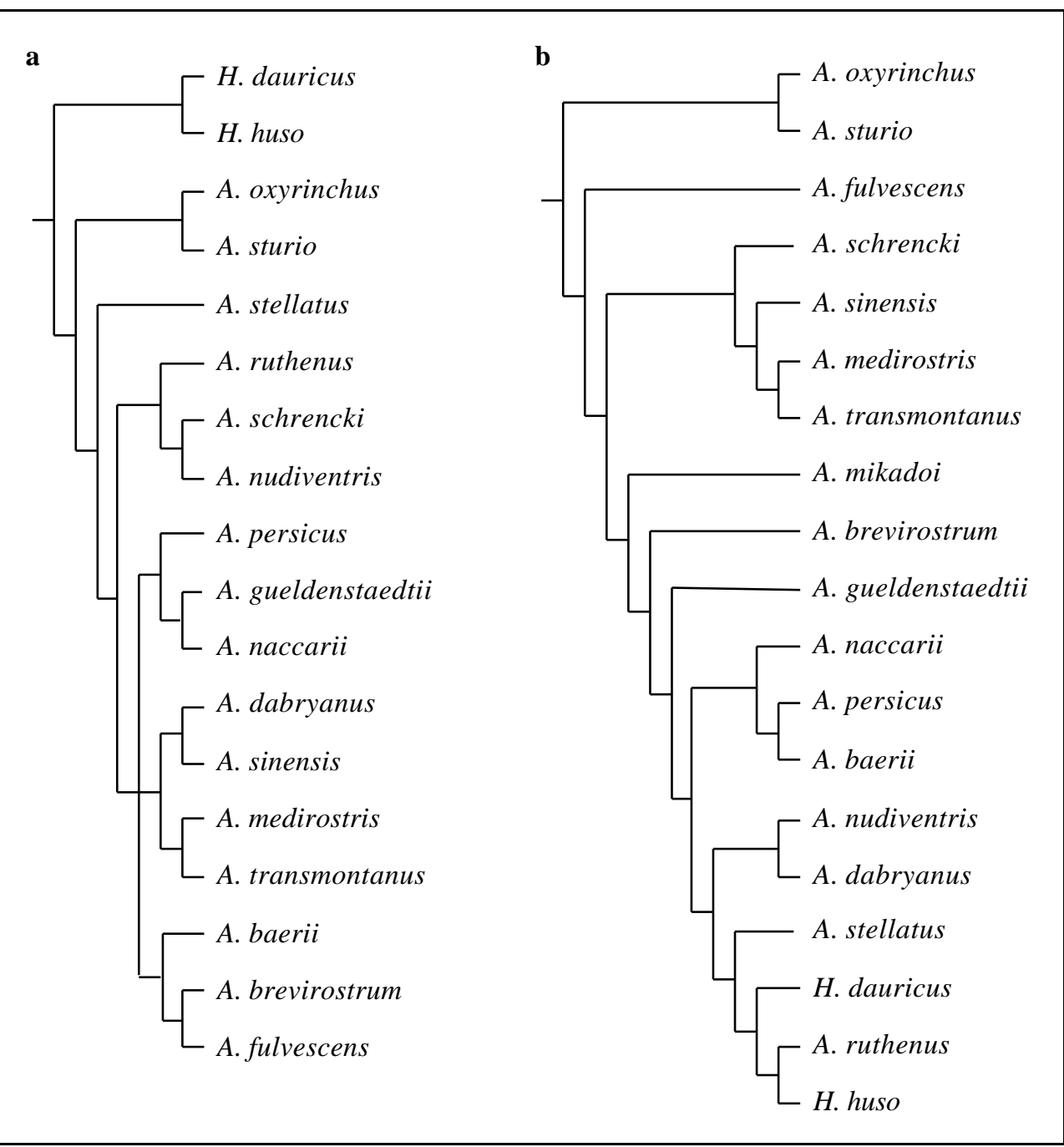

Abb. 3 Gegenüberstellung der anhand verschiedener Untersuchungsmethoden vermuteten verwandtschaftlichen Beziehungen der Arten innerhalb der Familie Acipenserinae

a, nach ARTYUKHIN (1995) und b, nach BIRSTEIN \& DESALLE (1998)

In der Literatur sind erst seit kurzer Zeit verschiedene Ansätze zur Beschreibung der verwandtschaftlichen Beziehungen innerhalb des Genus Acipenser zu finden. So basierte der von ARTYUKHIN (1995) erstellte phylogenetische Stammbaum auf der Verwendung morphologischer und karyologischer Daten unter der Berücksichtigung der biogeographischen Verbreitung der Arten. Basierend auf partiellen Sequenzen der drei mitochondrialen Gene 12S rRNA (150 bp), 16S rRNA (350 bp) sowie des Cytochrom b 
(650 bp) präsentierten BIRSTEIN \& DESALLE (1998) eine stammesgeschichtliche Entwicklung der Acipenserinae, die sich von der bei ARTYUKHIN (1995) dargestellten z.T. unterschied (Abb. 3).

Es wurde vermutet, dass die Haupt-Diversifikation der Acipenser in der adriatischponto-kaspischen Region stattfand (ARTYUKHIN 1995). Diese Zone wies die größte Artenvielfalt auf (ARTYUKHIN 1995, BEMIS \& KYNARD 1997) und war in den letzten 150 Millionen Jahren sehr unstabil (BEMIS \& KYNARD 1997). Eine Übersicht über die wesentlichen geologischen und paleogeographischen Veränderungen der ponto-kaspischen Region während der letzten 15 Millionen Jahre war bei BIRSTEIN \& DESALLE (1998) ebenso zu finden wie deren Hypothesen über die zeitliche phylogenetische Entwicklung der Acipenseriformes im Allgemeinen und der Acipenserinae im Speziellen.

\section{Überblick über die Zytogenetik der Acipenseriformes}

\subsubsection{Karyotypen, DNA-Gehalt und Ploidielevel der Acipenseriformes}

Das Gros der Arten der Acipenseriformes ließ sich in zwei chromosomale Gruppen einordnen, eine mit ca. 120 Chromosomen und eine weitere mit 240 - 260 Chromosomen (Übersichten bei BIRSTEIN et al. 1997a, FONTANA 1997, siehe Tab. 1). Ungefähr die Hälfte der Chromosomen sind sogenannte Mikrochromosomen, die durch eine sehr geringe Größe charakterisiert sind (BIRSTEIN et al. 1997a). Die Störspezies mit 120 Chromosomen wiesen ähnliche Karyotypen mit nur geringen Unterschieden auf, welches eine generell geringe karyologische Evolutionsrate der Acipenseriformes andeutete (BIRSTEIN et al. 1997a). Dieser Hinweis wurde in der Form untermauert, dass nur ein geringer Anteil an Nukleotidsubstitutionen durch molekulare Hybridisierungen genomischer DNA zwischen verschiedenen Spezies gefunden werden konnte (KEDROVA et al. 1980). Die ungewöhnlich geringe Variabilität partieller Fragmente der genomischen 18S rRNA sowie mitochondrialer 12S rRNA, 16S rRNA und des Cytochrom b könnte ebenso mit der geringen Karyotyp-Evolution korreliert sein (BIRSTEIN et al. 1997a). KEDROVA et al. (1980) sahen in der Ähnlichkeit der genomischen Struktur innerhalb der Acipenseridae die 
molekulare und genetische Basis für das Vorkommen lebensfähiger und fertiler Hybriden zwischen verschiedenen Arten begründet.

Der DNA-Gehalt der Arten mit 120 Chromosomen lag zwischen 3,17 und 4,89 pg DNA/Zelle, wohingegen dieser bei den Spezies, die 240-260 Chromosomen aufwiesen, mit 7,87 - 9,46 pg ungefähr doppelt so hoch war (Übersicht bei BIRSTEIN et al. 1997a). Zwei weitere Störspezies besaßen einen noch höheren DNA-Gehalt. Bei A. brevirostrum wurde ein DNA-Gehalt von 13,075 pg/Zelle ermittelt (BLACKLIDGE \& BIDWELL 1993), jener bei A. mikadoi betrug 14,2 pg per Nukleus (BIRSTEIN et al. 1993). Im Vergleich zu den in diesen Arbeiten simultan untersuchten Arten kamen BLACKLIDGE \& BIDWELL (1993) zu dem Schluss, dass A. brevirostrum ca. 360 Chromosomen besitzen müsse. Da der DNA-Gehalt von A. mikadoi viermal so hoch wie bei Spezies mit 120 Chromosomen und ca. doppelt so hoch wie bei Arten mit 240 Chromosomen war, folgerten BIRSTEIN et al. (1993), dass es sich hier um eine Störspezies mit ungefähr 500 Chromosomen handelte.

Tab. 1 Überblick über die direkt nachgewiesene bzw. abgeleitete Zugehörigkeit bisher untersuchter Störarten $\mathrm{zu}$ den bislang bekannten chromosomalen Gruppen

\begin{tabular}{cl}
\hline Chromosomengruppe & \multicolumn{1}{c}{ Spezies } \\
\hline 120 & A. nudiventris, A. oxyrhinchus, A. ruthenus, A. stellatus, \\
& A. sturio, H. dauricus, H. huso, P. kaufmanni, P. spathula, \\
& S. platorhynchus \\
& A. baerii, A. fulvescens, A. gueldenstaedtii, A. medirostris, \\
& A. naccarii, A. persicus, A. schrenckii, A. sinensis, A. trans- \\
& montanus \\
ca. 360 & A. brevirostrum \\
ca. 500 & A. mikadoi \\
\hline
\end{tabular}

Hinsichtlich des Ploidiestatus' der einzelnen Arten bestand in der Literatur wiederum Uneinigkeit. OHNO et al. (1969) stellten fest, dass die ersten 32 Chromosomenpaare von 
S. platorynchus in 16 verschiedene Gruppen zu je vier Homologen geordnet werden konnten. Diese Spezies mit insgesamt 112 Chromosomen wäre dann unter der Voraussetzung, dass bei der Untersuchung weiterer Störarten solche mit 60 Chromosomen gefunden würden, als tetraploid anzusehen (OHNO et al. 1969). P. spathula war eine Art tetraploiden Ursprungs, da ihre 120 Chromosomen in 30 Gruppen zu je vier Homologen geordnet werden konnten (DINGERKUS \& HOWELL 1976). Anhand der nach einer Silberfärbung ermittelten Anzahl an aktiven Nukleoli (NOR, Nukleus-OrganisatorRegionen) eines Nukleus kamen BIRSTEIN \& VASILIEV (1987) ebenfalls zu der Auffassung, dass Arten mit 120 Chromosomen tetraploiden und Spezies mit 240 Chromosomen octaploiden Urspungs sein müssten. Des Weiteren führten BIRSTEIN et al. (1997a) mehrere Literaturquellen an, welche auf das Vorhandensein duplizierter proteinkodierender Loci hinwiesen. Dagegen waren verschiedene Publikationen zu finden, in denen die Arten mit 120 Chromosomen als diploid und die Spezies mit 240 Chromosomen als tetraploid postuliert wurden. Auf der Basis von eingehenden NOR-Studien wurde in diesen Literaturquellen nachgewiesen, dass die NOR-haltigen Chromosomen bei Arten mit der niedrigeren Chromosomenzahl auf verschiedenen, nicht-homologen Chromosomenpaaren zu finden waren (FONTANA 1994, FONTANA et al. 1998a). Bei der 240 chromosomalen Gruppe ließen sich NORs auf verschiedenen Quadruplets nachweisen (FONTANA 1994, FONTANA et al. 1996). Eine densitometrische Analyse der Albumine aus dem Blutserum kam zu der gleichen Schlussfolgerung (KUZ'MIN 1996). Obwohl FonTANA (1994) für die Arten mit 120 Chromosomen einen diploiden Status postulierte, schloss er eine hypothetische Tetraploidisierung des acipenseriformen Ahnen mit einem Karyotyp von $2 n=60$ Chromosomen nicht aus. Seiner Meinung nach erfolgte dann aber die Wiederherstellung des funktionell diploiden Zustands in diesem Vorfahren. Das Erreichen des diploiden Ploidiestatus wurde in einer Studie synaptonemaler Komplexe an 52 männlichen Individuen von A. transmontanus, einer Spezies mit 250 Chromosomen, vermutet, da keine Hinweise auf multivalente Formationen beobachtet werden konnten (VAn EenEnNAAM et al. 1998). Nach der Auffassung von BlackLIDGE \& BidwelL (1993) war es sogar wahrscheinlich, dass die lebenden Acipenseriformes funktionell diploid seien. Da sich die DNA-Gehalte in den Zellen zwischen zwei isolierten Populationen der Art A. transmontanus signifikant unterschieden, mutmaßten diese Autoren sogar, dass der Diploidisierungsprozess innerhalb einer Spezies sogar unterschiedlich vonstatten gehen könnte. 


\subsubsection{Ploidisierungereignisse in der Evolution der Acipenseriformes}

In der Stammesgeschichte besaßen die Acipenseriformes und die Neopterygii einen gemeinsamen Vorfahren (BEMIS et al. 1997a, siehe auch Abb. 1). BIRSTEIN et al. (1997a) arbeiteten anhand einer Literaturrecherche heraus, dass jener gemeinsame Ahne einen Karyotyp mit ca. 60 Chromosomen aufwies, Mikrochromosomen enthielt und einen DNAGehalt von ca. 2,0 pg je Zellkern aufwies. Bislang wurde keine Störart charakterisiert, die einen ähnlichen Chromosomensatz besaß. Wichtige Informationen über ein mögliches Tetraploidisierungsereignis könnten durch die Untersuchung von $P$. gladius, der mit P. spathula engverwandtesten Art, erhalten werden (DINGERKUS \& HOWELL 1976). Generell sind zytogenetische Informationen hilfreich, um einige verwandtschaftliche Verhältnisse innerhalb der Gattung Acipenser zu verstehen (BIRSTEIN et al. 1997a). ARTYUKHIN (1995) verwendete innerhalb der Acipenser den Übergang von 120 zu 240 Chromosomen als zusätzliches, einmalig in deren Stammesgeschichte vorkommendes Merkmal. Dagegen kamen BIRSTEIN \& DeSALle (1998) zu dem Schluss, dass maximal acht verschiedene Ploidisierungsereignisse bei den Acipenser auftraten. Polyploidisierung wurde dabei als einer der wesentlichen genetischen Mechanismen für die Artenbildung angesehen (BIRSTEIN et al. 1997a). Die Entstehung von A. mikadoi mit ca. 500 Chromosomen wurde auf ein Polyploidisierungsereignis bei einem Ahnen mit 240 Chromosomen zurückgeführt (BIRSTEIN et al. 1993, BIRSTEIN et al. 1997a, BIRSTEIN \& DeSALLE 1998). In der Evolution der Art A. brevirostrum (ca. 360 Chromosomen) war entweder ein Triploidisierungsereignis oder eine Hybridisierung beteiligt (BACKLIDGE \& BIDWELL 1993). Ein triploides Individuum der Art A. fulvescens (240 Chromosomen) wies den gleichen DNA-Gehalt wie die untersuchten Tiere von A. brevirostrum auf, welches ein weiteres Indiz auf der bei dieser Spezies postulierten Chromosomenzahl von 360 war (BLACKLIDGE \& BIDWELL 1993). Auf der anderen Seite erachteten es BIRSTEIN et al. (1997a) für plausibler, dass Individuen der Art A. brevirostrum ca. 500 Chromosomen besitzen, da Alloploidie bei keiner acipenseriden Spezies bekannt sei. Demgegenüber wiesen z.B. die meisten Spezies bei Eurasischen Cypriniden mit $2 n=50$ einen diploiden chromosomalen Status auf, es kommen aber auch tetra-, hexa- und octaploide Arten vor (YU et al. 1987). 


\subsection{Aquakulturelle Bedeutung der Acipenseriformes}

Die kommerzielle aquakulturelle Produktion an Acipenseriformes hat in den letzten Jahren weltweit stark zugenommen, welches in deren hohen Wertschöpfung begründet liegt (Abb.4).

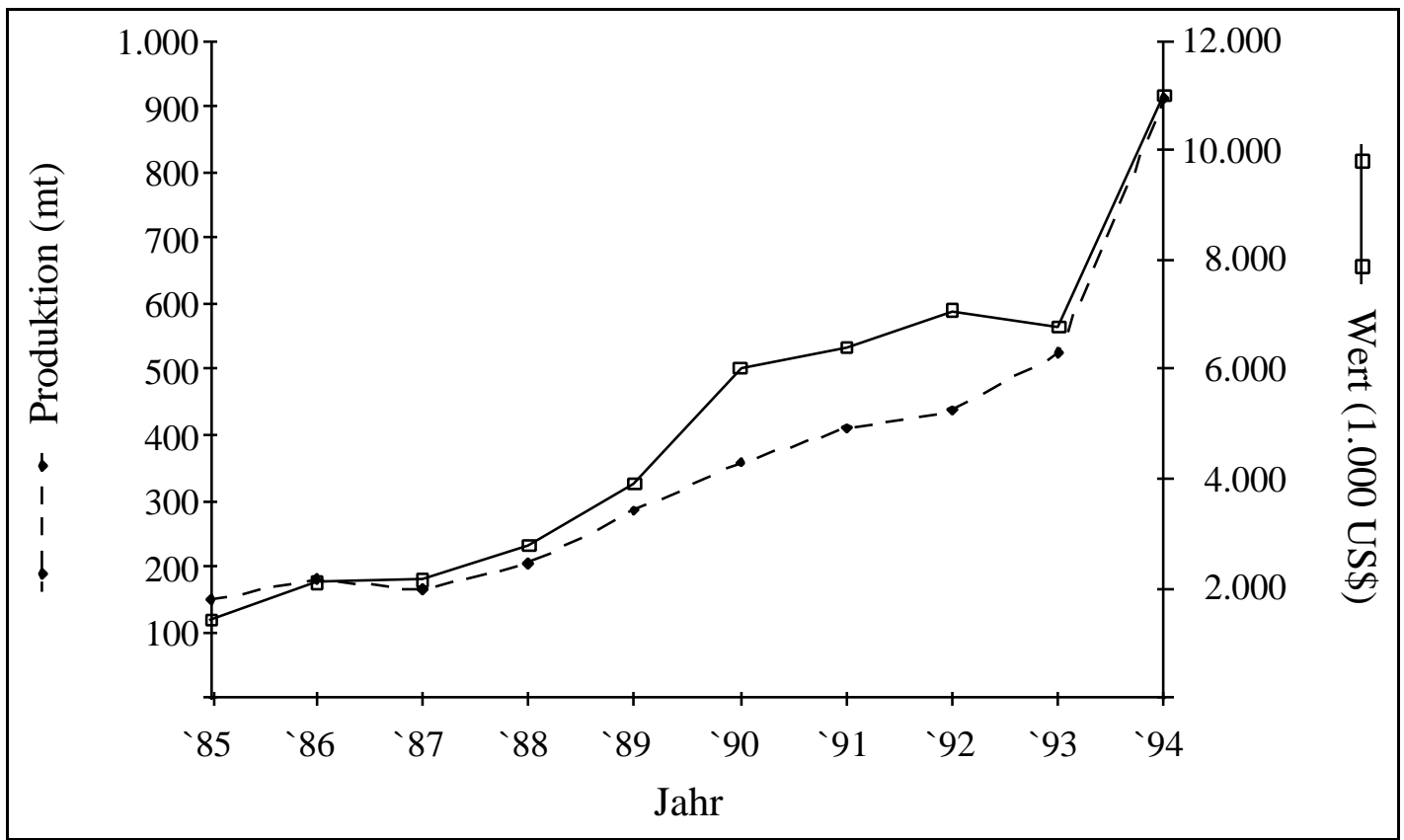

Abb. 4 Entwicklung der Störproduktion und deren Wertschöpfung in der Aquakultur (FAO 1996)

Im Gegensatz zu den schon seit langem in der Aquakultur gehaltenen Fischspezies, wie z.B. Forellen oder Karpfen, bieten sich verschiedene Störarten vor allem für die Produktion von Kaviar an. Ein Weiteres, wenn auch nicht so wertvolles Produkt wie der Kaviar, ist das Störfleisch (HOUSTON 1987, ROCHARD et al. 1990, DOROSHOV \& BINKOWSKI 1985). Das Fleisch von A. fulvescens kostete 6-7 US\$ pro kg (HOUSTON 1987) und REICHLE (1997b) gab einen Ladenverkaufspreis von 48,- DM pro kg an.

Eine Störfarm in Frankreich produzierte 1996 bereits $400 \mathrm{~kg}$ Kaviar sowie $200 \mathrm{t}$ Störfleisch von A. baerii und hofft ab dem Jahr 2000 den Markt mit vier bis fünf Tonnen Kaviar beliefern zu können (HJUL 1996a, 1996b). In den USA plant eine Station im Jahr 2002 eine jährliche Produktion von mindestens 10 t Kaviar von A.transmontanus 
(ANONYMUS 1997). Mit derselben Spezies erzeugte eine italienische Fischfarm 1998 ca. $500 \mathrm{~kg}$ Kaviar - bei einem Verkaufserlös von bis zu 600 US\$ pro kg - und plant die Ausdehnung der jährlichen Produktion auf 3.000 kg (NEGRONI 1999).

Die Rentabilität einer kombinierten Erzeugung von Störfleisch und -kaviar hängt dabei von verschiedenen Parametern, wie z.B. dem Eintritt der Geschlechtsreife, dem Produktionsrhythmus, Verkaufserlösen, etc. ab (LOGAN et al. 1995, WADE \& FADEL 1997). Einen sehr großen Einfluss auf die Rentabilität besitzt zudem die verwendete Spezies. Zwischen verschiedenen Kaviarsorten - jene werden durch die Art des Kaviarlieferanten bestimmt - sind größere Preisunterschiede zu finden. Für eine reine Fleischproduktion bieten sich neben verschiedenen Störspezies (REICHLE 1997a, REICHLE \& BERGLER 1998) auch deren Hybriden an (RÜMMLER \& PFEIFFER 1998). Methoden zur Spezieserkennung und Populationsdifferenzierung

Eine einwandfreie Speziesidentifikation ist eine Grundvoraussetzung für jedes Programm der Arterhaltung (AVISE 1989). Dies gilt besonders für gefährdete oder bedrohte Arten, wenn sie kommerziell genutzt werden (CHERFAS 1989, BAKER \& PALUMBI 1994, BAKER et al. 1996).

\subsubsection{Identifizierung von Störkaviar}

Neben den drei traditionellen für die Kaviarproduktion genutzten Spezies A. gueldenstaedtii, A. stellatus und H. huso wird im Handel auch Kaviar von anderen Acipenseriformes angeboten (DESALLE \& BIRSTEIN 1996, BIRSTEIN et al. 1998a). Falschdeklarationen die Speziesherkunft betreffend wurden in verschiedenen Untersuchungen nachgewiesen (REHBEIN 1985, COHEN 1997, DESALLE \& BIRSTEIN 1996, BIRSTEIN et al. 1998b). Eine Studie zeigte, dass $32 \%$ der untersuchten Kaviarsorten falsch deklariert waren (BIRSTEIN et al. 1998a). Als Ursache hierfür wurde der starke Populationsrückgang der drei traditionellen Kaviarlieferanten bei steigender 
Kaviarnachfrage vermutet (BIRSTEIN et al. 1998a). Diese Arbeitsgruppe vertrat die Auffassung, dass eine Differenzierung dieses wertvollen Produktes hinsichtlich der Speziesherkunft wichtig für die Protektion von vormals nicht für die Kaviarproduktion genutzen und bedrohten Störarten sei. Zudem könnten durch die Überprüfung der im Handel befindlichen Kaviarsorten Verbraucher, Handel und Zollbehörden vor Täuschung geschützt werden (DESALLE \& BIRSTEIN 1996, REHBEIN 1997). Eine Unterscheidung von Kaviar erfolgte lange Zeit anhand der Eigröße und -erscheinung, der Textur, Farbe und Geruch des Kaviars (CHEN et al. 1996, DESALLE \& BIRSTEIN 1996). Proteinbiochemische Methoden wurden dann auf ihr Potential hin untersucht, Kaviarsorten unterscheiden zu können (REHBEIN 1985, KEYVANFAR et al. 1988, CHEN et al. 1996, REHBEIN 1997). Während mit der Natriumdodecylsulfat-Polyacrylamidelelektrophorese Kaviarsorten nichtacipenseriformer Herkunft (z.B. vom Seehasen, Lachs oder der Forelle) anhand ihres Proteinmusters differenzierbar waren, konnten Kaviarsorten von verschiedenen Störarten nicht unterschieden werden (REHBEIN 1997). Dagegen konnte mit der isoelektrischen Fokussierung (IEF) die acipenseriforme Speziesherkunft bestimmt werden (REHBEIN 1985, KEYVANFAR et al. 1988, CHEN et al. 1996, REHBEIN 1997). Mit Hilfe dieses Verfahrens war es sogar möglich, Kaviar von den eng verwandten Arten A. gueldenstaedtii und A. persicus zu unterscheiden (KEYVANFAR et al. 1988). Die sich in der IEF darstellenden Bandenmuster waren dabei innerhalb der Arten konstant (REHBEIN 1985, CHEN et al. 1996). Die Differenzierung der Artherkunft lag dabei weniger in dem Bandenmuster als vielmehr in Unterschieden der Bandenintensität begründet (REHBEIN 1997). Nachteile dieses Verfahrens lagen in dem hohen Bedarf an Ausgangsmaterial (DESALLE \& BIRSTEIN 1996) und der Charakterisierung von bislang nur wenigen Arten (REHBEIN 1997).

Jüngste Untersuchungen zur Unterscheidung der acipenseriformen Kaviarherkunft basierten auf zwei verschiedenen, PCR-gestïtzen Methoden (DESALLE \& BIRSTEIN 1996, REHBEIN 1997, BIRSTEIN et al. 1998a). Das Verfahren bei DESALLE \& BIRSTEIN (1996) und BIRSTEIN et al. (1998a) beruhte auf einer speziesspezifischen Amplifikation innerhalb des mitochondrialen Cytochrom b (mt Cyt b). Grundlage hierfür bildeten artspezifische, potentiell konservierte Nukleotidunterschiede in diesem Gen, welche zuvor durch Sequenzvergleiche zwischen 21 der 27 existenten Arten innerhalb der Ordnung der Acipenseriformes ermittelt worden sind (BIRSTEIN \& DESALlE 1998). Mit diesem 
Verfahren waren die Kaviarsorten von den drei Arten A. gueldenstaedtii, A. stellatus und H. huso direkt nachweisbar (DESALLE \& BIRSTEIN 1996, BIRSTEIN et al. 1998a). Die Ermittlung der anderen Spezies hingegen erfolgte über Sequenzvergleiche (BIRSTEIN et al. 1998a). REHBEIN (1997) hingegen verwendete für die Differenzierung das Verfahren des Einzelstrang-Konformationspolymorphismus (single strand conformation polymorphism, SSCP). In dieser Methode unterschieden sich die drei traditionellen Kaviarlieferanten in dem Laufverhalten eines 358 bp langen, in der PCR generierten Fragments des mt Cyt b.

\subsubsection{Identifizierung von Individuen}

Die klassische Charakterisierung von acipenseriformen Einzelindividuen erfolgte anhand morphometrisch unterscheidbarer Merkmale, welche die Grundlage der Bestimmungsschlüssel darstellten (z.B. SOKOLOV \& BERDICHEVSKII 1989a, 1989b, SOKOLOV 1989, ARTYUKHIN 1995, DEBUS 1995, HOCHLEITHNER 1996).

Bislang waren dagegen nur eine geringe Anzahl molekularbiologischer Diagnoseverfahren für eine Determination der Spezieszugehörigkeit einzelner Individuen in der Literatur beschrieben. Die Artidentifizierung von sechs Störwildfängen führten BIRSTEIN et al. (1998b) auf der Basis von Sequenzvergleichen durch. Hierfür amplifizierten sie bei den einzelnen Tieren partielle Fragmente aus dem mt Cyt b und glichen die anschließend ermittelten individuellen Sequenzinformationen gegen die von BIRSTEIN \& DESALLE (1998) etablierte Datenbank, welche partielle Sequenzen partieller mitochondrialer Gene von 22 acipenseriformen Spezies enthielt, ab. Vier der sechs Individuen stellten sich als A. sturio heraus, eines der Tiere stand A. baerii sehr nahe, wohingegen das andere eng mit $A$. naccarii verwandt war (BIRSTEIN et al. 1998b). Für A. gueldenstadtii, A. stellatus und H. huso könnte auch das Nachweisverfahren der speziesspezifischen Amplifikation von DESALLE \& BIRSTEIN (1996) und BIRSTEIN et al. (1998a) eingesetzt werden (BIRSTEIN et al. 1998b). Bei einem Vergleich der beiden Spezies A. naccarii und A. sturio fanden LUDWIG \& KIRSCHBAUM (1998) insgesamt sieben artunterschiedlich konservierte Nukleotide in einem Fragment der mitochondrialen 12S rDNA, von denen zwei zu speziesspezifischen Restriktionsfragment-Längenpolymorphismen (RFLPs) führten. Individuen der beiden Subspezies A. oxyrinchus desotoi und A. oxyrinchus oxyrinchus 
wiesen in einem 203 bp Fragment aus der mitochondrialen Kontrollregion (D-loop) insgesamt 15 verschiedene Nukleotidpolymorphismen auf (ONG et al. 1996), von denen drei aufgrund ihrer Konservierung eine Unterscheidung der beiden Subspezies gestatteten (ONGet al. 1996, WIRGIN et al. 1997). Die Untersuchung des gleichen Fragments eines $A$. sturio wies im Vergleich zu den Individuen der beiden Subspezies A. oxyrinchus zwischen 31 und 33 Nukleotidsubstitutionen sowie an drei Stellen Nukleotidinsertionen oder -deletionen auf (WIRGIN et al. 1997). Beide Arten sind eng miteinander verwandt (BIRSTEIN \& BEMIS 1997, siehe auch Abb. 3). Dagegen war eine Unterscheidung der drei Arten der Gattung Scaphirhynchus anhand eines 435 bp-Fragments aus der D-loop nicht möglich (CAMPTON et al. 1995).

In der Literatur wurde auch die Verwendung einer an A. naccarii charakterisierten Satelliten-DNA als Sonde für die Unterscheidung zu A. sturio im Dot-Blot beschrieben (GARRIDO-RAMOS et al. 1997). Bei den diskreten DNA-Fragmenten, die nach der Spaltung genomischer DNA mit verschiedenen Restriktionsendonukleasen auftraten und als Satelliten-DNA angenommen wurden, waren hingegen keine Unterschiede zwischen den vier Spezies A. gueldenstaedtii, A. ruthenus, A. stellatus und $H$. huso bezüglich der Bandengröße oder -verteilung festzustellen (MiKHAILOVA et al. 1995).

Eine weitere Methode mit der es möglich war, verschiedene Störspezies zu unterscheiden, stellte die zufällige Amplifikation polymorpher DNA (random amplified polymorphic DNA, RAPD) dar (COMINCINI et al. 1998, JENNECKENS et al. 1998). Die intraindividuelle Reproduzierbarkeit von RAPD-Markern wurde allerdings in der Literatur kontrovers diskutiert (BIELAWSKI et al. 1995, KHANDA et al. 1997, PEREZ et al. 1998). Insbesonders zwischen verschiedenen Laboratorien schien unter Verwendung derselben Template-DNA und Primer die Wiederholbarkeit stark eingeschränkt zu sein (PENNER et al. 1993).

Eine RFLP-Analyse an acht verschiedenen, in der PCR amplifizierten nukleären Genen erlaubte hingegen keine Differenzierung von den drei Spezies der Gattung Scaphirhynchus (GENETIC ANALYSES INC. 1994). Dagegen zeigt sich, daß die Spaltung des kompletten mitochondrialen Genoms mit bestimmten Restriktionsendonukleasen zu intraspezifisch monomorphen aber interspezifisch variablen Fragmentmustern führte (BROWN et al. 1996). 
In der Literatur waren Untersuchungen verschiedener proteinbiochemischer Marker im Hinblick auf eine Speziesdifferenzierung beschrieben. Die beiden Arten S. albus und S. plathorhynchus konnten nach der Analyse von 37 Allozymloci anhand der auftretenden Allelfrequenzen nicht voneinander unterschieden werden (PHELPS \& ALLENDORF 1983). Von drei untersuchten Allozymsystemen sowie der Blutplasmafraktion erwies sich in einer Studie an fünf Acipenserinae die Phosphoglucomutase als Kandidatenmarker für die Spezies A. stellatus (JENNECKENS et al. 1998). Während KIRPICNIKOV (1987) auf eine strenge Spezifität der Hämoglobinfraktionen der Arten A. gueldenstaedtii, A. nudiventris, A. ruthenus, A. stellatus und H. huso hinwies, erwähnten SOKOLOV \& VASIL'EV (1989a), dass diese zwischen A. nudiventris und A. ruthenus identisch waren. Ferner zeigte A. baerii an diesem Marker eine hohe interindividuelle Heterogenität (SOKOLOV \& VASIL'EV 1989b). Bei der Auftrennung sakroplasmatischer Muskelproteine ließen sich zehn verschiedene Acipenseridae anhand von den in der DISC-Elektrophorese erhaltenen Mustern in drei verschiedene Gruppen einteilen (KUZ'MIN 1994). Dieses Verfahren erlaubte die Zuordnung von Einzelindividuen zu einer Gruppe, wobei sich die einzelnen Gruppen aus folgenden Spezies zusammensetzten: Gruppe I - A. nudiventris, A. ruthenus, A. stellatus, P. kaufmanni; Gruppe II - A. baerii, A. gueldenstaedtii, A. schrenckii und Gruppe III - H. dauricus, H. huso (KUZ'MIN 1994).

ADKINSON et al. (1996) zeigten, dass gegen die schwere Kette des Immunoglobulin (Ig) von A. transmontanus erzeugte monoklonale Antikörper für diese Spezies hochspezifisch waren und nicht mit den Ig anderer Acipenseriformes kreuzreagierten. Einem ähnlichen Ansatz gingen SUBBOTKIN \& SubBOTKINA (1998) zur Abgrenzung von A. persicus gegen die fünf Spezies A. baerii, A. gueldenstaedtii, A. nudiventris, A. ruthenus und A. stellatus nach. In dieser Untersuchung führte die Verwendung von Antikörpern, welche gegen die Serumalbumine von A.persicus gerichtet waren, zu unterschiedlichen Immunoelektropherogrammen zwischen den Arten. 


\subsubsection{Identifizierung und Charakterisierung von Populationen}

Das klassische Verfahren zur Charakterisierung von Populationen innerhalb verschiedener Fischspezies basierte auf der Verwendung von biochemischen Markern. Populationen konnten dabei anhand der Allelfrequenzen polymorpher Loci differenziert werden (Übersicht bei KIRPICNIKOV 1987). So war bei den Eurasischen Spezies A. baerii, A. gueldenstaedtii, A. stellatus und $H$. huso eine Differenzierung verschiedener Populationen mittels biochemischer Marker möglich (SHUBINA et al. 1989, PIROGOVSKII 1989, SOKOLOV \& VASIL'EV 1989a, VlaSENKO et al. 1989b). Dagegen gestaltete sich eine Differenzierung von verschiedenen Populationen von A. nudiventris im Kaspischen Meer schwierig (SOKOLOV \& VASIL'EV 1989b). Gleiches galt für die amerikanische Spezies $P$. spathula. Eine Untersuchung an 35 Enzymloci aus verschiedenen Geweben ermöglichte keine genetische Differenzierung zwischen den Populationen aus dem Mississippi und Alabama (CARLSON 1982). Duplizierte polymorphe Genloci (SLYN'KO 1976, NIKONOROV et al. 1986) und proteinspezifisch unterschiedliche Quartärstrukturen (KIRPICNIKOV 1987) führten insbesondere bei den Störspezies mit 240 Chromosomen zu komplexen Elektropherogrammen. Darüber hinaus wiesen verschiedene biochemische Marker gewebespezifisch unterschiedliche Loci auf (KIRPICNIKOV 1987).

In jüngeren Studien erfolgte die Untersuchung von Populationen verschiedener Spezies innerhalb der Acipenseridae anhand mitochondrialer bzw. genomischer DNA.

Das mitochondriale Genom amerikanischer Acipenser besaß eine aus RFLP-Daten abgeleitete Größe zwischen 16,1 - 16,7 kb (BROWN et al. 1992a, BROWN et al. 1996). Innerhalb der untersuchten Spezies konnte dabei ein zum Teil erheblicher Längenpolymorphismus des mitochondrialen DNA-Moleküls auftreten, welcher aus der unterschiedlichen Kopienzahl einer 78 - 82 bp langen Wiederholungseinheit innerhalb der Kontrollregion (D-loop) resultierte (BUROKER et al. 1990; BROWN et al. 1996). Zudem konnte bei den Arten A.transmontanus, A. medirostris und der Subspezies A. oxyrinchus desotoi ein beachtliches Ausmaß an mitochondrialer Heteroplasmie in RFLP-Analysen beobachtet werden (BUROKER et al. 1990, BROWN et al. 1992b, MiRAClE \& CAMPTON 1995, BROWN et al. 1996). BROWN et al. (1992b) befanden, 
dass dieses Phänomen in A. transmontanus überwiegend eine Eigenschaft mitochondrialer Linien und weniger von Populationen war.

RFLP-Studien unter Verwendung mitochondrialer DNA waren für die Charakterisierung von Populationen innerhalb einer Spezies bislang ausnahmslos an amerikanischen Stören durchgeführt worden. Es zeigte sich, dass nur eine geringe Anzahl der verwendeten Restriktionsendonukleasen zu polymorphen Fragmentmustern innerhalb verschiedener Spezies führten (BROWN et al. 1992a, FERGUSON et al. 1993, GUÉNETTE et al. 1993, StABILE et al. 1996). Die interspezifische Sequenzdivergenz war zwischen vier amerikanischen Störarten mindestens um ein Vierfaches größer, als die intraspezifische (BROWN et al. 1996). Dieses Verfahren fand zudem Eingang in Populationsstudien. So waren die Populationen von A. transmontanus aus dem Columbia und dem Fraser River durch signifikant unterschiedliche Genotypfrequenzen charakterisiert (BROWN et al. 1992a). Ebenso wiesen die beiden Subspezies der Art A. oxyrinchus signifikante Unterschiede in den mitochondrialen Haplotypfrequenzen zwischen Regionen und sogar verschiedenen Flüssen auf (BOWEN \& AVISE 1990, AVISE 1992, STABILE et al. 1996, WALDMAN et al. 1996). Jene Autoren vermuteten, dass diese Beobachtungen in einer hohen „homing fidelity“ begründet lag, welche zu einem äußerst begrenzten Genfluss zwischen den Populationen führte. Dagegen war die genetische Divergenz zwischen zwei A. fulvescens-Populationen aus verschiedenen Regionen nur gering (GUÉNETTE et al. 1993).

Die Spezies A. transmontanus wies in der mitochondrialen Kontrollregion eine vierbis fünffach höhere Nukleotidsubstitutionsrate verglichen zu der gesamten mitochondrialen DNA auf (BROWN et al. 1993). Aus diesem Grund waren BROWN et al. (1993) der Ansicht, dass diese hypervariable Region als genetischer Marker für Populationsstudien verwendet werden könnte. Dagegen konnte diese Beobachtung weder bei A. fulvescens (FERGUSON et al. 1993, FERGUSON \& DUCKWORTH 1997) noch bei A. oxyrinchus desotoi (MIRACLE \& CAMPTON 1995) bestätigt werden.

Obwohl BIRSTEIN et al. (1998b) bei nur vier verschiedenen Individuen von A. sturio, die aus drei unterschiedlichen Regionen stammten, Sequenzvergleiche an zwei partiellen Fragmenten des mitochondrialen Cytochrom b anstellten, kamen sie zu dem Schluss, dass 
die Tiere aufgrund intraspezifischer Sequenzdivergenzen verschiedenen Populationen angehörten.

Weder RFLP-Analysen noch Sequenzvergleiche erlaubten eine Differenzierung zwischen Populationen der Spezies A. fulvescens auf mitochondrialer Ebene (FERGUSON \& DUCKWORTH 1997). Die Autoren schlugen aus diesem Grund eine Untersuchung genomischer Mikrosatelliten-Loci für die Charakterisierung von Populationen vor. Von 18 verwendeten Primerpaaren, die ursprünglich für die Amplifikation von Mikrosatelliten-Loci in den Arten Merlangius merlangus (Weißfisch), Gasterosteus aculeatus (Stichling) und Gadus morhua (Dorsch) entwickelt wurden, amplifizierten sieben erfolgreich bei verschiedenen Fischspezies, so auch bei A. fulvescens (RICO et al. 1996). MAY et al. (1997) charakterisierten für A. fulvescens elf verschiedene solcher nukleären Marker, die zum Teil bei weiteren fünf Arten der Gattung Acipenser sowie bei zwei des Genus' Scaphirhynchus Amplifikationsprodukte erbrachten. Bislang waren aber Populationsstudien unter Verwendung von Mikrosatelliten-Loci bei Stören nicht in der Literatur beschrieben. 
Die für diese Arbeit zur Verfügung stehenden Störspezies und Störhybriden, deren Anzahl und Herkunftsort werden in der folgenden Tabelle beschrieben. Sämtliches Untersuchungsmaterial lag in Form von Blutproben vor.

Tab. 2 Herkunft und Probenumfang der Störarten und -hybriden

\begin{tabular}{|c|c|c|c|c|c|c|c|c|}
\hline \multirow{2}{*}{$\begin{array}{l}\text { Spezies bzw. } \\
\text { Kreuzung }\end{array}$} & \multicolumn{8}{|c|}{ Herkunftsort (Probenumfang) } \\
\hline & $\mathrm{A}^{1}$ & $\mathrm{~B}^{1}$ & $\mathrm{C}^{1}$ & $\mathrm{D}^{1}$ & $\mathrm{E}^{1}$ & $\mathrm{~F}^{1}$ & $\mathrm{G}^{3}$ & $\Sigma$ \\
\hline A. baerii & - & 50 & 60 & - & 2 & 13 & - & 125 \\
\hline A. gueldenstaedtii & - & - & 60 & - & $2^{2}$ & 10 & 19 & 91 \\
\hline A. naccarii & - & - & - & - & 2 & - & - & 2 \\
\hline A. persicus & - & - & - & - & - & - & 4 & 4 \\
\hline A. ruthenus & 10 & - & - & - & $7^{2}$ & 21 & - & 38 \\
\hline A. stellatus & - & - & & 3 & $4^{2}$ & 20 & 15 & 42 \\
\hline H. huso & - & - & - & 50 & $2^{2}$ & 16 & 4 & 72 \\
\hline P. spathula & - & - & - & - & $2^{2}$ & - & - & 2 \\
\hline A. baerii x A. ruthenus & - & 60 & - & - & - & - & - & 60 \\
\hline H. huso х A. gueldenstaedtii & - & - & - & 10 & - & - & - & 10 \\
\hline H. huso х A. ruthenus & 10 & - & - & - & - & - & - & 10 \\
\hline (H. huso x A. ruthenus) $\mathrm{x}$ & - & 10 & - & - & - & - & - & 10 \\
\hline
\end{tabular}

\footnotetext{
${ }^{1}$ Aquakultur, ${ }^{2}$ Wildfänge, in Aquakultur gehalten, ${ }^{3}$ Wildfänge
} 
Schlüssel der Herkunftsorte:

A Institut für Binnenfischerei e.V., Potsdam-Sacrow, Jägerhof am Sacrower See, D-14476 Groß Glienicke.

B Fischanlage Blei, Dorfstr. 1a, D-14828 Locktow.

C Warmwasseranlage Boxberg, D-02943 Sprey.

D Fischzucht Rhönforelle, D-36093 Künzell-Dietershausen.

E Teichwirtschaftlicher Beispielsbetrieb Wöllershof, D-92721 Störnstein.

F Rybnikárství Hluboká a.s., CZ-37341 Hluboká nad Vltavou, CZ.

G Kaspisches Meer im Astrachaner Gebiet, GUS.

Die Angabe über die jeweilige Spezies bzw. Kreuzung wurde bei den Proben, die aus der Aquakultur stammten (A-F), vom Fachpersonal nach bestem Wissen vor bzw. während der Blutprobennahme gegeben. Die Absicherung der taxonomischen Klassifikation der Wildfänge (Herkunft G) erfolgte durch Herrn Dr. Debus, einem Störexperten von der Universität Rostock, direkt vor Ort vor der Probenentnahme.

\subsubsection{Störkaviar}

Neben dem in Tabelle 2 aufgeführten Probenmaterial wurden zusätzlich drei handelsübliche Störkaviar-Sorten untersucht. Hierbei handelte es sich um Beluga-, Ossetra- und Sevruga-Kaviar (Nordsee, Göttingen), die von den Störspezies H. huso (Beluga), A. gueldenstaedtii (Ossetra) und A. stellatus (Sevruga) stammten.

\subsubsection{Puffer und Stammlösungen}

Der Übersicht halber werden die Zusammensetzungen aller verwendeten Puffer und Stammlösungen in den entsprechenden Kapiteln der Sektion Methoden (Kap. 3.2ff) aufgeführt. Das Ansetzen der Lösungen für den routinemäßigen Gebrauch in der Molekularbiologie erfolgte nach SAMBROOK et al. (1989). 


\subsubsection{Chemikalien, Enzyme, Verbrauchsmaterial und Geräte}

\subsubsection{Chemikalien}

$\beta$-Nicotinamid-Adenindinucleotid

$\beta$-Nicotinamid-Adenindinucleotidphosphat

Tris-(hydroxymethyl)aminomethan

Acrylamid-, Bisacrylamidlösungen

4-Methylumbelliferylacetat

7-Acetoxy-4-Methylcumarin

Aceton

Adenosin

Adenosindiphosphat

Agar

Agarose

Ammoniumacetat

Ammoniumpersulfat

Borsäure

Bromphenolblau

Cetyltrimethylammoniumbromid

Chloroform-Isoamylalkohol

Coomassie-Blue G 250

Di-Natriumhydrogenphosphat

Dichlorophenol-Indophenol

DL-Lactat

dNTPs

Elektrophoresepuffer für den ABI Prism 310

Essigsäure

Ethanol, 100\%ig

Ethidiumbromid

Ethylendinitrilotetraessigsäure
Boehringer Mannheim GmbH

Boehringer Mannheim GmbH

Biomol Feinchemikalien GmbH

Carl Roth $\mathrm{GmbH}+$ Co.

Sigma-Aldrich Chemie GmbH

Sigma-Aldrich Chemie GmbH

Merck KGaA

Boehringer Mannheim GmbH

Boehringer Mannheim GmbH

Difco Laboratories

Carl Roth GmbH + Co.

Sigma-Aldrich Chemie GmbH

Sigma-Aldrich Chemie GmbH

Merck KGaA

Merck KGaA

Merck KGaA

Merck KGaA

Merck KGaA

Merck KGaA

Merck KGaA

Merck KGaA

PE Applied Biosystems GmbH

PE Applied Biosystems GmbH

Carl Roth $\mathrm{GmbH}+\mathrm{Co}$.

Carl Roth $\mathrm{GmbH}+\mathrm{Co}$.

Merck KGaA

Merck KGaA 
Ethylendinitrilotetraessigsäure Dinatriumsalz-

Dihydrat (Titriplex III)

Fast Garnet GBC Salz

Formamid, ultrapur

Fructose-6-Phosphat

Gluconat-6-Phosphat

Glucose

Glucose-1,6-di-Phosphat

Glucose-1-Phosphat

Heparin-Natrium-25000-ratiopharm

HPLC-Wasser

Isopropanol

Kalium-Dihydrogenphosphat

Lithiumhydroxid

Magnesiumchlorid-Hexahydrat

Maleinsäure

Molekulargewichtstandards

Methanol

N,N,N',N'-Tetramethylethylendiamin

Natrium- $\alpha$-Glycerophosphat

Natrium- $\alpha$-Naphthylphosphat

Natrium-Dihydrogenphosphat

Natriumacetat

Natriumcarbonat

Natriumchlorid

Natriumcyanid

Natriumdodecylsulfat

Natriumhydroxid

Natriumthiosulfat
Merck KGaA

Sigma-Aldrich Chemie GmbH

PE Applied Biosystems GmbH

Boehringer Mannheim $\mathrm{GmbH}$

Boehringer Mannheim GmbH

Merck KGaA

Boehringer Mannheim GmbH

Boehringer Mannheim GmbH

Ratiopharm GmbH

Carl Roth $\mathrm{GmbH}+\mathrm{Co}$.

Merck KGaA

Merck KGaA

Merck KGaA

Merck KGaA

Merck KGaA

MBI-Fermentas

MWG-Biotech AG

PE Applied Biosystems GmbH

Merck KGaA

Serva Electrophoresis $\mathrm{GmbH}$

Merck KGaA

Sigma-Aldrich Chemie GmbH

Merck KGaA

Merck KGaA

Sigma-Aldrich Chemie GmbH

Merck KGaA

Merck KGaA

Merck KGaA

Merck KGaA

Sigma-Aldrich Chemie GmbH 
Oligonukleotide

Perchlorsäure

Performance Optimized Polymer 4 (POP4)

Performance Optimized Polymer 6 (POP6)

Phenazinmethosulfat

Phenol-Chloroform-Isoamylalkohol

Repellsilan

Salzsäure, $25 \%$ ig

Silbernitrat

Sucrose

Template Suppression Reagent

Thiazolylblau

Toronto-Stärke

Xylencyanol

Zitronensäure
MWG-Biotech AG

OPERON Technologies Inc.

PE Applied Biosystems GmbH

Merck KGaA

PE Applied Biosystems GmbH

PE Applied Biosystems GmbH

Merck KGaA

Carl Roth $\mathrm{GmbH}+\mathrm{Co}$.

Fluka Chemie AG

Merck KGaA

Sigma-Aldrich Chemie GmbH

Merck KGaA

PE Applied Biosystems GmbH

Biomol Feinchemikalien GmbH

Biomol Feinchemikalien GmbH

Merck KGaA

Merck KGaA

\subsubsection{Enzyme}

BigDye RR Terminator Cycle Sequencing Kit

Glucose-6-Phosphatdehydrogenase

Hexokinase

Nukleosid-Phophorylase

Proteinase K

Restriktionsendonukleasen (EcoRI, MseI)

RNAse A

T4-DNA-Ligase

Taq-DNA-Polymerase

Xanthin-Oxidase
PE Applied Biosystems GmbH

Boehringer Mannheim GmbH

Boehringer Mannheim GmbH

Boehringer Mannheim GmbH

Merck KGaA

New England Biolabs GmbH

Pharmacia Biotech Europe GmbH

New England Biolabs GmbH

MBI-Fermentas GmbH

Stratagene $\mathrm{GmbH}$

Boehringer Mannheim GmbH 


\subsubsection{Verbrauchsmaterial}

Chelex® 100

Einmal-Injektions-Kanülen, Sterican

Einmalspritzen, $5 \mathrm{ml}$

Einweghandschuhe

Kapillaren (41 und $63 \mathrm{~cm}$ )

Kleenex

Mikrozentrifugengefässe ( $0,5 \mathrm{ml} ; 1,5 \mathrm{ml})$

Pipettenspitzen $(10,100,1000 \mu \mathrm{l})$

Probengefäß, $5 \mathrm{ml}(58$ x $27 \mathrm{~mm})$

Probengefäße $(0,5 \mathrm{ml})$

QIAEX Blood and Tissue Kit

QIAEX II Gel Extraction Kit

QIAquick Gel Extraction Kit

Saran Wrap

Septen

Whatman-Papier, $3 \mathrm{~mm}$

\subsubsection{Geräte}

ABI Prism 310 Genetic Analyzer

Analoge Videoanlage

Autoklav

Biofuge A

Elektronische Analysenwaage 1602 MP 6

Elektronische Präzisionswaage U 4100 S

Horizon 58 Gelelektrophorese (BRL)

LiCor, Modell 4200

LKB 2012 Maxiphor Submarine Electrophoresis Unit ECPS 3000/150
BioRad Laboratories GmbH

B. Braun Melsungen AG

B. Braun Melsungen AG

Gerätebau Ochs GmbH

PE Applied Biosystems GmbH

Gerätebau Ochs GmbH

Sarstedt AG + Co.

Carl Roth GmbH + Co.

Sarstedt AG + Co.

PE Applied Biosystems GmbH

QIAGEN GmbH

QIAGEN GmbH

QIAGEN GmbH

Carl Roth GmbH + Co.

PE Applied Biosystems GmbH

Schleicher \& Schuell GmbH

PE Applied Biosystems GmbH

Intas $\mathrm{GmbH}$

Schütt Labortechnik GmbH

Heraeus Sepatech GmbH

Sartorius AG

Sartorius AG

Biometra GmbH

MWG-Biotech AG

Pharmacia Biotech Europe GmbH 
Magnetrührer Ikamag Rec-G, beheizbar

Mikrowellenherd, Genius (Panasonic)

Nahaufnahme-Kamera, CU - 5

pH-Meter Microprocessor, pH 535 Multical

Photometer PMQ3

Pipetten, Pipetman

Plastikröhrchen, $13 \mathrm{ml}$

Schüttel-Wasserbad (Köttermann)

Sterilisator, Typ T 5110 E

Thermocycler, Omnigene

Transilluminator, $302 \mathrm{~nm}$

Trockenschrank

UV-Aufleuchte

Vertikal-Elektrophorese-System, Modell B

Vertikal-Elektrophorese-System, Modell SA

Videoprinter (Mitsubishi)

Vortex Genie 2
Schütt Labortechnik GmbH

Tronic Markt

Intas $\mathrm{GmbH}$

Schütt Labortechnik GmbH

Zeiss Feinmechanik Optik Elektronic

Abimed Analysen-Technik GmbH

Sarstedt AG + Co.

Schütt Labortechnik GmbH

Heraeus Electronic GmbH

MWG-Biotech AG

Bachhofer Laboratoriumsgeräte

Schütt Labortechnik GmbH

Schütt Labortechnik GmbH

Kriegesmann \& Jansen Cons. GbR

Gibco Life Technologies GmbH

Intas $\mathrm{GmbH}$

Schütt Labortechnik GmbH

\subsubsection{Sterilisationstechniken}

Glasgefäße, Spatel und Magnetrührstäbchen wurden nach der Reinigung in der Spülmaschine in einem Trockenschrank bei $60{ }^{\circ} \mathrm{C}$ getrocknet, anschließend mit Aluminiumfolie abgedeckt bzw. in diese eingewickelt und in einem Sterilisator für 4-8 h bei $225{ }^{\circ} \mathrm{C}$ trocken sterilisiert. Glaspipetten wurden in einem Sammelbehälter aus Aluminium ebenso trocken sterilisiert. Für Nährmedien, Lösungen und Kunststoffmaterialien erfolgte die Sterilisierung im Autoklaven für 20 min bei $121{ }^{\circ} \mathrm{C}$ und einem Druck von einem Hektopascal. Nicht hitzebeständige Lösungen wurden durch eine Celluloseacetat-Membran mit einem Porendurchmesser von $0,22 \mu \mathrm{m}$ bzw. $0,45 \mu \mathrm{m}$ 
sterilfiltriert. Nicht autoklavierbares Material wurde für $10 \mathrm{~min}$ in $70 \%$ igem (v/v) Ethanol gespült.

\subsubsection{Blutprobengewinnung und -aufbereitung}

Die Blutprobenentnahme erfolgte an den Herkunftsorten A-F an lebenden, betäubten Stören mittels einer Herzpunktion. Hierzu wurden die Tiere einzeln aus dem jeweiligen Behältnis mit einem Kescher entnommen, mit dem Rücken auf eine mit Wasser durchnäßten Schaumstoffmatte plaziert und von zwei Personen fixiert. Eine dritte Person führte dann die Herzpunktion durch. Verwendet wurden hierfür $5 \mathrm{ml}$ Einmalspritzen entweder 0,70 x $30 \mathrm{~mm}$ oder 0,90 x $40 \mathrm{~mm}$ Einmal-Injektions-kanülen. Bei den Wildfängen (Herkunftsort G) stammte das Blut entweder aus den Kiemen oder der Schwanzvene (Vena cauda cranialis) (L. Debus, pers. Mitteilung). Das Probenvolumen umfasste in Abhängigkeit von der Größe des Probanden zwischen 0,5 und $4 \mathrm{ml}$ und wurde in ein nummeriertes $5 \mathrm{ml}$ Probengefäß überführt, welches $10.000 \mathrm{IE}$ Heparin als Antikoagulanz enthielt. Da die zehn A. ruthenus-Individuen der Herkunft A eine zu geringe Größe besaßen, wurde diesen nur ca. $20 \mu$ l Blut entnommen. Bis zur weiteren Verarbeitung wurden die Blutproben bei $4{ }^{\circ} \mathrm{C}$ verwahrt.

In dem ersten Aufbereitungsschritt wurden die Blutkörperchen für 5 min bei $1.500 \mathrm{xg}$ sedimentiert. Bis zu $1 \mathrm{ml}$ Blutplasma wurde für biochemische Untersuchungen in ein 1,5 ml Reaktionsgefäss überführt, der restliche Überstand verworfen. Nach einmaliger Waschung des Sediments mit physiologischer Kochsalzlösung (0,9\% (w/v) $\mathrm{NaCl}$ in $\mathrm{ddH}_{2} \mathrm{O}$ ) erfolgte die Aufteilung der Blutkörperchen auf zwei 1,5 ml Reaktionsgefäße, von denen das eine für biochemische Methoden und das andere für die DNA-Isolierung verwendet wurde. Die kurzfristige Lagerung erfolgte im Kühlschrank bei $4{ }^{\circ} \mathrm{C}$, längerfristig wurde das Probenmaterial bei $-20{ }^{\circ} \mathrm{C}$ aufbewahrt. Eine Kennzeichnung der Reaktionsgefäße zusammengesetzt aus Art bzw. Kreuzung, fortlaufender Nummerierung innerhalb Art bzw. Kreuzung sowie Herkunftsort sicherten deren Identifikation. 


\subsubsection{Biochemische Untersuchungsmethoden}

Im Rahmen dieser Arbeit wurden sowohl Allozymsysteme im Blutplasma und in den Blutkörperchen wie auch nichtenzymatische Proteine im Blutplasma auf ihre Eignung hin untersucht, Arten und Arthybriden unterscheiden zu können.

\subsubsection{Verwendete Trennmedien und Probenapplikation}

Die gelelektophoretische Trennung der Allozyme erfolgte entweder in Agarose- oder Stärkegelen, Plasmaproteine wurden in Stärkegelen oder nativen Polyacrylamidgelen aufgetrennt. Die für die Gelelektrophorese notwendigen Puffer sind bei den jeweiligen biochemischen Markern aufgeführt.

\subsection{Agarosegele}

Die Auftrennung von Allozymen erfolgte in 1\%igen (w/v) Agarosegelen. Als Lösungsmedium wurden die für den jeweils zu untersuchenden biochemischen Marker vorbereiteten Gelpuffer verwendet, deren Zusammensetzungen den folgenden Kapiteln entnommen werden können. Die in der horizontalen Elektrophorese eingesetzten Gele wurden auf Glasplatten (300 x 220 x 4 mm) gegossen. Der Auftrag von Blutkörperchen $(10 \mu \mathrm{l})$ auf die Agarosegele erfolgte in zwei auf das Gel aufgelegte Applikationsstreifen. Der erste war $6,5 \mathrm{~cm}$ und der zweite $15,5 \mathrm{~cm}$ parallel vom Gelrand der schmalen Gelseite entfernt. Nach einer zehnminütigen Inkubationszeit bei Raumtemperatur zur Diffusion von Molekülen in das Gel wurde das überschüssige Probenmaterial mit einem Filterpapierstreifen sowie die Applikationsstreifen entfernt und danach mit der gelelektrophoretischen Auftrennung begonnen. Das Gel wurde hierfür mit der 6,5 cm vom Gelrand entfernten Auftragsstelle zur Kathode hin ausgerichtet. 


\subsection{Stärkegele}

Nach dem Kochen der hydrolysierten Stärke (30 g) in 280 ml Allozym-spezifischen Gelpuffer wurde das Gel auf eine mit einem Rahmen versehene Glasplatte (300 x 220 x 4 mm) gegossen. Vor der Verwendung der Stärkegele wurden mit einem Kamm gleichzeitig 20 Taschen (7 mm breit) in die $300 \mathrm{~mm}$ breite Seite der Trennmatrix in einem Abstand von $5 \mathrm{~cm}$ vom unteren Gelrand parallel zur Längsachse gestanzt. In die Taschen erfolgte die Applikation von $4 \times 7 \mathrm{~mm}$ großen Whatman 3-Filterpapierstiuckchen, welche mit dem Probenmaterial (Blutkörperchen oder -plasma) getränkt waren. In der Elektrophoresekammer wurde der lange Matrixabschnitt zur Anode hin ausgerichtet.

\subsection{Native Polyacrylamidgele}

Die Herstellung von in der horizontalen Elektrophorese eingesetzten Polyacrylamidgelen erfolgte in Anlehnung an GAHNE et al. (1977). Hierfür wurde zwischen zwei 200 x 225 x 4 mm große, zuvor mit $\mathrm{ddH}_{2} \mathrm{O}$ gesäuberten Glasplatten, ein an drei Seiten geschlossener Gummirahmen $(25 \times 2 \mathrm{~mm})$ als Abstandhalter plaziert. Nach der Fixierung der so erstellten Gießküvette mit Klemmen wurde zuerst eine 15,5 cm hohe 12\%ige (w/v) Polyacrylamid-Gelschicht gegossen und mit $500 \mu 1$ Isobutanol überschichtet. Diese Polyacrylamid-Schicht war nach 15 min polymerisiert. Das Isobutanol wurde abgegossen und im Anschluss daran eine 4,5 cm hohe 4\%ige (w/v) PolyacrylamidGelschicht gegossen. Nach einer weiteren Stunde erfolgte das Gießen der letzten Polyacrylamidschicht (8\%ig, $2 \mathrm{~cm}$ hoch). Im Anschluss an deren Polymerisation, welche 30 min benötigte, wurden die Klammern, eine der beiden Glasplatten und der Gummirahmen entfernt und das Gel in der eindimensionalen PolyacrylamidGelelektrophorese (1D-PAGE) zur Auftrennung der Albumine und Transferrine eingesetzt. Für die Probenapplikation wurden Filterpapierstïckchen (Whatman 3) von 7 x 4 mm in das Plasma der zu untersuchenden Probe getaucht und auf einem Kamm gelegt. Mit dem Kamm erfolgte die Plazierung der getränkten Filterpapierstückchen ca. 0,5 cm vor der 12\%igen Gelschicht auf die 4\%ige Gelschicht. Zur elektrophoretischen Diffusion der Plasmaproteine wurde das Gel mit der 8\%igen Polaycrylamid-Gelschicht zur Kathode hin 
ausgerichtet und für 20 min eine Stromstärke von $70 \mathrm{~mA}$ angelegt. Im Anschluss daran wurden die Filterpapierstückchen entfernt und mit der Auftrennung begonnen.

Gelpuffer:

$$
\begin{aligned}
& \text { 0,5 Vol } 0,75 \text { M Tris } \\
& \text { 0,5 Vol } 0,05 \text { M Zitronensäure } \\
& \text { 1/250 Vol TEMED }
\end{aligned}
$$

Trennmatrix, 12\%ig:

0,37 Vol 30\%ige Acrylamid-, 0,8\%ige Bisacrylamidlösung

$0,13 \mathrm{Vol} \mathrm{ddH} \mathrm{H}_{2} \mathrm{O}$

0,25 Vol Gelpuffer

0,25 Vol 0,002\%iges (w/v) Ammoniumpersulfat

Trennmatrix, 4\%ig:

0,125 Vol 30\%ige Acrylamid-, 0,8\%ige Bisacrylamidlösung

$0,500 \mathrm{Vol} \mathrm{ddH}_{2} \mathrm{O}$

0,125 Vol Gelpuffer

0,250 Vol 0,002\%iges (w/v) Ammoniumpersulfat

Trennmatrix, 8\%ig:

0,250 Vol 30\%ige Acrylamid-, 0,8\%ige Bisacrylamidlösung

$0,375 \mathrm{Vol} \mathrm{ddH}_{2} \mathrm{O}$

0,125 Vol Gelpuffer

0,250 Vol 0,002\%iges (w/v) Ammoniumpersulfat

\subsubsection{Untersuchte Allozymsysteme und Plasmaproteine}

Im Folgenden werden die Methoden für die Evaluierung der verschiedenen Allozymsysteme und Plasmaproteine aufgeführt. 


\subsection{Adenosindeaminase (ADA, E.C. 3.5.4.4)}

Die Darstellung der ADA aus Erythrozyten erfolgte in Anlehnung an die von KIRCHBERG \& WENDT (1970) beschriebene Methode. Der Elektrodenpuffer wurde vor der Gelelektrophorese frisch angesetzt. Hierfür wurden $125 \mathrm{ml}$ des ADA-Puffers A und $91 \mathrm{ml}$ des ADA-Puffers B zusammengegeben, ad $2.000 \mathrm{ml}$ mit $\mathrm{ddH}_{2} \mathrm{O}$ aufgefüllt und wies einen $\mathrm{pH}-$ Wert von $\mathrm{pH}$ 6,5 auf. Für die Herstellung des 1\%igen (w/v) Agarosegels wurde eine zehnfache Verdünnung des Elektrodenpuffers als Gelpuffer verwendet. Nach der Probenapplikation erfolgte die elektrophoretische Auftrennung bei $10 \mathrm{~V} / \mathrm{cm}$ Gellänge für $45 \mathrm{~min}$ bei $10{ }^{\circ} \mathrm{C}$. Im Anschluss an die Elektrophorese wurde die frisch angesetzte ADAspezifische Färbelösung auf die Geloberfläche gegeben. Die Inkubationsdauer betrug ca. 30 min bei $37^{\circ} \mathrm{C}$.

Puffer A:

Puffer B:

ADA-Färbelösung:
0,5 M Kalium-Dihydrogenphosphat $\left(\mathrm{KH}_{2} \mathrm{PO}_{4}\right)$

$$
\text { 0,5 M Di-Natriumhydrogenphosphat }\left(\mathrm{Na}_{2} \mathrm{HPO}_{4}\right)
$$

\author{
$\mathrm{zu} \quad 10 \mathrm{ml}$ einer $25 \mathrm{mM} \quad \mathrm{KH}_{2} \mathrm{PO}_{4}$-Lösung wurden \\ zugegeben: \\ $15 \mathrm{mg}$ Adenosin \\ 2,5 mg MTT \\ 2,5 mg PMS \\ 0,5 U Xanthin-Oxidase \\ 0,5 U Nukleosid-Phosphorylase
}

\subsection{Adenylatkinase (AK, E.C. 2.7.4.3)}

Die Gelelektrophorese erfolgte unter denselben Bedingungen, wie bei der ADA beschrieben (siehe Kap. 3.2.3.2.1). Die Visualisierung dieses in den Erythrozyten vorkommenden Allozyms geschah durch den Auftrag einer frisch angesetzten AK- 
spezifischen Färbelösung auf die Geloberfläche und einer anschließenden Inkubation für 0,5 Stunden bei $37{ }^{\circ} \mathrm{C}$ (KIRCHBERG \& WENDT 1970).

AK-Färbelösung:

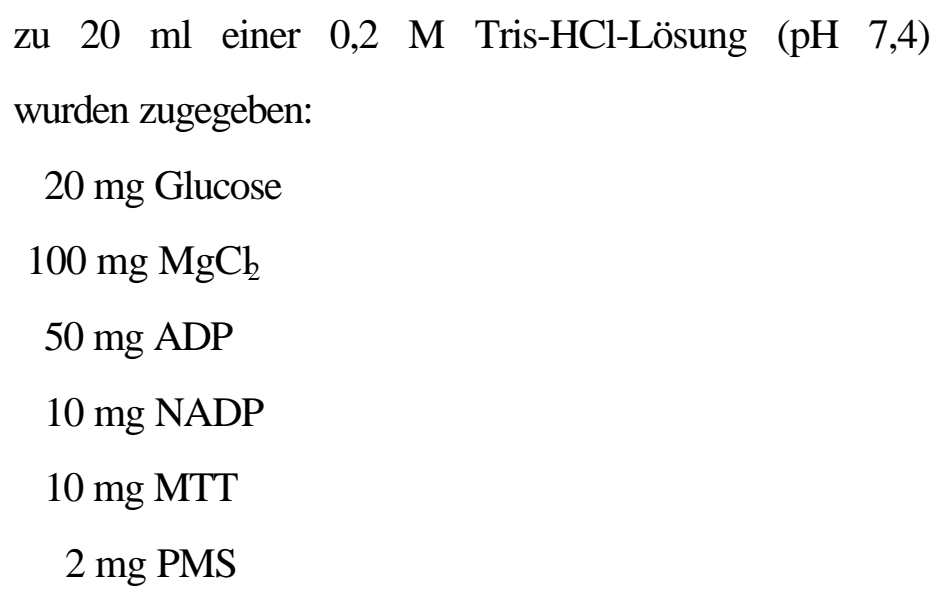

\subsection{Albumine (ALB) und Transferrine (TF)}

Für die Auftrennung in der 1D-PAGE und Färbung der im Blutplasma enthaltenen Albumine und Transferrine wurde ein Protokoll von GAHNE et al. (1977) in modifizierter Form verwendet. Vor der elektrophoretischen Diffusion erfolgte die Zugabe von $200 \mu 1$ einer 1\%igen (w/v) Bromphenolblau-Lösung zu dem Kathodenpuffer zur Kennzeichnung der Laufstrecke. Die elektrophoretische Auftrennung erfolgte bei $4{ }^{\circ} \mathrm{C}$ und einer Stromstärke von 70 mA. Die Elektrophoresedauer betrug insgesamt 3,5 Stunden. Der 12\%ige Polyacrylamid-Gelteil wurde anschließend für $20 \mathrm{~min}$ in der Färbelösung inkubiert. Dem schlossen sich drei Waschschritte á $1 \mathrm{~min}$ in $\mathrm{ddH}_{2} \mathrm{O}$ an. Die Entfärbung des Gels erfolgte in 5\%iger (v/v) Essigsäure über Nacht. Die Auswertung konnte am nächsten Tag erfolgen.

Elektrodenpuffer:

0,0650 M Tris

0,0325 M Borsäure

$\mathrm{pH} 5,6$ 
Färbelösung: $\quad$ 0,02\% (w/v) Coomassie-Blue G 250

$3,50 \%(v / v)$ Perchlorsäure

\subsection{Alkalische Phosphatase (AKP, E.C. 3.1.3.1)}

Die Untersuchung der alkalischen Phosphatase aus Blutplasma wurde bis auf die Färbung, welche in Anlehnung an GAHNE (1963) erfolgte, nach einem ursprünglich für die Carboanhydrase (CA) entwickelten Protokoll (KLOSTER et al. 1970) durchgeführt. Für die Herstellung von 12\%igen (w/v) Stärke- oder 1\%igen (w/v) Agarosegelen wurde AKPGelpuffer verwendet. Die Elektrophorese fand bei einer konstanten Spannung von $10 \mathrm{~V} / \mathrm{cm}$ Gellänge für 3,5 Stunden bei $10{ }^{\circ} \mathrm{C}$ unter Einsatz des AKP-Elektrodenpuffers statt. Im Anschluss an die elektrophoretische Auftrennung wurde das Gel für 1,5 Stunden in der AKP-Färbelösung inkubiert und danach bis zur vollständigen Entfärbung des Gels in CA/AKP-Entfärber inkubiert.

CA/AKP-Gelpuffer:

0,079 M Tris

0,007 M Zitronensäure

$\mathrm{pH} 8,5$

CA/AKP-Elektrodenpuffer: $\quad$ 0,060 M Lithiumhydroxid

0,229 M Borsäure

$\mathrm{pH} 8,5$

AKP-Färbelösung:

$50 \mathrm{ml} \mathrm{0,1} \mathrm{M} \mathrm{Tris-HCl} \mathrm{Puffer} \mathrm{(pH} \mathrm{8,6)}$

2,5 ml 0,8 M Magnesiumchlorid-Hexahydratlösung

$4 \mathrm{ml} 1 \%$ iges (w/v) Natrium- $\alpha$-Naphthylphosphat

0,1 g Fast Garnet GBC Salz

CA/AKP-Entfärber:

4,5 : 5,5 : 1 Methanol-Wasser-Essigsäure 


\subsection{Carboanhydrase (CA, E.C. 4.2.1.1)}

Die Darstellung der CA aus dem Blutplasma erfolgte nach KLOSTER et al. (1970) und glich bis auf die Färbung der unter Kapitel 3.2.3.2.4 beschriebenen Vorgehensweise. Für die Färbung wurden $125 \mathrm{ml}$ CA-Färbelösung mit dem gleichen Volumen absoluten Methanol frisch vermischt. Die Hälfte der Lösung wurde dann auf das Gel gegeben, der verbliebene Rest wurde mit $3 \mathrm{ml}$ 2\%iges (w/v) $\alpha$-Naphthylacetat gelöst in 50\%igem (v/v) Aceton sowie $100 \mathrm{mg}$ Fast Blue B-Salz gemischt und ebenfalls aufgetragen. Die Inkubationsdauer betrug 1,5 Stunden bei $37^{\circ} \mathrm{C}$.

CA-Färbelösung: $\quad$ 0,2 M Tris $\quad$ 0,2 M Maleinsäure
pH 7,0

\subsection{Diaphorase (DIA, E.C. 1.6.9.1)}

Die in den Erythrozyten enthaltene DIA wurde nach der Methode von TARIVERDIAN et al. (1970) dargestellt. Als Trennmatrix diente ein 1\%iges (w/v) Agarosegel, welches unter Verwendung von DIA-Gelpuffer hergestellt wurde. Nach dem Probenauftrag über den Applikationsstreifen erfolgte die Elektrophorese mit DIA-Elektrophoresepuffer bei einer angelegten Spannung von $25 \mathrm{~V} / \mathrm{cm}$ Gellänge, $4{ }^{\circ} \mathrm{C}$ für eine Stunde. Der Auftrennung schloss sich dann eine Inkubation in DIA-Färbepuffer für eine Stunde bei $37{ }^{\circ} \mathrm{C}$ an.

DIA-Elektrodenpuffer: $\quad$ 0,42 M Tris

0,07 M Zitronensäure

$\mathrm{pH} 8,6$

DIA-Gelpuffer: $\quad 0,050 \mathrm{M}$ Tris

0,015 M Zitronensäure

$\mathrm{pH} \mathrm{7,2}$ 
DIA-Färbelösung: $\quad$ zu $30 \mathrm{ml}$ einer $0,25 \mathrm{M}$ Tris-HCl-Lösung $(\mathrm{pH} \mathrm{8,5)}$
werden gegeben
$0,3 \mathrm{~g}$ Agar
$2 \mathrm{ml}$ NADH-Lösung $(5 \mathrm{mg} \mathrm{NADH} / \mathrm{ml})$
$2 \mathrm{ml}$ MTT-Lösung $(3,5 \mathrm{mg} \mathrm{MTT} / \mathrm{ml})$
$0,5 \mathrm{ml} \mathrm{DCIP-Lösung}(2,25 \mathrm{mg} \mathrm{DCIP} / \mathrm{ml})$

\subsection{Esterase-D (EST-D, E.C. 3.1.1.1)}

In Anlehnung an die Methode von BOYER (1961) erfolgte die Darstellung der in den Erythrozyten enthaltenen EST-D. Für die Herstellung der 1\%igen (w/v) Agarosematrix wurde ein fünfzehnfach verdünnter Elektrodenpuffer als Gelpuffer eingesetzt. Die Auftrennung der EST-D geschah für $1,5 \mathrm{~h}$ bei $10{ }^{\circ} \mathrm{C}$ mit $10 \mathrm{~V} / \mathrm{cm}$ Gellänge. Im Anschluss an die Elektrophorese erfolgte der Auftrag der spezifischen Färbelösung auf die Geloberfläche. Nach 15 min konnte dieses Allozym unter UV-Licht visualisiert werden.

Elektrodenpuffer:

$$
\begin{aligned}
& \text { 0,25 M Tris } \\
& \text { 0,06 M Zitronensäure } \\
& \text { pH 8,0 }
\end{aligned}
$$

EST-D-Färbelösung:

$$
\begin{aligned}
& \text { zu } 10 \mathrm{ml} \text { einer 0,03 M Tris-HCl-Lösung (pH 8,0) } \\
& \text { wurden gegeben } \\
& 5 \mathrm{mg} \text { 4-Methylumbelliferylacetat (gelöst in } 50 \mu \mathrm{l} \\
& \text { Aceton) }
\end{aligned}
$$

\subsubsection{8 $\alpha$-Glycerophosphatdehydrogenase ( $\alpha$-GPDH, E.C. 1.1.1.8)}

Die im Blutplasma enthaltene $\alpha$-GPDH wurde nach der bei SHAW \& PRASAD (1970) beschriebenen Methode in einem 1\%igem (w/v) Agarosegel unter Verwendung der unten angegebenen Puffer untersucht. Die elektrophoretische Auftrennung fand bei $10 \mathrm{~V} / \mathrm{cm}$ 
Gellänge und $10{ }^{\circ} \mathrm{C}$ für 1,5 Stunden statt. Für die Visualisierung dieses Allozyms wurde eine spezifische Färbelösung verwendet, in welcher das Gel für eine Stunde bei $37{ }^{\circ} \mathrm{C}$ inkubiert wurde.

$\alpha$-GPDH-Gelpuffer:

$50 \mathrm{mM}$ Tris

$75 \mathrm{mM}$ Borsäure

1,5 mM Titriplex III

$\mathrm{pH} 7,7$

$\alpha$-GPDH-Elektrodenpuffer: $\quad$ 0,5 M Tris

0,5 M Borsäure

15 mM Titriplex III

$\mathrm{pH} \mathrm{7,7}$

$\alpha$-GPDH-Färbelösung:

$10 \mathrm{ml}$ 0,5 M Tris-HCl-Puffer (pH 7,1)

$5 \mathrm{ml} 1 \mathrm{M}$ Natrium- $\alpha$-Glycerophosphat $(\mathrm{pH} 7,0)$

$2 \mathrm{ml} \mathrm{0,1} \mathrm{M} \mathrm{Natriumcyanid}$

15 mg NAD

$8 \mathrm{mg}$ MTT

$1 \mathrm{mg}$ PMS

\subsection{Glucosephosphatisomerase (GPI, E.C. 5.3.1.9)}

Für die Darstellung der in den Erythrozyten lokalisierte GPI wurde die bei ANDRESEN (1970) beschriebene Vorgehensweise modifiziert. Die verwendeten Puffer entsprachen den bei der EST-D beschriebenen (siehe Kap. 3.2.3.2.7). Gleiches galt für die Auftrennung. Für die Färbung fand ein GPI-spezifischer Färbepuffer Verwendung. Dieser wurde auf die Geloberfläche aufgetragen und für $45 \mathrm{~min}$ bei $37^{\circ} \mathrm{C}$ inkubiert. 
GPI-Färbepuffer:

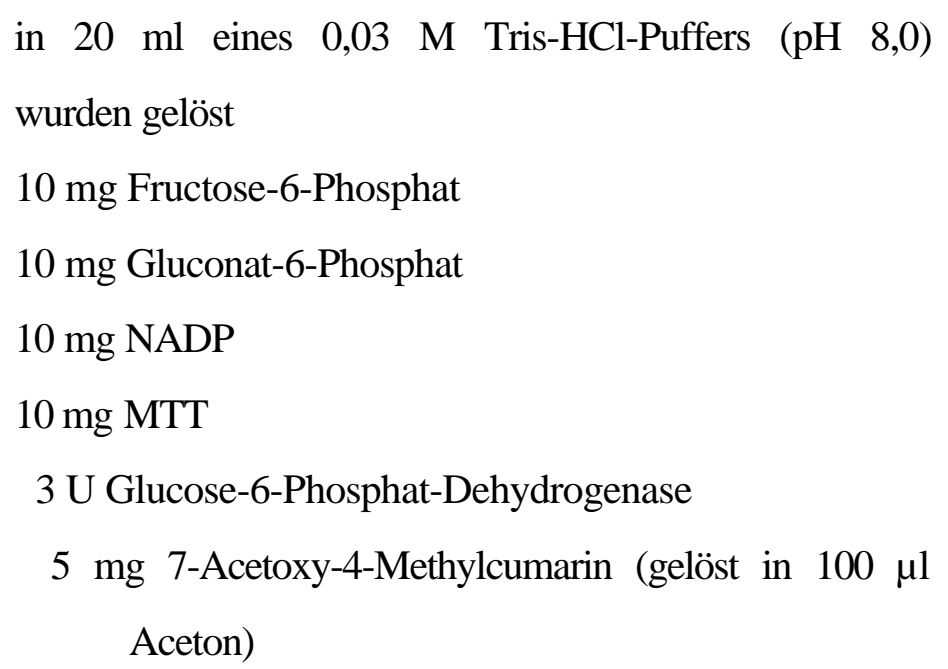

\subsection{Laktatdehydrogenase (LDH, E.C. 1.1.1.27)}

Für die Darstellung der LDH aus den Erythrozyten kamen dieselben Puffer wie bei der $\alpha$-GPDH in Kap. 3.2.3.2.8 beschrieben zum Einsatz. Im Anschluss an die elektrophoretische Auftrennung bei $300 \mathrm{~V}$ und $10{ }^{\circ} \mathrm{C}$ für 1,5 Stunden erfolgte die Visualisierung in Anlehnung an SHAW \& PRASAD (1970). Vor der Färbung mußte das Gel in 0,2 M Tris-HCl (pH 8,0) für 10 min abgepuffert werden. Danach wurde der Puffer dekantiert und die Färbelösung auf das Gel aufgetragen, dem eine einstündige Inkubation bei $37^{\circ} \mathrm{C}$ folgte.

LDH-Färbelösung:

$$
\begin{aligned}
& 20 \text { ml DL-Laktat-Lösung } \\
& 2 \text { mg NAD } \\
& 5 \text { mg MTT } \\
& 5 \text { mg PMS }
\end{aligned}
$$

DL-Laktat-Lösung:

$$
\begin{aligned}
& \text { 0,20 M Tris } \\
& \text { 0,33 M DL-Laktat } \\
& \text { pH 7,0 }
\end{aligned}
$$




\subsection{Phosphoglucomutase (PGM, E.C. 2.7.5.1)}

Mit leichten Modifikationen wurde das bei SPENCER et al. (1964) beschriebene Verfahren für die Darstellung der in den Erythrozyten lokalisierten PGM verwendet. Die Herstellung des 1\%igen (w/v) Agarosegels erfolgte mit zehnfach verdünntem Elektrodenpuffer, wobei mit $1 \mathrm{M}$ Maleinsäure der $\mathrm{pH}$ 7,45 eingestellt wurde. Die Elektrophorese wurde für $2 \mathrm{~h}$ bei $3,5 \mathrm{~V} / \mathrm{cm}$ Gellänge und $10{ }^{\circ} \mathrm{C}$ durchgeführt. Im Anschluss wurde eine Inkubation mit PGM-Färbepuffer bei $37^{\circ} \mathrm{C}$ für 45 min durchgeführt.

Elektrodenpuffer

$$
\begin{aligned}
& \text { 0,120 M Tris } \\
& \text { 0,100 M Maleinsäure } \\
& 0,010 \mathrm{M} \text { EDTA } \\
& 0,035 \mathrm{M} \mathrm{MgCh} \\
& \text { ad pH 7,9 mit } 1 \mathrm{~N} \mathrm{NaOH}
\end{aligned}
$$

PGM-Färbepuffer:

$$
\begin{aligned}
& \text { in } 20 \mathrm{ml} \text { eines } 0,03 \mathrm{M} \text { Tris-HCl-Puffers (pH 8,0) } \\
& \text { wurden gelöst } \\
& 100 \mathrm{mg} \text { Glucose-1-Phosphat } \\
& 100 \mathrm{mg} \mathrm{MgCh} \\
& 10 \mathrm{mg} \text { NADP } \\
& 10 \mathrm{mg} \text { MTT } \\
& 1 \mathrm{mg} \text { PMS } \\
& \text { 0,1 mg Glucose-1,6-Di-Phosphat } \\
& \text { 3,5 U Glucose-6-Phosphatdehydrogenase }
\end{aligned}
$$

\subsection{6-Phosphogluconat-Dehydrogenase (6PGD, E.C. 1.1.1.43)}

Die in den Erythrozyten enthaltene 6PGD wurde nach dem bei TARIVERDIAN et al. (1971) beschriebenen Verfahren dargestellt. Das 1\%ige (w/v) Agarosegel wurde mit zwanzigfach verdünntem Elektrodenpuffer angesetzt. Die Auftrennung erfolgte bei $10 \mathrm{~V} / \mathrm{cm}$ 
Gellänge für 1,5 h und $10^{\circ} \mathrm{C}$. Danach erfolgte die Applikation des 6PGD-Färbepuffers auf die Geloberfläche, der sich eine Inkubation bei $37^{\circ} \mathrm{C}$ für $45 \mathrm{~min}$ anschloss.

Färbepuffer:

$$
\begin{aligned}
& \text { 0,125 M Tris- } \mathrm{HCl}(\mathrm{pH} 7,5) \\
& \text { 0,040 M MgCh } \\
& 20 \text { mg Gluconat-6-Phosphat } \\
& 2 \text { mg NADP } \\
& 4 \text { mg MTT } \\
& 1 \text { mg PMS }
\end{aligned}
$$

Elektrodenpuffer: $\quad$ 0,09 M Natrium-Dihydrogenphosphat 0,09 M Di-Natriumhydrogenphosphat

\subsubsection{Molekularbiologische Methoden}

\subsubsection{Isolierung von Nukleinsäuren}

Verschiedene Techniken wurden für die Isolierung genomischer DNA aus unterschiedlichen Geweben und DNA-Fragmenten aus Agarosegelen angewendet.

\subsection{Isolierung von DNA aus Blut durch Aussalzung}

Für die Isolierung von DNA aus Blut bzw. der angereicherten Fraktion der Blutkörperchen (siehe Kap. 3.2.2) wurde ein von WINK \& WEHRLE (1994) beschriebenes Protokoll leicht modifiziert verwendet.

Für die Präparation wurden 0,1 bis $0,5 \mathrm{ml}$ von der angereicherten Fraktion der Blutkörperchen in $5 \mathrm{ml}$ Isolierungspuffer gegeben und kräftig geschüttelt. Danach erfolgte die Zugabe von $50 \mu 1$ Proteinase K-Stammlösung und 0,3 ml einer 20\%igen (w/v) SDSLösung. Dem nachfolgenden Mischen schloss sich eine Inkubation bei $37{ }^{\circ} \mathrm{C}$ über Nacht 
an. Am nächsten Tag wurden $3 \mathrm{ml}$ einer gesättigten $\mathrm{NaCl}$-Lösung addiert, das Gemisch kräftig geschüttelt und die Proteine bei 4.000 x g für 10 min sedimentiert. Der Überstand wurde in ein neues Reaktionsgefäß überführt und mit zwei Volumen 100\%igem Ethanol versetzt. Bei den Proben der Herkunftsorte A bis F wurde die DNA mit einem Glashaken aus der Lösung gezogen, in 70\%igem (v/v) Ethanol gewaschen, 1 min getrocknet und anschließend in $500 \mu 1$ Lösungspuffer überführt und über Nacht gelöst. Bei den Proben der Herkunft G erfolgte die Präzipitierung der DNA bei 7.500 x g für 20 min, da kein DNAKnäuel sichtbar war. Das Pellet wurde mit 70\%igem (v/v) Ethanol gespült, $10 \mathrm{~min}$ luftgetrocknet und anschließend in $100 \mu \mathrm{l}$ Lösungspuffer aufgenommen.

Isolierungspuffer:

Proteinase K-Stammlösung:

SDS-Lösung, 20\%ig (w/v):

NaCl-Lösung, gesättigt:

Lösungspuffer:
25 mM EDTA

$75 \mathrm{mM} \mathrm{NaCl}$

$10 \mathrm{mM}$ Tris

$\mathrm{pH} 7,5$

Autoklavierung der Lösung

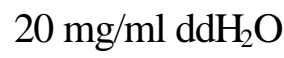

Aliquotierung und Aufbewahrung bei $-20{ }^{\circ} \mathrm{C}$

$20 \mathrm{~g}$ Natriumdodecylsulfat wurden in $90 \mathrm{ml} \mathrm{ddH}_{2} \mathrm{O}$ bei $68{ }^{\circ} \mathrm{C}$ gelöst, der $\mathrm{pH}$-Wert 7,2 mit konzentrierter $\mathrm{HCl}$ eingestellt und ad $100 \mathrm{ml}$ mit $\mathrm{ddH}_{2} \mathrm{O}$ aufgefüllt.

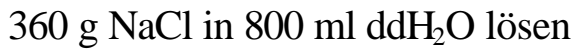

ad 11 Endvolumen mit $\mathrm{ddH}_{2} \mathrm{O}$ auffüllen

Autoklavierung

$10 \mathrm{mM}$ Tris

pH 8,0

Autoklavierung 


\subsection{Freisetzung von DNA aus Blut mittels Chelex ${ }^{\circledR} 100$}

Wegen der sehr geringen Probenmenge von den zehn Individuen der Störspezies A. ruthenus aus der Herkunft A erfolgte eine Freisetzung der genomischen DNA für PCRAnwendungen mittels Chelex ${ }^{\circledR} 100$ (WALSH et al. 1991). Hierzu wurde $1 \mathrm{ml} \mathrm{ddH}_{2} \mathrm{O}$ zu 3-10 $\mu 1$ Probenmaterial gegeben und gemischt. Nach einer Inkubation bei Raumtemperatur für 30 min, während der die Probe ab und an geschwenkt wurde, erfolgte eine Sedimentierung durch Zentrifugation für $3 \mathrm{~min}$ bei $15.000 \mathrm{x}$ g. Der Überstand wurde bis auf einen Rest von ca. $20 \mu \mathrm{l}$ verworfen, die Probe anschließend mit einer 5\%igen (w/v) Chelex-Lösung auf ein Volumen von $200 \mu \mathrm{l}$ gebracht. Einer Inkubation bei $56{ }^{\circ} \mathrm{C}$ für 30 min folgte eine kräftige Durchmischung der Lösung sowie eine nachfolgenden Inkubation bei $100{ }^{\circ} \mathrm{C}$ für 8 min. Vor dem Einsatz der mittels Chelex freigesetzten DNA als Template in der PCR wurde die Probe ca. $10 \mathrm{sec}$ kräftig geschüttelt, 3 min bei $15.000 \mathrm{x} \mathrm{g}$ zentrifugiert und $1 \mu \mathrm{l}$ des Überstandes für die Amplifikation verwendet.

\subsection{Isolierung von DNA aus Kaviar}

Die DNA-Isolierung aus Kaviar erfolgte in Anlehnung an MöLLER et al. (1992). Für die Präparation wurden ca. $3 \mathrm{mg}$ Kaviar in einem Mörser unter Zugabe von flüssigem Stickstoff mechanisch aufgeschlossen. Das derart verarbeitete Probenmaterial wurde danach in 7,5 ml TES-Puffer aufgenommen, mit $75 \mu$ l Proteinase K-Stammlösung versetzt und eine Stunde bei $55{ }^{\circ} \mathrm{C}$ inkubiert. Der Ansatz wurde während der Inkubation gelegentlich vorsichtig geschwenkt und anschließend in ein $65^{\circ} \mathrm{C}$ Wasserbad überführt. Es wurden 2,1 ml einer $5 \mathrm{M} \mathrm{NaCl-Lösung} \mathrm{sowie} 975 \mu \mathrm{l}$ einer 10\%igen (w/v) CTAB-Lösung zugegeben. Beide Lösungen waren zuvor ebenfalls auf $65{ }^{\circ} \mathrm{C}$ temperiert worden. Nach einer 10 minütigen Inkubation wurde der Ansatz mit $10 \mathrm{ml}$ Chloroform-Isoamylalkohol (24:1) vermischt und für $30 \mathrm{~min}$ auf Eis inkubiert. Eine Phasentrennung und somit die Extraktion der komplexierten Proteine und Polysaccharide geschah durch eine zehnminütige Zentrifugation bei $15.000 \mathrm{x}$ g. Der wässrige Überstand wurde in eine neues Zentrifugengefäß überführt, mit $3.375 \mu$ l einer $5 \mathrm{M}$ Ammoniumacetat-Lösung versetzt und mindestens $1 \mathrm{~h}$ bei $0{ }^{\circ} \mathrm{C}$ inkubiert. Im Anschluss erfolgte die Präzipitierung verbliebener 
Verunreinigungen durch Zentrifugation (15.000 x g, $\left.4{ }^{\circ} \mathrm{C}, 10 \mathrm{~min}\right)$. Der wässrige Überstand wurde wiederum in ein neues Gefäß überführt und RNA durch die Zugabe von $45 \mu$ leiner RNAse A-Stammlösung für $1 \mathrm{~h}$ bei $37^{\circ} \mathrm{C}$ verdaut. Einer anschließenden Reinigung mit $10 \mathrm{ml}$ Phenol-Chloroform-Isoamylalkohol (25:24:1) zur Entfernung des Enzyms folgte ein letzter Extraktionsschritt des wässrigen Überstandes mit $10 \mathrm{ml}$ Chloroform-Isoamylalkohol (24:1). Schließlich wurde die DNA durch Zugabe von 0,55 Volumen Isopropanol gefällt und durch Zentrifugation bei 15.000 x g für 15 min sedimentiert. Das verbliebene Pellet wurde mit 70\%igem (v/v) Ethanol gespült, luftgetrocknet und in $50 \mu$ Lösungspuffer resuspendiert.

TES-Puffer:

$100 \mathrm{mM}$ Tris

10 mM EDTA

$2 \%(\mathrm{w} / \mathrm{v}) \mathrm{SDS}$

$\mathrm{pH} 8,0$

CTAB-Lösung:

$10 \%(\mathrm{w} / \mathrm{v}) \mathrm{CTAB}$

$0,7 \mathrm{M} \mathrm{NaCl}$

$10 \mathrm{mM}$ Tris

1 mMEDTA

$\mathrm{pH} \mathrm{7,6}$

RNAse A-Stammlösung: $\quad 10 \mathrm{mg}$ RNAse A wurden in $1 \mathrm{ml} 0,01 \mathrm{M}$ Natriumacetat (pH 5,2) gelöst, 15 min bei $100{ }^{\circ} \mathrm{C}$ inkubiert und anschließend 0,1 Volumen $1 \mathrm{M}$ Tris (pH 7,4) zugegeben. Aliquots wurden bei $-20{ }^{\circ} \mathrm{C}$ gelagert.

\subsection{Isolierung von DNA-Fragmenten aus Agarosegelen}

Die Isolierung von in der PCR amplifizierten DNA-Fragmenten erfolgte nach der elektrophoretischen Auftrennung aus Agarosegelen mit dem QIAEX II Gel Extraction Kit oder mit dem QIAquick Gel Extraction Kit nach Anleitung des Herstellers. 


\section{QIAEX II Gel Extraction}

Nach der elektrophoretischen Auftrennung der DNA im maximal 2\%igen (w/v), Ethidiumbromid-haltigen Agarosegel wurde das gewünschte Fragment aus dem Gel mit einem Skalpell, das zuvor mit 70\%igem (v/v) Ethanol gesäubert wurde, herausgeschnitten und in ein 1,5 ml Reaktionsgefäß überführt. Das Gewicht des Gelstückchens wurde bestimmt und pro mg Gel wurden drei Volumen $(\mu \mathrm{l})$ des Puffers QX1 addiert. Im Anschluss an die Zugabe von $10 \mu \mathrm{l}$ zuvor gut durchgemischter QIAEX II-Silikatpartikel erfolgte eine zehnminütige Inkubation bei $50{ }^{\circ} \mathrm{C}$. Um eine hohe Extraktionseffizienz zu erreichen, wurde durch kräftiges Schütteln der Lösung im zeitlichen Abstand von jeweils 2 min eine Sedimentierung der DNA-bindenden Silikatpartikel unterbunden. Der Inkubation schloss sich eine Sedimentierung der Partikel bei 15.000 x g für $30 \mathrm{sec}$ an. Das Pellet wurde danach mit $500 \mu 1$ des Puffers QX1 sowie zweimal mit je $500 \mu 1$ des Puffers PE gewaschen und für 10 bis 15 min luftgetrocknet. Danach wurde es in $20 \mu \mathrm{HPLC}-\mathrm{H}_{2} \mathrm{O}$ aufgenommen und $5 \mathrm{~min}$ bei Raumtemperatur inkubiert, wobei auch hier die Sedimentierung der Silikatpartikel durch zeitweiliges Schütteln unterbunden wurde. Durch eine Zentrifugation $(15.000 \mathrm{x} \mathrm{g}, 30 \mathrm{sec})$ wurden die Silikatpartikel sedimentiert und der DNA-haltige wässrige Überstand in ein neues Reaktionsgefäß überführt.

\section{QIAquick Gel Extraction}

Das gewünschte DNA-Fragment wurde nach der elektrophoretischen Auftrennung aus maximal 2\%igen (w/v) Agarosegel mit einem Skalpell ausgeschnitten, in ein 1,5 ml Reaktionsgefäß überführt und gewogen. Anschließend erfolgte die Zugabe von drei Volumen des Puffers QG zu einem Gelvolumen. Das Gelvolumen wurde dabei aus dem Gewicht abgeleitet (z.B. $100 \mathrm{mg} \mathrm{Gel} \approx 100 \mu \mathrm{l}$ ). Dem folgte eine Inkubation des Ansatzes bei $50{ }^{\circ} \mathrm{C}$ für $10 \mathrm{~min}$, eine vollständige Durchmischung wurde durch regelmäßiges Schütteln im Abstand von zwei bis drei Minuten gewährleistet. Nachdem das Gel aufgelöst war, erfolgte die Zugabe von einem Gelvolumen an absolutem Isopropanol. Das Gemisch wurde in eine QIAquick-Säule überführt, die sich in einem $2 \mathrm{ml}$ Kollektionsgefäß befand. Nach der Zentrifugation bei 15.000 x g für 1 min erfolgte nochmals ein Waschschritt mit $500 \mu \mathrm{l}$ Puffer QG unter Verwendung eines neuen Kollektionsgefäßes. Im Anschluss daran wurde die Säule mit $750 \mu l$ Puffer PE aufgefüllt und der Ansatz für 5 min bei Raumtemperatur inkubiert. Zwei Zentrifugationsschritte für $1 \mathrm{~min}$ bei $15.000 \mathrm{x}$ g, bei denen jeweils neue 
Kollektionsgefäße zum Einsatz kamen, sorgten für die vollständige Entfernung des Waschpuffers. Die Säule wurde dann in ein beschriftetes 1,5 ml Reaktionsgefäß überführt, $30 \mu \mathrm{HPLC}-\mathrm{H}_{2} \mathrm{O}$ zugegeben und bei $50{ }^{\circ} \mathrm{C}$ für 1 min inkubiert. Die derart aus dem Gel isolierte und gereinigte DNA wurde in einem letzten Zentrifugationsschritt bei $15.000 \mathrm{x}$ g für 1 min von der Säule in das Reaktionsgefäß überführt.

\subsubsection{Reinigung und Fällung von Nukleinsäuren}

Die hier aufgeführten Methoden kamen nur dann zum Einsatz, wenn das ausschließliche Vorhandensein des (der) DNA-Fragments (-Fragmente) gesichert war. Traten neben dem (den) gewünschten DNA-Fragment(en) zusätzlich unspezifische Produkte auf, wurde eine DNA-Isolierung durchgeführt (siehe Kap. 3.2.4.1.4).

\subsection{Reinigung mittels Anionenaustauschchromatographie}

Für die Reinigung von PCR-Fragmenten aus Agarosegelen wurde der QIAquick Gel Extraction Kit eingesetzt. Die Vorgehensweise hierfür erfolgte nach der Vorschrift des Herstellers.

Für die Reinigung von PCR-Produkten wie auch enzymatisch modifizierten Nukleinsäuren wurde der QIAquick PCR Purification Kit eingesetzt. Die Vorgehensweise hierfür erfolgte anhand des Handbuchs vom Hersteller.

Fünf Volumen des Puffers PB wurden zu einem Volumen des Reaktionsansatzes gegeben, beide Lösungen gemischt und in eine Säule gegeben, welche eine silikathaltige Membran zur DNA-Bindung enthält. Die Säule wurde in ein $2 \mathrm{ml}$ Kollektionsgefäß plaziert und $1 \mathrm{~min}$ bei $15.000 \mathrm{x}$ g zentrifugiert. Der Durchfluss wurde verworfen und die an die silikathaltige Membran gebundene DNA mit 0,75 ml Puffer PE gewaschen. Nach der Zugabe von $30 \mu \mathrm{l}$ Lösungspuffer und einer einminütigen Inkubation bei Raumtemperatur erfolgte die Elution der DNA durch Zentrifugation (15.000 x g, $1 \mathrm{~min})$ in ein 1,5 ml Reaktionsgefäß. 


\subsection{DNA-Fällung mittels Natriumacetat und Ethanol}

Für die Natriumacetat-Ethanol-Fällung wurde zu der DNA-haltigen Lösung ein Zehntel ihres Volumens einer $3 \mathrm{M}$ Natriumacetat-Lösung ( $\mathrm{pH} 4,6)$ sowie 2,5 Volumen an absolutem Ethanol gegeben. Lag das Ausgangsvolumen der DNA-haltigen Lösung unter $100 \mu \mathrm{l}$, so wurde dieses zuvor mit $\mathrm{ddH}_{2} \mathrm{O}$ ad $100 \mu \mathrm{l}$ aufgefüllt. Nach der Vermischung des Ansatzes erfolgte eine Inkubation für $15 \mathrm{~min}$ bei Raumtemperatur, der sich eine Zentrifugation bei 15.000 x g für 15 min anschloss. Das Pellet wurde danach mit $300 \mu \mathrm{l}$ 70\%igem (v/v) Ethanol gewaschen, luftgetrocknet und in der gewünschten Menge an Lösungspuffer aufgenommen.

Natriumacetat-Lösung: $\quad 3$ M Natriumacetat

Einstellen des pH-Wertes 4,6 mit Essigsäure

Autoklavierung

\subsubsection{Konzentrationsbestimmung von DNA}

Die DNA-Konzentration der Lösungen, die eine relativ hohe Menge an DNA enthielten, wurden photometrisch gemessen. Die photometrische Analyse erfolgte mit zwei Quarzglasküvetten, von denen eine als Referenzwert diente und nur $\mathrm{ddH}_{2} \mathrm{O}$ enthielt. In der anderen befand sich die zu untersuchende, in $\mathrm{ddH}_{2} \mathrm{O}$ verdünnte DNA. Eine Messung erfolgte bei den drei Extinktionswerten $260 \mathrm{~nm}, 280 \mathrm{~nm}$ und $320 \mathrm{~nm}$. Aus der LichtAbsorbtion einer DNA-Lösung bei $260 \mathrm{~nm}$ konnte die DNA-Konzentration in der Lösung berechnet werden, wobei eine optische Dichte (OD) von 1 einer Konzentration von $50 \mu \mathrm{g} / \mathrm{ml}$ doppelsträngiger DNA entsprach. Anhand des aus den Extinktionswerten bei $260 \mathrm{~nm}$ und $280 \mathrm{~nm}$ errechneten Quotienten konnte der Reinheitsgrad der DNA hinsichtlich möglicher Verunreinigungen durch Proteine ermittelt werden. Reine DNA wies einen Quotienten von 1,8 auf (SAMBROOK et al. 1989). Demgegenüber konnten Verunreinigungen mit Salzen bei $320 \mathrm{~nm}$ festgestellt werden.

Lag die DNA hingegen in geringer Menge in einem kleinen Volumen vor, so wurde ihre Konzentration durch Ethidiumbromid-Fluoreszenz im Agarosegel im Vergleich zu dem 
Molekulargewichtstandard $\lambda$ DNA/Hind III bei nur sehr geringem Probeneinsatz $(1 \mu \mathrm{l})$ ermittelt. Da von dem Molekulargewichtstandard eine definierte Menge an DNA $(0,5 \mu \mathrm{g})$ aufgetragen wurde, konnte jedes seiner elektrophoretisch aufgetrennten Fragmente quantifiziert werden. Somit war es möglich, die DNA-Menge der zu untersuchenden Probe unter UV-Licht hinsichtlich ihrer visuell ermittelten Fluoreszenz im Vergleich zu den Fragmenten des Molekulargewichtstandards abzuschätzen.

\subsubsection{Elektrophoretische Trennung von DNA}

Die elektrophoretische Trennung von DNA erfolgte in Agarosegelen, Polyacrylamidgelen oder bei Verwendung des Sequenzierautomaten ABI Prism 310 in viskosen Polymeren innerhalb einer Kapillare. Für die Agarose- und PolyacrylamidGelelektrophorese wurde 1 x TBE als Laufpuffer verwendet, der aus einer fünffach konzentrierten Stammlösung hergestellt wurde. Die gleiche Endkonzentration an TBE war auch in der jeweiligen Trennmatrix enthalten. Für den Sequenzierautomaten ABI Prism 310 wurde hingegen ein kommerziell erhältlicher, zehnfach konzentrierter Elektrophoresepuffer, der die Komponenten EDTA und Ethylendiamin-Tetraessigsäure ohne näher spezifizierte Konzentrationsangaben enthielt, in Form einer zehnfachen Verdünnung eingesetzt.

In den Fällen, in denen eine Abschätzung der Fragmentlängen von der elektrophoretisch aufgetrennten DNA notwendig war, wurden in Abhängigkeit von der (den) Fragmentlänge(n) verschiedene DNA Molekulargewichtstandards eingesetzt. Ausgenommen hiervon waren native Polyacrylamidgele und Sequenzierungen. Auf die spezielle Verwendung der einzelnen Molekulargewichtstandards wird in den nachfolgenden Kapiteln hingewiesen.

5 x TBE-Puffer-Stammlösung: $\quad 445 \mathrm{mM}$ Tris

445 mM Borsäure

10 mM EDTA

$\mathrm{pH} 8,0$

Autoklavierung 


\subsection{Agarose-Gelelektrophorese}

Die Wahl der Agarosekonzentration richtete sich nach der zu erwartenden Größe der DNA-Fragmente sowie nach dem Anwendungsbereich. Analytische Gele wiesen Agarosekonzentrationen von $1 \%, 1,4 \%$ und $2 \%(w / v)$ in $1 \times$ TBE auf, präparative Gele zur Isolierung von DNA-Fragmenten enthielten entweder $1 \%$ oder 1,4 \% (w/v) Agarose gelöst in 1 x TBE. Für eine Visualisierung der DNA-Fragmente unter UV-Licht (302 nm) wurde Ethidiumbromid nach der vollständigen Lösung der Agarose, die in einem Mikrowellenherd geschah, direkt in das Gel $(0,5 \mu \mathrm{g} / \mathrm{ml})$ gegeben.

Für den Auftrag auf das Gel wurden maximal $20 \mu \mathrm{l}$ der DNA-haltigen Lösung mit einem Fünftel Ladungspuffer versetzt. Die Auftrennung der DNA-Fragmente erfolgte durch eine horizontale Gelelektrophorese in 1 x TBE Puffer bei 3-5 V/cm Gellänge. Die Trenndauer richtete sich nach der Agarosekonzentration des jeweiligen Gels in Abhängigkeit von einer optimalen Auflösung. So wurden z.B. durch das Verfahren der Random Amplified Polymorphic DNA (RAPD) generierte DNA-Fragmente in 1,4\%igen (w/v) Agarosegelen bei $3 \mathrm{~V} / \mathrm{cm}$ Gellänge für $6 \mathrm{~h}$ elektrophoretisch getrennt.

Ladungspuffer:

$$
\begin{aligned}
& 33,0 \%(w / v) \text { Sucrose } \\
& 0,2 \%(w / v) \text { Bromphenolblau } \\
& \text { gelöst in } 5 \text { x TBE-Puffer-Stammlösung }
\end{aligned}
$$

\subsection{Native Polyacrylamid-Gelelektrophorese}

Die native Polyacrylamid-Gelelektrophorese wurde für Untersuchungen von DNAPolymorphismen zwischen verschiedenen DNA-Fragmenten gleicher Länge verwendet. Dieses von ORITA et al. (1989) beschriebene Verfahren basierte auf sequenzabhängigen Konformationsunterschieden von DNA-Einzelsträngen (Single Strand Conformation Polymorphism, SSCP).

Im Rahmen dieser Arbeit wurden 15\%ige Trenngele, welche Acrylamid und Bisacrylamid im Verhältnis 37,5 : 1 enthielten, verwendet. Die Trennmatrix wurde zwischen 
zwei Glasplatten gegossen, welche zuvor gründlich mit $\mathrm{ddH}_{2} 0,70 \%$ igem (w/v) Ethanol, wiederum mit $\mathrm{ddH}_{2} \mathrm{O}$ und abschließend mit absolutem Isopropanol gesäubert waren. Die Matrixdicke war durch zwei Abstandhalter zwischen den Glasplatten auf 0,5 mm eingestellt, die Trennstrecke belief sich in der vertikalen Gelelektrophorese auf $12 \mathrm{~cm}$. Für den späteren Probenauftrag wurden rechteckige Geltaschen durch Einsetzen eines Zahnkamms ausgespart. Die Polymerisationszeit des Polyacrylamidgels betrug mindestens $1 \mathrm{~h}$.

Für den Probenauftrag wurden $5 \mu$ l Stop-Mix mit $5 \mu$ l von der Lösung des zu untersuchenden DNA-Fragments sowie $1 \mu$ EDTA-SDS-Lösung vermischt, 10 min bei 95 ${ }^{\circ} \mathrm{C}$ denaturiert und anschließend für 5 min auf Eis gestellt. Fünf Mikroliter des Ansatzes wurden auf das Gel appliziert. Die Elektrophorese erfolgte bei konstanter Spannung $(120 \mathrm{~V})$ für $10 \mathrm{~h}$.

Trennmatrix, $15 \%$ : $\quad 0,5 \mathrm{Vol} 30 \%$ ige Acrylamid-, 0,8\%ige Bisacrylamidlösung

$$
\begin{aligned}
& 0,2 \text { Vol } 5 \times \text { TBE-Puffer-Stammlösung } \\
& 0,3 \text { Vol } \mathrm{ddH}_{2} \mathrm{O} \\
& 1 / 200 \mathrm{Vol} 10 \%(\mathrm{w} / \mathrm{v}) \text { Ammoniumpersulfat } \\
& 1 / 1000 \text { Vol TEMED }
\end{aligned}
$$

Stop-Mix: $\quad 95 \%(w / v)$ Formamid

$20 \mathrm{mM}$ EDTA

$0,05 \%(\mathrm{w} / \mathrm{v})$ Bromphenolblau

0,05\% (w/v) Xylencyanol

$$
\begin{array}{lll}
\text { EDTA-SDS-Lösung: } & 10 \mathrm{mM} & \text { EDTA } \\
& 0,1 \%(\mathrm{w} / \mathrm{v}) & \text { SDS }
\end{array}
$$




\subsection{Denaturierende Polyacrylamid-Gelelektrophorese}

Zum Zweck der hochauflösenden Analyse von DNA-Fragmenten wurde die horizontale Elektrophorese im denaturierenden Polyacrylamidgel durchgeführt. Zwei verschiedene Elektrophoreseapparaturen sind hierfür verwendet worden.

\section{$\underline{\text { Sequenziergel-Elektrophoresesystem }}$}

Da für eine spätere Detektion der DNA-Fragmente im Polyacrylamidgel (siehe Kap. 3.2.4.5.2) eine vollständige Loslösung des Gels ohne dessen mechanische Beschädigung vonnöten war, wurde die kürzere Glasplatte $(34$ x $19 \mathrm{~cm})$ vor erstmaliger Verwendung in "Repellsilan" getaucht. Überschüssiges "Repellsilan" wurde abgegossen und die auf der Glasplatte verbliebene Lösung durch Einbrennen bei $100{ }^{\circ} \mathrm{C}$ permanent auf ihr fixiert. Die längere Glasplatte (36 x $19 \mathrm{~cm}$ ) wurde nicht behandelt. Vor dem Gießen des Gels wurden die Glasplatten, wie unter 3.2.4.4.2 beschrieben, gesäubert. Die Geldicke $(0,4 \mathrm{~mm})$ war durch die Verwendung zweier Abstandhalter zwischen den Glasplatten definiert, Geltaschen wurden durch die Verwendung eines Zahnkammes ausgespart. In Abhängigkeit von der Länge der DNA-Fragmente wurden entweder 4\%ige (w/v) oder 6\%ige (w/v) denaturierende Polyacrylamidgele verwendet, welche aus gebrauchsfertigen Lösungen zusammengemischt wurden. Die Polymerisationsdauer betrug mindestens $1 \mathrm{~h}$. Nach dem Einspannen des Gels in das Elektrophoresesystem und der Befüllung der Puffertanks mit 1 x TBE wurde ein Vorlauf für 30 min bei $40 \mathrm{~W}$ durchgeführt. Währenddessen wurden die Proben wie bei der nativen Polyacrylamid-Gelelektrophorese vorbereitet und denaturiert. Nach dem Vorlauf wurden die Geltaschen mit Puffer gespült und die Proben aufgetragen. Die elektrophoretische Trennung der einzelsträngigen DNA-Fragmente erfolgte bei $1.450 \mathrm{~V}$ und $35 \mathrm{~W}$ über einen Zeitraum, der von den Fragmentlängen abhing. Die während der Elektrophorese entstehende Wärme sorgte in Verbindung mit dem in dem Gel enthaltenen Harnstoff (8,3 M) für eine Beibehaltung des einzelsträngigen Zustands der aufgetragenen DNA. 


$\begin{array}{lll}\text { Polyacrylamidgel, 6\%ig: } & 6 & \%(w / v) \text { Polyacrylamid }(19: 1) \\ 8,3 & \text { M Harnstoff } \\ 1 \mathrm{x} & \text { TBE } \\ 1 / 125 & \text { Vol } 10 \% \text { iges (w/v) Ammoniumpersulfat } \\ 1 / 2.500 & \text { Vol TEMED }\end{array}$

\section{$\underline{\text { LiCor, Modell } 4200}$}

Vor dem Gießen des denaturierenden 8\%igen Polyacrylamidgels wurden die beiden Glasplatten $(330 \times 250 \mathrm{~mm})$ mit Spülmittel gereinigt, mit $\mathrm{ddH}_{2} \mathrm{O}$ abgewischt und danach mit Isopropanol gesäubert. Die Geldicke von 0,2 mm wurde durch die Verwendung von zwei Abstandhaltern zwischen den Glasplatten erhalten. Die Fixierung der so erhaltenen Gießküvette erfolgte mittels Klemmen. Die Matrixerstellung des aus gebrauchsfertigen Lösungen vorbereiteten 8\%igen Polyacrylamidgels geschah unter Verwendung einer $20 \mathrm{ml}$ Einwegspritze mit Filtervorsatz $(0,45 \mu \mathrm{m})$. Geltaschen für die spätere Probenapplikation wurden durch das Einsetzen eines Zahnkammes ausgespart. Die Polymerisationsdauer für das Gel betrug ca. eine Stunde. Anschließend wurde das Gel in die Elektrophoreseeinheit eingespannt, die Puffertanks mit 1 x TBE befüllt, der Zahnkamm aus dem Gel entfernt und die Geltaschen mit Puffer gespült. Vor der Probenapplikation wurden $3 \mu \mathrm{l}$ der Amplifaktionsprodukte mit $7 \mu$ Auftragspuffer vermischt, 5 min bei $94{ }^{\circ} \mathrm{C}$ denaturiert und 10 min auf Eis gehalten. Für die Probenapplikation in das Gel wurde $1 \mu l$ von diesem Gemisch verwendet. Zum Zweck der späteren Determinierung der Fragmentlängen von den zu untersuchenden Proben erfolgte der Auftrag des IRD800 markierten Molecular Weight Marker jeweils neben den beiden äußeren Proben. Die Auftrennung der Fragmente geschah im elektrophoretischen Feld bei $2.000 \mathrm{~V}$ für 2,5 $\mathrm{h}$.

Auftragspuffer:

zu $18 \mathrm{ml}$ Formamid wurde zugegeben

$$
200 \mu 10,2 \text { M EDTA }
$$

$25 \mathrm{mg}$ Bromphenolblau

ad $20 \mathrm{ml}$ mit Formamid auffüllen 


Polyacrylamidgel, 8\%ig: $\begin{aligned} 8 \%(w / v) \text { Polyacrylamid }(19: 1) \\ 7 \text { M Harnstoff } \\ 1 \text { x TBE } \\ 1 / 125 \text { Vol } 10 \% \text { iges (w/v) Ammoniumpersulfat } \\ 1 / 2.500 \text { Vol TEMED }\end{aligned}$

\subsection{Elektrophorese im viskosen Polymer}

Der Sequenzierautomat ABI Prism 310 trennte die DNA-Fragmente in einer mit viskosem Polymer gefüllten Kapillare auf. Mit dem Gerät wurden die beiden unterschiedlichen Verfahren Fragmentlängenanalyse sowie Sequenzierung durchgeführt.

\section{Fragmentlängenanalyse}

Die Fragmentlängenanalyse wurde bei Mikrosatelliten-Loci angewendet. Die elektrophoretische Trennung der DNA-Fragmente erfolgte in einer $47 \mathrm{~cm}$ langen Kapillare, die einen Durchmesser von $50 \mu \mathrm{m}$ aufwies. Für die Fragmentlängenanalyse wurde das Polymer mit der Bezeichnung POP4 verwendet.

Bis zu drei unterschiedlich fluoreszenzmarkierte Amplifikationsprodukte wurden für die Analyse gemischt. Ein Mikroliter von den Amplifikationsprodukten wurde mit $12 \mu \mathrm{l}$ Formamid und 0,5 $\mu \mathrm{l}$ von dem internen, fluoreszenzmarkierten Längenstandard GeneScan500 TAMRA in ein 0,5 ml Probengefäß gegeben und gemischt. Das Probengefäß wurde mit einer Septe verschlossen, die Proben anschließend für $10 \mathrm{~min}$ bei $95{ }^{\circ} \mathrm{C}$ denaturiert und für 5 min auf Eis gestellt. Dann erfolgte die Plazierung der Proben in einen Ständer, der 48 Proben aufnahm und auf den "Autosampler" des Sequenzierautomaten gestellt wurde. Die Proben wurden nach der im Software-Programm ABI Prism 310 Collection durch den Benutzer festgelegten Reihenfolge für den Anwendungsbereich GeneScan abgearbeitet. Die elektrophoretische Trennung der DNA-Fragmente erfolgte bei konstanten $15 \mathrm{kV}$ für 24 $\min$. 


\section{Sequenzierung}

Nach der Natriumacetat-Ethanol-Fällung des Sequenzieransatzes wurde das Pellet in $25 \mu 1$ Template Suppression Reagent (TSR) aufgenommen und in ein 0,5 ml Probengefäß überführt. Das Probengefäß wurde mit einer Septe verschlossen, 2 min bei $90{ }^{\circ} \mathrm{C}$ denaturiert und für 5 min auf Eis gestellt. Dann wurde es in den Probenständer überführt und auf dem "Autosampler" des Sequenzierautomaten plaziert. Die elektrophoretische Auftrennung erfolgte unter Verwendung des Polymers POP6 in einer $61 \mathrm{~cm}$ langen Kapillare $(\varnothing \quad 50 \mu \mathrm{m})$ bei konstanter Stromspannung $(12,5 \mathrm{kV})$ für $2 \mathrm{~h}$ pro Sequenzieransatz.

\subsubsection{Detektion von DNA nach der gelelektrophoretischen Trennung}

\subsection{Detektion im Agarosegel}

Für die Detektion von DNA-Fragmenten wurde nach der Lösung der Agarose in $1 \times$ TBE-Puffer in einem Mikrowellenherd dem Gel eine Ethidiumbromid-Stammlösung zugesetzt, so dass die Endkonzentration 0,5 $\mu \mathrm{g}$ Ethidiumbromid pro $\mathrm{ml}$ Gel betrug. Die Basen der DNA absorbieren im ultravioletten Wellenlängenbereich Licht und regen interkaliertes Ethidiumbromid zur Lichtemission (590 nm) an. Als UV-Lichtquelle diente ein Transilluminator, dessen Hauptemissionsbereich bei einer Wellenlänge von $302 \mathrm{~nm}$ lag.

Ethidiumbromid-Stammlösung: $10 \mathrm{mg}$ Ethidiumbromid gelöst in $1 \mathrm{ml} \mathrm{ddH_{2 } \mathrm { O }}$

\subsection{Detektion im Polyacrylamidgel durch Silberfärbung}

Die Visualisierung von DNA-Fragmenten in nativen wie auch denaturierenden Polyacrylamidgelen erfolgte - außer bei den für Sequenzierautomat LiCor verwendeten Gelen - durch eine Silberfärbung (BASSAM et al. 1991).

Nach dem Gellauf konnte die mit "Repellsilan" behandelte, kürzere Glasplatte von dem Polyacrylamidgel ohne dessen mechanische Beschädigung entfernt werden. Das Gel wurde 
danach samt der anderen Glasplatte in eine Plastikwanne entsprechenden Ausmaßes überführt. Nach der Zugabe von 10\%iger (v/v) Essigsäure konnte unter vorsichtigem Schütteln das Polyacrylamidgel von der zweiten Glasplatte gelöst werden, die daraufhin entfernt wurde. Eine Fixierung der DNA-Fragmente erfolgte durch eine Inkubation in der 10\%igen (v/v) Essigsäure für $20 \mathrm{~min}$ auf einem Tischrundschüttler bei 40 UPM. Anschließend wurde die Lösung abgesaugt und das Gel dreimal in $\mathrm{ddH}_{2} \mathrm{O}$ für je 2 min auf dem Tischrundschüttler gewaschen. Die Imprägnierung erfolgte in einer Imprägnierlösung für 30 min. Nach dem Absaugen der Lösung wurde überschüssiges Silbernitrat durch Abspülen des Gels mit $\mathrm{ddH}_{2} \mathrm{O}$ entfernt und die Trennmatrix in Entwickler inkubiert. Die Entwicklung, d.h. die Visualisierung der DNA-Fragmente, wurde durch die Zugabe von einem Volumen 10\%iger Essigsäure gestoppt.

Imprägnierlösung:

Silbernitratlösung $\left(1 \mathrm{~g} \mathrm{AgNO}_{3} / \mathrm{l}\right)$

Formaldehydlösung, 37\%ig (v/v)

Ansetzten der Imprägnierlösung unmittelbar vor

Gebrauch durch Vermischung von 1 Vol Silbernitrat-

lösung mit 1/666 Vol der Formaldehydlösung

Entwickler:

\author{
Natriumcarbonatlösung $\left(30 \mathrm{~g} \mathrm{Na}_{2} \mathrm{CO}_{3} / \mathrm{l}\right)$ \\ Formaldehydlösung, 37\%ig (v/v) \\ Natriumthiosulfat-Stammlösung ( $\left.5 \mathrm{mg} \mathrm{Na}_{2} \mathrm{~S}_{2} \mathrm{O}_{3} / \mathrm{ml}\right)$ \\ Ansetzten des Entwicklers unmittelbar vor Gebrauch \\ durch Vermischung von 1 Vol Natriumcarbonatlösung \\ mit 1/666 Vol Formaldehydlösung und 1/25.000 Vol \\ Natriumthiosulfat-Stammlösung
}

\title{
3.2.4.5.3 Detektion im Polyacrylamidgel durch Fluoreszenzmarkierung
}

Die Detektion der DNA-Fragmente mit dem Squenzierautomaten LiCor (Modell 4200) erfolgte durch eine Anregung der an einen Primer gekoppelten Markierung mittels Laserlicht. Die Markierung emittierte durch das auftreffende Laserlicht fluoreszierendes 
Licht mit einer Wellenlänge von $800 \mathrm{~nm}$. Die erhaltenen Daten wurden dann in dem angeschlossenen Computer durch die entsprechende Software in Elektropherogramme umgewandelt.

\subsection{Detektion im Polymer durch Fluoreszenzmarkierung}

Der Sequenzierautomat ABI Prism 310 basiert, wie der Sequenzierautomat LiCor, ebenfalls auf einer Anregung des mit dem Primer verbundenen Fluoreszenzmoleküls durch Laserlicht. Das Laserlicht gelangte bei diesem System durch ein in die Kapillare befindliches Glasfenster in das Polymer. Das Fluoreszenzmolekül wurde durch das auftreffende Laserlicht zur Lichtemission angeregt, diese über eine CCD-Kamera registriert und durch eine entsprechende Software interpretiert. Bis zu vier unterschiedliche an die DNA gekoppelte Fluoreszenzmoleküle konnten unter der Bedingung, dass ihr Hauptemissionsspektrum unterschliedlich war, simultan verwendet und detektiert werden. Dabei wurden durch ein angelegtes elektrophoretisches Feld die DNA-Fragmente aufgrund ihres Molekulargewichts separiert und passierten das Glasfenster der Kapillare während der Elektrophorese.

\subsubsection{Anwendungsbereiche der Polymerase-Kettenreaktion (PCR)}

Die Polymerase-Kettenreaktion (PCR) wurde das erste Mal von SAIKI et al. (1985) beschrieben und basierte auf der enzymatischen in vitro-Vermehrung (Amplifikation) eines i.d.R. definierten DNA-Bereiches.

Die spezifische Annealingtemperatur (AT) der verwendeten Primer wurde durch die Verwendung der Formel von BOLTON \& MCCARTHY (1962) in vereinfachter Form berechnet:

$\mathrm{AT}=76,5+0,41(\% \mathrm{G}+\mathrm{C})-(600 / \mathrm{N})$

wobei $\% \mathrm{G}+\mathrm{C}$ den relativen Gehalt der Basen Guanin und Cytosin im Primer und $\mathrm{N}$ dessen Länge (mer) wiedergibt. 
Die verschiedenen Anwendungsbereiche der PCR werden in den nachfolgenden Kapiteln näher beschrieben. Allen gemeinsam war die Amplifikation in 0,5 ml Reaktionsgefäßen und die Überschichtung des jeweiligen Reaktionsansatzes mit dickflüssigem Paraffin. Der Standardreaktionsansatz umfasste ein Volumen von $25 \mu \mathrm{l}$ und enthielt für die spezifische Amplifikation eines definierten DNA-Fragments $10 \mathrm{mM}$ Tris$\mathrm{HCl}\left(\mathrm{pH} 8,8\right.$ bei $25^{\circ} \mathrm{C}$ ), $50 \mathrm{mM} \mathrm{KCl}, 1,5 \mathrm{mM} \mathrm{MgCh}, 0,1 \mu \mathrm{g} / \mu \mathrm{l}$ bovines Serumalbumin (BSA), 0,08\% (v/v) Nonidet P40, $100 \mu \mathrm{M}$ von jedem der vier dNTPs (dATP, dCTP, dGTP, dTTP), 5 pmol je Primer, 0,25 U Taq-DNA-Polymerase und 50 ng MatrizenDNA (Template-DNA).

Im Folgenden werden nur die speziellen Abweichungen von diesem Standardreaktionsansatz aufgeführt.

\subsection{Amplifikation von Mikrosatelliten-Loci}

MAY et al. (1997) charakterisierten elf verschiedene Mikrosatelliten-Loci für den in Amerika vorkommenden roten Stör (A. fulvescens). Diese Arbeitsgruppe zeigte auch, dass neun dieser Primerpaare in der PCR bei fünf weiteren amerikanischen Störspezies der Gattungen Acipenser sowie Scaphirhynchus amplifizierten. In dieser Arbeit wurden diese neun Mikrosatelliten-Loci an dem vorliegenden Tiermaterial untersucht (Tab. 3).

Die Amplifikation der meisten Mikrosatelliten-Loci wurde bei dem folgenden Temperaturprofil durchgeführt:

$94{ }^{\circ} \mathrm{C}-5 \mathrm{~min}$

$94{ }^{\circ} \mathrm{C}-30 \mathrm{sec}, 57{ }^{\circ} \mathrm{C}-30 \mathrm{sec}, 72{ }^{\circ} \mathrm{C}-30 \mathrm{sec}$

$72{ }^{\circ} \mathrm{C}-10 \mathrm{~min}$
(1 Zyklus)

(30 Zyklen)

(1 Zyklus) 


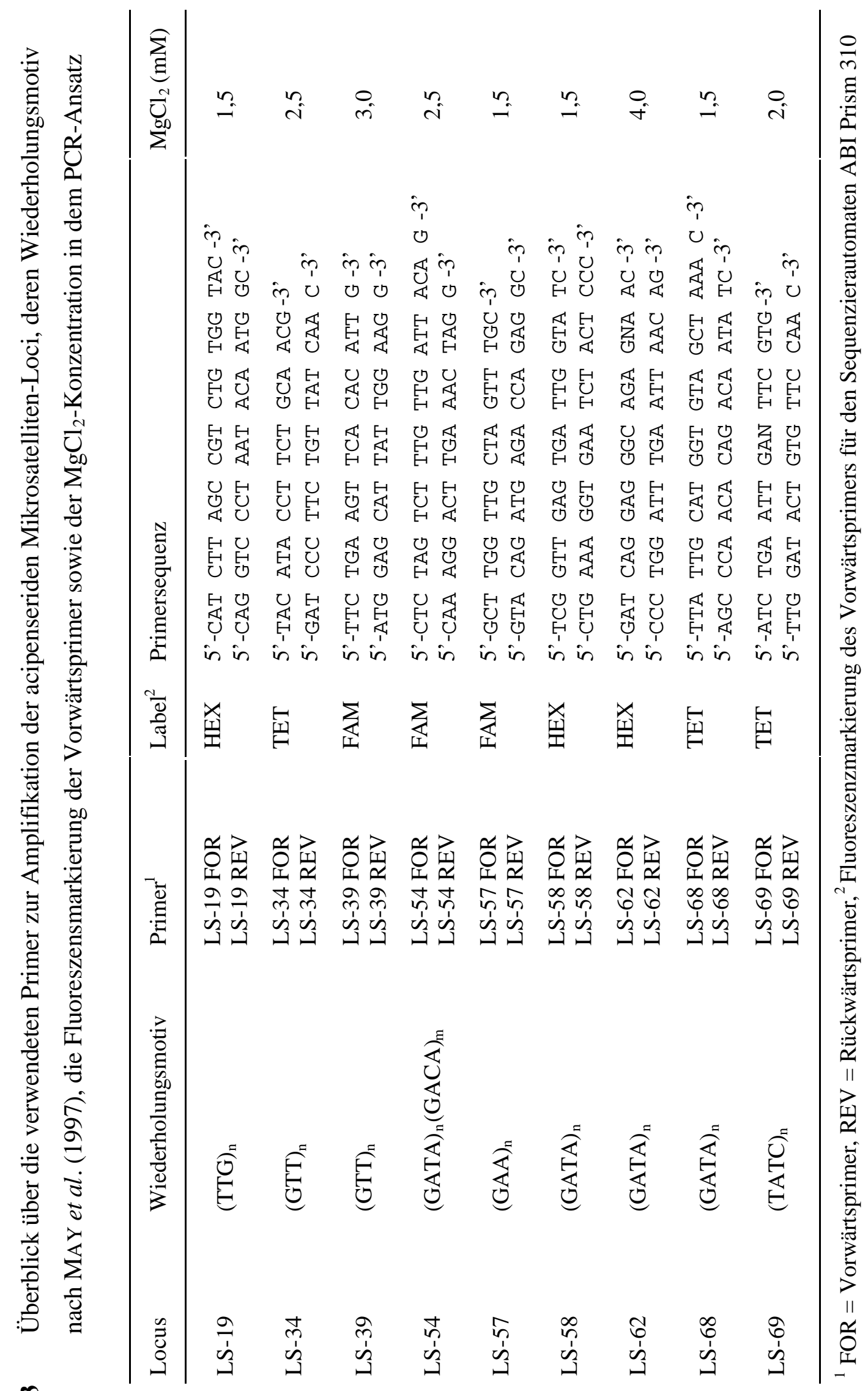

$\stackrel{\text { m. }}{\frac{0}{\sigma}}$ 
Bei einigen Loci stellte sich das folgende Touchdown-Temperaturprofil zur Vermeidung bzw. Verminderung von Artefakten als geeignet heraus:
$94{ }^{\circ} \mathrm{C}-5 \mathrm{~min}$
(1 Zyklus)
$94{ }^{\circ} \mathrm{C}-30 \mathrm{sec}, 65^{\circ} \mathrm{C}-30 \mathrm{sec}, 72{ }^{\circ} \mathrm{C}-30 \mathrm{sec}$
(2 Zyklen)
$94{ }^{\circ} \mathrm{C}-30 \mathrm{sec}, 63{ }^{\circ} \mathrm{C}-30 \mathrm{sec}, 72{ }^{\circ} \mathrm{C}-30 \mathrm{sec}$
(2 Zyklen)
$94{ }^{\circ} \mathrm{C}-30 \mathrm{sec}, 61{ }^{\circ} \mathrm{C}-30 \mathrm{sec}, 72{ }^{\circ} \mathrm{C}-30 \mathrm{sec}$
(2 Zyklen)
$94{ }^{\circ} \mathrm{C}-30 \mathrm{sec}, 59{ }^{\circ} \mathrm{C}-30 \mathrm{sec}, 72{ }^{\circ} \mathrm{C}-30 \mathrm{sec}$
(4 Zyklen)
$94{ }^{\circ} \mathrm{C}-30 \mathrm{sec}, 57{ }^{\circ} \mathrm{C}-30 \mathrm{sec}, 72{ }^{\circ} \mathrm{C}-30 \mathrm{sec}$
(20 Zyklen)
$72{ }^{\circ} \mathrm{C}-10 \mathrm{~min}$
(1 Zyklus)

Die Auftrennung der Amplifikationsprodukte ist Kap. 3.2.4.4.4 zu entnehmen.

\subsection{Random Amplified Polymorphic DNA (RAPD)}

Diese Technik basierte auf der Amplifikation multipler DNA-Fragmente unbekannter DNA-Bereiche unter Verwendung eines einzelnen Primers bei reduzierten Stringenzbedingungen während der PCR. Das Grundprinzip der RAPD wurde von WiLLIAMS et al. (1990) sowie WELSH \& MCCLELLAND (1990) beschrieben und in Abhängigkeit von den verwendeten Primern modifiziert.

Der Reaktionsansatz enthielt $2 \mathrm{mM} \mathrm{MgCh}$ sowie 25 pmol eines Primers. Die Reagenzien wurden auf Eis zusammenpipettiert, mit Öl überschichtet und in dem auf $94{ }^{\circ} \mathrm{C}$ vorgeheizten Thermocycler plaziert.

Für die zwanzig 10 mer Primer aus dem Operon Kit H (Tab. 4) wurde die Amplifikation nach dem folgenden Temperaturprofil durchgeführt:
$94{ }^{\circ} \mathrm{C}-5 \mathrm{~min}$
(1 Zyklus)
$94{ }^{\circ} \mathrm{C}-1 \mathrm{~min}, 36^{\circ} \mathrm{C}-1 \min , 72{ }^{\circ} \mathrm{C}-2 \min$
(45 Zyklen)
$72{ }^{\circ} \mathrm{C}-10 \mathrm{~min}$
(1 Zyklus) 
Neben den 10 mer Primern des Operon Kit H wurden zudem weitere 20 Primer, welche eine Länge zwischen 17 und 34 Basen (Tab. 4) aufwiesen, untersucht. Das Temperaturprofil für die Amplifikation baute sich bei der Verwendung dieser Primer wie folgt auf:
$94{ }^{\circ} \mathrm{C}-5 \mathrm{~min}$
(1 Zyklus)
$94{ }^{\circ} \mathrm{C}-1 \mathrm{~min}, 36{ }^{\circ} \mathrm{C}-1 \min , 72{ }^{\circ} \mathrm{C}-2 \min$
(5 Zyklen)
$94{ }^{\circ} \mathrm{C}-1 \min , 50{ }^{\circ} \mathrm{C}-1 \min , 72{ }^{\circ} \mathrm{C}-2 \min$
(40 Zyklen)
$72{ }^{\circ} \mathrm{C}-10 \mathrm{~min}$
(1 Zyklus)

Tab. 4 Nukleotidsequenz der in der RAPD verwendeten Primer

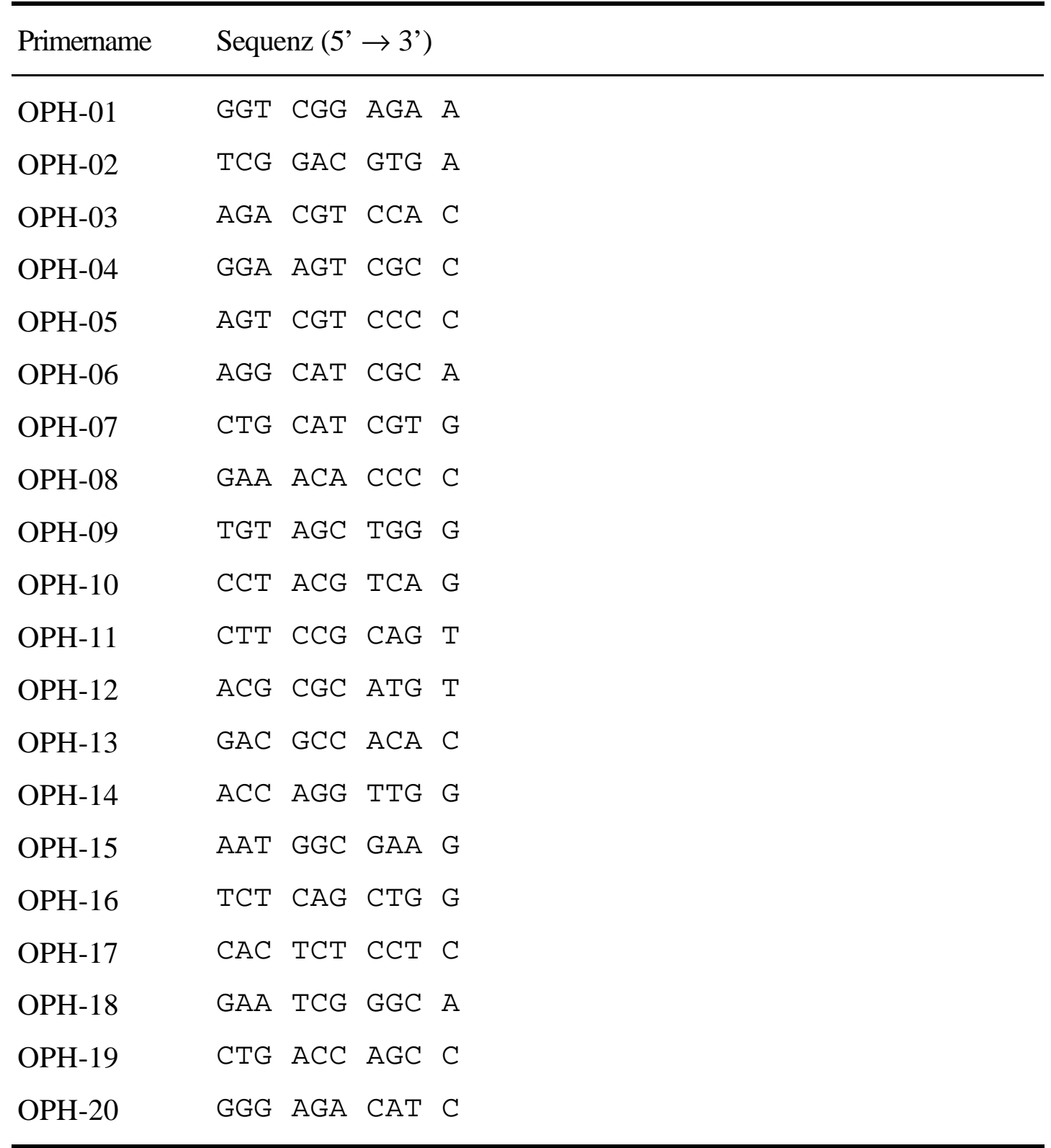


Tab. 4 Fortsetzung

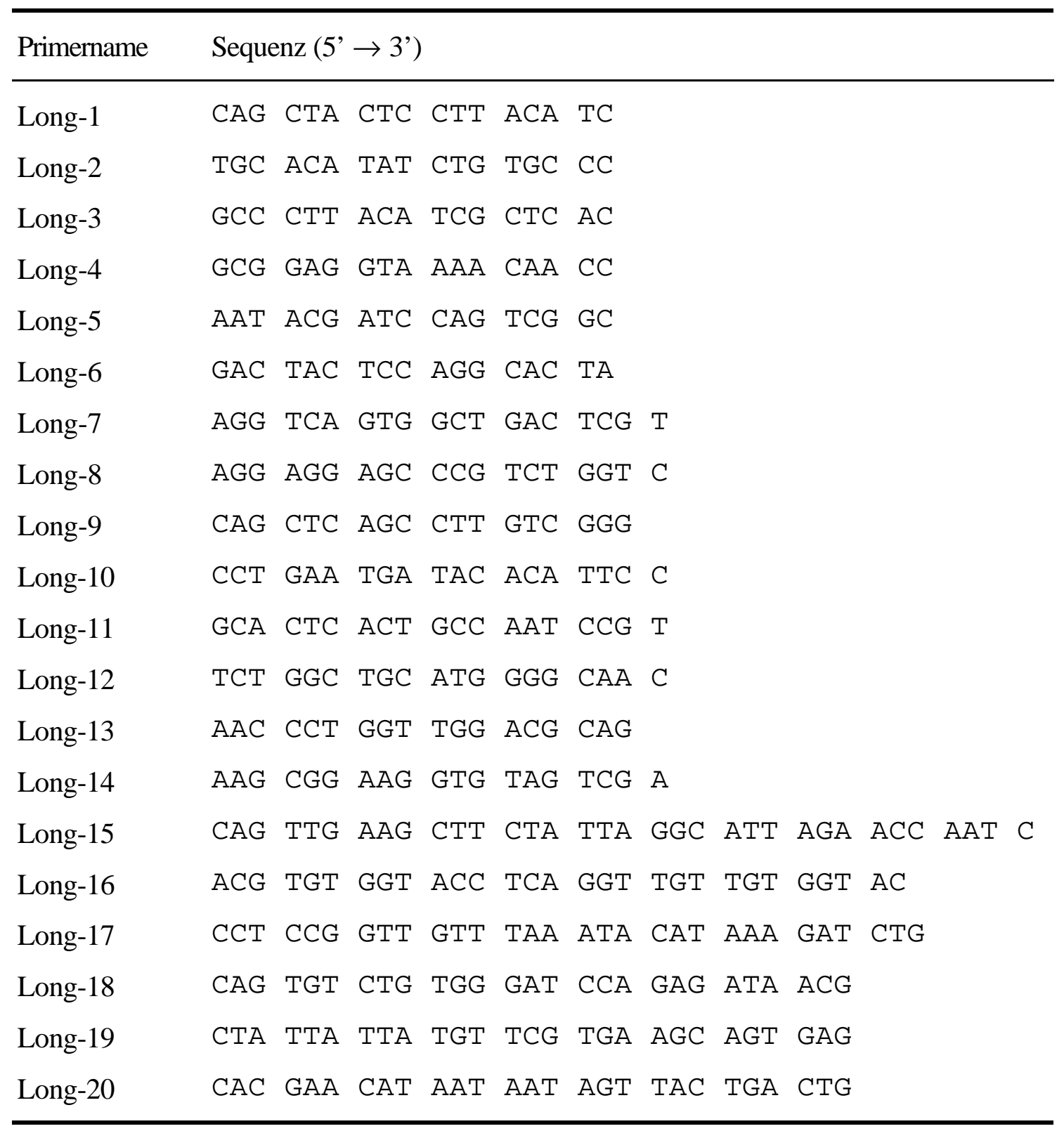

Die Amplifikationsprodukte wurden im 1,4\%igen (w/v) Agarosegel für $6 \mathrm{~h}$ elektrophoretisch bei $3 \mathrm{~V} / \mathrm{cm}$ Gellänge aufgetrennt. Als Molekulargewichtstandard wurde die 100 bp Ladder Plus verwendet. 


\subsection{Short Interspersed Elements-PCR (SINE-PCR)}

Short interspersed elements (SINEs) sind kurze repetitive DNA-Sequenzen, welche zu der Gruppe der im Genom zerstreuten repetitiven Sequenzen (dispersed repetitive sequences) gehören (SINGER 1982). Durch den Vergleich von SINE-Sequenzen mit tRNA $^{\text {Lys }}$-ähnlicher Struktur über fünf sehr entfernt verwandte Spezies kamen OHSHIMA $e t$ al. (1993) zu der Schlussfolgerung, dass diese Sequenzen durch ein gemeinsames "Ahnen"-Retrovirus in das Genom verschiedener Spezies überführt worden sein könnten. Auffällig war eine hohe Sequenzkonservierung innerhalb der tRNA ${ }^{\text {Lys }}$-verwandten Region, anhand derer für diese Arbeit der Primer 5'-CAG TNG GTA GAG CAT-3' abgeleitet und in dem Standardreaktionsansatz der PCR verwendet wurde. Das für die Amplifikation verwendete Temperaturprofil hatte die folgende Kontur:
$94{ }^{\circ} \mathrm{C}-5 \mathrm{~min}$
(1 Zyklus)
$94{ }^{\circ} \mathrm{C}-1 \min , 50{ }^{\circ} \mathrm{C}-1 \min , 72{ }^{\circ} \mathrm{C}-2 \min$
(45 Zyklen)
$72{ }^{\circ} \mathrm{C}-10 \min$
(1 Zyklus)

Die Amplifikationsprodukte wurden im 1,4\%igen (w/v) Agarosegel für $6 \mathrm{~h}$ elektrophoretisch bei $3 \mathrm{~V}$ pro cm Gellänge aufgetrennt. Als Längenstandard wurde die 100 bp Ladder Plus verwendet.

\subsection{Inter-Simple Sequence Repeat PCR (Inter-SSR PCR)}

Auch diese Technik war durch eine simultane Amplifikation multipler DNA-Fragmente bei Verwendung eines Primers in der Standard-PCR-Reaktion gekennzeichnet. Grundlage für den Einsatz dieser Methode war die Erkenntnis, dass sich verschiedene Organismen in dem generierten Fragmentmuster voneinander unterschieden (ZIETKIEWICZ et al. 1994, ISHIBASHI et al. 1995).

Die für diese Arbeit verwendeten Primer wiesen einen sehr hohen Homologiegrad zu Mikrosatellitenmotiven (simple sequence repeats) auf, der je nach dem Zielmotiv des 
Mikrosatelliten zwischen $82 \%$ und $100 \%$ lag. Die folgenden fünf verschiedenen Primer sind für diese Methode verwendet worden:

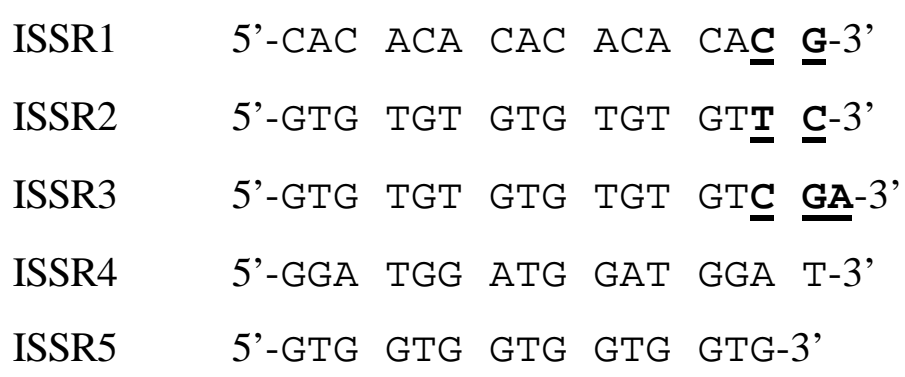

Während die beiden Primer ISSR4 und ISSR5 eine 100\%ige Homologie zu den vorgegebenen Tetra- bzw. Trinukleotidmotiven aufwiesen, waren die restlichen drei Primer durch eine nicht zu dem jeweiligen Mikrosatellitenmotiv homologe Extension um zwei bzw. drei Basen an deren 3'-Ende charakterisiert. Diese selektiven Nukleotide sind bei den oben dargestellten Primern zur Verdeutlichung fett und unterstrichen hervorgehoben.

Unter Verwendung einer Touchdown-PCR (DON et al. 1991) erfolgte die Amplifikation mit den fünf Primern in einem Standardreaktionsansatz mit folgendem Temperaturprofil:
$94{ }^{\circ} \mathrm{C}-5 \min$
(1 Zyklus)
$94{ }^{\circ} \mathrm{C}-1 \mathrm{~min}, 66^{\circ} \mathrm{C}-30 \mathrm{sec}, 72{ }^{\circ} \mathrm{C}-2 \mathrm{~min}$
(2 Zyklen)
$94{ }^{\circ} \mathrm{C}-1 \mathrm{~min}, 64{ }^{\circ} \mathrm{C}-30 \mathrm{sec}, 72{ }^{\circ} \mathrm{C}-2 \mathrm{~min}$
(2 Zyklen)
$94{ }^{\circ} \mathrm{C}-1 \mathrm{~min}, 62{ }^{\circ} \mathrm{C}-30 \mathrm{sec}, 72{ }^{\circ} \mathrm{C}-2 \mathrm{~min}$
(2 Zyklen)
$94{ }^{\circ} \mathrm{C}-1 \mathrm{~min}, 60^{\circ} \mathrm{C}-30 \mathrm{sec}, 72{ }^{\circ} \mathrm{C}-2 \mathrm{~min}$
(4 Zyklen)
$94{ }^{\circ} \mathrm{C}-1 \mathrm{~min}, 58^{\circ} \mathrm{C}-30 \mathrm{sec}, 72{ }^{\circ} \mathrm{C}-2 \mathrm{~min}$
(25 Zyklen)
$72{ }^{\circ} \mathrm{C}-10 \mathrm{~min}$
(1 Zyklus).

Die Amplifikationsprodukte wurden im 1,4\%igen (w/v) Agarosegel für $6 \mathrm{~h}$ elektrophoretisch bei $3 \mathrm{~V} / \mathrm{cm}$ Gellänge aufgetrennt. Als Längenstandard wurde die $100 \mathrm{bp}$ Ladder Plus verwendet. 


\subsection{Amplified Fragment Length Polymorphism (AFLP)}

Mit Hilfe des AFLP können molekulare Marker in einer multiplex Reaktion ohne vorherige Kenntnisse über das Genom des zu untersuchenden Organismus amplifiziert werden (VOS et al. 1995). Im Rahmen dieser Arbeit wurde ein im Internet erhältliches Protokoll für die Durchführung dieser Methode in leicht modifizierter Form verwendet (LISCUM \& OELLER 1995). Die nachfolgenden Angaben beziehen sich, wie auch in den vorigen Kapiteln, jeweils auf einen Probenansatz. Je zehn Individuen der Spezies A. baerii, A. gueldenstaedtii, A. ruthenus und A. stellatus wurden mit diesem Verfahren untersucht.

Je Individuum wurden $100 \mathrm{ng}$ DNA in einer Doppelspaltung mit den beiden Restriktionsendonukleasen EcoRI (1,75 U) und $M s e \mathrm{I}(0,875$ U) in einem Reaktionsvolumen von $40 \mu \mathrm{l}$ bei $37^{\circ} \mathrm{C}$ für $3 \mathrm{~h}$ inkubiert. Der Reaktionsansatz enthielt neben der DNA und den Restriktionsendonukleasen $5 \mathrm{mM} \mathrm{NaCl}, 1 \mathrm{mM}$ Tris- $\mathrm{HCl}, 1 \mathrm{mM}$ $\mathrm{MgCh}_{2}, 0,1 \mathrm{mM}$ Dithiothreitol (DTT) sowie 0,12 $\mu \mathrm{g} / \mu \mathrm{l} \mathrm{BSA}(\mathrm{pH} 7,9)$. Im Anschluss daran erfolgte die Zugabe von $10 \mu \mathrm{l}$ Ligationslösung, welche 5pmol EcoRI-Adapter, 50 pmol MseI-Adapter, 1 U T4 DNA-Ligase, 1 mM ATP bei gleicher Pufferzusammensetzung wie der Restriktionsansatz enthielt. Die zu den generierten Schnittstellen der DNA kohäsiven Adapter bestanden jeweils aus zwei zueinander komplementären Oligonukleotiden (EcoRIAdapter $=$ EcoRI-oligo.1 und EcoRI-oligo.2; MseI-Adapter $=$ MseI-oligo.1 + MseIoligo.2) und wurden zuvor in separaten Ansätzen durch Zusammenmischen, Denaturierung für 5 min bei $94{ }^{\circ} \mathrm{C}$ und Abkühlung auf Raumtemperatur vorbereitet. Der erhaltene Reaktionsansatz wies ein Gesamtvolumen von $50 \mu \mathrm{l}$ auf. Durch die nachfolgende Inkubation bei $37^{\circ} \mathrm{C}$ für weitere $3 \mathrm{~h}$ erfolgte sowohl eine Spaltung bisher unrestringierter DNA als auch die Ligation der Adapter an gespaltene DNA-Fragmente. Ein Mikroliter der erhaltenen Ligationsreaktion wurde in einer Präamplifikation als Template verwendet. Das Reaktionsvolumen betrug $20 \mu \mathrm{l}$, die Reaktionslösung enthielt neben dem Template $10 \mathrm{mM}$ Tris- $\mathrm{HCl}(\mathrm{pH} 8,3$ ), 1,5 mM MgCh, $5 \mathrm{mM} \mathrm{KCl,} 2 \mu \mathrm{M}$ von jedem der vier dNTPs, $50 \mathrm{ng}$ von EcoRI-oligo.1 als Primer sowie 0,4 U Taq DNA-Polymerase. 
Das Temperaturprofil für die Präamplifikation baute sich wie folgt auf:

$94{ }^{\circ} \mathrm{C}-2 \min$

$94{ }^{\circ} \mathrm{C}-1 \mathrm{sec}, 50{ }^{\circ} \mathrm{C}-30 \mathrm{sec}, 72{ }^{\circ} \mathrm{C}-1 \mathrm{~min}$
(1 Zyklus)

(34 Zyklen).

Für die Hauptamplifikation wurde $1 \mu \mathrm{l}$ von der Präamplifikation als Template in einem Reaktiosansatz mit einem Gesamtvolumen von $20 \mu \mathrm{l}$ verwendet. Der Unterschied gegenüber dem für die Präamplifikation verwendeten Reaktionsansatzes bestand in der Verwendung von $200 \mu \mathrm{M}$ je dNTP und in dem Einsatz von den beiden selektiven Primern EcoRI-CC (5 ng) sowie MseI-CC (30 ng). Beide Primer wiesen eine im Vergleich zu der Adaptersequenz ausgewählte Extension um je zwei Nukleotide (CC) auf, welche eine partielle, selektive Amplifikation aus dem Gesamtpool der Ligationsfragmente bewirkte. Des Weiteren war der Primer EcoRI-CC für eine Detektion durch den Sequenzierautomaten LiCor (Modell 4200) mit IRD800 fluoreszenzmarkiert. Das Temperaturprofil für die Hauptamplifikation war wie folgt charakterisiert:

$94{ }^{\circ} \mathrm{C}-2 \min$

$94{ }^{\circ} \mathrm{C}-1 \mathrm{~min}, 65^{\circ} \mathrm{C}\left(-0,7{ }^{\circ} \mathrm{C}\right.$ pro neuem

Zyklus)- $30 \mathrm{sec}, 72{ }^{\circ} \mathrm{C}-1 \mathrm{~min}$

$94{ }^{\circ} \mathrm{C}-1 \mathrm{~min}, 50{ }^{\circ} \mathrm{C}-30 \mathrm{sec}, 72{ }^{\circ} \mathrm{C}-2 \mathrm{~min}$

$72{ }^{\circ} \mathrm{C}-2 \min$
(1 Zyklus)

(11 Zyklen)

(25 Zyklen)

(1 Zyklus).

Die Auftrennung der amplifizierten Fragmente erfolgte in der horizontalen Elektrophorese unter Verwendung 6\%iger (w/v) Polyacrylamidgele (siehe Kap. 4.2.4.4.3) 
Tab. 5 Im Rahmen des AFLP verwendete Oligonukleotide

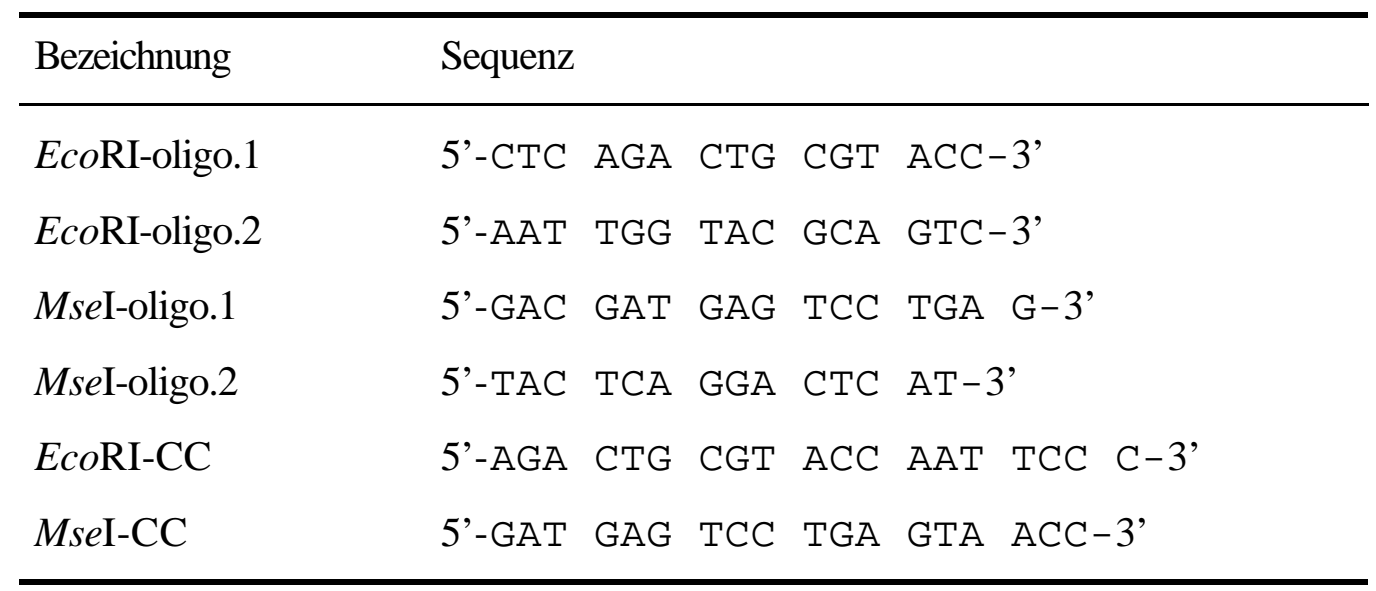

\subsection{Amplifikation des mitochondrialen Cytochrom b}

Die Nukleotidsequenz des mitochondrialen (mt) Apocytochrom b (Cyt b) umfasst 1140 bp (BROWN et al. 1989). Stromaufwärts von diesem Gen liegt die mt tRNA Glu, stromabwärts die mt tRNA ${ }^{\text {Thr }}$ (GILBERT et al. 1988, BROWN et al. 1989). Da keine Sequenzinformation über die $\mathrm{tRNA}^{\mathrm{Glu}}$ bei Stören vorlag, wurde der externe Vorwärtsprimer anhand eines Sequenzvergleichs der $\mathrm{tRNA}^{\mathrm{Glu}}$ über verschiedene Spezies entwickelt. Die in der EMBL Nukleotidsequenz-Datenbank vorhandenen Sequenzen von dem mt Cyt b sowie der tRNA ${ }^{\text {Thr }}$ verschiedener Störspezies dienten für die Konstruktion von weiteren fünf Primern. Durch unterschiedliche Kombinationen der Primer konnte je nach Zielsetzung das vollständige mt Cyt b oder partielle Fragmente von diesem in einer Standardreaktion amplifiziert werden. 
Tab. 6: Verwendete Primer für die Amplifikation des vollständigen bzw. partiellen mitochondrialen Cytochrom b (mt Cyt b) und deren Annealingpositionen (Pos.)

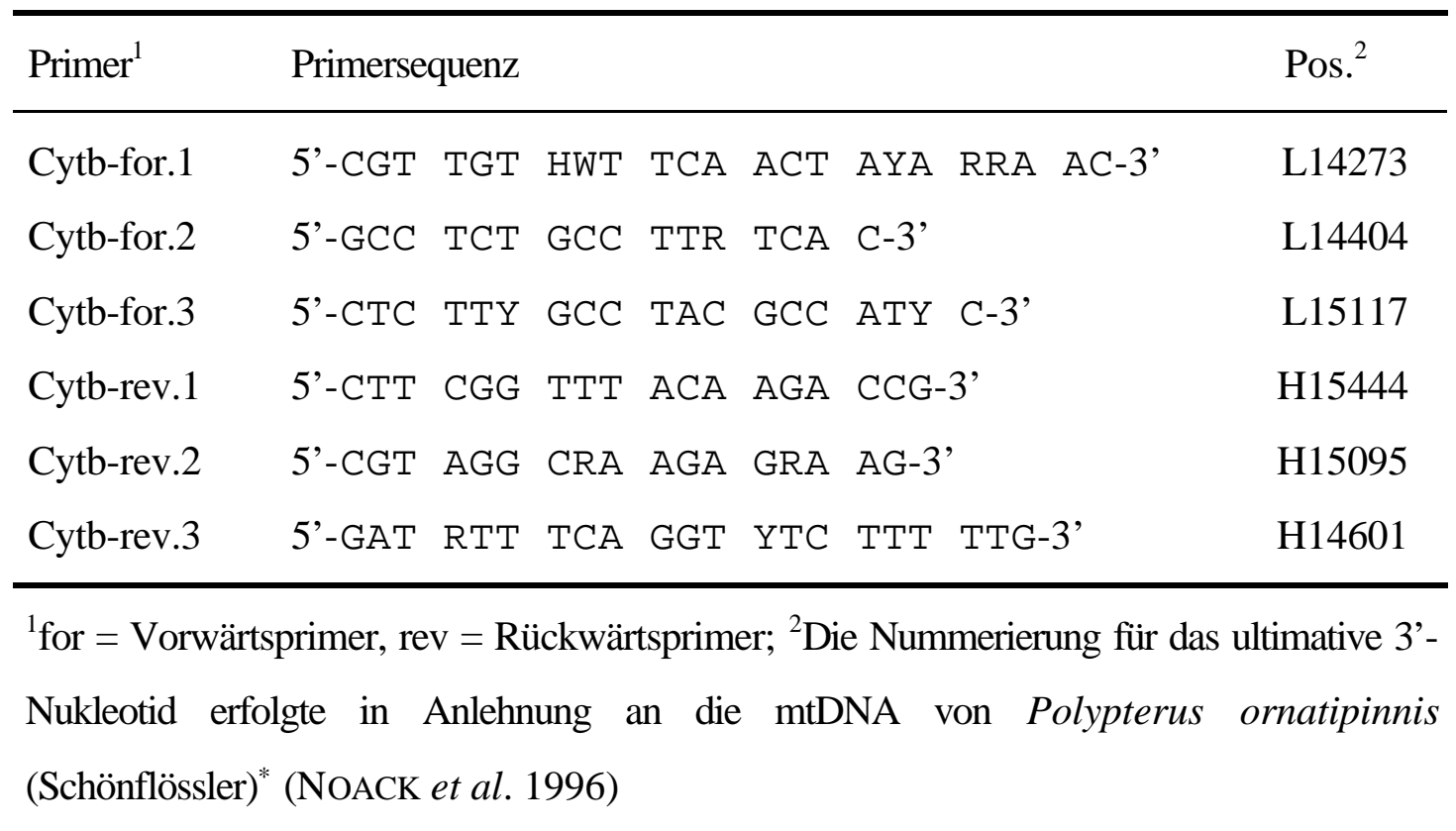

\subsubsection{Sequenzierung}

Im Rahmen deser Arbeit wurde das vollständige $\mathrm{mt}$ Cyt $\mathrm{b}$ von mindestens einem Individuum der verschiedenen Störspezies sequenziert. Für die Sequenzierung erfolgte der Einsatz des BigDye RR Terminator Cycle Sequencing Kit. Der Sequenzieransatz setzte sich wie folgt zusammen:

\section{$2 \mu 1$ BigDye RR Terminator Premix}

5 pmol Primer

50 ng doppelsträngige DNA (siehe Kap. 3.2.4.1.4)

ad $10 \mu \mathrm{l}$ Endvolumen mit HPLC- $\mathrm{H}_{2} \mathrm{O}$

Dieser Reaktionsansatz wurde mit einem Tropfen Paraffinöl überschichtet. Das Cycle Sequencing erfolgte für 25 Zyklen nach dem Temperaturprofil $96^{\circ} \mathrm{C}$ für $30 \mathrm{sec}, 50{ }^{\circ} \mathrm{C}$ für

*Polypterus ornatipinnis ist die in der Systematik zu den Stören (Chondrostei: Acipenseriformes) engverwandteste Art (Chondrostei: Polypteriformes), dessen vollständiges mitochondriales Genom charakterisiert ist. 
$15 \mathrm{sec}$ und $60{ }^{\circ} \mathrm{C}$ für $4 \mathrm{~min}$. Nach Beendigung der Sequenzierreaktion wurden die Extensionsprodukte von nicht inkorporierten dNTPs, dem Primer und markierten ddNTPs durch eine Natriumacetat-Ethanol-Fällung (siehe Kap. 3.2.4.2.2) separiert und die Sequenz determiniert. Dies erfolgte für die sechs in Tabelle 6 (siehe Kap. 3.2.4.6.6) aufgeführten Primer, so dass Sequenzinformationen sowohl vom Plus- wie auch vom Minusstrang vorlagen.

\subsubsection{Dokumentation der Untersuchungsergebnisse}

Die im Agarosegel oder silbergefärbten Polyacrylamidgel visualisierten DNAFragmente konnten mittels eines Dokumentationssystems, bestehend aus Videokamera und Videoprinter, abgelichtet werden. Die Dokumentation und Auswertung der Fragmentlängenanalysen sowie von den Sequenzierungen erfolgte bei den Sequenzierautomaten über den angeschlossenen Computer unter Verwendung der entsprechenden Software (Fragmentlängenanalyse: RFLPSCAN V3.0 beim LiCor, GeneScan V.2.1 beim ABI Prism 310; Sequenzierung: Sequencing Analysis und SequenceEditor V.1.0.3 beim ABI Prism 310).

\subsubsection{Berechnungen und statistische Auswertungen}

\subsubsection{Auswertung der Mikrosatelliten-Daten}

Für jedes Individuum wurden die an den amplifizierten Mikrosatelliten-Loci determinierten Fragmente (Peaks) ausgewertet. Stellte sich ein Locus innerhalb einer Spezies als diploid heraus, repräsentierte ein detektierter Peak zwei Allele. Heterozygote Individuen waren durch zwei Peaks unterschiedlicher Längen charakterisiert. Dagegen entsprach nur ein detektierter Peak an einem tetraploiden Locus vier, an einem sich octaploid darstellenden Locus sogar acht Allelen. An polyploiden Loci wurde die Zuweisung von Allelen zu den korrespondierenden Peaks anhand der durch das Programm GeneScan 2.1 aufgezeichneten Peakhöhe und -fläche vorgenommen. Betrug z.B. an einem 
tetraploiden Locus das Peakhöhenverhältnis von zwei detektieren Peaks $3: 1$, so wurde angenommen, dass der höhere Peak drei Allele und der niedrigere Peak ein Allel repräsentierte. Innerhalb einer Spezies erfolgte die Berechnung der Allelfrequenzen $\left(\mathrm{p}_{\mathrm{i}}\right)$ innerhalb eines jeden Locus nach der Formel

[1] $\quad \mathrm{p}_{\mathrm{i}}=\mathrm{P}_{\mathrm{i}} / \mathrm{N}$,

wobei $\mathrm{P}_{\mathrm{i}}$ die Häufigkeit des Allels i und $\mathrm{N}$ die Anzahl aller beobachteten Allele darstellte.

Mittels des $\chi^{2}$-Tests wurden Herkünfte wie auch Spezies mit einer Probengröße von $\mathrm{n} \geq 10$ daraufhin überprüft, ob sie sich im Hardy-Weinberg-Gleichgewicht (HWG) befanden. Die Berechnung der Erwartungswerte erfolgte anhand der ermittelten Allelfrequenzen mit dem Programm EWERTE (BRANDT 1998).

\subsubsection{Auswertung der AFLP-Daten}

Zuerst wurden die Längen der einzelen im AFLP generierten Fragmente für jedes Individuum determiniert. Unter- wie Obergrenze waren dabei durch den mit aufgetragenen Marker bestimmt (50 - 350 bp). Die Ähnlichkeit der generierten Fragmentmuster zwischen zwei Individuen innerhalb Spezies wurden mittels dem Ähnlichkeitsindex (SI) berechnet (NEI \& LI 1979).

[2] $\mathrm{SI}=\frac{2 \mathrm{n}_{\mathrm{xy}}}{\mathrm{n}_{\mathrm{x}}+\mathrm{n}_{\mathrm{y}}}$

$2 \mathrm{n}_{\mathrm{xy}}=$ Anzahl gemeinsamer Fragmente zwischen den Individuen $\mathrm{x}$ und $\mathrm{y}$

$\mathrm{n}_{\mathrm{x}}=$ Anzahl der Fragmente in Individuum $\mathrm{x}$

$\mathrm{n}_{\mathrm{y}}=$ Anzahl der Fragmente in Individuum y

Für die Berechnung des Ähnlichkeitsindexes über alle Individuen innerhalb einer Spezies wurde der Mittelwert aus den berechneten paarweisen SI gebildet.

Ein Vergleich zwischen den untersuchten Spezies wurde wie folgt vorgenommen: Fragmente von gleicher Länge wurden als ein und derselbe Locus über alle Individuen und 
Spezies hinweg betrachtet. Die Berechnung der Frequenz des rezessiven Allels (q) erfolgte innerhalb Spezies separat für jeden Locus (x) nach WEIR (1990), wobei dessen Formel um den Ploidiestatus (z) extendiert wurde:

[3] $\mathrm{q}_{\mathrm{x}}=\sqrt[z]{\mathrm{Q} / \mathrm{n}}$.

Q stellte die Anzahl Individuen mit fehlendem Fragment an dem betrachteten Locus innerhalb einer Spezies dar und $\mathrm{n}$ die Individuenzahl. Die Frequenz des dominanten Allels (p), d.h. dem Vorhandensein des Fragments an dem entsprechenden Locus (x), errechnete sich wie folgt:

[4] $\quad \mathrm{p}_{\mathrm{x}}=1-\mathrm{q}_{\mathrm{x}}$

Die derart berechneten Allelfrequenzen wurden für die Kalkulation des genetischen Distanzmaßes $\mathrm{D}_{\mathrm{A}}$ (NEI et al. 1983) unter Verwendung des Programms DISPAN (OTA 1993) herangezogen. In diesem Programm waren für die Konstruktion phylogenetischer Stammbäume die beiden Verfahren UPGMA (SNEATH \& SOKAL 1973) und Neighbor Joining (SAITOU \& NEI 1987) implementiert. Die Robustheit der phylogenetischen Stammbäume konnte durch den Bootstrap-Test (FELSENSTEIN 1985) mit dem Programm untersucht werden.

\subsubsection{Phylogenetische Analyse der mt Cyt b-Daten}

Für die Rekonstruktion phylogenetischer Stammbäume auf der Basis des mt Cyt bGens wurde das Programm MEGA V1.0.2 (KumAR et al. 1993) verwendet. In die Analysen wurden A. transmontanus (BROWN et al. 1989, EMBL Accession number: X14944) und die in der GenBank erhältlichen mt Cyt b-Sequenzen der drei Spezies der Gattung Scaphirhynchus (Accession numbers: U55994, U56983-56988) mit einbezogen. Als Außengruppen wurden Polypterus ornatipinnis und Salmo salar verwendet (GenBank accession numbers: U62532 und U12143). 


\section{$4 \quad$ Ergebnisse}

Zielsetzung der vorliegenden Arbeit war die Untersuchung verschiedener biochemischer und molekulargenetischer Marker, um Individuen verschiedener Störarten und Hybriden identifizieren zu können. Daher wurden für jede Art die Daten über die Herkünfte gepoolt betrachtet. Auf detaillierte Vergleiche zwischen Herkünften innerhalb Spezies wurde hingegen weitestgehend verzichtet. Außerdem wurden nur dann Hybriden in die Untersuchungen mit einbezogen, wenn sich ein Marker als speziesspezifisch herausstellte.

\subsection{Ergebnisse der biochemischen Untersuchungen}

Von den 13 untersuchten biochemischen Markern konnten nur die Systeme AK, ALB, EST-D, GPI und PGM für die Herkünfte A - F dargestellt und analysiert werden. Eine Auswertung der Herkunft G war aufgrund des schlechten Zustands, in dem sich die Blutproben befanden, nicht möglich. Trotz Veränderung der pH-Werte bei den verwendeten Puffern und Färbelösungen war eine Darstellung von den anderen biochemischen Markern nicht möglich.

Im allgemeinen gestaltet sich die Auswertung der Pherogramme bei diploiden Spezies unproblematisch. Demgegenüber können biochemische Systeme an polyploiden Spezies nur mit densitometrischen Verfahren qualitativ ausgewertet werden. Dagegen ist eine optische Bestimmung der Anzahl an Allelen, die zu einer beobachteten Bande führen, bei polyploiden Spezies nicht möglich. Für eine Vergleichbarkeit zwischen den untersuchten Störspezies wurden daher für jeden Marker einheitlich die Phänotypfrequenzen einzeln ausgewiesen. Die Benennung der beobachteten Banden erfolgte an dem betrachteten Locus in alphabetischer Reihenfolge. Dabei wurde die über alle Spezies im elektrischen Feld am wenigsten mobile Isoform eines biochemischen Markers nach internationaler Abstimmung in der International Society for Animal Genetics (I.S.A.G.) mit A benannt. 


\subsubsection{Alkalische Phosphatase (AK)}

Über alle fünf untersuchten Spezies konnten lediglich zwei Isoformen an diesem Locus gefunden werden (A, B). Abbildung 5 zeigt die Phänotypen der AK nach der Färbung.

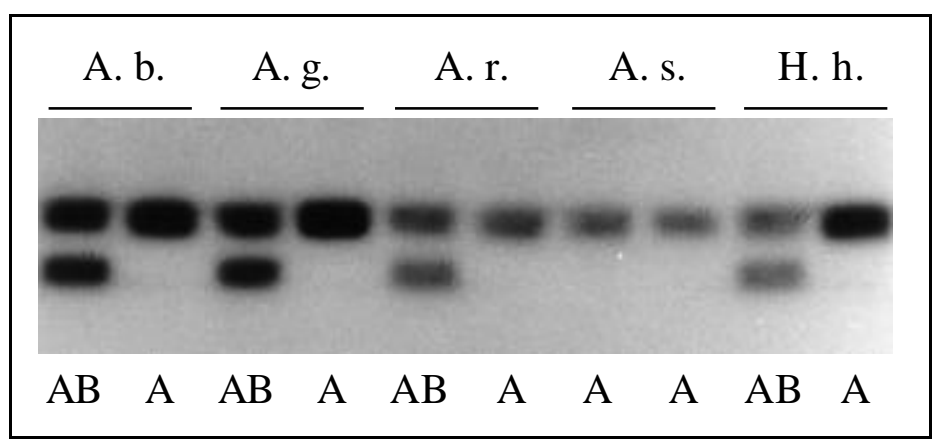

Abb. 5 Elektropherogramm der beobachteten Phänotypen an der AK

A. b. =A. baerii; A. g. = A. gueldenstaedtii; A. r. = A. ruthenus; A. s. = A. stellatus; H. h. = H. huso

Tabelle 7 gibt einen Überblick über die beobachteten, gepoolten Phänotypfrequenzen der verschiedenen Spezies.

Tab. 7 Phänotypfrequenzen der fünf Störspezies an dem Locus AK

\begin{tabular}{lccccc}
\hline & \multicolumn{5}{c}{ Spezies } \\
\cline { 2 - 6 } Phänotyp & A. baerii & A. gueldenst. & A. ruthenus & A. stellatus & H. huso \\
\hline A & 0,720 & 0,764 & 0,963 & 1,000 & 0,779 \\
AB & 0,280 & 0,236 & 0,037 & 0,000 & 0,221 \\
B & 0,000 & 0,000 & 0,000 & 0,000 & 0,000 \\
\hline
\end{tabular}

Auffällig war, dass trotz des beobachteten heterozygoten Phänotyps $A B$ bei den drei Spezies A. baerii, A. gueldenstaedtii und $H$. huso kein Individuum mit dem homozygoten Phänotyp B gefunden wurde. Die untersuchten Individuen der Art A. stellatus waren am AK-Locus für den Phänotyp A fixiert. 
Betrachtet man die Phänotypfrequenzen innerhalb Spezies, konnten zwischen Herkünften - außer bei A. stellatus, die für das Allel a fixiert waren - Unterschiede festgestellt werden, wie exemplarisch für A. baerii in Tabelle 8 dargestellt.

Tab. 8 Gegenüberstellung der AK-Phänotypfrequenzen zwischen den verschiedenen Herkünften der Spezies A. baerii

\begin{tabular}{lcccc}
\hline & \multicolumn{4}{c}{ Herkunft } \\
\cline { 2 - 5 } Phänotyp & B & C & E & F \\
\hline A & 0,860 & 0,533 & 1,000 & 1,000 \\
AB & 0,140 & 0,467 & 0,000 & 0,000 \\
B & 0,000 & 0,000 & 0,000 & 0,000 \\
\hline
\end{tabular}

Das alleinige Vorkommen des Phänotyps A innerhalb einer Herkunft konnte auch bei den anderen Spezies beobachtet werden.

\subsubsection{Albumine (ALB)}

Während sich die Spezies A. baerii und A. gueldenstadtii bei der Untersuchung dieses Plasmaproteins als sehr heterogen erwiesen, konnten bei A. ruthenus nur drei

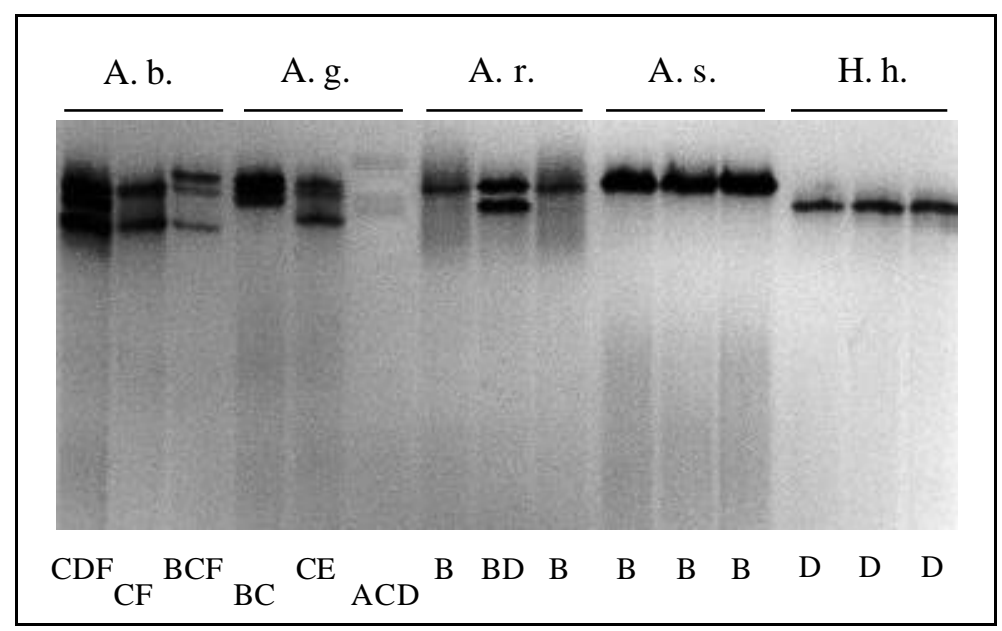

Abb. 6 Beispiele verschiedener Phänotypen in dem System ALB 
und bei A. stellatus nur zwei Phänotypen beobachtet werden. H. huso war an diesem Locus für den Phänotyp D fixiert (siehe Abb. 6 und Tab. 9).

Wie Tabelle 9 entnommen werden kann, traten bestimmte Phänotypenklassen nicht in dem Untersuchungsmaterial auf, wie z.B. A, AB, etc..

Tab. 9 Phänotypfrequenzen der untersuchten Spezies an dem System ALB

\begin{tabular}{|c|c|c|c|c|c|}
\hline \multirow[b]{2}{*}{ Phänotyp } & \multicolumn{5}{|c|}{ Spezies } \\
\hline & A. baerii & A. gueldenst. & A. ruthenus & A. stellatus & H. huso \\
\hline $\mathrm{ACD}$ & 0,000 & 0,049 & 0,000 & 0,000 & 0,000 \\
\hline B & 0,072 & 0,000 & 0,357 & 0,833 & 0,000 \\
\hline $\mathrm{BC}$ & 0,180 & 0,000 & 0,464 & 0,167 & 0,000 \\
\hline $\mathrm{BD}$ & 0,036 & 0,000 & 0,179 & 0,000 & 0,000 \\
\hline $\mathrm{BF}$ & 0,108 & 0,000 & 0,000 & 0,000 & 0,000 \\
\hline $\mathrm{BCD}$ & 0,000 & 0,016 & 0,000 & 0,000 & 0,000 \\
\hline $\mathrm{BCF}$ & 0,279 & 0,000 & 0,000 & 0,000 & 0,000 \\
\hline $\mathrm{BDF}$ & 0,009 & 0,000 & 0,000 & 0,000 & 0,000 \\
\hline $\mathrm{C}$ & 0,000 & 0,049 & 0,000 & 0,000 & 0,000 \\
\hline $\mathrm{CD}$ & 0,000 & 0,115 & 0,000 & 0,000 & 0,000 \\
\hline $\mathrm{CE}$ & 0,000 & 0,066 & 0,000 & 0,000 & 0,000 \\
\hline $\mathrm{CF}$ & 0,288 & 0,180 & 0,000 & 0,000 & 0,000 \\
\hline $\mathrm{CDE}$ & 0,000 & 0,180 & 0,000 & 0,000 & 0,000 \\
\hline $\mathrm{CDF}$ & 0,009 & 0,246 & 0,000 & 0,000 & 0,000 \\
\hline $\mathrm{CEF}$ & 0,000 & 0,033 & 0,000 & 0,000 & 0,000 \\
\hline $\mathrm{D}$ & 0,000 & 0,000 & 0,000 & 0,000 & 1,000 \\
\hline $\mathrm{DF}$ & 0,009 & 0,066 & 0,000 & 0,000 & 0,000 \\
\hline $\mathrm{E}$ & 0,009 & 0,000 & 0,000 & 0,000 & 0,000 \\
\hline
\end{tabular}

Bei A. baerii und A. gueldenstaedtii konnten insgesamt neun bzw. zehn verschiedene Phänotypen in dem System ALB beobachtet werden. Dagegen wiesen A. ruthenus drei und A. stellatus zwei Phänotypen auf. H. huso war für den Phänotyp D fixiert. Während 
bestimmte Phänotypen gleichzeitig bei mindestens zwei Arten auftraten, konnten auch solche Klassen beobachtet werden, die nur bei einer der fünf Spezies zu finden war, wie z.B. der Phänotyp CDE bei A. baerii.

\subsubsection{Esterase-D (EST-D)}

Auch an diesem Locus konnte eine größere Heterogenität innerhalb der Spezies A. baerii und A. gueldenstaedtii gegenüber den drei anderen Arten festgestellt werden. Sechs unterschiedliche Phänotypen wurden bei A. baerii, acht bei A. gueldenstaedtii, drei bei $A$. ruthenus und zwei bei A. stellatus festgestellt. Individuen aller untersuchten Herkünfte der Spezies H. huso waren an dem EST-D-Locus für den Phänotyp A fixiert (Tab. 10).

Tab. 10 Phänotypfrequenzen der fünf Acipenserinae an dem EST-D-Locus

Spezies

\begin{tabular}{lccccc}
\cline { 2 - 5 } Phänotyp & A. baerii & A. gueldenst. & A. ruthenus & A. stellatus & H. huso \\
\hline A & 0,000 & 0,000 & 0,000 & 0,833 & 1,000 \\
AB & 0,000 & 0,222 & 0,000 & 0,167 & 0,000 \\
ABC & 0,000 & 0,056 & 0,000 & 0,000 & 0,000 \\
ABD & 0,000 & 0,000 & 0,000 & 0,000 & 0,000 \\
ABCD & 0,000 & 0,111 & 0,000 & 0,000 & 0,000 \\
B & 0,504 & 0,097 & 0,000 & 0,000 & 0,000 \\
BC & 0,176 & 0,181 & 0,000 & 0,000 & 0,000 \\
BCD & 0,192 & 0,236 & 0,000 & 0,000 & 0,000 \\
BD & 0,000 & 0,069 & 0,107 & 0,000 & 0,000 \\
C & 0,096 & 0,028 & 0,000 & 0,000 & 0,000 \\
CD & 0,024 & 0,000 & 0,750 & 0,000 & 0,000 \\
D & 0,008 & 0,000 & 0,143 & 0,000 & 0,000 \\
\hline
\end{tabular}


Die Phänotypenklassen $\mathrm{ABC}$ und $\mathrm{ABCD}$ traten nur bei der Spezies A. gueldenstaedtii auf. Dagegen waren die anderen Phänotypen jeweils bei zwei verschiedenen Spezies vertreten. Die Phänotypenklassen AC, ACD und AD konnten in dem Untersuchungsmaterial nicht beobachtet werden.

Abbildung 7 zeigt Beispiele verschiedener Phänotypen der sich unter UV-Licht darstellenden EST-D.

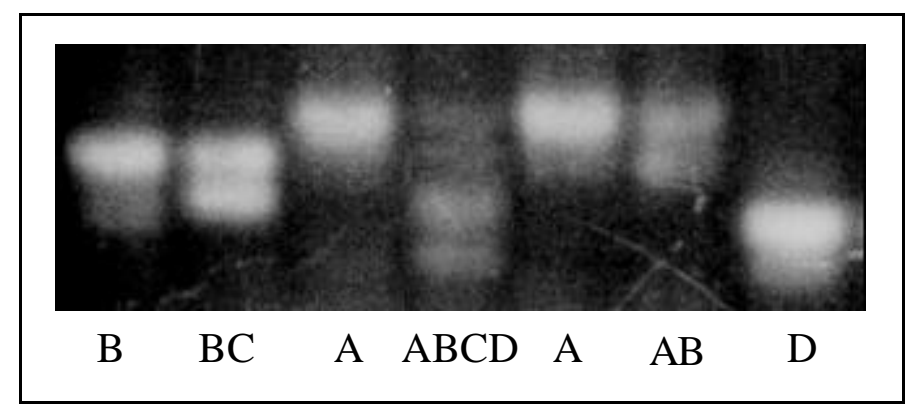

Abb. 7 Beispiele verschiedener Phänotypen am Locus EST-D

\subsubsection{Glucosephosphatisomerase (GPI)}

Über die fünf untersuchten Spezies konnten insgesamt vier verschiedene Phänotypen am GPI-Locus beobachtet werden. Abbildung 8 zeigt ein Pherogramm der GPI von unterschiedlichen Individuen.

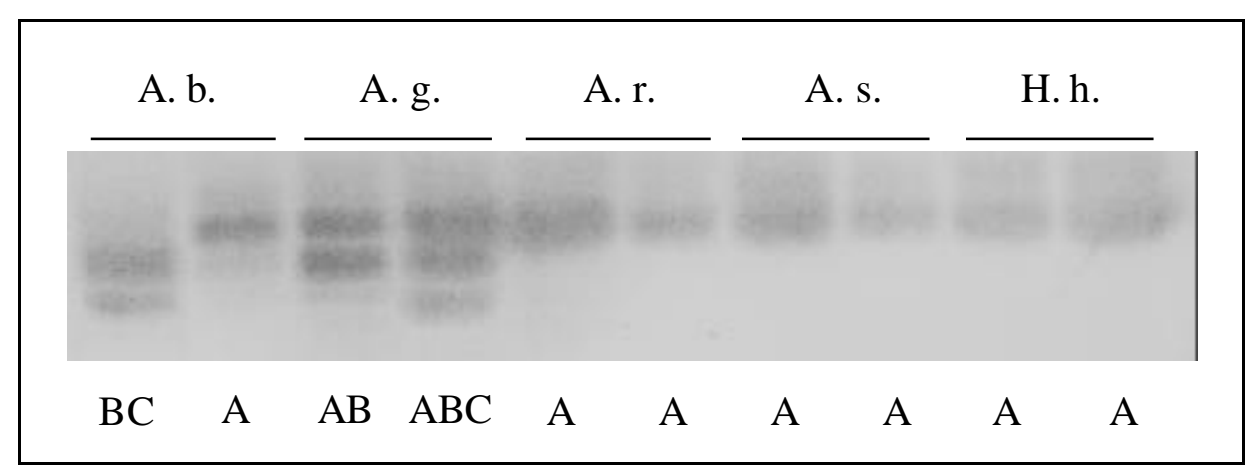

Abb. 8 Pherogramm der GPI von Individuen der verschiedenen Spezies

A. b. = A. baerii; A. g. = A. gueldenstaedtii; A. r. = A. ruthenus; A. s. = A. stellatus; H. h. = H. huso 
Die einzige Spezies, welche die vier beobachteten Phänotypen $\mathrm{A}, \mathrm{AB}, \mathrm{ABC}$ und $\mathrm{BC}$ aufwies, war A. baerii. Dagegen konnte bei A. gueldenstaedtii der Phänotyp BC nicht festgestellt werden. Die drei anderen Spezies waren für den Phänotyp A fixiert (Tab. 11).

Tab. 11 Phänotypfrequenzen der fünf Störarten am GPI-Locus

\begin{tabular}{lccccc}
\hline & \multicolumn{5}{c}{ Spezies } \\
\cline { 2 - 6 } Phänotyp & A. baerii & A. gueldenst. & A. ruthenus & A. stellatus & H. huso \\
\hline A & 0,024 & 0,111 & 1,000 & 1,000 & 1,000 \\
AB & 0,675 & 0,528 & 0,000 & 0,000 & 0,000 \\
ABC & 0,293 & 0,361 & 0,000 & 0,000 & 0,000 \\
BC & 0,008 & 0,000 & 0,000 & 0,000 & 0,000 \\
\hline
\end{tabular}

Im Untersuchungsmaterial traten die drei Allele a, b und c an diesem Locus auf. Die Phänotypen $\mathrm{AC}, \mathrm{B}$ und $\mathrm{C}$ konnten hingegen nicht beobachtet werden.

\subsubsection{Phosphoglucomutase (PGM)}

Dieser Locus war dadurch charakterisiert, dass über alle Individuen die Allele a, b und c immer in Verbindung mit dem Allel d auftraten (siehe Abb. 9). Während die Spezies A. baerii und $A$. ruthenus ausschließlich den Phänotyp $\mathrm{AD}$ aufwiesen, war A. gueldenstaedtii an diesem Locus für den Phänotyp BD und A. stellatus für CD fixiert. Demgegenüber wies $H$. huso als einzige von den untersuchten Arten den Phänotyp ABD neben dem Phänotyp BD auf (Tab. 12). 


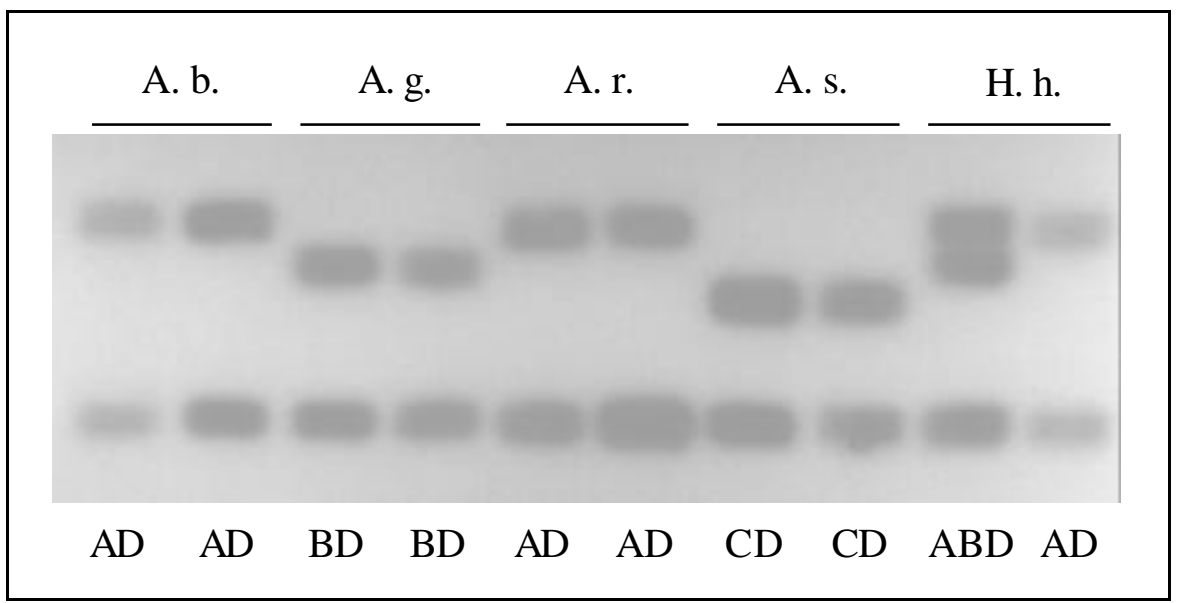

Abb. 9 Pherogramm der PGM von Individuen der verschiedenen Spezies

A. b. = A. baerii; A. g. = A. gueldenstaedtii; A. r. = A. ruthenus; A. s. $=$ A. stellatus; H. h. = H. huso

Tab. 12 Phänotypfrequenzen der untersuchten Störspezies an dem PGM-Locus

\begin{tabular}{lccccc}
\hline & \multicolumn{5}{c}{ Spezies } \\
\cline { 2 - 6 } Phänotyp & A. baerii & A. gueldenst. & A. ruthenus & A. stellatus & H. huso \\
\hline AD & 1,000 & 0,000 & 1,000 & 0,000 & 0,000 \\
ABD & 0,000 & 0,000 & 0,000 & 0,000 & 0,603 \\
BD & 0,000 & 1,000 & 0,000 & 0,000 & 0,397 \\
CD & 0,000 & 0,000 & 0,000 & 1,000 & 0,000 \\
\hline
\end{tabular}

\subsection{Ergebnisse der molekulargenetischen Untersuchungen}

Die molekulargenetischen Untersuchungen wurden - bis auf die Analyse der Mikrosatelliten-Loci - an nur maximal zehn potentiell unverwandten Individuen pro Spezies durchgeführt. Die Charakterisierung dieser zehn Tiere erfolgte anhand der erhaltenen Mikrosatelliten-Ergebnisse. Die Untersuchung der Mikrosatelliten-Loci wurde hingegen an allen Individuen der Herkünfte A-G der fünf Spezies durchgeführt. 


\subsubsection{Ergebnisse der Mikrosatelliten-Analyse}

Zu Beginn der Mikrosatelliten-Analyse wurde in Vorversuchen die Amplifikationsfähigkeit der jeweiligen Primerpaare an drei Individuen der fünf Spezies untersucht. Hierfür wurden die bei MAY et al. (1997) beschriebenen Reaktionsbedingungen verwendet. Zeigten sich im Agarosegel Amplifikationsprodukte an dem betrachteten Locus, erfolgte eine Analyse mit dem Sequenzierautomaten ABI Prism 310. Andernfalls wurde das Temperaturprofil und/oder die $\mathrm{MgCl}_{2}$-Konzentration variiert. Gleiches wurde auch dann durchgeführt, wenn an dem betrachteten Locus bei mehreren Individuen der Spezies störende Artefakte auftraten oder keine Einordnung in einen der für eine Art möglichen Ploidiestatus vorgenommen werden konnte.

Von den neun verwendeten Mikrosatellitenloci konnten nur LS-19, LS-34, LS-39 und LS-54 bei den beiden Spezies A. baerii und A. gueldenstaedtii ausgewertet werden. Bei A. ruthenus, A. stellatus und $H$. huso kam zu den vier genannten noch der Locus LS-68 hinzu, wobei der Locus LS-54 bei A. ruthenus nicht amplifiziert werden konnte (Tab. 13). Trotz Variation der verwendeten $\mathrm{MgCl}_{2}-$ Konzentration im PCR-Ansatz und Änderung des PCR-Temperaturprofils konnten die übrigen Mikrosatelliten-Loci nicht amplifiziert bzw. ausgewertet werden. Letzteres war durch das Auftreten von störenden Artefakten und/oder einem Peakmuster bedingt, so dass keine Einordnung der betrachteten Spezies in einen bestimmten Ploidiestatus möglich war.

Der Sequenzierautomat setzte die während der Elektrophorese registrierten Daten in ein Elektropherogramm um. Die Alleldetermination sowie die Allelquantifizierung erfolgte manuell im Anschluss an den Lauf. Da bei MAY et al. (1997) Informationen über Größeund Wiederholungsmotiv von je einem Allel der elf Mikrosatelliten-Loci gegeben waren, konnten die erwarteten Allelgrößen daraus abgeleitet werden. 
Tab. 13 Übersicht über den Amplifikationserfolg und die Auswertbarkeit der neun untersuchten Mikrosatelliten-Loci

\begin{tabular}{llllll}
\hline & \multicolumn{5}{c}{ Spezies } \\
\cline { 2 - 6 } Locus & A. baerii & A. gueldenst. & A. ruthenus & A. stellatus & H. huso \\
\hline LS-19 & $\mathrm{P}(7)^{1}$ & $\mathrm{P}(10)$ & $\mathrm{P}(4)$ & $\mathrm{P}(4)$ & $\mathrm{P}(6)$ \\
LS-34 & $\mathrm{P}(5)$ & $\mathrm{P}(6)$ & $\mathrm{P}(4)$ & $\mathrm{P}(4)$ & $\mathrm{P}(2)$ \\
LS-39 & $\mathrm{P}(8)$ & $\mathrm{P}(16)$ & $\mathrm{P}(3)$ & $\mathrm{M}^{2}$ & $\mathrm{P}(4)$ \\
LS-54 & $\mathrm{P}(14)$ & $\mathrm{P}(15)$ & -4 & $\mathrm{P}(8)$ & $\mathrm{P}(10)$ \\
LS-57 & $\mathrm{NA}$ & $\mathrm{NA}$ & $\mathrm{NA}$ & $\mathrm{NA}$ & $\mathrm{NA}$ \\
LS-58 & - & - & - & - & - \\
LS-62 & - & - & - & - & - \\
LS-68 & $\mathrm{NA}$ & $\mathrm{NA}$ & $\mathrm{P}(12)$ & $\mathrm{P}(9)$ & $\mathrm{P}(7)$ \\
LS-69 & $\mathrm{NA}$ & $\mathrm{NA}$ & $\mathrm{NA}$ & $\mathrm{NA}$ & $\mathrm{NA}$ \\
\hline
\end{tabular}

${ }^{1}$ Polymorpher, auswertbarer Mikrosatelliten-Locus unter Angabe der Anzahl an beobachteten Allelen; ${ }^{2}$ Monomorpher, auswertbarer Mikrosatelliten-Locus; ${ }^{3} \mathrm{Nicht}$ auswertbarer Locus (Artefakte bzw. keine Einordnung in einen bestimmten Ploidiestatus möglich); ${ }^{4}$ Keine Amplifikation.

Im Gegensatz zu den biochemischen Markern konnte eine Allelquantifizierung über alle Individuen für solche Mikrosatelliten-Loci vorgenommen werden, die sich innerhalb einer Spezies als di- und tetraploid darstellten. Die Definition des Ploidiestatus bezog sich dabei immer auf den betrachteten Locus innerhalb einer Spezies und nicht auf die Spezies selbst.

Die Allelquantifizierung wurde wie nachfolgend beschrieben vorgenommen. An einem diploiden Locus repräsentierte ein in dem erwarteten Größenbereich detektierter Peak dabei zwei Allele und an einem tetraploiden Locus vier Allele. Ein heterozygotes Individuum besaß an einem diploiden Locus zwei Peaks von unterschiedlicher Größe (in bp), d.h. zwei Allele. An einem tetraploiden Locus wurde hingegen die Allelverteilung bei zwei oder drei detektierten, unterschiedlich hohen Peaks aus dem Verhältnis der im Programm GeneScan V.2.1 aufgezeichneten Peakflächen abgeleitet (Abb. 10). 


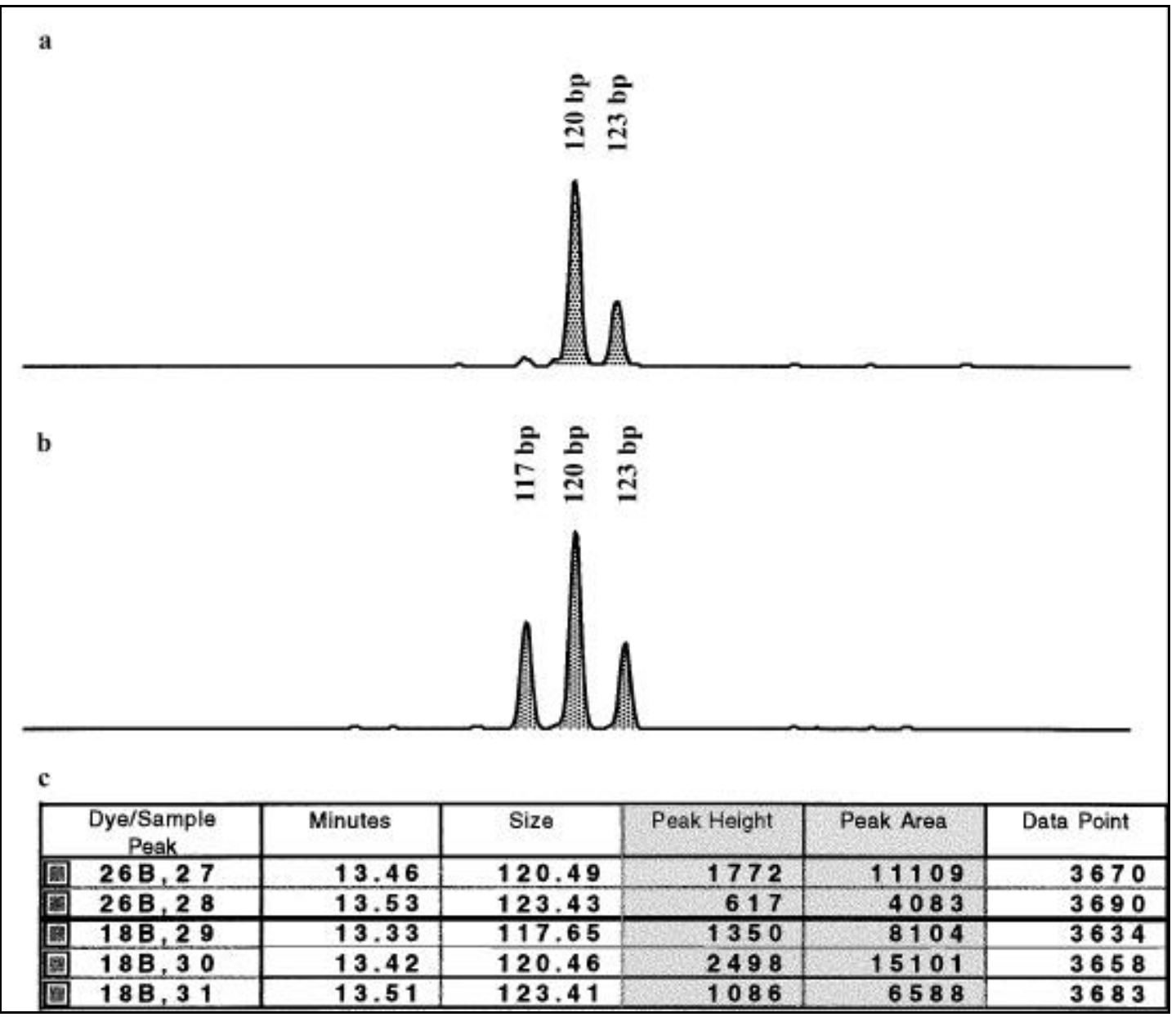

Abb. 10 Beispiele für die Ableitung der Allelverteilung für zwei Individuen von A. gueldenstaedtii an dem Mikrosatelliten-Locus LS-39

a, zwei detektierte Peaks mit der Allelverteilung 3:1; b, drei detektierte Peaks mit der Allelverteilung 1:2:1; c, GeneScan-Ergebnistabelle; Allelgrößen (bp) sind über den Peaks angegeben

Im Folgenden werden die ausgewerteten Mikrosatelliten-Loci einzeln vorgestellt und Allelfrequenzen der fünf Spezies gegenübergestellt. 


\subsubsection{Mikrosatelliten-Locus LS-19}

LS-19 präsentierte sich bei allen Individuen und Herkünften der Arten A. ruthenus, A. stellatus und $H$. huso als diploid. Bei A. baerii und A. gueldenstaedtii konnten maximal vier verschiedene Allele bei Einzeltieren beobachtet werden (Abb. 11).

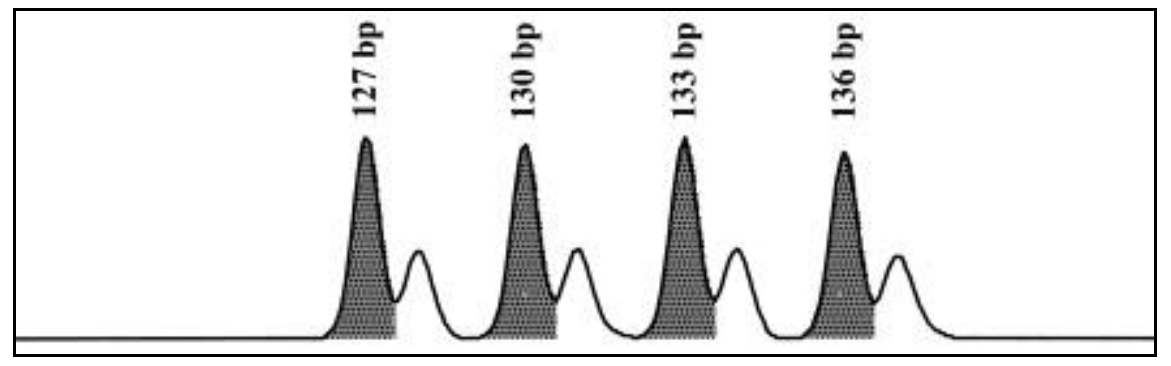

Abb. 11 Elektropherogramm eines A. gueldenstaedtii mit vier Allelen am Mikrosatelliten-Locus LS-19

Allelgrößen sind über den Peaks angegeben

Wie in der Abbildung $11 \mathrm{zu}$ sehen ist, wiesen die ausgewerteten Amplifikationsprodukte an diesem Locus Doppelpeaks auf.

Bei den Spezies A. baerii, A. gueldenstaedtii und H. huso fiel auf, dass zwischen dem kleinsten und größten Allel einige Allelgrößen nicht beobachtet werden konnten (Tab. 14). Dagegen waren bei A. ruthenus und A. stellatus keine Allellücken vorhanden. Besonders deutlich war dies bei H. huso festzustellen. Bei dieser Spezies differierte das kürzeste (127 bp) von dem nächstgrößeren Allel mit 145 bp um sechs Wiederholungseinheiten. Insgesamt konnten über die fünf Spezies 13 verschiedene Allele zwischen 118 und 157 bp beobachtet werden, wobei das Allel mit 121 bp bei keiner Spezies vorkam. Aufgrund des tetraploiden Status der Spezies A. baerii und A. gueldenstadtii konnten an diesem Mikrosatelliten-Locus Nullallele detektiert werden (Abb. 12). 


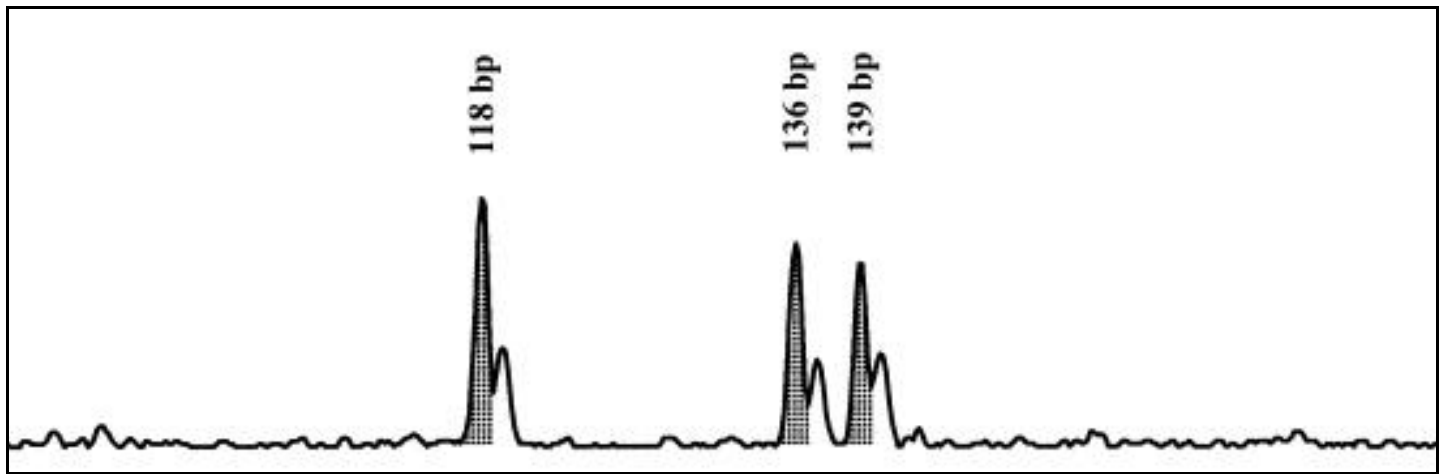

Abb. 12 Beispiel für ein detektiertes Nullallel eines $A$. baerii-Individuums an dem Mikrosatelliten-Locus LS-19

Allelgrößen (bp) sind über den Peaks angegeben

Tab. 14 Beobachtete Allele und berechnete Allelfrequenzen an dem Locus LS-19

\begin{tabular}{cccccc}
\hline Allelgrößen & \multicolumn{5}{c}{ Spezies } \\
\cline { 2 - 6 }$(\mathrm{bp})$ & A. baerii & A. gueldenst. & A. ruthenus & A. stellatus & H. huso \\
\hline 118 & 0,027 & 0,016 & 0,000 & 0,000 & 0,000 \\
121 & 0,000 & 0,000 & 0,000 & 0,000 & 0,000 \\
124 & 0,000 & 0,006 & 0,000 & 0,000 & 0,000 \\
127 & 0,056 & 0,401 & 0,000 & 0,000 & 0,147 \\
130 & 0,031 & 0,022 & 0,013 & 0,295 & 0,000 \\
133 & 0,634 & 0,486 & 0,737 & 0,500 & 0,000 \\
136 & 0,243 & 0,034 & 0,237 & 0,167 & 0,000 \\
139 & 0,000 & 0,006 & 0,013 & 0,038 & 0,000 \\
142 & 0,000 & 0,003 & 0,000 & 0,000 & 0,000 \\
145 & 0,003 & 0,022 & 0,000 & 0,000 & 0,015 \\
148 & 0,000 & 0,000 & 0,000 & 0,000 & 0,404 \\
151 & 0,006 & 0,000 & 0,000 & 0,000 & 0,022 \\
154 & 0,000 & 0,003 & 0,000 & 0,000 & 0,147 \\
157 & 0,000 & 0,000 & 0,000 & 0,000 & 0,265 \\
\hline
\end{tabular}




\subsubsection{Mikrosatelliten-Locus LS-34}

Insgesamt konnten über alle fünf untersuchten Arten sechs verschiedene Allele zwischen 134 bp und 149 bp an diesem Locus detektiert werden. A. gueldenstaedtii präsentierte sich als die Spezies mit der größten Heterogenität. Demgegenüber wies H. huso die geringste Variabilität an diesem Locus mit zwei beobachteten Allelen bei sehr großen Frequenzunterschieden zwischen diesen auf. (Tab. 15).

Tab. 15 Beobachtete Allele und berechnete Allelfrequenzen an dem Locus LS-34

\begin{tabular}{cccccc}
\hline \multirow{2}{*}{\begin{tabular}{c} 
Allelgrößen \\
\cline { 2 - 6 } (bp)
\end{tabular}} & A. baerii & A. gueldenst. & A. ruthenus & A. stellatus & H. huso \\
\hline 134 & 0,370 & 0,072 & 0,000 & 0,000 & 0,000 \\
137 & 0,003 & 0,081 & 0,053 & 0,088 & 0,007 \\
140 & 0,477 & 0,611 & 0,184 & 0,013 & 0,993 \\
143 & 0,123 & 0,047 & 0,684 & 0,050 & 0,000 \\
146 & 0,027 & 0,177 & 0,079 & 0,850 & 0,000 \\
149 & 0,000 & 0,012 & 0,000 & 0,000 & 0,000 \\
\hline
\end{tabular}

Wie schon an dem Locus LS-19 beobachtet werden konnte, waren auch hier die beiden Arten A. baerii und A. gueldenstaedtii tetraploid. Die drei anderen Spezies wiesen einen diploiden chromosomalen Status an diesem Mikrosatelliten-Locus auf.

Da bei einigen Individuen der Spezies A. baerii und A. gueldenstaedtii triploide Genotypen beobachtet werden konnten, ist davon auszugehen, dass es sich hierbei um Tiere mit Nullallelen handelte. 


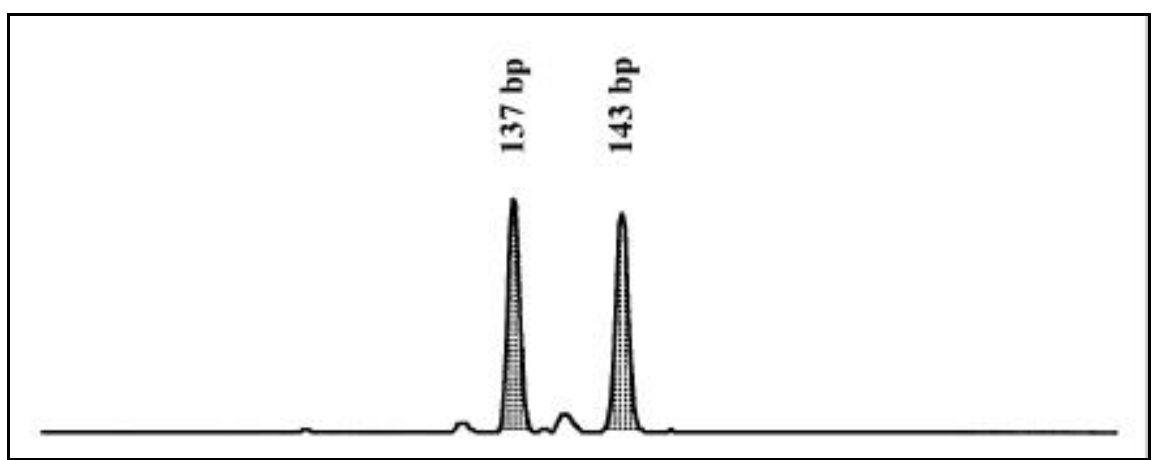

Abb. 13 Beispiel für ein heterozygotes Individuum der Spezies A. ruthenus an dem Mikrosatelliten-Locus LS-34

Allelgrößen (bp) sind über den Peaks angegeben

\subsubsection{Mikrosatelliten-Locus LS-39}

Insgesamt wurden 17 Allele über alle Individuen und Spezies in einem Größenbereich von 108 bis 156 bp an dem Mikrosatelliten-Locus LS-39 detektiert (Tab. 16).

Von den 17 beobachteten Allelen traten 16 bei A. gueldenstaedtii, acht bei A. baerii, vier bei $H$. huso und drei Allele bei A. ruthenus auf. Alle Individuen der Spezies A. stellatus waren an diesem Locus für das Allel von 111 bp fixiert. Dieses Allel trat zudem nur bei dieser Störart auf. LS-39 wurde daraufhin an den drei Kaviarsorten Beluga (H. huso), Ossetra (A. gueldenstaedtii) und Sevruga (A. stellatus) amplifiziert. Nur der Sevruga-Kaviar wies das Fragment von 111 bp auf (Abb. 14).

Im Gegensatz zu den untersuchten Individuen der Spezies A. gueldenstaedtii, welche maximal vier Peaks an diesem Locus aufwiesen, konnten beim Ossetra-Kaviar sieben Peaks mit den Größen 120, 123, 126, 132, 135, 150 und 153 bp detektiert werden. 
Tab. 16 Beobachtete Allele und berechnete Allelfrequenzen an dem Locus LS-39

\begin{tabular}{|c|c|c|c|c|c|}
\hline \multirow{2}{*}{$\begin{array}{l}\text { Allelgrößen } \\
\text { (bp) }\end{array}$} & \multicolumn{5}{|c|}{ Spezies } \\
\hline & A. baerii & A. gueldenst. & A. ruthenus & A. stellatus & H. huso \\
\hline 108 & 0,000 & 0,019 & 0,013 & 0,000 & 0,000 \\
\hline 111 & 0,000 & 0,000 & 0,000 & 1,000 & 0,000 \\
\hline 114 & 0,000 & 0,015 & 0,000 & 0,000 & 0,580 \\
\hline 117 & 0,075 & 0,017 & 0,000 & 0,000 & 0,000 \\
\hline 120 & 0,375 & 0,068 & 0,461 & 0,000 & 0,000 \\
\hline 123 & 0,460 & 0,223 & 0,526 & 0,000 & 0,051 \\
\hline 126 & 0,000 & 0,012 & 0,000 & 0,000 & 0,362 \\
\hline 129 & 0,000 & 0,185 & 0,000 & 0,000 & 0,000 \\
\hline 132 & 0,002 & 0,004 & 0,000 & 0,000 & 0,000 \\
\hline 135 & 0,020 & 0,031 & 0,000 & 0,000 & 0,000 \\
\hline 138 & 0,059 & 0,247 & 0,000 & 0,000 & 0,000 \\
\hline 141 & 0,000 & 0,005 & 0,000 & 0,000 & 0,000 \\
\hline 144 & 0,002 & 0,014 & 0,000 & 0,000 & 0,000 \\
\hline 147 & 0,006 & 0,036 & 0,000 & 0,000 & 0,000 \\
\hline 150 & 0,000 & 0,109 & 0,000 & 0,000 & 0,007 \\
\hline 153 & 0,000 & 0,009 & 0,000 & 0,000 & 0,000 \\
\hline 156 & 0,000 & 0,006 & 0,000 & 0,000 & 0,000 \\
\hline
\end{tabular}

Wie schon bei den Mikrosatelliten-Loci LS-19 und LS-34 konnten bei einigen Individuen der Arten A. baerii und A. gueldenstadtii nur drei Allele beobachtet werden, d.h. Nullallele traten auch an diesem Locus auf. 


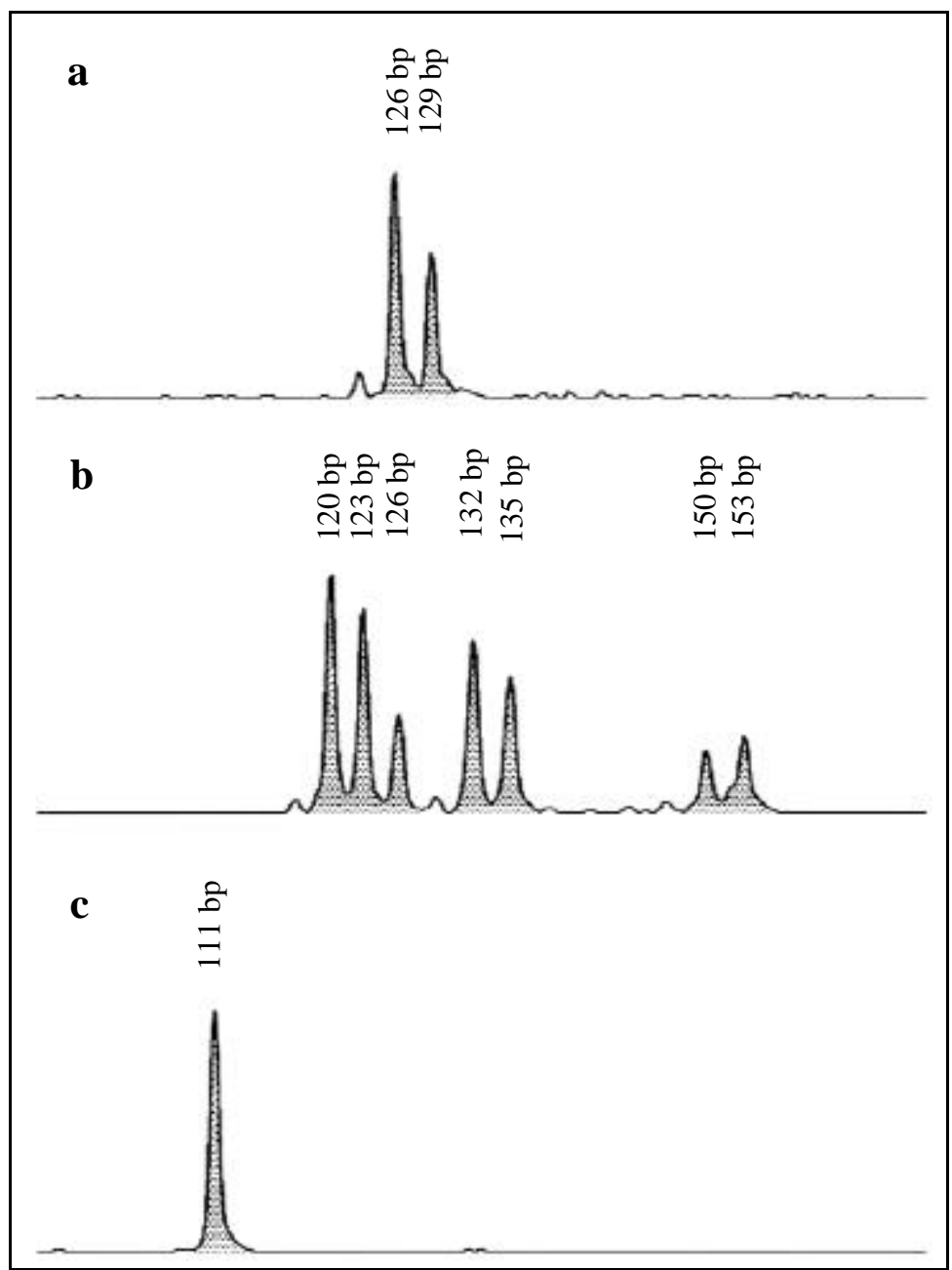

Abb. 14 Vergleich der Amplifikationsprodukte des Mikrosatelliten-Locus LS-39 von drei verschiedenen Kaviarsorten

a, Beluga-Kaviar (H. huso); b, Ossetra-Kaviar (A. gueldenstaedtii) und c, Sevruga-Kaviar (A. stellatus); Allelgrößen sind über den Peaks angegeben

\subsubsection{Mikrosatelliten-Locus LS-54}

Der Mikrosatelliten-Locus LS-54 konnte nicht bei A. ruthenus amplifiziert werden. Mit 14 bzw. 10 detektierten Allelen wies LS-54 bei A. baerii und $H$. huso den höchsten Polymorphiegrad von den Mikrosatelliten-Loci auf, an denen für alle Spezies Allelfrequenzen berechnet werden konnten. 
Tab. 17 Beobachtete Allele und berechnete Allelfrequenzen an dem Locus LS-54

\begin{tabular}{|c|c|c|c|c|}
\hline \multirow{2}{*}{$\begin{array}{l}\text { Allelgrößen } \\
\text { (bp) }\end{array}$} & \multicolumn{4}{|c|}{ Spezies } \\
\hline & A. baerii & A. gueldenst. & A. stellatus & H. huso \\
\hline 165 & 0,000 & 0,000 & 0,039 & 0,000 \\
\hline 169 & 0,000 & 0,000 & 0,026 & 0,000 \\
\hline 173 & 0,000 & 0,028 & 0,105 & 0,000 \\
\hline 177 & 0,029 & 0,000 & 0,092 & 0,000 \\
\hline 181 & 0,000 & 0,000 & 0,026 & 0,000 \\
\hline 185 & 0,000 & 0,009 & 0,132 & 0,000 \\
\hline 189 & 0,020 & 0,014 & 0,237 & 0,000 \\
\hline 193 & 0,148 & 0,097 & 0,342 & 0,000 \\
\hline 197 & 0,015 & 0,037 & 0,000 & 0,000 \\
\hline 201 & 0,294 & 0,060 & 0,000 & 0,000 \\
\hline 205 & 0,011 & 0,066 & 0,000 & 0,000 \\
\hline 209 & 0,126 & 0,228 & 0,000 & 0,000 \\
\hline 213 & 0,000 & 0,034 & 0,000 & 0,224 \\
\hline 217 & 0,254 & 0,171 & 0,000 & 0,015 \\
\hline 221 & 0,060 & 0,009 & 0,000 & 0,007 \\
\hline 225 & 0,020 & 0,234 & 0,000 & 0,000 \\
\hline 229 & 0,000 & 0,006 & 0,000 & 0,007 \\
\hline 233 & 0,009 & 0,003 & 0,000 & 0,000 \\
\hline 237 & 0,002 & 0,006 & 0,000 & 0,209 \\
\hline 241 & 0,009 & 0,000 & 0,000 & 0,239 \\
\hline 245 & 0,000 & 0,000 & 0,000 & 0,254 \\
\hline 249 & 0,000 & 0,000 & 0,000 & 0,022 \\
\hline 253 & 0,000 & 0,000 & 0,000 & 0,007 \\
\hline 269 & 0,002 & 0,000 & 0,000 & 0,000 \\
\hline 285 & 0,000 & 0,000 & 0,000 & 0,015 \\
\hline
\end{tabular}


Zwischen dem kleinsten Allel von 165 bp, das nur bei A. stellatus auftrat, und dem größten Allel von 285 bp, welches bei Individuen der Spezies H. huso beobachtet wurde, lag eine Differenz von 120 bp. Dies entspricht bei einem TetranukleotidWiederholungsmotiv einem Unterschied von 30 Wiederholungseinheiten.

Auffällig war, dass die beiden Arten A. stellatus und H. huso unterschiedliche, sich nicht überschneidene Allelklassen besaßen. Dagegen wiesen $A$. baerii und A. gueldenstaedtii eine sehr heterogene Allelverteilung über den Großteil der Allelklassen auf.

Während bei A. stellatus jede Allelklasse zwischen dem kleinsten und größten beobachteten Allel besetzt war, wiesen die drei übrigen Spezies unbesetzte Allelklassen auf.

LS-54 präsentierte sich bei den Arten A. stellatus und H. huso als ein diploider Locus. Demgegenüber war er tetraploid bei den beiden Spezies A. baerii und A. gueldenstaedtii. Nullallele konnten wiederum bei Individuen der beiden letztgenannten Arten direkt durch ein triploides Allelmuster nachgewiesen werden.

\subsubsection{Mikrosatelliten-Locus LS-68}

Während die Spezies A. ruthenus, A. stellatus und H. huso maximal zwei Allele an LS-68 aufwiesen und somit diploid an diesem Locus waren, präsentierte sich LS-68 bei den beiden Arten A. baerii und A. gueldenstaedtii als putativer octaploider Locus. Das bei den Individuen der beiden Spezies beobachtete Peakmuster gestattete jedoch keine sichere Allelquantifizierung (Abb. 15).

Von den ausgewerteten Mikrosatelliten-Loci wies LS-68 sowohl bei A. ruthenus als auch A. stellatus den höchsten Polymorphiegrad mit zwölf bzw. neun detektierten Allelen auf. Obwohl an diesem Locus für A. baerii und A. gueldenstaedtii keine Berechnung von Allelfrequenzen durchführbar war, konnten bei A. baerii 15 Allele und bei A. gueldenstaedtii 28 Allele beobachtet werden. Der Vollständigkeit halber wird für diese 
beiden Spezies anstelle der Allelfrequenzen das Vorhandensein bzw. die Abwesenheit der Peaks (Allele) in Tabelle 18 dargestellt.

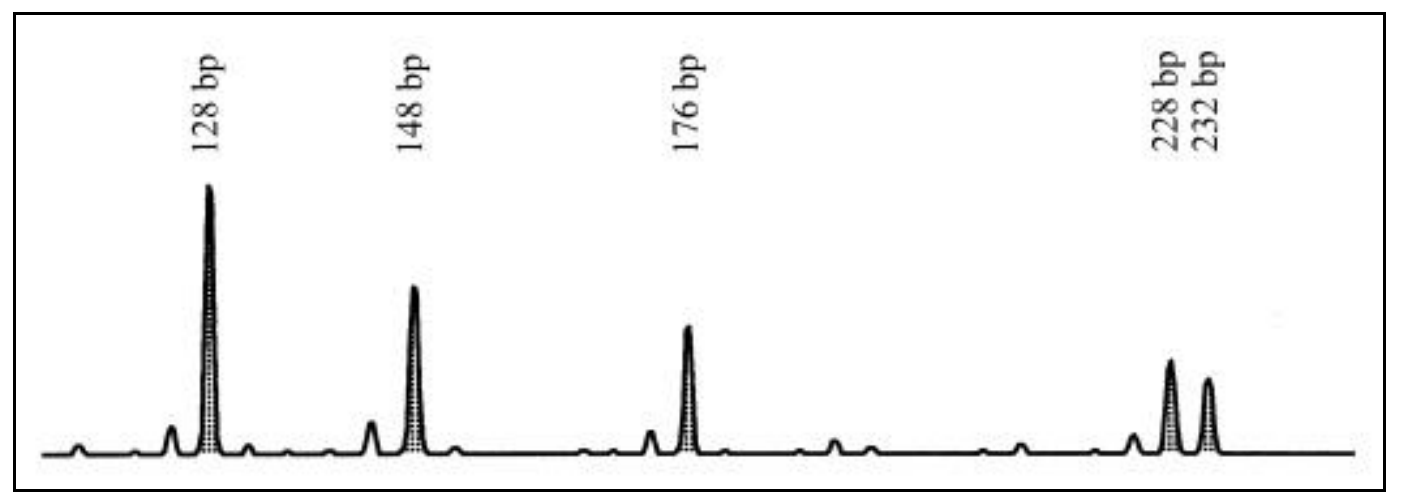

Abb. 15 Nicht quantifizierbares Peakmuster am Mikrosatelliten-Locus LS-68 bei einem Individuum der Spezies A. baerii

Allelgrößen sind über den Peaks angegeben

Tab. 18 Beobachtete Allele der fünf Spezies an dem Mikrosatelliten-Locus LS-68

\begin{tabular}{cccccc}
\hline \multirow{2}{*}{\begin{tabular}{c} 
Allelgrößen \\
\cline { 2 - 5 }$(\mathrm{bp})$
\end{tabular}} & A. baerii & A. gueldenst. & A. ruthenus & A. stellatus & H. huso \\
\cline { 2 - 6 } 104 & $-{ }^{2}$ & $\mathrm{x}^{2}$ & 0,000 & 0,000 & 0,000 \\
116 & - & $\mathrm{x}$ & 0,000 & 0,028 & 0,000 \\
120 & - & $\mathrm{x}$ & 0,000 & 0,069 & 0,000 \\
124 & - & $\mathrm{x}$ & 0,000 & 0,139 & 0,000 \\
128 & $\mathrm{x}$ & $\mathrm{x}$ & 0,000 & 0,153 & 0,000 \\
132 & - & $\mathrm{x}$ & 0,000 & 0,250 & 0,000 \\
136 & $\mathrm{x}$ & $\mathrm{x}$ & 0,000 & 0,139 & 0,923 \\
140 & $\mathrm{x}$ & $\mathrm{x}$ & 0,000 & 0,167 & 0,007 \\
144 & $\mathrm{x}$ & $\mathrm{x}$ & 0,000 & 0,042 & 0,000 \\
148 & $\mathrm{x}$ & $\mathrm{x}$ & 0,000 & 0,000 & 0,014 \\
152 & $\mathrm{x}$ & $\mathrm{x}$ & 0,000 & 0,014 & 0,000 \\
164 & - & - & 0,000 & 0,000 & 0,021 \\
168 & - & - & 0,028 & 0,000 & 0,000 \\
176 & $\mathrm{x}$ & $\mathrm{x}$ & 0,125 & 0,000 & 0,000 \\
\hline
\end{tabular}


Tab. 18 Fortsetzung

\begin{tabular}{|c|c|c|c|c|c|}
\hline \multirow{2}{*}{$\begin{array}{l}\text { Allelgrößen } \\
\qquad(\mathrm{bp})\end{array}$} & \multicolumn{5}{|c|}{ Spezies } \\
\hline & A. baerii & A. gueldenst. & A. ruthenus & A. stellatus & H. huso \\
\hline 180 & $\mathrm{x}$ & $\mathrm{x}$ & 0,056 & 0,000 & 0,000 \\
\hline 184 & - & $\mathrm{x}$ & 0,278 & 0,000 & 0,000 \\
\hline 188 & - & $\mathrm{x}$ & 0,000 & 0,000 & 0,000 \\
\hline 192 & - & $\mathrm{x}$ & 0,139 & 0,000 & 0,000 \\
\hline 196 & $\mathrm{x}$ & $\mathrm{x}$ & 0,111 & 0,000 & 0,000 \\
\hline 200 & $\mathrm{x}$ & $\mathrm{x}$ & 0,000 & 0,000 & 0,000 \\
\hline 204 & - & $\mathrm{x}$ & 0,056 & 0,000 & 0,000 \\
\hline 208 & $\mathrm{x}$ & $\mathrm{x}$ & 0,069 & 0,000 & 0,000 \\
\hline 212 & - & $\mathrm{x}$ & 0,028 & 0,000 & 0,000 \\
\hline 216 & - & - & 0,028 & 0,000 & 0,000 \\
\hline 220 & - & $\mathrm{x}$ & 0,000 & 0,000 & 0,000 \\
\hline 224 & $\mathrm{x}$ & $\mathrm{x}$ & 0,056 & 0,000 & 0,000 \\
\hline 228 & $\mathrm{x}$ & - & 0,000 & 0,000 & 0,021 \\
\hline 232 & $\mathrm{x}$ & $\mathrm{x}$ & 0,000 & 0,000 & 0,000 \\
\hline 236 & $\mathrm{x}$ & $\mathrm{x}$ & 0,028 & 0,000 & 0,000 \\
\hline 240 & - & $\mathrm{x}$ & 0,000 & 0,000 & 0,007 \\
\hline 244 & - & $\mathrm{x}$ & 0,000 & 0,000 & 0,000 \\
\hline 248 & - & $\mathrm{x}$ & 0,000 & 0,000 & 0,000 \\
\hline 260 & - & - & 0,000 & 0,000 & 0,007 \\
\hline
\end{tabular}

${ }^{1}$ Kein Peak dieser Größe in den Elektropherogrammen der Individuen innerhalb der Spezies vorhanden; ${ }^{2}$ Beobachteter, nicht quantifizierbarer Peak

Beim Vergleich der drei sich an diesem Loci als diploid präsentierenden Spezies A. ruthenus, A. stellatus und $H$. huso fiel auf, dass keines der zwölf bei A. ruthenus detektierten Allele bei den beiden anderen Arten vorkam. Von den neun bzw. sieben beobachteten Allelen bei A. stellatus bzw. H. huso kamen nur die Fragmente mit einer Größe von 136 und 140 bp bei beiden Spezies vor. Allerdings traten fast sämtliche Allele dieser Spezies auch bei A. baerii und A. gueldenstaedtii auf. 


\subsubsection{Test der Stichproben auf Hardy-Weinberg-Gleichgewicht}

Sowohl die Stichprobengüte der Herkünfte mit einer Stichprobengröße von $\mathrm{n} \geq 10$ als auch die Stichprobengüte der einzelnen Spezies wurden mittels des $\chi^{2}$-Tests auf das Hardy-Weinberg-Gleichgewicht (HWG) hin untersucht.

Tab. 19 Test der Spezies und Herkünfte innerhalb der Spezies auf HardyWeinberg-Gleichgewicht

\begin{tabular}{|c|c|c|c|c|c|c|c|}
\hline \multirow[b]{2}{*}{ Spezies } & \multirow[b]{2}{*}{ Herkunft } & \multirow[b]{2}{*}{$\mathrm{n}$} & \multicolumn{5}{|c|}{ Mikrosatelliten-Locus } \\
\hline & & & LS-19 & LS-34 & LS-39 & LS-54 & LS-68 \\
\hline \multirow[t]{4}{*}{ A. baerii } & $\mathrm{B}, \mathrm{C}, \mathrm{E}, \mathrm{F}$ & 125 & $* * *$ & $* * *$ & $* * *$ & $* * *$ & (1) \\
\hline & $\mathrm{B}$ & 50 & $* * *$ & $* * *$ & n.s. & n.s. & (1) \\
\hline & $\mathrm{C}$ & 60 & $* * *$ & $*$ & $* * *$ & $* * *$ & (1) \\
\hline & $\mathrm{F}$ & 13 & n.s. & n.s. & n.s. & $* *$ & (1) \\
\hline \multirow[t]{4}{*}{ A. gueldenst. } & $\mathrm{C}, \mathrm{E}, \mathrm{F}, \mathrm{G}$ & 91 & $* * *$ & $* *$ & $* * *$ & $* * *$ & (1) \\
\hline & $\mathrm{C}$ & 60 & $* * *$ & $* *$ & $* * *$ & $* * *$ & (1) \\
\hline & $\mathrm{F}$ & 10 & $* * *$ & n.s. & $* * *$ & n.s. & (1) \\
\hline & $\mathrm{G}$ & 19 & $* * *$ & n.s. & $* * *$ & $* * *$ & (1) \\
\hline \multirow[t]{3}{*}{ A. ruthenus } & $\mathrm{A}, \mathrm{E}, \mathrm{F}$ & 38 & n.s. & n.s. & n.s. & (2) & $* * *$ \\
\hline & A & 10 & n.s. & n.s. & n.s. & (2) & $* * *$ \\
\hline & $\mathrm{F}$ & 21 & n.s. & n.s. & $* *$ & (2) & n.s. \\
\hline \multirow[t]{3}{*}{ A. stellatus } & $\mathrm{D}, \mathrm{E}, \mathrm{F}, \mathrm{G}$ & 38 & n.s. & $* * *$ & (3) & n.s. & $*$ \\
\hline & $\mathrm{F}$ & 20 & n.s. & $* * *$ & (3) & n.s. & n.s. \\
\hline & $\mathrm{G}$ & 15 & n.s. & $*$ & (3) & n.s. & n.s. \\
\hline \multirow[t]{3}{*}{ H. huso } & $\mathrm{D}, \mathrm{E}, \mathrm{F}, \mathrm{G}$ & 72 & $* * *$ & n.s. & $* * *$ & $* * *$ & $* * *$ \\
\hline & $\mathrm{D}$ & 50 & $* * *$ & (3) & $* * *$ & $* * *$ & $* * *$ \\
\hline & $\mathrm{F}$ & 16 & $* * *$ & (3) & $* * *$ & n.s. & (3) \\
\hline
\end{tabular}

Signifikanzen: $\mathrm{p} \leq 0,001={ }^{* * *} ; \mathrm{p} \leq 0,01=* * ; \mathrm{p} \leq 0,05=* ; \mathrm{p} \geq 0,05=$ n.s.; (1) nicht auswertbarer Locus; (2) keine Amplifikation; (3) Allelfixierung. 
Bei der Betrachtung der Spezies wurden dabei die Allelfrequenzen an den einzelnen Loci über alle Herkünfte gepoolt berechnet. Für den $\chi^{2}$-Test wurden die Beobachtungswerte der Genotypfrequenzen aus dem Datenmaterial abgeleitet. Die Berechnung der Erwartungswerte erfolgte unter Verwendung der Allelfrequenzen und der Individuenzahl mit dem Programm EWERTE (BRANDT 1998).

Innerhalb der gepoolten Daten befanden sich A. ruthenus, A. stellatus und H. huso jeweils an mindestens einem Locus im HWG. Keine der drei Spezies erfüllte jedoch über alle Loci, für die der $\chi^{2}$-Test berechnet werden konnte, das HWG. A. baerii und A. gueldenstaedtii waren an den vier betrachteten Loci hochsignifikant vom HWG verschieden.

Die Auswertung der einzelnen Herkünfte innerhalb der Spezies mit einer Stichprobengröße von $n \geq 10$ zeigte ebenfalls, dass keine Herkunft das HWG über alle analysierbaren Loci hinweg erfüllen konnte.

\subsubsection{Auswahl von potentiell unverwandten Individuen innerhalb der Spezies}

Zehn potentiell unverwandte Individuen wurden je Spezies für die Durchführung der Methoden RAPD, SINE-PCR, Inter-SSR-PCR und AFLP ausgewählt. Die Selektion von Tieren, die aus derselben Herkunft stammten, erfolgte innerhalb Spezies anhand unterschiedlicher Mikrosatelliten-Genotypen. Von diesen Individuen wurde ebenso wie von Tieren aus verschiedenen Herkünften angenommen, dass sie unverwandt seien.

\subsubsection{Ergebnisse der RAPD}

In Voruntersuchungen wurden die einzelnen in der RAPD-PCR verwendeten Primer auf ihr Amplifikationspotential hin getestet. Je Spezies wurden hierfür drei Individuen unterschiedlicher Herkünfte ausgewählt. 


\subsubsection{Ergebnisse der Oligonukleotide des Operon Kit H}

Von den 20 Oligonukleotiden des Operon Kit H erbrachten 17 eine unterschiedliche Anzahl an Amplifikationsprodukten in der RAPD-PCR. Bei der Verwendung der drei Primer OPH-10, OPH-16 und OPH-17 konnten nach der Agarosegel-Elektrophorese keine Fragmente beobachtet werden. Die nach der elektrophoretischen Auftrennung im 1,4\%igen (w/v) Agarosegel visualisierten Fragmentmuster von 14 der 17 getesteten Primer wiesen keine Speziesspezifität auf. Häufig war die intraspezifische Variabilität der Bandenmuster höher als die interspezifische. Die Primer OPH-06, OPH-07 und OPH-11 zeigten in den Voruntersuchungen je ein für A. stellatus spezifisches Fragment mit einer Größe von ca. 500, 200 bzw. 300 bp, welches nicht bei den anderen Arten auftrat (Abb. 16).

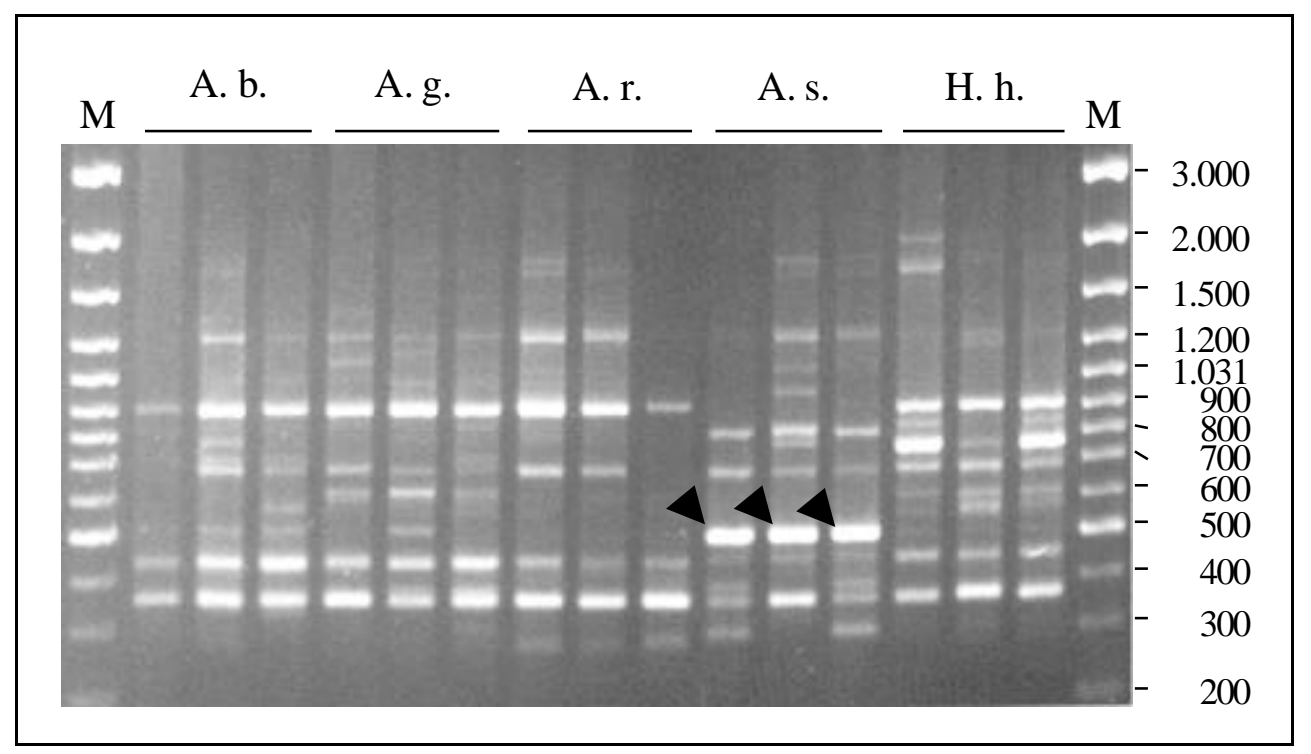

Abb. 16 Im Agarosegel visualisierte Amplifikationsprodukte des RADP-Primers OPH-06 in dessen Voruntersuchung an je drei unverwandten Individuen der fünf Spezies

M = Molekulargewichtstandard (100 bp DNA Ladder Plus); A. b. = A. baerii; A. g. = A. gueldenstaedtii; A. r. = A. ruthenus; A. s. = A. stellatus; H. h. = H. huso; Das potentiell für A. stellatus spezifische Fragment wird durch einen Pfeil markiert 
Das im Test aufgrund seiner Position und Leuchtintensität als potentiell A. stellatusspezifisch eingestufte Fragment konnte in der anschließenden Analyse bei allen zehn unverwandten Tieren dieser Art festgestellt werden. Es zeigte sich aber, dass dieses Fragment ebenfalls bei zwei der zehn untersuchten A. gueldenstaedtii mit einer hohen Leuchtintensität auftrat (Abb. 17).

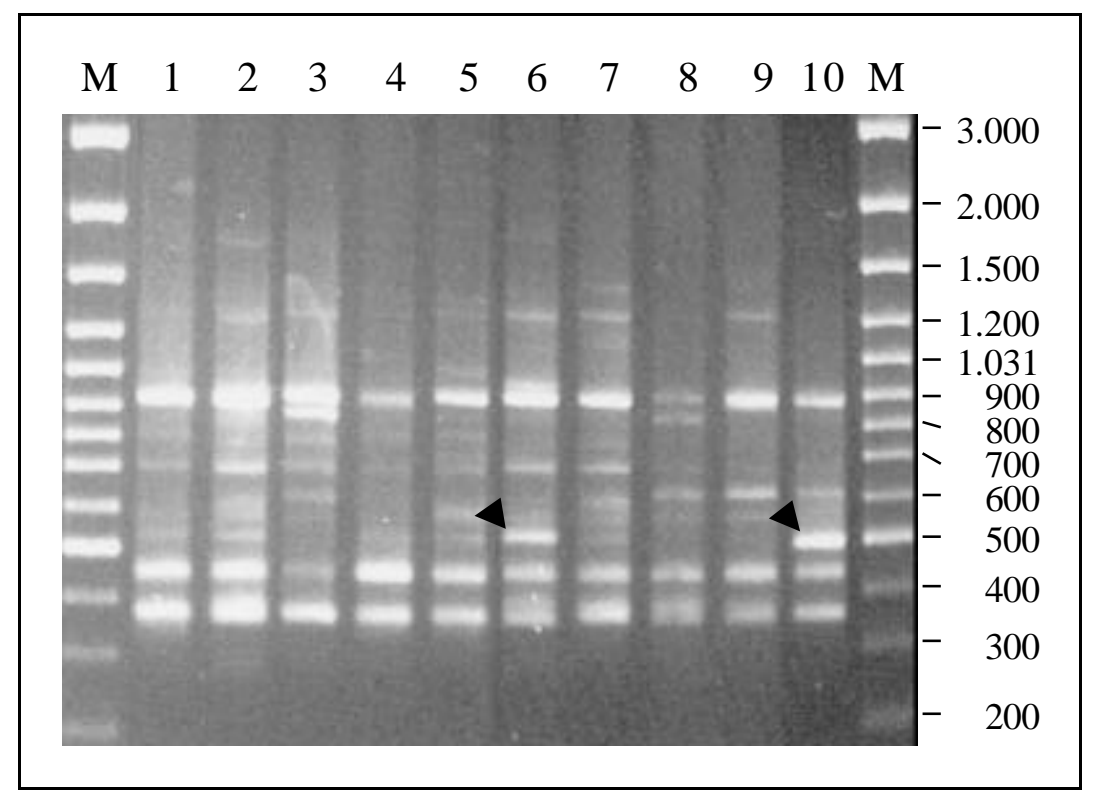

Abb. 17 Darstellung der mit dem Primer OPH-06 generierten Fragmentmuster bei sieben zusätzlich untersuchten Individuen $\operatorname{der}$ Art A. gueldenstaedtii $\mathrm{M}=$ Molekulargewichtstandard (100 bp DNA Ladder Plus)

Die in den Voruntersuchungen mit den Primern OPH-07 und OPH-11 für A. stellatus potentiell artspezifischen Fragmente wurden bei sieben weiteren Individuen nicht einheitlich amplifiziert.

Zusammenfassend lässt sich festhalten, dass keiner der zwanzig eingesetzten 10 mer Primer das Potential besaß, Spezies anhand der generierten Fragmentmuster zu differenzieren. 


\subsubsection{Ergebnisse der langen Primer}

Bis auf den Primer Long-3 konnten mit den übrigen 19 verwendeten Primern, die eine Länge zwischen 17 und 34 Nukleotiden aufwiesen, Amplifikationsprodukte in der PCR generiert werden. Nur mit den Primern Long-5 und Long-11 konnten in der Voruntersuchung an den drei unverwandten Individuen pro Spezies potentiell artcharakteristische Bandenmuster in der PCR erzeugt werden. Die drei Individuen der Spezies A. gueldenstaedtii zeigten ein sehr heterogenes Fragmentmuster für Long-5. Demgegenüber präsentierten sich die Individuen der übrigen vier Spezies mit sehr homogenen, zwischen den Arten unterscheidbaren Bandenmustern. Das mit Long-11 generierte Fragmentmuster gestattete eine Unterscheidung der Arten A.ruthenus, A. stellatus und H. huso. Die Beobachtungen wurden für beide Primer an sieben weiteren Individuen pro Spezies bestätigt.

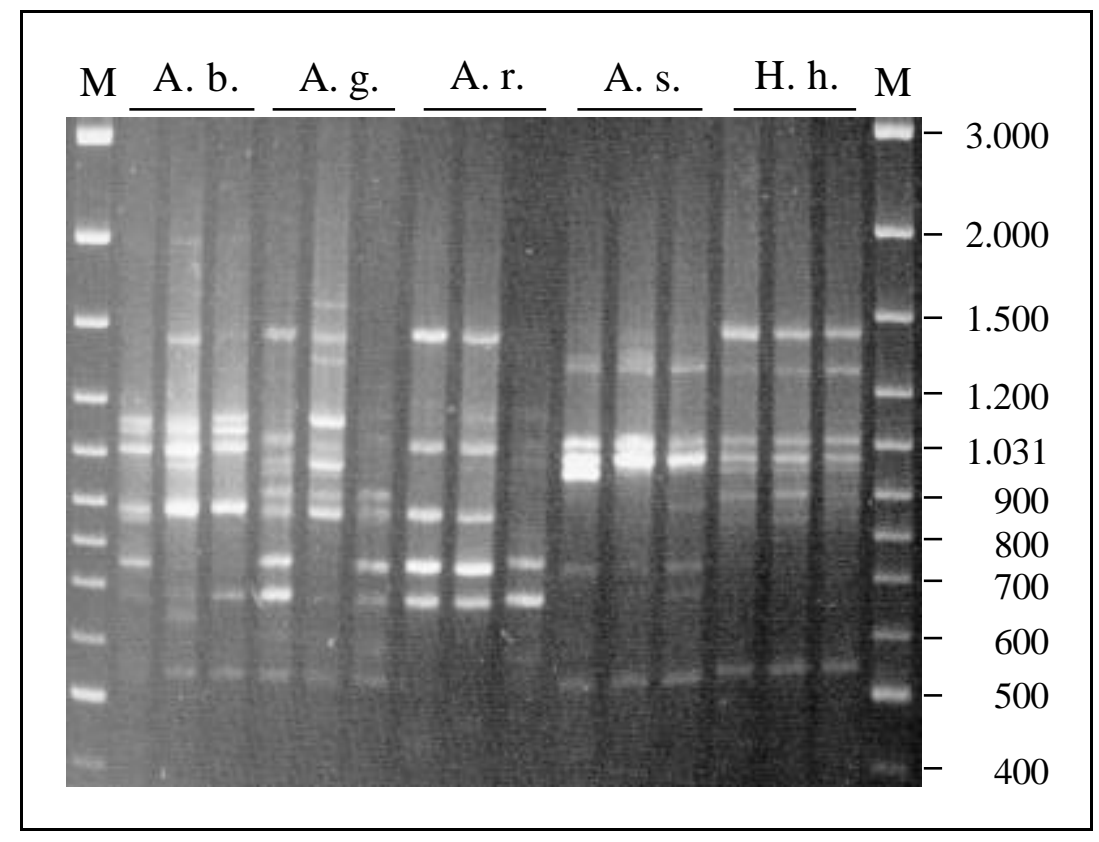

Abb. 18 Darstellung der in der Voruntersuchung mit dem Primer Long-5 generierten Fragmentmuster

$\mathrm{M}=$ Molekulargewichtstandard (100 bp DNA Ladder Plus); A. b. =

A. baerii; A. g. = A. gueldenstaedtii; A. r. = A. ruthenus; A. s. = A. stellatus; H. h. = H. huso 
Beide Primer wurden dann auf die Möglichkeit hin, Hybriden zu erkennen, untersucht. Insgesamt wurden je zehn Individuen der Kreuzungen A. baerii x A. ruthenus, H. huso x A. gueldenstaedtii, H. huso x A. ruthenus und (H. huso x A. ruthenus) $\mathrm{x}$ A. gueldenstaedtii untersucht. Das bei den Hybriden detektierte Bandenmuster erwies sich als sehr heterogen, so dass keine Rückschlüsse auf die Kreuzungseltern möglich waren (Abb. 19).

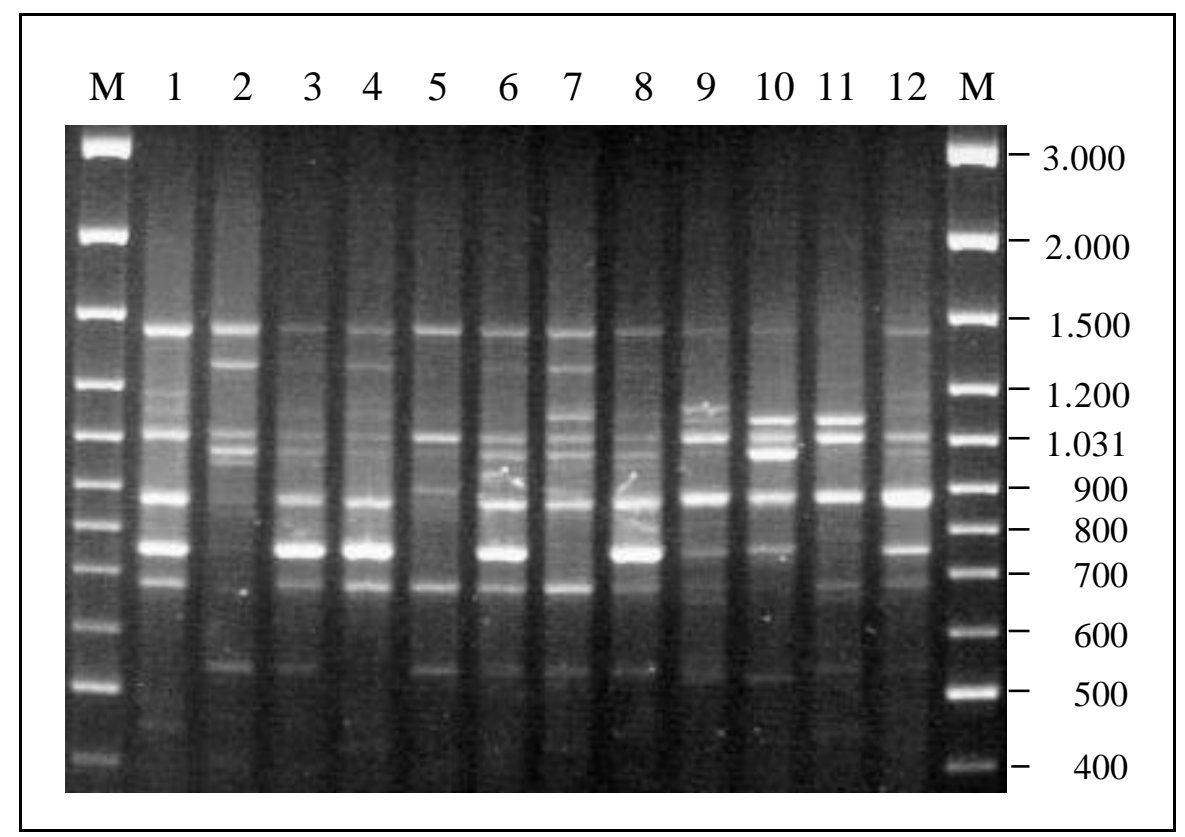

Abb. 19 Darstellung der mit Primer Long-5 generierten Fragmentmuster an zehn Hybriden der Kreuzung H. huso x A. ruthenus $\mathrm{M}=$ Molekulargewichtstandard (100 bp DNA Ladder Plus); $1=A$. ruthenus; $2=H$. huso; 3-12= Hybriden

\subsubsection{Wiederholbarkeit generierter Fragmentmuster}

Die Wiederholbarkeit der generierten individuellen Fragmentmuster wurde stichprobenhaft für den 10-mer Primer OPH-06, Long-5 und Long-11 an Individuen der verschiedenen Spezies überprüft. 


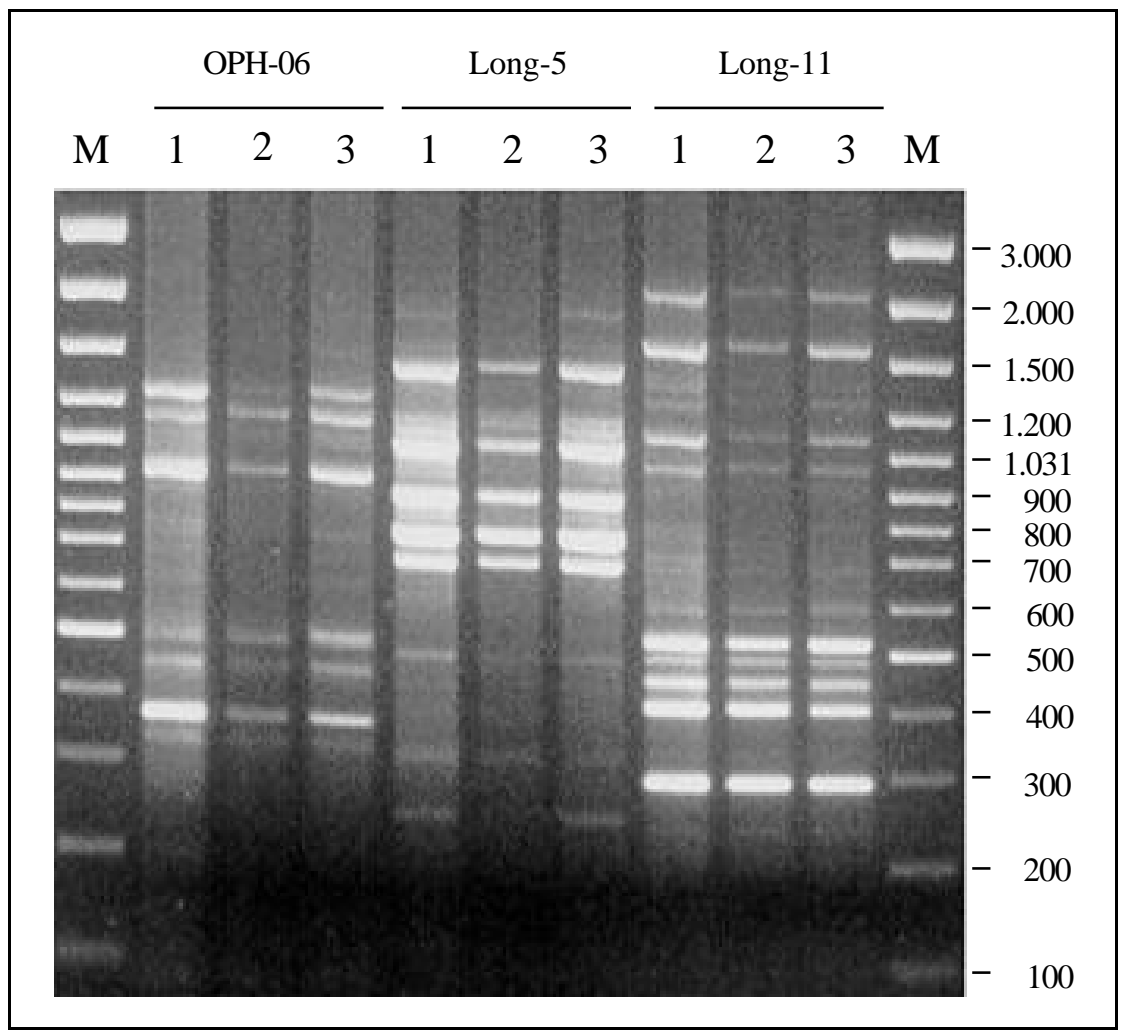

Abb. 20 Beispiel zur Wiederholbarkeit der individuellen Fragmentmuster der Primer OPH-06, Long-5 und Long 11 an einem Individuum der Spezies A. ruthenus

M = Molekulargewichtstandard (100 bp DNA Ladder Plus); 1-3 = intraindividuelle Wiederholung der RAPD-PCR

Abbildung 20 zeigt, dass eine geringe intraindividuelle Variabilität in den generierten Fragmentmustern bei zeitlich getrennten, wiederholten Amplifikationen festgestellt werden konnte. Diese war vor allem auf die Präsenz/Abwesenheit von Banden schwacher Leuchtintensität und in Unterschieden hinsichtlich der Leuchtintensität der Banden zurückzuführen.

\subsubsection{Ergebnisse der SINE-PCR}

Wie schon bei der RAPD, wurden auch hier je Spezies drei Individuen verschiedener Herkünfte getestet. Der verwendete Primer wurde anhand einer Konsenssequenz konstruiert, die aus SINE-Elementen mit einer tRNA ${ }^{\text {Lys }}$-ähnlichen Region verschiedener 
Spezies abgeleitet wurde (OHSHIMA et al. 1993). Trotzdem konnten unter stringenten PCR-Bedingungen $\left(1,5 \mathrm{mM} \mathrm{MgCh}, 50{ }^{\circ} \mathrm{C}\right.$ Annealingtemperatur) Amplifikationsprodukte generiert werden (Abb. 21).

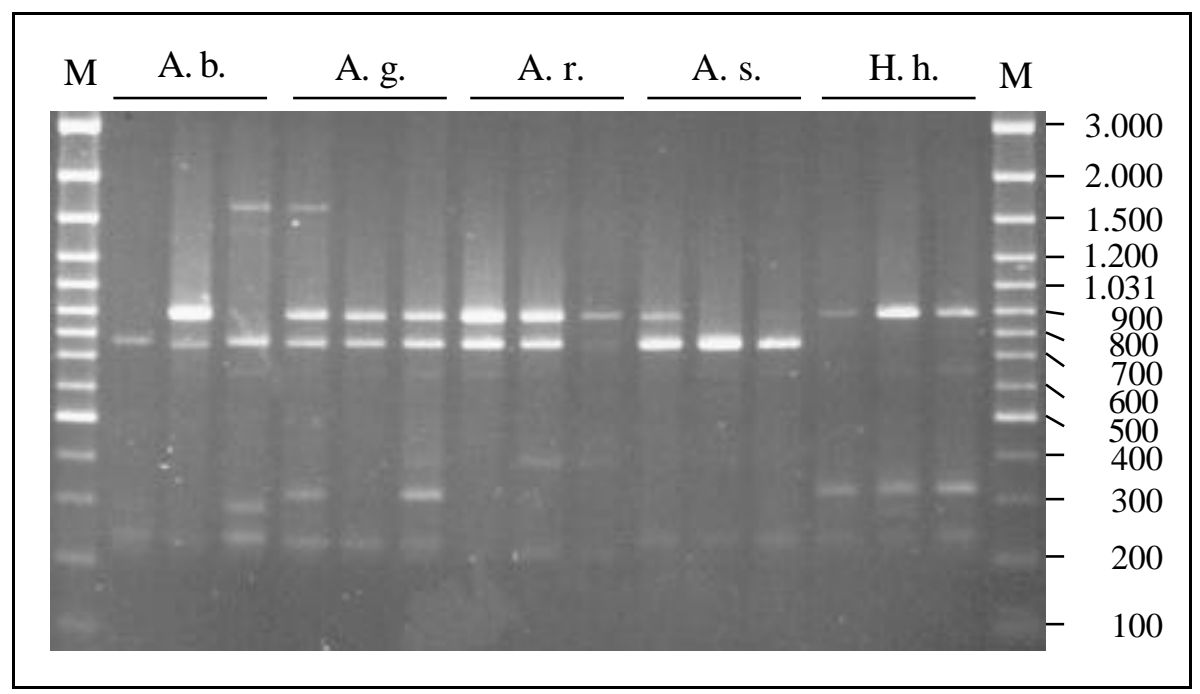

Abb. 21 Generierte Amplifikationsprodukte bei Individuen der fünf Spezies in der SINE-PCR

M = Molekulargewichtstandard (100 bp DNA Ladder Plus); A. b. = A. baerii; A. g. = A. gueldenstaedtii; A. r. = A. ruthenus; A. s. = A. stellatus; H. h. = H. huso

Innerhalb der Spezies konnte eine Variabilität hinsichtlich des Auftretens bestimmter Fragmente festgestellt werden. Fragmente, welche eine eindeutige Artcharakterisierung gestatteten, wurden nicht beobachtet.

\subsubsection{Ergebnisse der Inter-SSR PCR}

Jeder der einzeln in der PCR eingesetzten fünf Primer führte zu Amplifikationsprodukten. Die drei zu Dinukleotid-Wiederholungsmotiven homologen Primer ISSR 1, ISSR 2 und ISSR 3 generierten sehr komplexe Fragmentmuster, welche nur in silbergefärbten, 6\%igen (w/v) Polyacrylamidgelen dargestellt werden konnten. Auffällig war, dass jeder dieser Primer ein intraspezifisch heterogenes Bandenmuster erzeugte. 


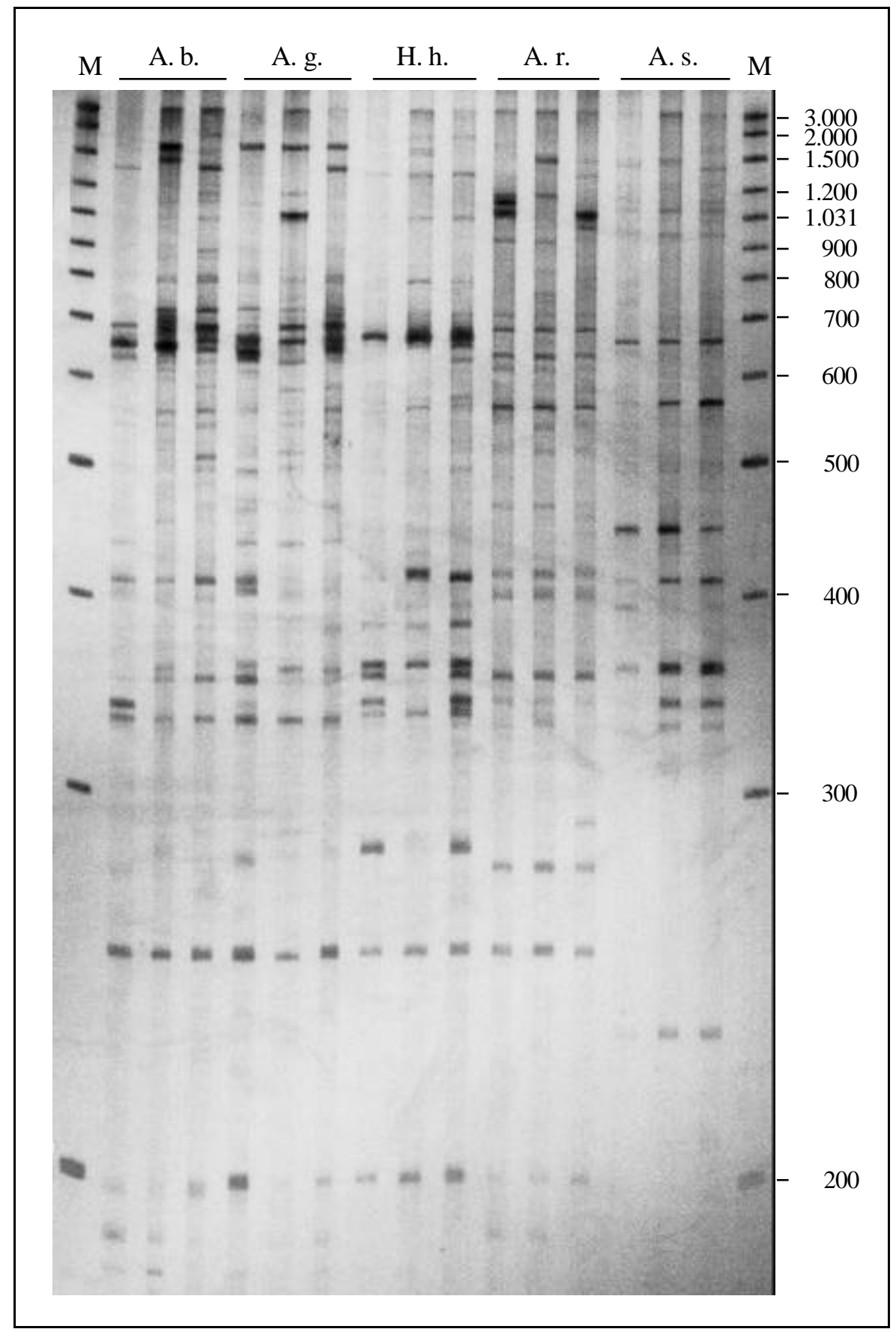

Abb. 22 Darstellung der generierten Amplifikationsprodukte des Primers ISSR2 im silbergefärbten Polyacrylamidgel

$\mathrm{M}=$ Molekulargewichtstandard (100 bp DNA Ladder Plus); A. b. = A. baerii; A. g. = A. gueldenstaedtii; A. r. = A. ruthenus; A. s. = A. stellatus; H. h. = H. huso 
Primer ISSR1 führte lediglich zu einem potentiell A. stellatus-spezifischen Fragment. Die Verwendung des Primers ISSR2 erzeugte je ein potentiell artspezifisches Fragment für die beiden Spezies A. ruthenus und A. stellatus (Abb. 22). Der Primer ISSR3 führte zu keinem artspezifischen Amplifikationsprodukt bei den fünf untersuchten Spezies.

Aufgrund einer wesentlich geringeren Anzahl an Amplifikationsprodukten konnten die generierten Fragmente der Primer ISSR4 und ISSR5 im 1,4\%igen (w/v) Agarosegel dargestellt werden. Keiner der beiden Primer führte $\mathrm{zu}$ einem artspezifischen Bandenmuster. Intraspezifisch heterogene Fragmente konnten besonders bei der Verwendung des Primers ISSR4 festgestellt werden (Abb. 23).

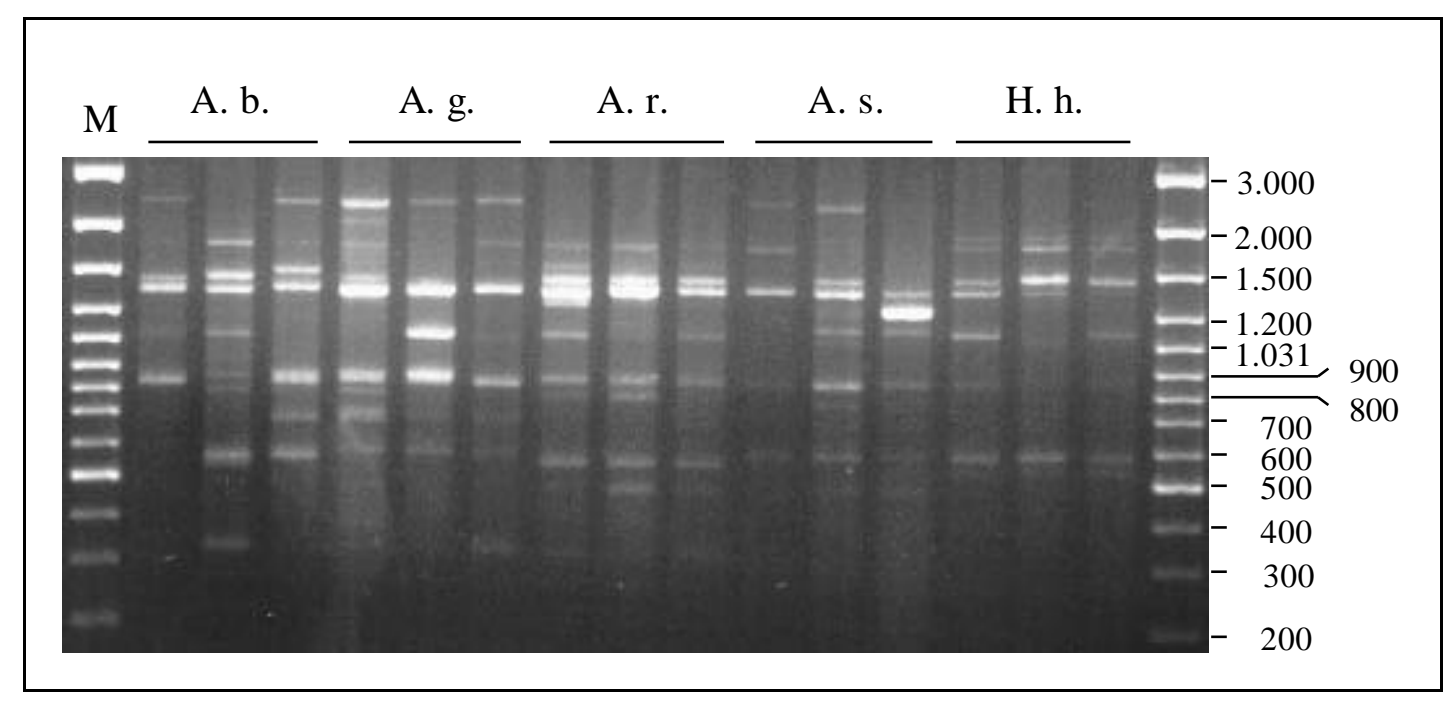

Abb. 23 Erzeugte Fragmentmuster bei Verwendung des Primers ISSR4

M = Molekulargewichtstandard (100 bp DNA Ladder Plus); A. b. = A. baerii; A. g. = A. gueldenstaedtii; A. r. = A. ruthenus; A. s. = A. stellatus; H. h. = H. huso 


\subsubsection{Ergebnisse des AFLP}

\subsubsection{Auswertung der generierten Fragmentmuster}

Von den fünf Spezies wurden im Rahmen der AFLP-Analyse je zehn unverwandte Individuen untersucht. Im Bereich des Molekulargewichtstandards (50 bis 350 bp) konnten über alle Arten insgesamt 297 unterschiedlich lange Fragmente mit dem Programm RFLPScan detektiert werden.

Die Anzahl erzeugter AFLP-Banden schwankte innerhalb der Spezies zwischen Individuen. Die Eckdaten der AFLP-Fragmente zwischen den Individuen derselben Störart können der Tabelle 20 entnommen werden.

Tab. 20 Eckdaten der ausgewerteten AFLP-Fragmente innerhalb der fünf untersuchten Spezies

Spezies

\begin{tabular}{lccccc}
\cline { 2 - 5 } & A. baerii & A. gueldenst. & A. ruthenus & A. stellatus & H. huso \\
\hline Maximum & 59 & 49 & 76 & 58 & 77 \\
Minimum & 39 & 37 & 60 & 43 & 55 \\
Mittelwert & 48,20 & 42,60 & 68,80 & 49,60 & 66,20 \\
Standardabw. & 6,84 & 4,43 & 5,51 & 5,19 & 6,14 \\
\hline
\end{tabular}

Da das Ziel dieser Arbeit eine Artbestimmung von Einzelindividuen war, wurde an dieser Stelle auf den statistischen Vergleich der oben aufgeführten Mittelwerte verzichtet.

Die von dem Sequenzierautomaten LiCor aufgezeichneten Elektropherogramme der Individuen konnten in Form eines sogenannten Image als Fragmentmuster visuell dargestellt werden. Das Bandenmuster sah innerhalb der Arten A. ruthenus, A. stellatus und H. huso sehr homogen aus und unterschied sich zwischen den drei Spezies (Abb. 24). 


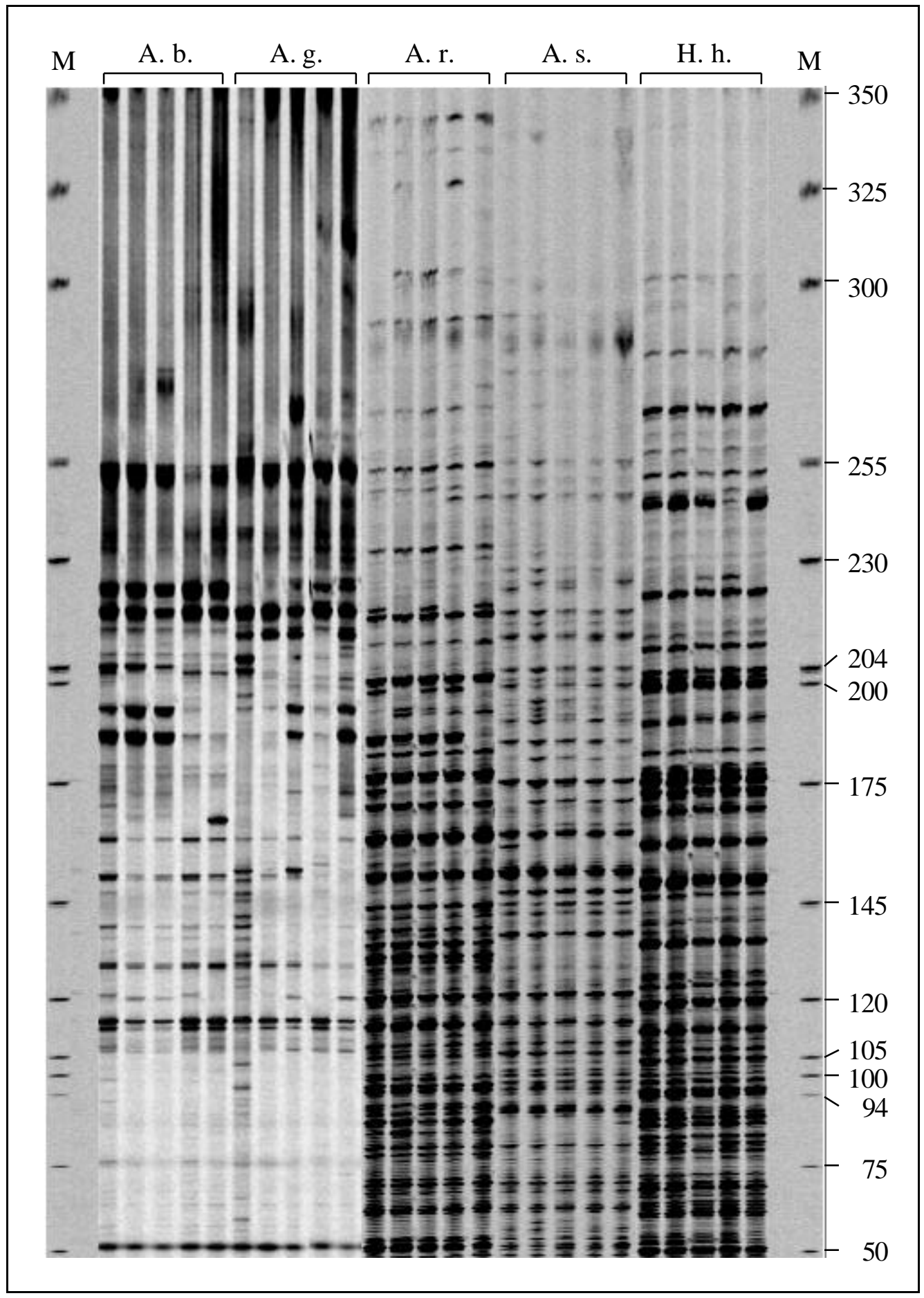

Abb. 24 Image des LiCor der im AFLP generierten Fragmentmuster für je fünf Individuen der untersuchten Spezies

$\mathrm{M}=$ Molecular Weight Marker; A. b. = A. baerii; A. g. = A. gueldenstaedtii; A. r. = A. ruthenus; A. s. = A. stellatus; H. h. = H. huso 
Die amplifizierten Fragmentmuster von A. baerii und A. gueldenstaedtii waren von denen der drei anderen Arten verschieden. Eine Unterscheidung der beiden Spezies war dagegen anhand der Bandenmuster nicht möglich. Die interindividuellen Fragmentmuster wiesen zudem visuell bei $A$. baerii und A. gueldenstaedtii eine höhere Variabilität als bei den übrigen Spezies auf.

Mit der Software RFLP-Scan wurden die Längen der einzelnen detektierten Fragmente (bp) anhand des mit auf das Gel aufgetragenen Molekulargewichtstandards berechnet. Ein Vergleich der kalkulierten Fragmentlängen innerhalb der Arten A. ruthenus, A. stellatus und H. huso zeigte, dass eine höhere intraspezifische Variablilität vorhanden war, als die visuelle Auswertung vermuten ließ. Dies spiegelte sich auch in den Mittelwerten der paarweisen Ähnlichkeitsindices (SI, siehe Kap. 3.2.6.2) wider, welche für Individuen innerhalb Spezies berechnet wurden (Tab. 21).

Tab. 21 Mittlere Ähnlichkeitsindices und deren Standardabweichungen zwischen Individuen innerhalb einer Spezies

Spezies
A. baerii
A. gueldenst.
A. ruthenus
A. stellatus
H. huso

\begin{tabular}{llllll}
\cline { 2 - 6 } Mittelwerte & 0,253 & 0,239 & 0,578 & 0,645 & 0,493 \\
Standardabw. & 0,117 & 0,127 & 0,121 & 0,078 & 0,164
\end{tabular}

Die Individuen innerhalb der Spezies A. ruthenus, A. stellatus und H. huso wiesen ein intraspezifisch homogeneres Fragmentmuster als die Individuen innerhalb A. baerii und A. gueldenstaedtii auf.

Innerhalb der Individuen von $A$. baerii konnte nicht eine Fragmentlänge beobachtet werden, die gleichzeitig bei allen zehn untersuchten Individuen vorkam. Gleiches traf auch bei den zehn A. gueldenstaedtii zu. Innerhalb A. ruthenus traten 13 Fragmente auf, die bei allen zehn Individuen detektiert werden konnten. Diese Fragmente wurden auch bei Individuen der anderen Spezies festgestellt. Bei A. stellatus und H. huso wurden sieben 
bzw. drei intraspezifisch konstant auftretende Fragmentlängen beobachtet. Auch hier waren bei den anderen Spezies Individuen mit den gleichen Fragmenten vorhanden.

\subsubsection{Berechnung des genetischen Distanzmaßes $D_{\mathrm{A}}$ und Konstruktion phylogenetischer Stammbäume}

Die Definition der Loci erfolgte anhand der über alle Individuen ausgewerteten Fragmente. Für die Berechnung des genetischen Distanzmaßes $\mathrm{D}_{\mathrm{A}}$ wurden Fragmente unterschiedlicher Größen als separate Loci betrachtet. Insgesamt konnten nach der Auswertung 297 verschiedene Loci über alle Spezies detektiert werden. Die Berechnung der Allelfrequenz des rezessiven Allels an einem Locus erfolgte nach der in Kapitel 3.2.6.2 angegebenen Formel [3]. Da in der Literatur kontroverse Ansichten hinsichtlich des Ploidiestatus der Acipenseriformes bestehen, wurden die Spezies A. ruthenus, A. stellatus und $H$. huso zuerst als diploid $(\mathrm{z}=2)$ und die Arten A. baerii und A. gueldenstaedtii als tetraploid $(\mathrm{z}=4)$ betrachtet. Ein weiterer Datensatz wurde erstellt, in dem für die drei erstgenannten Spezies ein tetraploider $(z=4)$ und für die beiden anderen Arten ein octaploider $(\mathrm{z}=8)$ Status für die Berechnung der Allelfrequenzen angenommen wurde. Die Allelfrequenzen der dominanten Allele wurden nach der Formel [4] ermittelt. Auf der Basis der Allelfrequenzen wurden dann die durchschnittlichen genetischen $\mathrm{D}_{\mathrm{A}^{-}}$ Distanzen mit dem Programm DISPAN (OTA 1993) berechnet (Tab. 22).

Tab. 22 Durchschnittliche genetische $\mathrm{D}_{\mathrm{A}}$-Distanzen zwischen den fünf Spezies

\begin{tabular}{l|ccccc}
\hline Spezies & A. baerii & A. gueldenst. & A. ruthenus & A. stellatus & H. huso \\
\hline A. baerii & - & 0,0138 & 0,0826 & 0,0861 & 0,0703 \\
A. gueldenst. & 0,0070 & - & 0,0832 & 0,0880 & 0,0682 \\
A. ruthenus & 0,0543 & 0,0554 & - & 0,0817 & 0,0697 \\
A. stellatus & 0,0681 & 0,0696 & 0,0632 & - & 0,0889 \\
H. huso & 0,0419 & 0,0409 & 0,0494 & 0,0710 & - \\
\hline
\end{tabular}

$\mathrm{z}=2$ oder 4 oberhalb der Diagonalen; $\mathrm{z}=4$ oder 8 unterhalb der Diagonalen 
Die berechneten durchschnittlichen Distanzwerte waren unter der Annahme eines dibzw. tetraploiden Status gegenüber der tetra-/octaploiden Einordnung der Spezies leicht erhöht.

Anhand dieser Daten wurden phylogenetische Stammbäume mit dem Programm DISPAN (OTA 1993) rekonstruiert. Die beiden in dem Programm implementierten unterschiedlichen Verfahren UPGMA und Neighbor Joining, wurden zur Erstellung der Stammbäume verwendet. Die Robustheit der erhaltenen AFLP-Dendrogramme wurde durch 10.000 Bootstrap-Replikationen überprüft. Das Programm lieferte Stammbäume, an deren Abzweigungen die erhaltenen Bootstrap-Werte angegeben wurden. Je höher dieser Wert war, desto abgesicherter war diese Abzweigung.

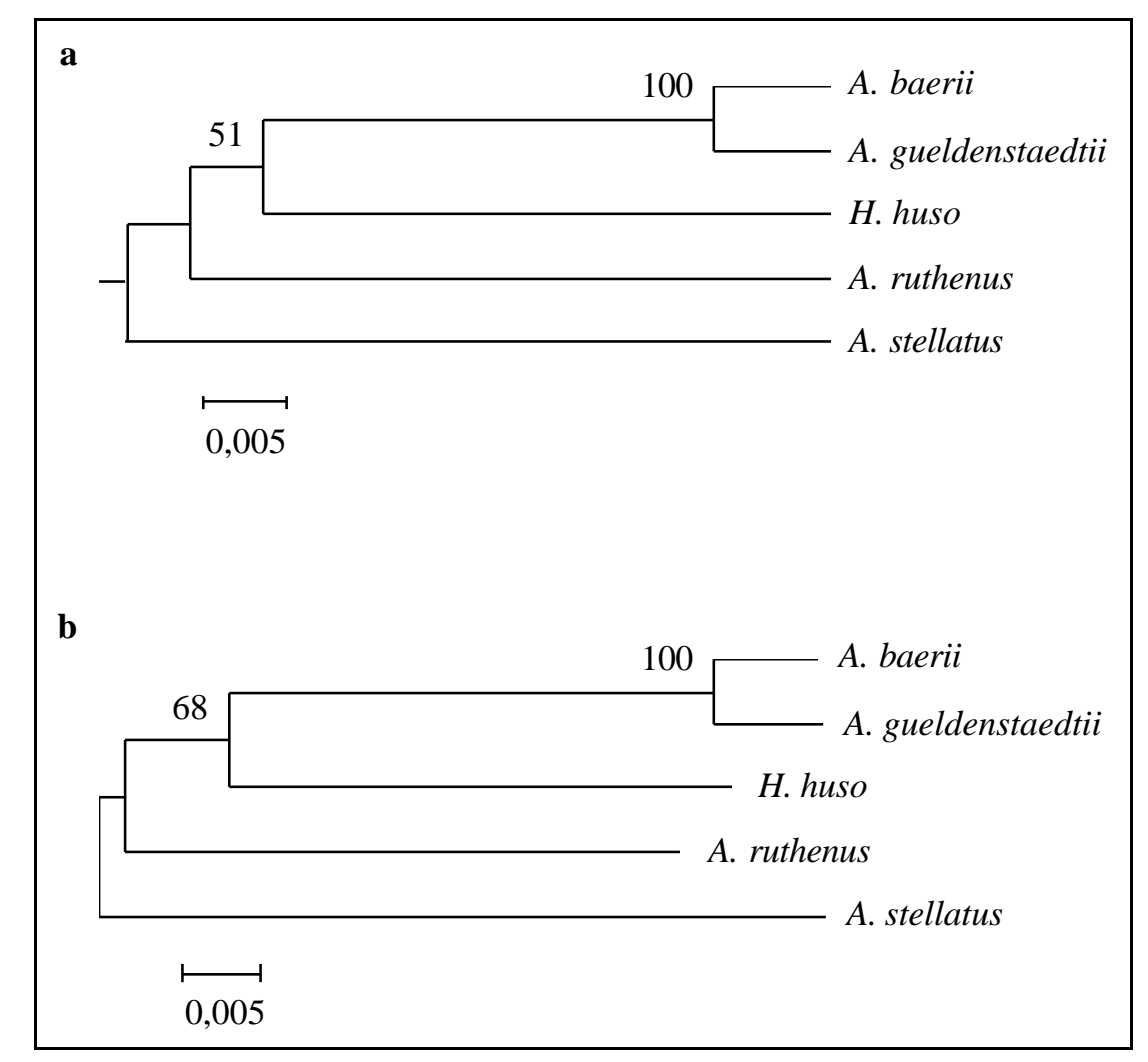

Abb. 25 Phylogenetische Stammbäume auf der Basis der AFLP-Daten unter der Annahme Di- bzw. Tetraploidie bei den Spezies

a, Dendrogramm nach dem UPGMA-Verfahren; b, Dendrogramm nach dem Verfahren Neighbor Joining; Prozentuale Bootstrap-Werte sind über den Verzweigungen aufgeführt; Längenmaßstäbe der genetischen Distanz sind unterhalb der Dendrogramme gegeben 
Die in Abbildung 25 dargestellten Stammbäume wurden unter der Annahme eines diploiden Status der Arten A. ruthenus, A. stellatus und $H$. huso sowie der Charakterisierung von A. baerii und A. gueldenstaedtii als tetraploide Spezies generiert. Beide nach verschiedenen Verfahren konstruierten Dendrogramme wiesen dieselbe Topologie auf. A. stellatus stand basal zu den anderen vier Spezies. Unter den fünf betrachteten Störspezies wiesen die beiden Spezies A. baerii und A. gueldenstaedtii den jüngsten evolutionären Ursprung auf. H. huso, welcher in der gängigen Systematik der Gattung Huso angehört, wird in diesen Stammbäumen innerhalb der Acipenser gruppiert. Allerdings wird die Plazierung dieser Spezies in beiden Dendrogrammen nur durch moderate Bootstrap-Werte bestätigt.

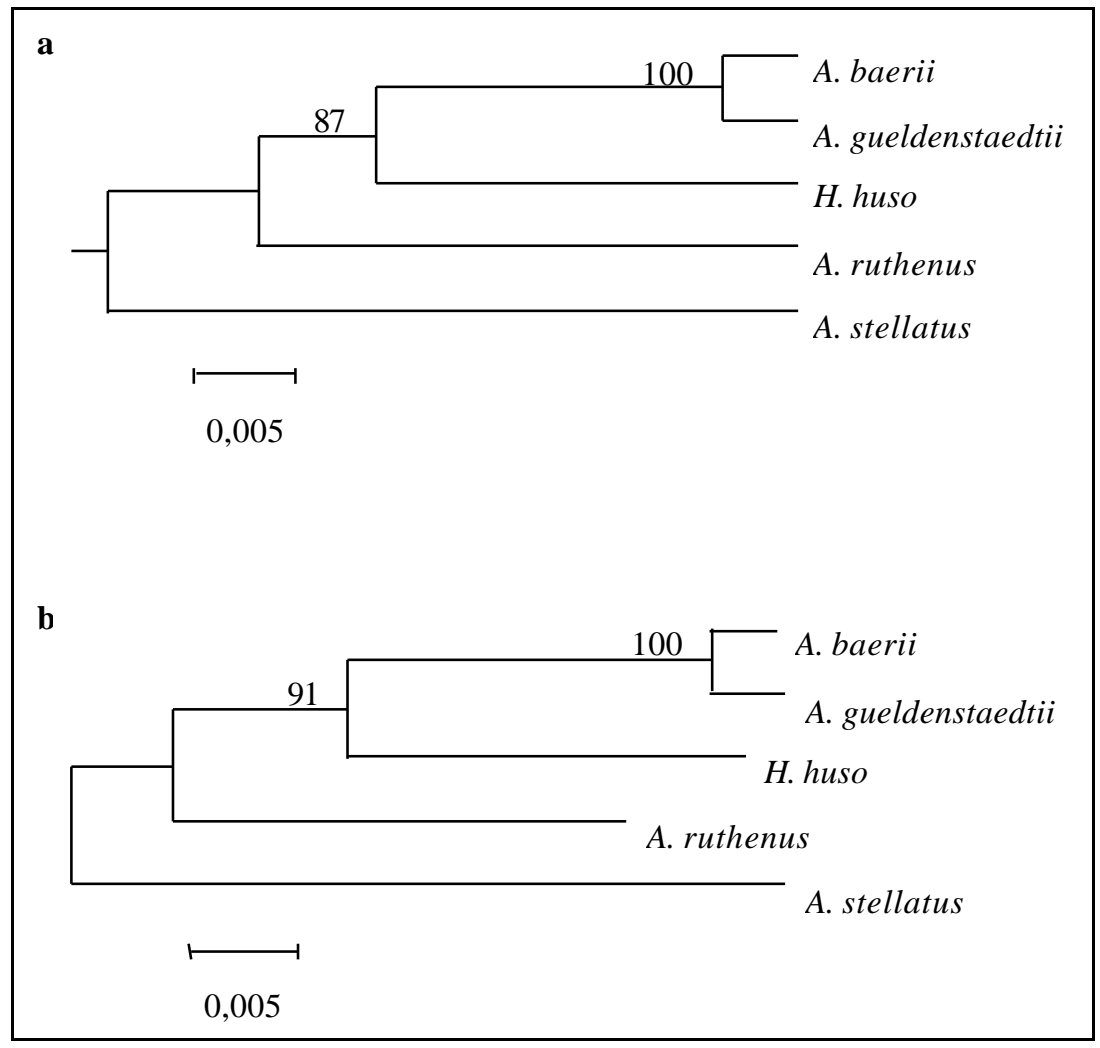

Abb. 26 Phylogenetische Stammbäume auf der Basis der AFLP-Daten unter der Annahme tetra- bzw. octaploider Stati der Spezies

a, UPGMA-Dendrogramm; b, Neighbor Joining-Dendrogramm; Prozentuale Bootstrap-Werte sind über den Verzweigungen aufgeführt; Längenmaßstäbe der genetischen Distanz sind unterhalb der Dendrogramme gegeben 
Für die Konstruktion der in Abbildung 26 dargestellten Dendrogramme wurde bei der Berechnung der Allelfrequenzen je nach Spezies ein tetra- bzw. octaploider Status angenommen. Diese beiden Dendrogramme glichen in der Topologie denen der in Abbildung 25 dargestellten Stammbäume. Im Gegensatz dazu wiesen die in der Abbildung 26 präsentierten Dendrogramme wegen der hohen berechneten Bootstrap-Werte eine sehr robuste Topologie auf.

\subsubsection{Ergebnisse des mitochondrialen Cytochrom b (mt Cyt b)}

Das vollständige Cytochrom b (mt Cyt b) konnte unter Verwendung der Primer Cytbfor.1 sowie Cytb-rev.1 in einer Standardreaktion generiert werden. Das PCR-Produkt umfasste insgesamt 1211 bp. Das mt Cyt b selbst wurde durch 1140 bp codiert (BROWN et al. 1989). Die anderen vier Primer wurden im Rahmen der Sequenzierung eingesetzt. Des Weiteren wurde mit den Primern Cytb-for.1 und Cytb-rev.3 ein partielles Fragment aus dem mt Cyt b amplifiziert.

\subsubsection{Untersuchung eines partiellen Cyt b-Fragments im SSCP}

Unter Verwendung der Primer Cytb-for.1 und Cytb-rev.3 wurde von den zehn potentiell unverwandten Individuen je Spezies sowie den Tieren der Herkunft G (Wildfänge aus Kaspischen Meer) ein 370 bp langes Fragment in der PCR generiert. Während die ersten 25 bp des Fragments inklusive der Primersequenz von Cytb-for.1 aus der mt tRNA $^{\text {Glu }}$ stammten, codierten die folgenden 345 bp für die ersten 115 N-terminalen Aminosäuren des mt Cyt b. Das Fragment wurde im SSCP-Verfahren für die Untersuchung nach innerartlichen Haplotypen eingesetzt.

Bei den untersuchten Individuen der Spezies A. baerii, A. ruthenus, A. stellatus und H. huso konnten keine intraspezifische Variationen in dem SSCP-Muster des $370 \mathrm{bp}$ Fragments festgestellt werden. Demgegenüber traten vier verschiedene Haplotypen bei unterschiedlichen Individuen der Art A. gueldenstaedtii auf (Abb. 27). 
Ein interspezifisch differenzierbares, artcharakteristisches SSCP-Muster konnte bei den Spezies A. ruthenus, A. stellatus und H. huso und den beiden Individuen von P. spathula beobachtet werden. Dagegen konnte ein bei A. gueldenstaedtii auftretender Haplotyp nicht von dem sich bei A. baerii darstellenden SSCP-Muster differenziert werden. In der SSCP-Analyse konnten ferner aufgrund gleicher Konformationen der Einzelstränge ebenfalls nicht A. naccarii und A. persicus und der Haplotyp 3 der Spezies A. gueldenstaedtii (AG3) unterschieden werden (Abb. 27)

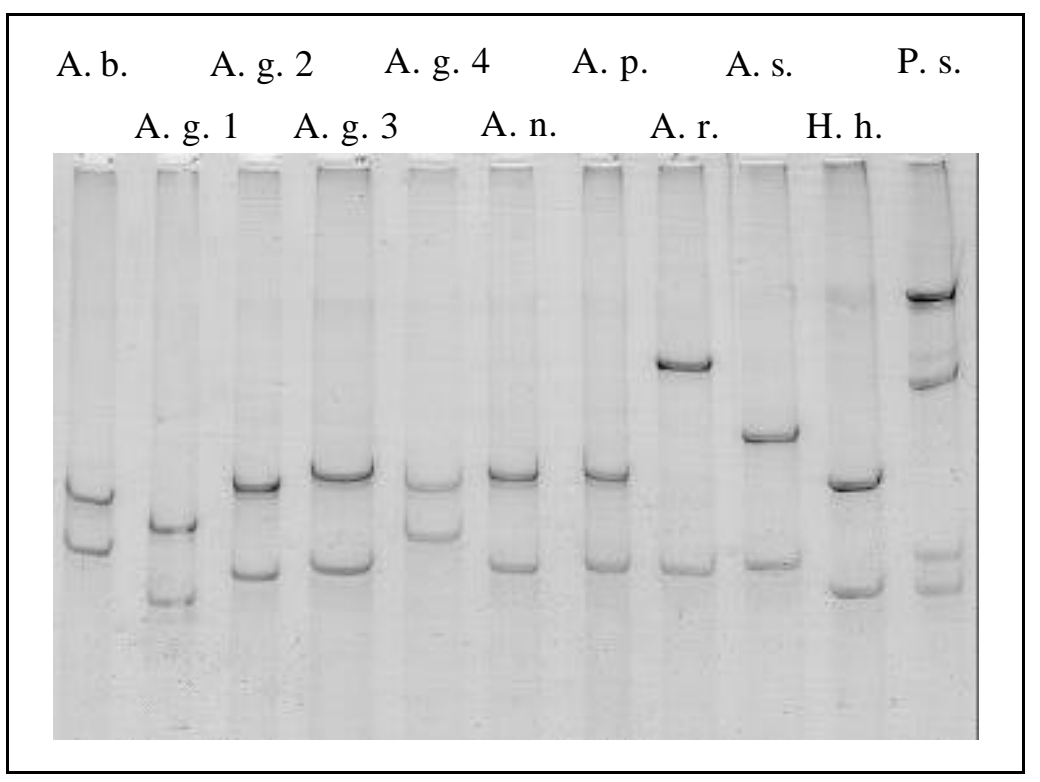

Abb. 27 Darstellung der inter- und intraspezifisch detektierten Haplotypen eines 370 bp großen Fragments im SSCP nach der Silberfärbung

A. b. $=$ A. baerii; A. g. 1-4 = A. gueldenstaedtii, Haplotypen 1-4; A. n. = A. naccarii; A. p. = A. persicus; A. r. = A. ruthenus; A. s. = A. stellatus; H. h. $=$ H. huso und P. s. = P. spathula

\subsubsection{Sequenzierungsergebnisse des mt Cyt b}

Das vollständige mt Cyt b wurde von je einem Individuum der Spezies A. baerii, A. gueldenstaedtii, A. naccarii, A. ruthenus, A. stellatus, H. huso und P. spathula sequenziert. Von der Spezies A. gueldenstaedtii wurden drei weitere Individuen der Herkunft G (Wildfänge) sequenziert, da sie im SSCP unterschiedliche Haplotypen 
zueinander und zu dem oben erwähnten Tier aufwiesen. Ebenso erfolgte die Sequenzierung des mt Cyt b von den vier Individuen der Art A. persicus. Von allen Individuen wurden beide Stränge sequenziert und die erhaltenen Sequenzen mit dem Programm SequenceEditor V.1.0.3 gegeneinander abgeglichen.

Abbildung A-1 (Anhang) zeigt einen Vergleich der proteincodierenden Nukleotidsequenzen des mt Cyt b über die verschiedenen Spezies. Neben den eigenen ermittelten wurden zusätzlich die in den Sequenzdatenbanken verfügbaren mt Cyt bSequenzen von A. transmontanus (Accession number X14944) und die drei ausgewählten Individuen der Arten des Genus Scaphirhynchus (Accession numbers: U55994, U56985, U56987) in der Abbildung A-1 dargestellt.

Bei keiner der betrachteten Spezies konnte ein DNA-codiertes Terminationscodon beobachtet werden. Bei jeder Spezies folgte der proteincodierenden Nukleotidsequenz, die 1140 bp umfasste, die Base Thymin (T) .

Tabelle 23 gibt eine Übersicht über die durchschnittliche Gesamtfrequenz der vier Basen Adenin (A), Thymin (T), Guanin (G) und Cytosin (C) sowie deren Frequenzen an den einzelnen Codonpositionen über alle Individuen und Spezies.

Tab. 23 Übersicht über die durchschnittliche Basenfrequenz im mt Cyt b sowie deren Frequenzen an den drei Nukleotidpositionen der Codons über alle Individuen und Spezies der betrachteten Acipenseriformes

\begin{tabular}{lcccc}
\hline & \multicolumn{5}{c}{ Base } \\
\cline { 2 - 5 } & $\mathrm{A}$ & $\mathrm{T}$ & $\mathrm{C}$ & $\mathrm{G}$ \\
\hline Durchschnitt & 27,0 & 26,0 & 31,8 & 15,2 \\
Codonposition 1 & 24,8 & 22,8 & 27,2 & 25,2 \\
Codonposition 2 & 20,8 & 40,4 & 25,1 & 13,7 \\
Codonposition 3 & 35,6 & 14,7 & 43,1 & 6,6 \\
\hline
\end{tabular}

Es zeigte sich, dass an den verschiedenen Codonpositionen stark unterschiedliche Basenfrequenzen auftraten. Während die vier Basen an der ersten Codonposition 
annährend gleiche Frequenzen aufwiesen, konnte an der zweiten Codonposition eine überdurchschnittlich erhöhte Frequenz des T und eine unterdurchschnittliche Frequenz von $\mathrm{G}$ festgestellt werden. Die dritte Codonposition wies zu ca. $80 \%$ die Base A oder C auf.

Insgesamt konnten über alle im Rahmen dieser Arbeit untersuchten und in den Datenbanken verfügbaren Sequenzen 273 variable Nukleotidpositionen detektiert werden. Davon entfielen 42 auf die erste, sechs auf die zweite und 225 auf die dritte Codonposition. Von den 380 Codons des mt Cyt b waren 236 variabel, aber nur das Codon 357 wies über die betrachteten Sequenzen Polymorphismen an allen drei Nukleotidpositionen auf.

Sehr auffällig war, dass der Haplotyp AG4, welcher von einem A. gueldenstaedtii aus der Astrachaner Region (Herkunft G) stammte, keine Nukleotidsubstitution im Vergleich zu A. baerii aufwies. Darüber hinaus konnten zwischen den Individuen der Spezies A. gueldenstadetii (ohne AG4), A. naccarii und A. persicus maximal acht Transitionen und eine Transversion beobachtet werden. Zwischen den in der GenBank verfügbaren Individuen der drei Arten der Gattung Scaphirhynchus konnten ebenfalls maximal acht Transitionen, wovon keine für eine Spezies fixiert war, detektiert werden. Die meisten Nukleotidsubstitutionen der einzelnen Arten aus der Gattung der Acipenseridae wurden zu der Spezies P. spathula festgestellt. Mit 150 beobachteten Nukleotidsubstitutionen (106 Transitionen, 44 Transversionen) wies H. huso dabei die geringste Differenz zu P. spathula auf, wohingegen das Individuum S. platorhynchus SD2 (Accession number U56988) mit 162 detektierten Nukleotidsubstitutionen (111 Transitionen, 51 Transversionen) die größte Differenz zu P. spathula besaß.

Die Nukleotidsequenz wurde mit dem Programm SequenceEditor V. 1.0.3 unter Verwendung des mitochondrialen genetischen Codes (für Mammalia) in die Aminosäuresequenz translatiert. Die Primärstruktur des mt Cyt b-Proteins bestand aus 380 Aminosäuren. In Abbildung 28 wird exemplarisch die deduzierte Aminosäuresequenz eines A. baerii-Individuums dargestellt. 


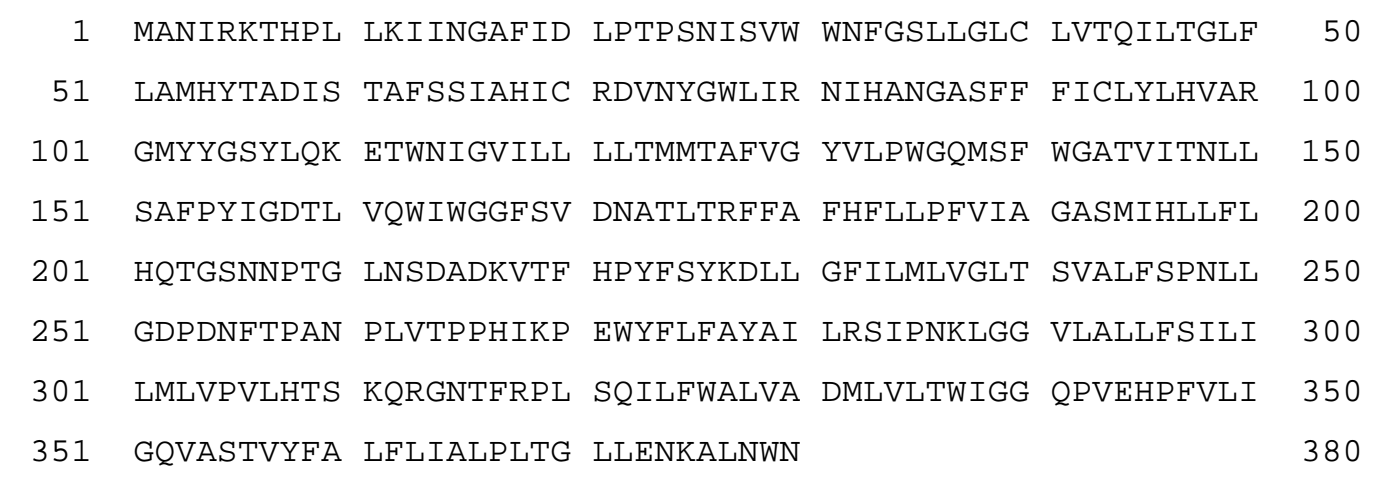

Abb. 28 Aus der Nukleotidsequenz deduzierte Aminosäuresequenz des mt Cyt b von A.baerii

Ein vollständiger Vergleich der Aminosäuresequenzen des mt Cyt b der verschiedenen Spezies ist im Anhang (Abb. A-2) zu finden. Die Individuen A. gueldenstaedtii 1-3 und A. persicus 2-4 wurden der Übersicht halber in der Abbildung A-2 zusammengefasst, da sie identische Aminosäuresequenzen aufwiesen. Zwischen den in der GenBank verfügbaren Sequenzen von verschiedenen Individuen der drei Arten der Gattung Scaphirhynchus konnte an keiner Position ein Aminosäureaustausch festgestellt werden. Daher wurde anstelle der einzelnen Arten das Genus beim Vergleich der Primärstruktur des Proteins aufgeführt.

Insgesamt konnten in dem Datenmaterial 24 variable Aminosäurepositionen festgestellt werden (Tab. 24). Nur an den beiden Positionen 306 und 357 wurden drei unterschiedliche Aminosäuresubstitutionen über alle Sequenzen detektiert. Die übrigen variablen Positionen wiesen jeweils zwei unterschiedliche Aminosäuren auf. An den Positionen 23, 155, 219, 233, 327 und 369 konnten Austausche von Aminosäuren mit unterschiedlichen Eigenschaften festgestellt werden. Während an der Position 155 die Spezies A. transmontanus eine Asparaginsäure (D) aufwies, welche eine saure Seitenkette hat, war bei den anderen Individuen/Spezies die ungeladene polare Aminosäure Tyrosin (Y) vorzufinden. An den restlichen fünf der oben erwähnten Positionen fanden Substitutionen zwischen jeweils verschiedenen unpolaren bzw. ungeladenen polaren Aminosäuren statt. Des Weiteren fielen die beiden Positionen 33 und 241 bei P. spathula im Vergleich zu den anderen Individuen/Spezies auf. Während die restlichen Individuen/Spezies an der Position 33 ein unpolares Phenylalanin (F) aufwiesen, war hier 


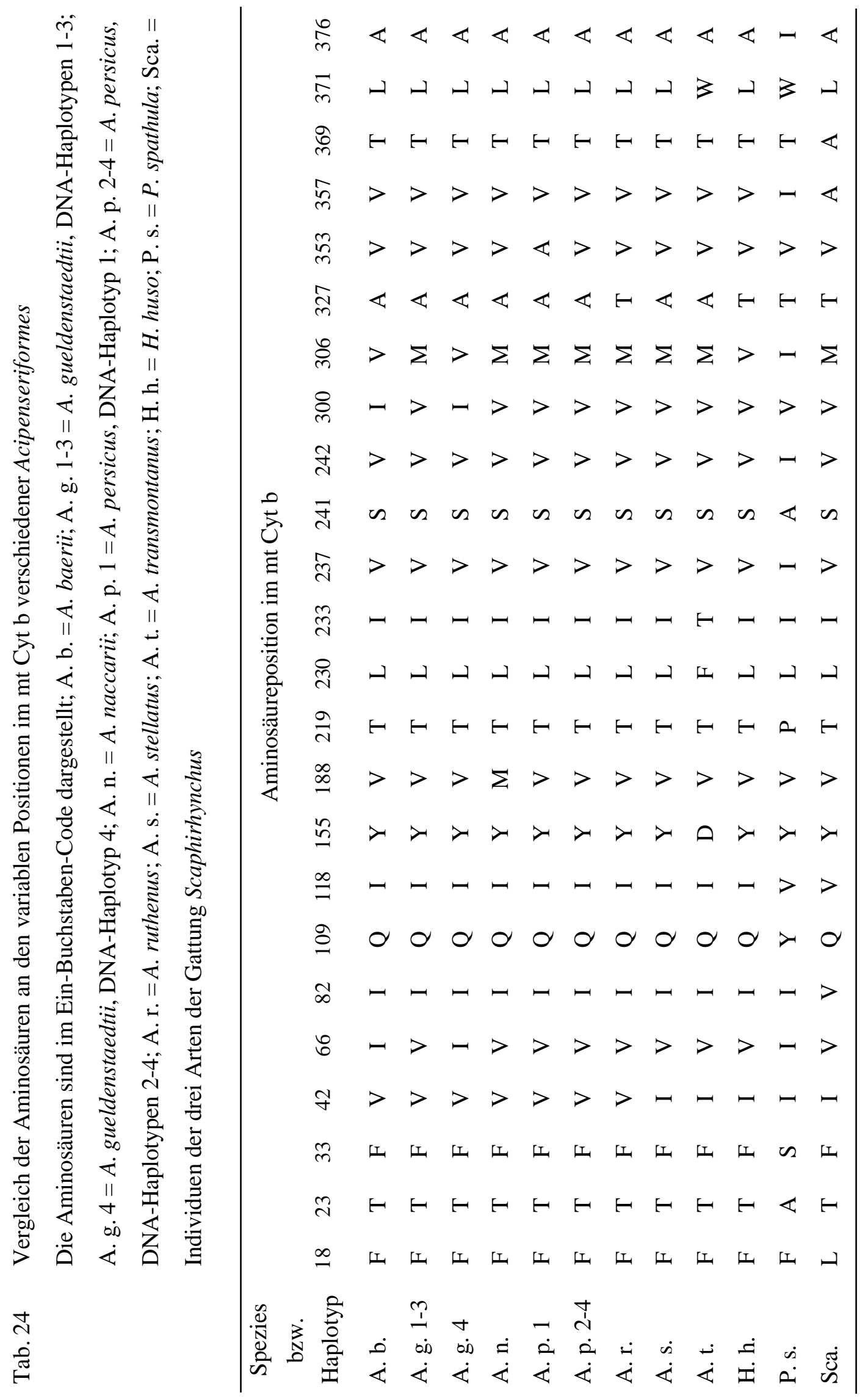


bei $P$. spathula ungeladenes polares Serin $(\mathrm{S})$ vorhanden. Dagegen wies $P$. spathula an Position 241 ein Serin auf, welches in den übrigen Aminosäuresequenzen durch ein unpolares Alanin (A) substituiert war. An den verbliebenen 16 variablen Positionen konnten jeweils Substitutionen zwischen Aminosäuren mit gleichen Eigenschaften festgestellt werden. Davon fanden 15 Substitutionen zwischen unpolaren Aminosäuren statt. An Position 109 wurde ein Austausch zwischen ungeladenen polaren Aminosäuren beobachtet. Bei Betrachtung der sehr ähnlichen Aminosäuresequenzen zwischen den DNA-Haplotypen 1-3 von A. gueldenstaedtii (AG1-3), A. naccarii und A. persicus konnten zwei Aminosäuresubstitutionen beobachtet werden. A. naccarii wies an der Aminosäureposition 188, ein Methion (M) anstelle eines Valins (V) auf. A. persicus 4 unterschied sich von den anderen Arten durch die Substitution eines Valins (V) durch ein Alanin (A) an der Aminosäureposition 353.

Die bei A. naccarii vorgefundene Aminosäuresubstitution an Position 188 wurde durch eine Transition $(\mathrm{G} \rightarrow \mathrm{A})$ an der ersten Codonposition bedingt. Aus diesem Grund wurde von dem zweiten Individuum dieser Art der die Mutation enthaltene partielle Abschnitt ebenfalls sequenziert. Die beobachtete Transsition konnte auch bei diesem Tier festgestellt werden.

\subsubsection{Konstruktion phylogenetischer Stammbäume anhand des mt Cyt b}

Unter Verwendung der p-Distanz in dem Programm MEGA V.1.0.2 (KuMAR et al. 1993) wurde ein auf den Aminosäurensequenzen basierendes phylogenetisches Dendrogramm mit dem Neighbor Joining-Verfahren konstruiert (Abb. 29). Die Robustheit der Topologie von dem rekonstruierten Stammbaum wurde durch einen Bootstrap-Test mit 1.000 Replikationen überprüft. Der Datensatz enthielt dabei alle der im Rahmen dieser Arbeit sequenzierten Individuen. Für eine korrekte Darstellung wurden zudem die in der Sequenzdatenbank erhältlichen, vollständigen Sequenzen des mt Cyt b von A.transmontanus (EMBL accession number: X14944) und die aller Individuen der Arten des Genus Scaphirhynchus (GenBank accession numbers: U55994, U56983-56988) mit einbezogen. Als sogenannte Außengruppen wurden die mt Cyt b-Sequenzen von 
Polypterus ornatipinnis und Salmo salar verwendet (GenBank accession numbers: U62532, U12143). Aufgrund sehr großer Distanzen der beiden Spezies zu den Acipenseriformes wurde aus Gründen der Übersichtlichkeit nur der Teil des Stammbaums in Abbildung 29 dargestellt, der die verwandtschaftlichen Beziehungen der Acipenseriformes enthielt.

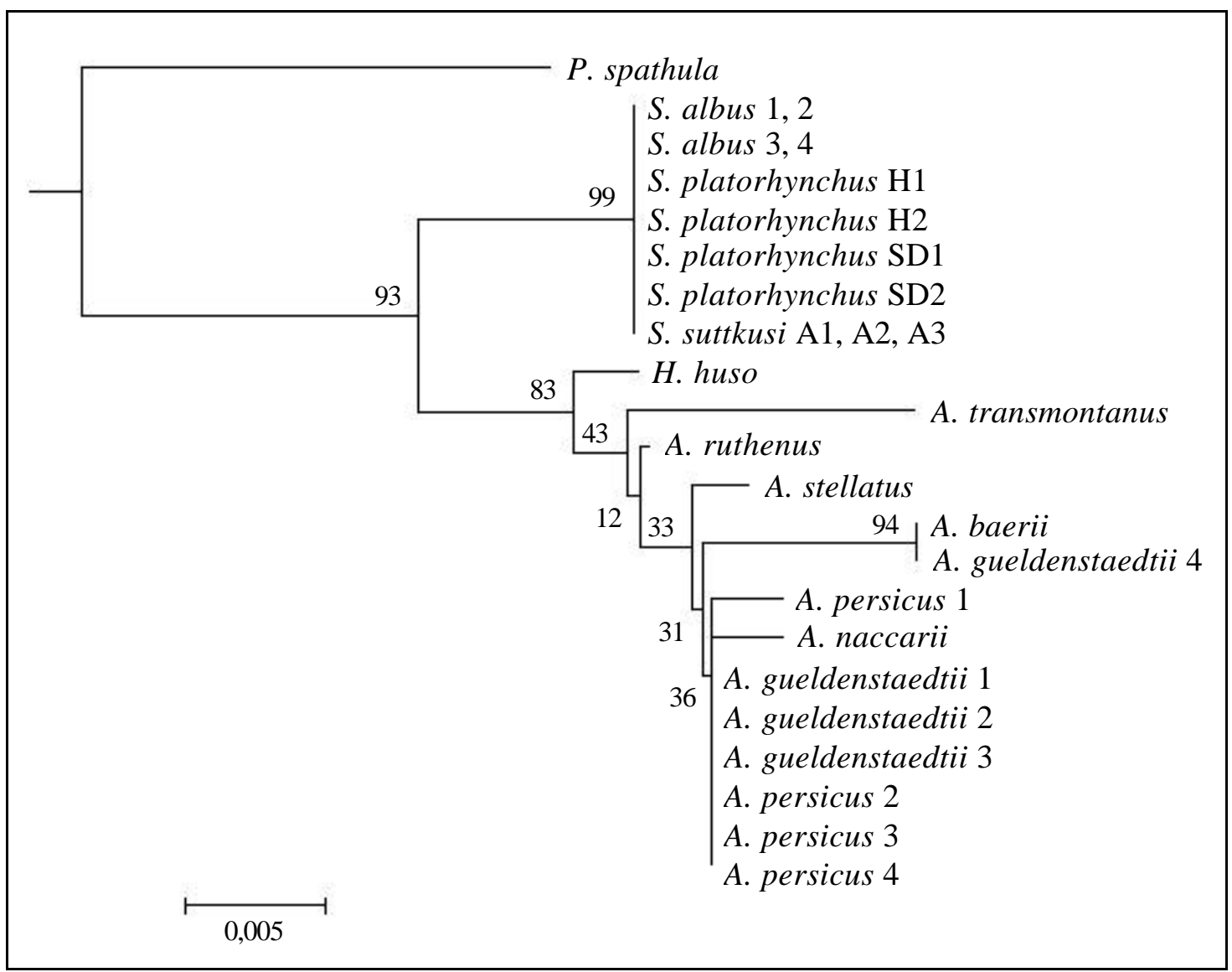

Abb. 29 Phylogenetischer Konsensstammbaum verschiedener Acipenseriformes auf der Basis der Aminosäuresequenzen des $m$ t Cyt $b$ nach dem Bootstrap-Test

Prozentuale Bootstrap-Werte werden an den Abzweigungen angegeben; Ein Längenmaß für die Distanzen befindet sich unter dem Dendrogramm

Das Dendrogramm zeigte, dass $P$. spathula eine basale Stellung zu den Acipenseriformes einnahm. Innerhalb der übrigen Spezies wies die Gattung Scaphirhynchus eine außenstehende Position auf, während $H$. huso und die Spezies des Genus Acipenser unter evolutionären Aspekten noch später divergierten. Die Distanzen, 
welche auf den Aminosäuresequenzen basierten, waren dabei sehr gering. Dies spiegelte sich in sehr geringen Bootstrap-Werten wider, die an den Abzweigungen angegeben waren. Anhand des präsentierten Stammbaums deutete sich eine nachfolgende Divergenz der Spezies A. transmontanus, A. stellatus und A. ruthenus an. Die Arten A. baerii, A. gueldenstaedtii, A. naccarii und A. persicus besaßen einen gemeinsamen Ahnen. Die Phylogenese der Spezies und Haplotypen innerhalb der Gruppe ist dabei inkonsistent. Haplotyp A. gueldenstaedtii 4 wurde mit A. baerii geclustert. Die Divergenz der Haplotypen 1-3 der Spezies A. gueldenstaedtii, A naccarii und die Haplotypen 1-4 der Spezies A. persicus konnte nicht einheitlich aufgelöst werden.

Um die evolutionären Beziehungen zwischen den Individuen/Spezies näher betrachten zu können, wurde ein phylogenetischer Stammbaum in MEGA V.1.0.2. auf der Basis stiller Nukleotidsubstitutionen konstruiert. Eine detaillierte Untersuchung der evolutionären Verwandtschaftsverhältnisse geschah dabei unter der Verwendung der zur Verfügung stehenden Nukleotidsequenzen des Cytochrom $b$ verschiedener acipenseriformer Individuen und Spezies.

Mit diesem Verfahren wurden höhere Distanzwerte berechnet, was mittlere bis sehr hohen Bootstrap-Werte bedingte (siehe Abb. 30). Die Topologie dieses Dendrogramms unterschied sich von der des in Abbildung 29 präsentierten Stammbaums im Wesentlichen durch die Plazierung von $H$. huso innerhalb der Acipenser. Bei der Betrachtung des Genus Scaphirhynchus konnte keine konsistente Separierung der einzelnen Spezies festgestellt werden. A. gueldenstaedtii 4 wurde wieder mit A. baerii geclustert und war durch einen hohen Bootstrap-Wert von dem Cluster bestehend aus A. gueldenstaedtii 1-3, A. naccarii und A. persicus 1-4 separiert. Auch unter Verwendung der stillen Nukleotidsubstitutionen konnte keine abgesicherte artspezifische Divergenz der drei Spezies aus dem oben genannten Cluster beobachtet werden. 


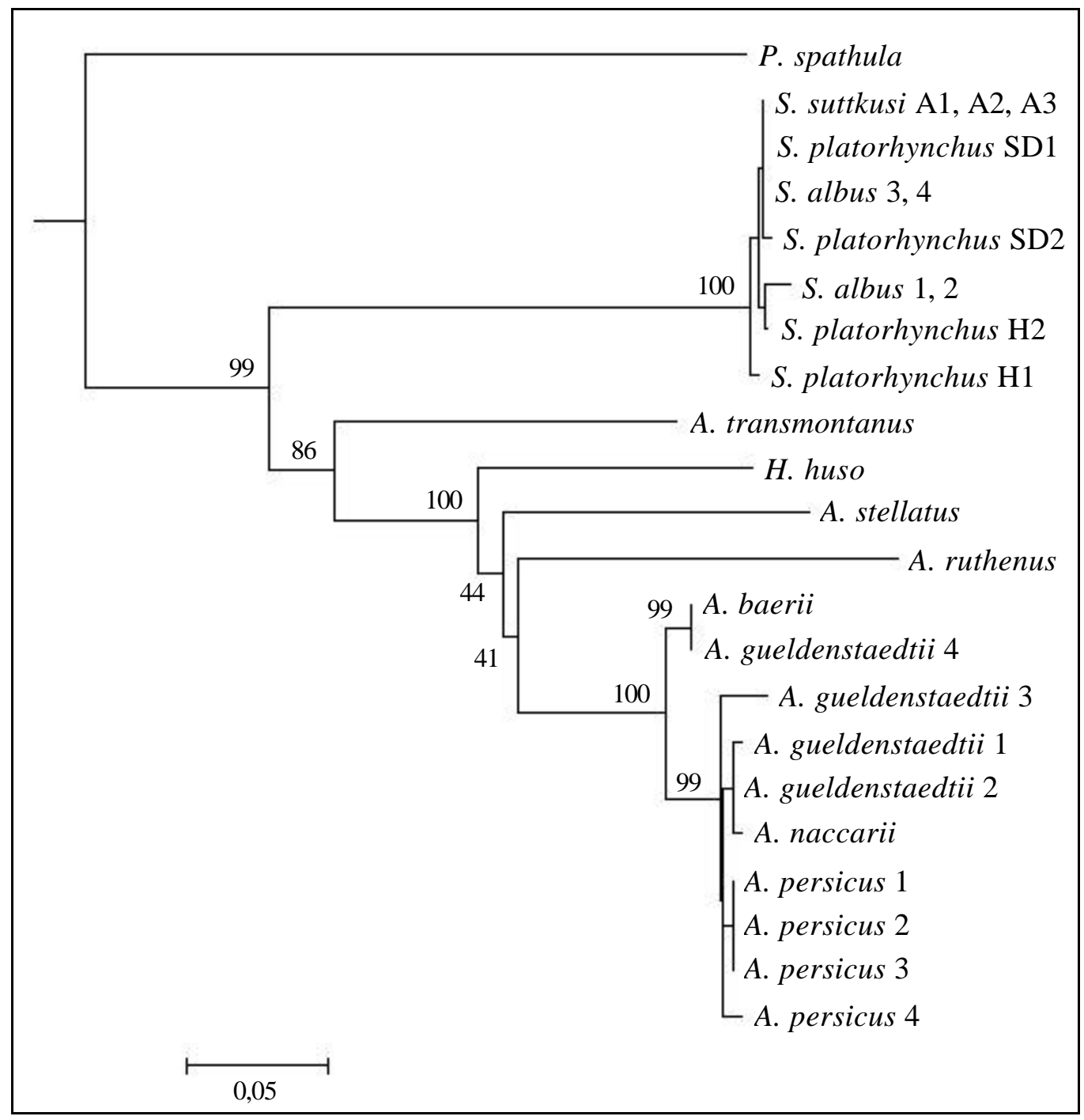

Abb. 30 Phylogenetischer Konsensstammbaum verschiedener Acipenseriformes auf der Basis stiller Nukleotidsubstitutionen im mt Cyt b nach dem Bootstrap-Test

Prozentuale Bootstrap-Werte werden an den Abzweigungen angegeben; Ein Längenmaß für die Distanzen befindet sich unter dem Dendrogramm 
Hauptziel der vorliegenden Arbeit war, biochemische und molekularbiologische Marker zu untersuchen, mit deren Hilfe eine Identifizierung von Individuen verschiedener Störarten und Hybriden erfolgen kann. Weiterhin konnten im Rahmen dieser Arbeit durch die Analyse von biochemischen Markern und Mikrosatelliten-Loci nähere Erkenntnisse über die Ploidielevel der untersuchten Spezies gewonnen werden, welche in der Literatur zum Teil kontrovers diskutiert werden. Durch die Sequenzierung des mt Cyt b von Einzeltieren der zur Verfügung stehenden Störarten und auf der Basis der AFLP-Daten wurden Stammbäume konstruiert, die Einblicke in die Phylogenie und taxonomische Einordnung der Arten gestatteten.

Einschränkend muß erwähnt werden, dass sich die hier getroffenen Aussagen nur auf die in die Untersuchungen eingebundenen Tiere beziehen.

\section{1}

\section{Die Eignung verschiedener Marker für eine Identifizierung der Störarten}

\subsubsection{Biochemische Marker}

In der Literatur sind diverse Untersuchungen von unterschiedlichen biochemischen Markern bei verschiedenen Spezies der Acipenseriformes beschrieben (Übersichten bei KIRPICNIKOV 1987, HOLCÍK 1989). Allerdings basierten sie fast ausnahmslos auf der Verwendung innerer Organe, wie z.B. Augenlinse, Herz, Leber und Muskulatur. Das Probenmaterial für diese Arbeit stammte hauptsächlich von Zuchttieren aus aquakulturellen Beständen. Da eine Tötung der Tiere ausgeschlossen war, wurde auf Blutproben zurückgegriffen. Eine Charakterisierung von Individuen setzt dabei generell die Unversehrtheit des Probanden nach der Probenentnahme voraus, wenn diese zur Zucht verwendet und/oder Arterhaltungsprogrammen zugeführt werden sollen.

Im Rahmen dieser Arbeit wurde versucht, 13 verschiedene im Blut vorkommende biochemische Marker bei den Spezies A. baerii, A. gueldenstaedtii, A. ruthenus, 
A. stellatus und $H$. huso darzustellen. Von diesen ließen sich nur die Allozymsysteme Adenylatkinase (AK), Esterase-D (EST-D), Glucosephosphatisomerase (GPI) sowie die Phosphoglucomutase (PGM) und die im Blutplasma vorhandenen Albumine (ALB) visuell darstellen. Bei den übrigen untersuchten Systeme konnten hingegen keine Banden detektiert werden. Es kann aber davon ausgegangen werden, dass sie auch bei den Acipenseriformes im Blut vorkommen müßten, da diese biochemischen Marker bei verschiedenen vertebraten Spezies im Blut zu finden sind. Die Visualisierung von im Blut vorkommenden Allozymsystemen stellte sich auch bei einer weiteren Arbeitsgruppe als schwierig heraus (A. Schreiber, pers. Mitteilung).

Eine Auswertung der fünf biochemischen Marker ALB, AK, EST-D, GPI und PGM erfolgte für die untersuchten Spezies anhand der beobachteten Phänotypen. Aus der intraspezifischen Phänotypverteilung wurden Phänotypfrequenzen hergeleitet. Auf eine Berechnung der Allelfrequenzen wurde verzichtet, da der funktionelle Ploidiestatus der einzelnen Arten nicht bekannt war und diese Marker keine qualitativen Aussagen gestatteten.

Mindestens eine der untersuchten Spezies war an den biochemischen Systemen ALB, AK, EST-D und GPI für einen bestimmten Phänotyp fixiert. Obwohl keine Allelquantifizierung vorgenommen wurde, bedeutete dies, dass die Spezies somit für das dem homozygoten Phänotyp entsprechende Allel fixiert war. Eine Artcharakterisierung ließen diese Systeme dennoch nicht zu, da dasselbe innerhalb einer Art konservierte Allel in heterozygoten Individuen bei mindestens einer weiteren Störspezies beobachtet werden konnte.

Die PGM unterschied sich von den oben erwähnten biochemischen Markern. Das bei sämtlichen Individuen beobachtete Allel $\mathrm{d}$ unterschied sich hinsichtlich seiner elektrophoretischen Mobilität deutlich von den Allelen a, b und c. Daher könnte es sich hier um duplizierte PGM-Loci handeln. Duplizierte Loci sind bei verschiedenen Acipenseriformes beschrieben (SLYN'KO 1976, CARLSON et al. 1982, NGUYEN et al. 1994). Die Präsenz zweier PGM-Loci konnte in der Skelettmuskulatur von A. stellatus nachgewiesen werden (NIKONOROV et al. 1986). Dies führte zu einer veränderten 
Interpretation der beobachteten Pherogramme und resultierte in einer Abänderung der Phänotypenklassen (Tab. 25; vergl. hierzu Tab. 12, Kap. 4.1.5).

A. baerii und $A$. ruthenus waren an dem Locus PGM-1 für das Allel a fixiert. A. gueldenstaedtii wies nur den Phänotyp B auf, wohingegen bei $H$. huso die Phänotypen $\mathrm{AB}$ und $\mathrm{B}$, nicht aber A beobachtet werden konnte. Die PGM-1 war nur für die Individuen von A. stellatus charakteristisch, da bei ihnen das Allel c fixiert war und nicht bei den anderen vier Spezies auftrat. Somit wäre die PGM-1 ein Marker für eine Differenzierung von A. stellatus von den anderen Spezies (JENNECKENS et al. 1998). An dem Locus PGM-2 waren alle untersuchten Individuen für den Phänotyp A fixiert.

Tab. 25 Phänotypfrequenzen der fünf Störspezies an dem System PGM bei Postulierung der duplizierten Loci PGM-1 und PGM-2

Spezies

\begin{tabular}{lcccccc}
\cline { 3 - 6 } Locus & Phänotyp & A. baerii & A. guelden. A. ruthenus & A. stellatus & H. huso \\
\hline PGM-1 & A & 1,000 & 0,000 & 1,000 & 0,000 & 0,000 \\
& AB & 0,000 & 0,000 & 0,000 & 0,000 & 0,603 \\
& B & 0,000 & 1,000 & 0,000 & 0,000 & 0,397 \\
& C & 0,000 & 0,000 & 0,000 & 1,000 & 0,000 \\
PGM-2 & A & 1,000 & 1,000 & 1,000 & 1,000 & 1,000 \\
\hline
\end{tabular}

Waren die biochemischen Marker innerhalb einer Spezies polymorph fiel auf, dass bestimmte Phänotypklassen nicht beobachtet werden konnten. Die beobachteten Allele wurden aus genannten Gründen nicht quantifiziert. Die aus den beobachteten Phänotypen abgeleiteten Allele innerhalb Spezies und Herkünfte hätten allerdings bei einer repräsentativen Stichprobe die nicht beobachteten Phänotypen erwarten lassen können. Daher musste angenommen werden, dass die Tiere derselben Art innerhalb Herkunft wie auch die innerhalb einer Spezies über alle Herkünfte gepoolten Daten sich nicht im HardyWeinberg-Gleichgewicht befanden. 
Zusammenfassend lässt sich festhalten, dass sich von den untersuchten biochemischen Markern im Blut nur die PGM-1 für A. stellatus als artspezifisch herausstellte. Die übrigen Marker eigneten sich nicht für eine Charakterisierung der untersuchten Störarten. Zum einen konnte eine nur begrenzte Anzahl an Systemen visuell dargestellt werden. Zum anderen kamen bei den übrigen darstellbaren Systemen gleiche Allele bzw. Phänotypen zwischen verschiedenen Arten vor. Generell trat trotz konstanter Parameter hinsichtlich des verwendeten Trennmediums, den Elektrophoresebedingungen und der Färbung das Problem der Phänotypbestimmung auf. Je polymorpher sich ein Marker darstellte, desto schwieriger war eine einheitliche Phänotyp-Klassifizierung der Einzelindividuen.

Mit zunehmender Lagerungsdauer der Proben wurde zudem eine sich verringernde Aktivität der Allozymsysteme festgestellt, wie sie auch bei anderen Spezies beobachtet werden kann.

\subsubsection{Molekularbiologische Marker}

\subsubsection{Mikrosatelliten-Loci}

MAY et al. (1997) charakterisierten elf Mikrosatelliten-Loci bei A. fulvescens. Diese Arbeitsgruppe zeigte, dass hiervon neun Loci bei verschiedenen acipenseriformen Spezies amplifiziert werden konnten. Daher wurden diese neun Mikrosatelliten-Loci im Rahmen dieser Arbeit an den Spezies A. baerii, A. gueldenstaedtii, A. ruthenus, A. stellatus und H. huso untersucht. In Abhängigkeit von der Spezies ließen sich von den neun Loci nur vier bzw. fünf innerhalb der fünf betrachteten Eurasischen Störarten auswertbar darstellen (siehe Tab. 13, Kap. 4.2.1). Die anhand der Mikrosatelliten-Loci gewonnenen Erkenntnisse hinsichtlich des Ploidiestatus der einzelnen Spezies werden in Kapitel 5.2 diskutiert.

Die untersuchten Mikrosatelliten-Loci ließen sich gruppieren in Loci, die 1.) amplifiziert und ausgewertet, 2.) amplifiziert aber aufgrund des sich darstellenden Peakmusters nicht ausgewertet und 3.) nicht amplifiziert werden konnten (siehe auch Tab. 13, Kap. 4.2.1). 
Nicht amplifizierbare oder amplifizierbare aber nicht auswertbare Mikrosatelliten-Loci sind nicht für eine Identifizierung von Stören geeignet.

Von den erfolgreich über alle fünf untersuchten Spezies amplifizierten Loci ließen sich nur LS-19, LS-34 und LS-39 auswerten. Gleiches galt partiell für LS-54, der allerdings bei A. ruthenus in der PCR zu keinen Amplifikationsprodukten führte. LS-68 konnte zwar bei A. baerii und A. gueldenstaedtii amplifiziert, aber aufgrund des komplexen Peakmusters nicht ausgewertet werden. Diese Beobachtung traf auch für die Mikrosatelliten-Loci LS-57 und LS-69 über alle fünf Störspezies zu. Trotz Variationen in den PCR-Bedingungen ( $\mathrm{MgCl}_{2}$-Konzentration, Absenkung der Annealingtemperatur) konnten LS-58 und LS-62 bei keiner der Arten amplifiziert werden.

Die innerhalb der Spezies ausgewerteten Loci LS-19, LS-34, LS-54 und LS-68 waren polymorph. An einigen Loci konnten Unterschiede zwischen den Spezies hinsichtlich der auftretenden Allelgrößen beobachtet werden. Dennoch gestatteten diese Mikrosatelliten-Loci keine Identifizierung der Störart, da die meisten innerhalb einer Art beobachteten Allele auch mindestens bei einer anderen zu finden waren. GÖTZ \& THALLER (1998) präsentieren in einer Simulationsstudie ein statistisches Verfahren, mit dem Individuen nach einer Genotypisierung an verschiedenen Mikrosatelliten-Loci mit einer hohen Wahrscheinlichkeit einer Population zugeordnet werden können. Diese Studie setzte allerdings bekannte Allelfrequenzen an den einzelnen Loci in den Populationen voraus. Zusätzlich müsste dieses Verfahren bei einer Identifizierung von Störindividuen die unterschiedlichen Ploidiestati der Spezies mit berücksichtigen.

Dagegen waren sowohl die Individuen der Spezies A. stellatus als auch der SevrugaKaviar an dem Mikrosatelliten-Locus LS-39 homozygot für das Allel von 111 bp fixiert. Dieses Allel konnte bei keinem Tier der vier übrigen Spezies detektiert werden. Zusätzlich wurden die Individuen von den Arten A. persicus, A. naccarii und $P$. spathula untersucht, um zu überprüfen, ob sie dieses bei A. stellatus beobachtete Allel aufwiesen. Während LS-39 nicht bei P. spathula amplifiziert werden konnte, besaßen die Exemplare der Spezies A. naccarii und A. persicus kein Allel dieser Größe. Anhand des vorliegenden Untersuchungsmaterials präsentierte sich LS-39 daher als artcharakteristischer Marker für A. stellatus. Ob sich diese Beobachtung auch bei der Einbeziehung der anderen Arten der 
Acipenseriformes bestätigt, muss in weiteren Untersuchungen evaluiert werden. Zudem sollten weitere Individuen von A. stellatus aus Wildpopulationen untersucht werden, um die Fixierung an diesem Locus zu überprüfen.

Die individuellen Pherogramme waren bei LS-19 durch das Auftreten von Doppelpeaks charakterisiert (Abb. 31). In der Auswertung zeigte sich, dass zwei Fragmente mit einer Größendifferenz von ca. einer Base den Doppelpeak bedingten. Das kleinere der beiden Fragmente stellte hierbei das "wahre" Allel dar. Das größere Allel kam durch eine in der PCR durch die Taq-DNA-Polymerase bedingte Template-unabhängige Addition eines Nukleotids zustande. Dieses Phänomen kann bei der Verwendung dieses Enzyms auftreten (CLARK 1988, HU 1993).

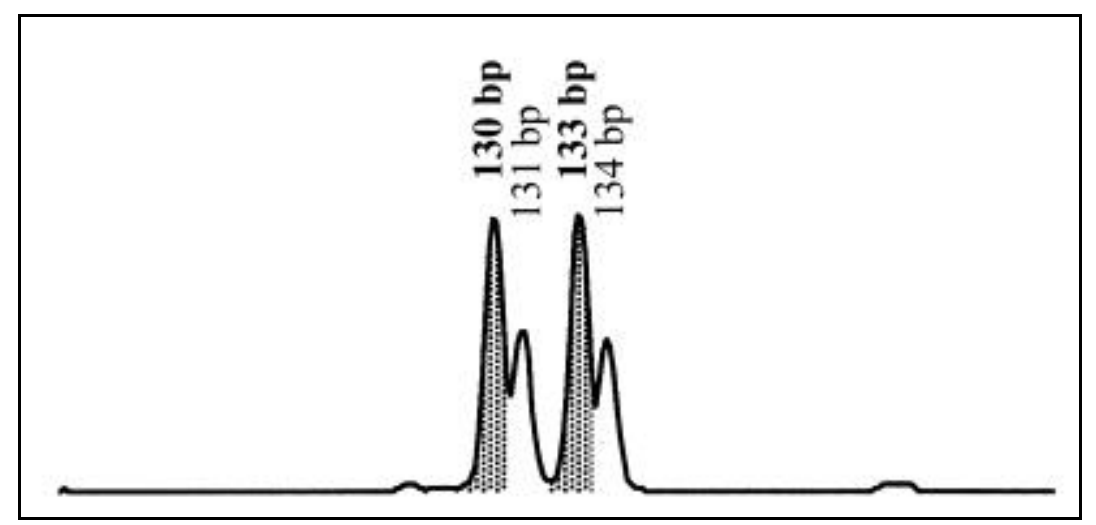
Abb. 31 Charakteristika von LS-19 dargestellt an einem heterozygoten Individuum der Spezies A. stellatus
Die beiden "wahren" Allele sind grau hinterlegt.

Des Weiteren konnte mit Ausnahme von LS-19 an den auswertbaren Loci beobachtet werden, dass kürzere Allele bei gleicher Allelanzahl leicht höhere Peaks aufwiesen als längere. Die Begründung hierfür liegt in einer Präferenz der Taq-DNA Polymerase für kürzere Fragmente (WALSH et al. 1992).

Bei den Mikrosatelliten-Loci waren Stotterbanden unterschiedlicher Ausprägung zu beobachten. Hierbei handelte es sich ausschließlich um in vitro generierte und in dem Wiederholungsmotiv verkürzte Artefakte des eigentlichen Allels (MURRAY et al. 1993, WALSH et al. 1996). 
Auffällig war, dass an den Mikrosatelliten-Loci LS-19, LS-39, LS-54 und LS-68 innerhalb der Arten bestimmte Allelgrößen teilweise nicht detektiert werden konnten. Dies könnte, wie schon bei den biochemischen Markern erwähnt, an einem zu geringen Stichprobenumfang liegen. In der Literatur ist allerdings das Vorhandensein unbesetzter Allelklassen an verschiedenen Mikrosatelliten-Loci bei diversen Populationen und Spezies beschrieben worden (GOMOLKA et al. 1994, VAN ZEVEREN et al. 1995).

Bei den Kaviar-Elektropherogrammen (siehe Abb. 14, Kap. 4.2.1.3) fiel auf, dass bei dem von der Spezies A. gueldenstaedtii stammenden Ossetra-Kaviar keine Allelquantifizierung an LS-39 möglich war. Da diese Beobachtung auch bei den Mikrosatelliten-Loci LS-19, LS-34 und LS-54 zutraf, kann angenommen werden, dass der Ossetra-Kaviar eine Mischcharge von mindestens zwei verschiedenen Individuen stammte, die unterschiedliche Allele an den betrachteten Loci aufwiesen.

Für die Arbeit stand kein Familienmaterial zur Verfügung. Daher konnte der Vererbungsgang an den Mikrosatelliten-Loci nicht untersucht werden. In der Literatur wurde ein mendelnder Erbgang dieser Mikrosatelliten-Loci bei verschiedenen Störspezies berichtet (MAY et al. 1997, PYATSKOWIT et al. 1997).

Bei den Individuen der Spezies A. baerii und A. gueldenstaedtii stellten sich LS-19, LS-34, LS-39 und LS-54 als tetraploide Loci dar. Bei einigen Tieren konnten nur drei Allele an bestimmten Loci beobachtet werden. Dass es sich hierbei um Hybriden zwischen Spezies unterschiedlicher Chromosomenzahlen handelte, konnte durch die Auswertung der anderen drei Mikrosatelliten-Loci ausgeschlossen werden. Daher liegt die Vermutung nahe, dass bei diesen Individuen Nullallele für beobachtete "triploide" Loci verantwortlich waren. Nullallele, d.h. nicht amplifizierte Allele, treten dann auf, wenn Mutationen in der Primer-Bindungsstelle vorhanden sind. Dies bedingt eine Reduktion in der Homologie zwischen Primer und Template-DNA. Eine Reduktion in der Homologie von einem Prozent bedingt eine Reduktion von $1-1,5{ }^{\circ} \mathrm{C}$ in der Annealingtemperatur (BONNER et al. 1973). Die Auswirkung einer solchen Mutation inmitten der PrimerBindungsstelle auf die Amplifikation wurde z.B. bei einem equinen Mikrosatelliten-Locus gezeigt (EGGLESTON-STOTT 1997). Durch eine Reduktion der Annealingtemperatur können solche Allele trotzdem amplifiziert werden. Dies ist allerdings nicht möglich, wenn 
die Mutation in der Template-DNA zu einer Fehlpaarung der letzten oder vorletzten 3'-endständigen Base des Primers führt (SAKAR et al. 1990). Da trotz einer Reduktion der Annealingtemperatur das vierte Allel bei den Individuen mit direkt nachweisbaren Nullallelen nicht amplifiziert werden konnte, liegt die Vermutung einer Mutation in der zum 3'-Ende des Primers homologen Template DNA nahe. Letztendliche Klarheit hierüber kann allerdings nur eine Sequenzierung der Primerbindungsstellen erbringen. Ob bei den Individuen der Spezies A. ruthenus, A. stellatus und $H$. huso ebenfalls Nullallele auftraten, konnte aufgrund des sich an diesem Mikrosatelliten-Locus darstellenden diploiden Status' dieser Arten nicht abgeschätzt werden.

Erfolgreiche speziesübergreifende Amplifikationen von Mikrosatelliten-Loci sind mehrfach in der Literatur beschrieben (MOORE et al. 1991, SCHLÖTTERER et al. 1991, FitZSimmONS et al. 1995, RICO et al. 1996, MAY et al. 1997). Allerdings zeigte sich in der vorliegenden Arbeit, dass bei den polyploiden Spezies A. baerii und A. gueldenstaedtii Nullallele direkt an den tetraploiden Mikrosatelliten-Loci LS-19, LS-34, LS-39 und LS-54 detektiert werden konnten. Einige der an A. fulvescens entwickelten Primerpaare amplifizierten zudem nicht bei den hier untersuchten Eurasischen Störspezies. Diese Beobachtungen legen nahe, dass für speziesübergreifende Amplifikationen von Mikrosatelliten-Loci innerhalb der Acipenseriformes der Primerentwicklung besondere Beachtung gewidmet werden muss. Im Idealfall sollten die das Mikrosatelliten-Motiv flankierenden Bereiche bei allen Arten sequenziert werden, um interspezifisch konservierte Bereiche für eine optimale Primerentwicklung verwenden zu können.

Bei der Untersuchung der gepoolten Daten sowohl der innerhalb Spezies über die Herkünfte als auch der einzelnen Herkünfte mit einem Stichprobenumfang von zehn oder mehr Individuen stellte sich heraus, dass das Hardy-Weinberg-Gleichgewicht (HWG) in keinem Fall über alle Loci erfüllt wurde.

Eine mögliche Erklärung für die beobachtete Abweichung vom HWG könnte das Auftreten von Nullallelen sein, da diese eine Verzerrung in den berechneten Allelfrequenzen bedingen. Andererseits wird durch das Fehlen bestimmter Phänotypen bei den biochemischen Markern die Hypothese, dass sich weder Herkünfte noch Spezies im HWG 
befanden, erhärtet. Bei einzelnen Herkünften kann dieses allerdings auch durch eine zu geringe Stichprobengröße bedingt sein. Bei den aquakulturellen Herkünften A-F könnte die Nichterfüllung des HWG auch darin begründet liegen, dass die Individuen wahrscheinlich von nur wenigen Elterntieren abstammten.

Für Populationsstudien innerhalb einer Spezies erscheinen Mikrosatelliten-Loci aufgrund ihres polymorphen Charakters sehr gut geeignet. Darüber hinaus könnten sie für den Aufbau von aquakulturellen Beständen und/oder Arterhaltungsprogrammen Verwendung finden. Unter diesen Aspekten wäre eine Genotypisierung der Individuen die Basis für eine Selektion möglichst unverwandter Individuen.

\subsubsection{RAPD}

Für die Amplifikationen mit den Primern des OPERON-Kit $\mathrm{H}$ wies das Temperaturprofil eine Annealingtemperatur von $36^{\circ} \mathrm{C}$ für jeden der 40 Zyklen auf und führte i.d.R. zu deutlich erkennbaren Fragmenten. In Voruntersuchungen zeigte sich, dass dieses Temperaturprofil bei der Verwendung der langen Primer in der RAPD-PCR einen störenden Hintergrund generierte. Vermutlich handelte es sich hierbei um einzelsträngige DNA-Fragmente. Dagegen konnte durch die Anhebung der Annealingtemperatur auf $50{ }^{\circ} \mathrm{C}$ ab dem sechsten PCR-Zyklus das Hintergrundrauschen erheblich reduziert werden.

Von den insgesamt 40 verwendeten Primern generierten nur zwei (Long-5 und Long11) interspezifisch differenzierbare Fragmentmuster. In der Voruntersuchung an drei unverwandten Individuen je Spezies schienen die Amplifikationsprodukte der drei in der RAPD-PCR verwendeten 10-mer Primer OPH-06, OPH-07 und OPH-11 jeweils ein für A. stellatus charakteristisches Fragment aufzuweisen. Eine Untersuchung von sieben weiteren Individuen dieser Spezies zeigte, dass die mit OPH-07 und OPH-11 generierten Fragmente nicht konstant bei allen Individuen auftraten. Dagegen war das als potentiell artcharakteristisch eingestufte Fragment, das unter Verwendung des Primers OPH-06 amplifiziert wurde, bei den sieben zusätzlich untersuchten Individuen dieser Spezies konstant vorhanden. Das Fragment trat aber auch bei Individuen der Art 
A. gueldenstaedtii auf, so dass mit keinem der 20 Primer des OPERON-Kit H eine Artcharakterisierung erfolgen konnte.

Das in der RAPD-PCR verwendete 17 Basen lange Oligonukleotid Long-5 und der 19 Basen lange Primer Long-11 generierten artcharakteristische Fragmentmuster. Die Amplifikationsprodukte der übrigen langen Primer ließen demgegenüber keine Artcharakterisierung zu. Durch die Verwendung des Primers Long-5 konnten die fünf untersuchten Arten A. baerii, A. gueldenstaedtii, A. ruthenus, A. stellatus und H. huso - jede Spezies wurde durch zehn unverwandte Individuen repräsentiert - differenziert werden. A. baerii und A. gueldenstaedtii wiesen dabei sehr ähnliche Fragmentmuster auf. Die Unterscheidung dieser beiden Spezies war durch ein ca. 2.400 bp langes Fragment möglich, da dieses bei A. baerii auftrat und bei A. gueldenstaedtii fehlte. Das mit Primer Long-11 generierte Fragmentmuster gestattete eine Differenzierung der drei Spezies A. baerii, A. ruthenus, A. stellatus und $H$. huso. Allerdings stellten sich die Individuen der Spezies A. gueldenstaedtii mit einem interindividuell sehr heterogenen Fragmentmuster dar, so dass einige Tiere nicht von A. baerii unterschieden werden konnten.

Die Charakterisierung von Störarten mit dem RAPD-Verfahren war zwar in der Literatur beschrieben (FONATANA et al. 1998b, JENNECKENS et al. 1998), jedoch stellte sich bei der Untersuchung von Hybriden in der vorliegenden Arbeit heraus, dass die amplifizierten Fragmentmuster eine hohe interindividuelle Variabilität aufwiesen. Kreuzungstiere konnten mit diesem Verfahren weder als solche identifiziert noch zweifelsfrei den Elternarten zugeordnet werden.

Vorteile der RAPD-PCR liegen in dem einfachen und flexiblen Verfahren sowie darin, dass für die Generierung multipler Fragmente keine Sequenzinformationen des zu untersuchenden Organismus vorhanden sein müssen. Die fünf an mehr Tieren getesteten Primer OPH-06, OPH-07, OPH-11, Long-5 und Long-11 wiesen dabei eine hohe intraindividuelle Reproduzierbarkeit in dem amplifizierten Fragmentmuster auf. $\mathrm{Ob}$ die in dieser Untersuchung für eine Artcharakterisierung geeigneten Primer Long-5 und Long-11 in der RAPD-PCR bei Einbeziehung weiterer Störarten weiterhin das Potential für eine Artcharakterisierung besitzen, kann allerdings nicht abgeschätzt werden. Darüber hinaus ist fraglich, ob dieselben Ergebnisse auf ein anderes Labor übertragbar sind. Es hat sich 
gezeigt, dass die Wiederholbarkeit zwischen verschiedenen Laboratorien trotz Verwendung derselben Template-DNA und Primer eingeschränkt war (PENNER et al. 1993).

\subsubsection{SINE-PCR}

Aus der bei OHSHIMA et al. (1993) dargestellten tRNA ${ }^{\text {Lys }}$-Konsenssequenz wurde im Rahmen dieser Arbeit ein Primer entwickelt und in der PCR unter stringenten Bedingungen verwendet. Es wurde angenommen, dass tRNA ${ }^{\text {Lys }}$-SINEs in inverser und mit ihren 3'-Termini einander zugerichteten Orientierung in dem Genom der verschiedenen Störspezies vorkommen. OKADA (1991) bezeichnete SINEs als zeitliche Markierungssteine in der Evolution. Für die Familie Salmonidae wurde gezeigt, dass SINEs nicht nur für diese Familie spezifisch waren, sondern auch für einzelne Gattungen und sogar für verschiedene Spezies (KIDO et al. 1991, MURATA et al. 1993, TAKASAKI et al. 1994). Die Verwendung des Primers in der PCR erfolgte daher unter der Annahme, dass in der acipenseriformen Evolution tRNA ${ }^{\text {Lys }}$-SINEs interspezifisch an unterschiedlichen Positionen im Genom konserviert sind. Treten dabei wie oben beschrieben invers zueinander orientierte Elemente in kurzer Entfernung zueinander auf, können Amplifikationsprodukte erwartet werden.

Der in der SINE-PCR verwendete Primer generierte bei den Störspezies wenige Fragmente. Das Vorhandensein von Amplifikationprodukten läßt a priori zwei Interpretationsmöglichkeiten zu. Die erste wäre, dass SINEs mit einer $\operatorname{tRNA}^{\mathrm{Lys}}$-ähnlichen Struktur auch bei Stören zu finden sind. Aufgrund der hohen Homologie des Primers zur nukleären $\mathrm{tRNA}^{\mathrm{Lys}}$ und dem Vorhandensein eines genomischen $\mathrm{tRNA}^{\mathrm{Lys}}$-Gencluster bei verschiedenen Spezies (DORAN et al. 1987, MATSOU et al. 1995) könnte es sich aber auch um Amplifikationsprodukte invers zueinander orientierter tRNA ${ }^{\text {Lys }}$-Gene handeln. Da kein Fragment sequenziert wurde, blieb diese Frage offen.

Die geringe Anzahl amplifizierter Fragmente gestatteten keine Speziesdifferenzierung. Zudem konnte bei den Spezies eine intraspezifische Variabilität beobachtet werden. Es ist bekannt, dass innerhalb einer Population die Retroposition von SINEs an einem 
betrachteten genomischen DNA-Abschnitt zwischen Individuen variabel, d.h. insertiert oder nicht insertiert sein kann (TAKASAKI et al. 1997).

\subsubsection{Inter-SSR PCR}

Fünf verschiedene Primer wurden in den Untersuchungen verwendet. Drei waren zu Dinukleotid-Wiederholungsmotiven homolog. ISHIBASHI et al. (1995) fanden in ihrer Untersuchung heraus, dass degenerierte Primerextensionen zu keinem klaren Bandenmuster in einer Fischspezies (Oncorhynchus masou) führten. Aus diesem Grund wiesen die im Rahmen dieser Arbeit verwendeten Primer ISSR1 und ISSR2 zwei, der Primer ISSR3 sogar drei definierte Nukleotidextensionen am 3'-Terminus auf. Unter der Annahme, dass Tri- und Tetranukleotid-haltige Mikrosatelliten-Motive mit einer geringeren Frequenz als Dinukleotid-haltige im Genom vorkommen, enthielten die Primer ISSR4 und ISSR5 keine Extension am 3'-Terminus.

In den Amplifikationen wurde jeder Primer einzeln eingesetzt. Für die Amplifikation wurde ein Touchdown Temperaturprofil verwendet, da SHARMA et al. (1995) zeigten, dass ein solches Verfahren eine hohe Reproduzierbarkeit hinsichtlich des erzeugten Fragmentmusters bedingte.

Die drei Primer ISSR1-ISSR3 generierten in der PCR trotz der selektiven Extension ein sehr komplexes Bandenmuster, welches nur in 6\%igen denaturierenden PolyacrylamidGelen nach einer Silberfärbung aufgelöst werden konnte. Die Fragmentmuster wiesen dabei eine hohe intraspezifische Variabilität auf. Primer ISSR1 führte in der Voruntersuchung lediglich zu einem potentiell A. stellatus-spezifischen Fragment. Die Verwendung des Primers ISSR2 erzeugte je ein potentiell artspezifisches Fragment für die beiden Spezies A. ruthenus und A. stellatus. Der Primer ISSR3 führte zu keinem artspezifischen Amplifikationsprodukt bei den fünf untersuchten Spezies. Da der Arbeitsaufwand gemessen an dem erzielten Ergebnis zu groß war, wurde auf eine Analyse der weiteren sieben unverwandten Individuen verzichtet.

Die Amplifikationsprodukte der Primer ISSR4 und ISSR5 konnten im Agarosegel ausgewertet werden, da hier, wie angenommen, eine geringere Anzahl an Fragmenten 
amplifiziert wurde. Primer ISSR4 erbrachte in der PCR dabei eine höhere Anzahl an Amplifikationsprodukten als Primer ISSR5. Allerdings konnten bei Verwendung dieser Primer keine artcharakteristischen Fragmente detektiert werden.

\subsubsection{AFLP}

Im Rahmen dieser Arbeit wurde untersucht, ob eine Differenzierung von Störspezies mit dem AFLP-Verfahren möglich war. Von zehn unverwandten Individuen der Spezies A. baerii, A. gueldenstaedtii, A. ruthenus, A. stellatus und $H$. huso wurden die in der PCR generierten Fragmentmuster mit dem Sequenzierautomat LiCor ausgewertet. Die in ein Image umgewandelten Elektropherogramme wiesen visuell eine hohe intraspezifische Homogenität für die Arten A.ruthenus, A. stellatus und H. huso auf. Heterogener präsentierten sich hingegen die Individuen der Spezies A. baerii und A. gueldenstaedtii. Hierfür könnte der höhere Ploidiestatus dieser Arten verantwortlich sein, da gegenüber den drei anderen Spezies die doppelte Menge an genetischem Material pro Zelle vorliegt.

Die Auswertung der Fragmente erfolgte im Bereich des mit auf das Gel aufgetragenen Molekulargewichtstandards von 50-350 bp. Insgesamt konnten über die 50 Individuen 297 Fragmente unterschiedlicher Länge beobachtet werden. Innerhalb der Individuen wurden zwischen 37 und 77 Fragmente detektiert.

Gegenüber der visuellen Betrachtung des Image war nach der Auswertung der Fragmente die Ähnlichkeit von Individuen innerhalb der Arten geringer, als erwartet. Ein möglicher Grund hierfür könnte in der manuellen Fragmenterkennung liegen, die zu einer Über- oder Unterklassifizierung hinsichtlich der detektierten Fragmente führen kann. Die daraus resultierende Folge war, dass die berechneten durchschnittlichen Ähnlichkeitsindices innerhalb der Spezies' zwischen 0,239 für A. gueldenstaedtii und 0,645 für A. stellatus schwankten.

Innerhalb der Individuen von A. baerii konnte nicht eine Fragmentlänge beobachtet werden, die gleichzeitig bei allen zehn untersuchten Individuen vorkam. Gleiches wurde auch bei den zehn A. gueldenstaedtii festgestellt. Innerhalb A. ruthenus traten 13 Fragmente auf, die bei allen zehn Individuen detektiert werden konnten. Bei A. stellatus 
und H. huso wurden sieben bzw. drei intraspezifisch konstant auftretende Fragmentlängen gefunden. Fragmente, die innerhalb einer Spezies bei allen Individuen vorkommen, können als potentiell artcharakteristische Banden angesehen werden. Kann ein solches Fragment hingegen auch bei Tieren einer anderen Art beobachtet werden, so besitzen sie keine Artspezifität mehr. Da die bei A. ruthenus, A. stellatus und H. huso intraspezifisch konstant auftretenden Banden auch interspezifisch auftraten, ließ dieses Verfahren keine Charakterisierung der Arten zu.

LIU et al. (1998) zeigten, dass annähernd $50 \%$ der gesamten AFLP-Fragmente für eine der beiden untersuchten Ictalurus-Spezies spezifisch waren. Durch Modifikationen des im Rahmen der vorliegenden Arbeit verwendeten AFLP-Protokolls könnte vielleicht eine Identifizierung von Störarten erfolgen. Zum einen würde eine Reduktion der amplifizierten Fragmente die Auswertung erleichtern, zum anderen müssten für eine Artidentifizierung intraspezifisch homogene aber interspezifisch differenzierbare Fragmentmuster erzeugt werden. Durch die Verwendung von Oligonukleotiden in der finalen PCR-Reaktion, welche anstatt der hier verwendeten zwei stattdessen drei selektive Nukleotide an dem 3'-Terminus besitzen, kann die Anzahl amplifizierter Fragmente vermindert werden. AJMONE-MARSAN et al. (1997) generierten durch den Einsatz der beiden Restriktionsendonukleasen EcoRI und TaqI bei Rindern ein sehr homogenes Fragmentmuster über die in der Studie untersuchten Individuen. Im Rahmen dieser Arbeit wurden die Restriktionsendonukleasen EcoRI und MseI verwendet. Möglicherweise könnte die Verwendung der Restriktionsendonukleasen EcoRI und TaqI ebenfalls zu einem interindividuell homogeneren Fragmentmuster insbesondere bei den beiden Störspezies A. baerii und $A$. gueldenstaedtii führen.

Da mit der im Rahmen dieser Arbeit verwendeten Vorgehensweise nach der Fragmentauswertung keine Artcharakterisierung erfolgen konnte, ist die Erkennung von Hybriden ebenfalls nicht möglich. Ob durch die oben erwähnten Modifikationen Hybriden und Rückkreuzungen erkannt werden können, kann allerdings nicht abgeschätzt werden. 


\subsubsection{Mitochondriales Cytochrom b}

In der SSCP-Untersuchung zeigten die zehn Individuen der Spezies A. baerii, A. ruthenus, A. stellatus und $H$. huso ein einheitliches Fragmentmuster. Differenzieren ließen sich dabei A. ruthenus, A. stellatus und H. huso. Darüber hinaus konnten die beiden Individuen der Art $P$. spathula von den übrigen Spezies im SSCP-Verfahren unterschieden werden. Innerhalb der Spezies A. gueldenstaedtii konnten über die zehn unverwandten Individuen aquakultureller Herkunft und den 19 Wildfängen (Herkunft G) vier verschiedene Haplotypen beobachtet werden (AG1 bis AG4). Der Haplotyp AG3 sowie A. naccarii und A. persicus konnten aufgrund des gleiches SSCP-Musters nicht voneinander differenziert werden. Demgegenüber glich der Haplotyp AG4 dem SSCPMuster der Individuen von A. baerii. Von den 19 A. gueldenstaedtii wiesen insgesamt sieben den nicht von A. baerii unterscheidbaren Haplotyp AG4 auf.

Aufgrund des Auftretens gleicher Haplotypen konnten A. baerii, A. gueldenstaedtii, A. naccarii und A. persicus nicht einwandfrei mit dem SSCP-Verfahren voneinander differenziert werden. Unter der Voraussetzung, dass bei den Spezies A. ruthenus, A. stellatus, $H$. huso und $P$. spathula keine weiteren Haplotypen sowohl in aquakulturellen Beständen als auch in Wildpopulationen auftreten, ist der SSCP unter Verwendung dieses partiellen Fragmentes des mt Cyt b ein geeigneter Marker, um diese Spezies auf mitochondrialer Ebene zu unterscheiden. Vorteil dieser Methode ist, dass sie sowohl bei der Untersuchung von Individuen als auch bei verschiedenen Störprodukten (Kaviar, Fleisch) angewandt werden kann. Die Verwendung des SSCP für die Überprüfung von Kaviar ist bereits in der Literatur beschrieben (REHBEIN 1997). Der Nachteil dieser Methode ist allerdings, dass Hybriden nicht als solche erkannt werden können, da es sich hier eben um einen mitochondrialen Marker handelt.

Die Sequenzierung des mt Cyt b von Individuen verschiedener Spezies zeigte, dass eine Verzerrung in der Basenzusammensetzung auftrat. Die Base Guanin $(\mathrm{G})$ wies über alle Codonpositionen betrachtet die geringste durchschnittliche Frequenz auf. Dieses Phänomen ist bei poikilothermen Spezies bekannt, die Gründe hierfür sind jedoch unklar (MEYER 1993). In der dritten Codonposition wiesen die mt Cyt b-Sequenzen der Störe einen hohen 
Anteil der Basen Adenin (A) sowie Cytosin (C), aber eine sehr geringe Frequenz von G auf, was aber ebenfalls bei anderen Fischspezies vorgefunden wurde (MEYER 1993).

Die für das mt Cyt b codierende DNA wies bei keiner der sequenzierten Individuen ein erkennbares Stop-Codon auf, welches für einen Abbruch der späteren Translation notwendig ist. Bei $A$. transmontanus konnte ebenfalls kein für eine Termination codierendes Nukleotidtriplett festgestellt werden (BROWN et al. 1989). Bei allen untersuchten Störarten folgte die Base Thymin der proteincodierenden Nukleotidsequenz. ANDERSON et al. (1981) zeigten, dass nach der Transkription eine Polyadenylierung der mitochondrialen mRNA stattfindet, welche zu dem Ochre-Stop-Codon UAA führt.

Die größten Sequenzdivergenzen in dem mt Cyt b der betrachteten Acipenseriformes traten zwischen $P$. spathula und allen übrigen Spezies auf. Sowohl Transitionen als auch Transversionen konnten beobachtet werden. Dagegen konnten zwischen den mt Cyt bSequenzen der Arten A. baerii, A. gueldenstaedtii, A. naccarii und A. persicus nur wenige Nukleotisubstitutionen festgestellt werden. Es ist bekannt, dass mit zunehmender Divergenz zwischen Spezies die Anzahl an Nukleotidsubstitutionen zunimmt. Während Transitionen (A $\leftrightarrow \mathrm{G}, \mathrm{C} \leftrightarrow \mathrm{T}$ ) auch zwischen eng verwandten Spezies auftreten, sind Transversionen $(\mathrm{A}, \mathrm{G} \leftrightarrow \mathrm{C}, \mathrm{T})$ bei entfernt verwandten Arten zu finden (MEYER et al. 1990). Die berechneten relativen Verhältnisse an Nukleotidsubstitutionen lagen zwischen der ersten, zweiten und dritten Codonposition bei den mt Cyt b der Störe mit $7: 1: 37,5$ in ähnlichen Bereichen wie die von IRWIN et al. (1991) bei Säugern beobachteten.

Obwohl die Sequenzen verschiedener Individuen der drei Scaphirhynchus-Arten in der Sequenzdatenbank GenBank erhältlich waren, konnte keine Publikation hierzu gefunden werden. Daher werden im Rahmen dieser Arbeit auch die für das Genus Scaphirhynchus erhaltenen Beobachtungen mitdiskutiert.

Ein Vergleich der Sequenzen der drei Arten des Genus Scaphirhynchus zeigte, dass keine artspezifisch unterschiedlich konservierten Nukleotidsubstitutionen auftraten. Über die verschiedenen Haplotypen konnten sieben Transitionen detektiert werden, die ausschließlich an der dritten Codonposition auftraten. Auf der Basis des mt Cyt b lassen sich folglich die drei Arten nicht unterscheiden. Des Weiteren war eine Differenzierung dieser Arten auch an einem 435 bp langen Fragment aus der mitochondrialen D-loop nicht 
möglich (CAMPTON et al. 1995). In einer Untersuchung an 37 Allozym-Loci konnten die beiden Spezies $S$. albus und S. platorhynchus ebenfalls nicht voneinander unterschieden werden (PHELPS \& ALLENDORF 1983). Ähnliches musste auch bei der RFLP-Analyse an acht verschiedenen nukleären Genen festgestellt werden (GENETIC ANALYSIS INC. 1994). Es gibt keine zweifelsfreien Kriterien für die Interpretation molekularer Daten hinsichtlich der Bestimmung des taxonomischen Status (O’BRIEN \& MAYR 1991, WAYNE 1992). Auf der Basis der vorliegenden Arbeit verbunden mit den Ergebnissen anderer Arbeitsgruppen scheint aber das Genus Scaphirhynchus nur eine Spezies zu enthalten, welche die drei bisherigen Arten zusammenfasst.

Auffällig war in dieser Arbeit, dass der Haplotyp A. g. 4 (A. gueldenstaedtii) vollkommen homolog zu A. baerii war. Während die übrigen drei sequenzierten Haplotypen innerhalb A. gueldenstaedtii (A. g. 1 - A. g. 3) maximal sieben Transitionen aufwiesen, die keine Aminosäuresubstitution zur Folge hatten, konnten bei AG4 elf zusätzliche Transitionen beobachtet werden. Drei dieser Transitionen fanden in ersten Codonpositionen statt und führten zu Aminosäuresubstitutionen. Zwei mögliche Hypothesen sind für diese Beobachtung denkbar.

Die erste Hypothese basiert auf der Annahme, dass die Wildfänge von A. gueldenstaedtii mit dem Haplotyp A. g. 4 Hybriden sind. Da mitochondriale DNA maternal vererbt wird, müsste A. g. 4 durch eine Kreuzung zwischen männlichen Individuen Spezies von A. gueldenstaedtii und weiblichen Exemplaren der Art A. baerii hervogegangen sein. Beide Arten kamen ursprünglich in unterschiedlichen, nicht überlappenden Habitaten vor (HOCHLEITHNER 1996, SOKOLOV \& VASIL'EV 1989a, VlASENKO et al. 1989b). In der ehemaligen UdSSR gab es allerdings verschiedene Versuche, A. baerii und A. gueldenstaedtii (und andere Störarten) in neuen Habitaten anzusiedeln (SOKOLOV \& VASIL'EV 1989a, VlasenKo et al. 1989b). Da beide Spezies die gleiche Chromosomenanzahl besitzen, sind deren Kreuzungsnachkommen fertil (NIKOLJUKIN 1966, RONYAI \& VARADI 1995). Natürlich vorkommende Hybriden zwischen verschiedenen Störspezies sind bekannt (Übersicht bei BIRSTEIN et al. 1997a). Die beiden Arten A. baerii und A. gueldenstaedtii sind morphologisch sehr verschieden (Übersicht bei HOCHLEITHNER 1996), so dass dem Störexperten ein F1-Hybride zwischen beiden Arten sicherlich aufgefallen wäre. Aufgrund des maternalen Erbgangs mitochondrialer DNA 
könnten sich die Hybriden aber bei einer über mehrere Generationen stattfindenden natürlichen Rückkreuzung mit der paternalen Elternspezies A. gueldenstaedtii der letzteren morphologisch angleichen.

Obwohl aufgrund der Sequenzhomologie zwischen A. baerii und A. g. 4 die "Hybridtheorie" plausibel erscheint, wäre auch folgende zweite Hypothese denkbar. Die in den Abbildungen 29 und 30 (Kap. 4.2.6.3) dargestellten phylogenetischen Stammbäume auf der Basis des mt Cyt b deuten an, dass beide Spezies in der Evolution aus einem gemeinsamen Ahnen hervorgingen. Es ist bekannt, dass die Spezies A. gueldenstaedtii hinsichtlich ihrer Morphologie sehr heterogen ist (HOCHLEITHNER 1996, VLASENKO et al. 1989b). VECSEI (1997) portraitierte sogar ein Individuum der selten vorkommenden nackten Form dieser Spezies, die gegenüber den anderen Formen keine knöchernen Rücken- und Seitenschilder aufweist. Es stellt sich hier die Frage, ob unter A. gueldenstaedtii verschiedene Spezies zusammengefasst werden. Eine dieser hypothetisch separaten Spezies könnte dabei maternal gesehen phylogenetisch sehr eng mit A. baerii verwandt sein.

Weitere Untersuchungen erscheinen daher sinnvoll, um zu überprüfen, ob entweder verschiedene Spezies unter dem Artnamen A. gueldenstaedtii zusammengefasst werden oder ob fertile Hybriden eine "genetische Kontaminierung" von A. gueldenstaedtii bedingt haben.

A. gueldenstaedtii, A. naccarii und A. persicus sind sich morphologisch sehr ähnlich (TORTONESE 1989, VlASENKO et al. 1989a, 1989b). Abgesehen von dem Haplotyp AG4 spiegelte sich diese Beobachtung in den geringen Sequenzdivergenzen wider (siehe auch Tab. A-1, Anhang). Obwohl der Haplotyp 1 von A. persicus (A. p. 1) gegenüber den anderen Haplotypen dieser Spezies eine Aminosäuresubstitution an der Position 353 aufwies, war die dafür verantwortliche Nukleotidsubstitution nicht artspezifisch konserviert. Zwischen den Individuen der beiden Spezies A. gueldenstaedtii und A. persicus konnten keine potentiell speziesspezifisch konservierten Nukleotidsubstitutionen detektiert werden. Natïrlich vorkommende Hybriden zwischen beiden Arten sind bekannt (VLASENKO et al. 1989b). Unter der Voraussetzung, dass die hier untersuchten Individuen keine Hybriden 
sind, konnte der Artstatus von A. persicus auf der Grundlage des mt Cyt b nicht bestätigt werden.

Das Exemplar der Spezies A. naccarii unterschied sich in den Nukleotidpositionen 345 und 562 von allen anderen mt Cyt b Sequenzen. Die Transition an der Nukleotidposition 562 bedingte zudem eine Aminosäuresubsitution ( $\mathrm{V} \rightarrow \mathrm{M}$, Position 188). Daher wurde von dem zweiten Individuum dieser Spezies ein partielles mt Cyt b Fragment amplifiziert und sequenziert, welches die erwähnten Nukleotidpositionen enthielt. Die Transitionen konnten ebenfalls bei diesem Tier detektiert werden. Inwiefern diese Nukleotidsubstitutionen für $A$. naccarii charakteristisch sind, muss an weiteren Individuen verschiedener Populationen untersucht werden, um eine stichprobenbedingte Fehlinterpretation ausschließen zu können (DAVIS \& NIXON 1992). Beide Individuen stammten nämlich aus derselben aquakulturellen Herkunft und können somit maternal eng verwandt sein.

Streng genommen werden durch das $\mathrm{mt}$ Cyt $\mathrm{b}$ nur maternale Linien betrachtet. Nukleotidsubstitutionen in diesem Gen haben sich aber auch für Populationsstudien als geeignet herausgestellt (BARTLETT \& DAVIDSON 1991, SMith \& PATTON 1991). Sequenzdivergenzen von unterschiedlichem Ausmaß konnten auch in der vorliegenden Arbeit zwischen den Haplotypen innerhalb der beiden Spezies A. gueldenstaedtii und A. persicus festgestellt werden (siehe Abb. A-1, Anhang).

Ein Vergleich der mt Cyt b-Sequenzen über die verschiedenen Individuen (siehe Tab. A-1, Anhang) zeigte, dass die Spezies A. naccarii, A. ruthenus, A. stellatus, A. transmontanus, H. huso, P. spathula und der Gattung Scaphrihynchus potentiell artcharakteristische Nukleotidsubstitutionen aufwiesen. Eine Untersuchung weiterer Individuen dieser und der anderen Störspezies kann zur Definition von artcharakteristischen und somit speziesdiagnostischen Nukleotiden führen. Wie schon für das SSCP-Verfahren angemerkt, können allerdings Hybriden nicht als solche erkannt werden. PCR-gestützte Verfahren, die für eine Überprüfung von Störkaviar auf artdiagnostischen Nukleotiden im mt Cyt b basieren, wurden bereits in der Literatur beschrieben (DESALLE \& BIRSTEIN 1996, BIRSTEIN et al. 1998b). Die partiellen Sequenzen aus dem mt Cyt b, auf denen die Artcharakterisierung von dieser Arbeitsgruppe basierte, sind in den Sequenzdatenbanken 
EMBL (Accession numbers: X95053-X95061) und GenBank (Accession numbers: AF006123-AF006188) erhältlich. Einige der in den Sequenzdatenbanken hinterlegten partiellen Sequenzen des mt Cyt b wiesen an den 3'-Termini zu den hier präsentierten Sequenzen zunehmende Nukleotiddifferenzen auf. Abbildung 32 zeigt einen Vergleich der Nukleotid- und deduzierten Aminosäuresequenzen des Fragments mit der EMBLZugangsnummer AF006183 zu den in dieser Arbeit ermittelten für die Spezies P. spathula.

Die deduzierte Aminosäuresequenz von AF006183 wies am 3'-Terminus ein OchreStop-Codon auf. Da es sich bei der Nukleotidsequenz um ein partielles Fragment mitten aus dem mt Cyt b handelt, würde dieses Stop-Codon eine Termination der Transkription nach 186 Aminosäuren bedingen. Ein derart kurzes $\mathrm{mt}$ Cyt $\mathrm{b}$ ist bislang nicht in der Literatur beschrieben, weshalb die Funktionalität des Proteins angezweifelt werden muss. Insgesamt wiesen inklusive AF006183 neun der 75 von dieser Arbeitsgruppe in den Datenbanken abgelegten partiellen mt Cyt b-Fragmenten eine solche Termination auf.

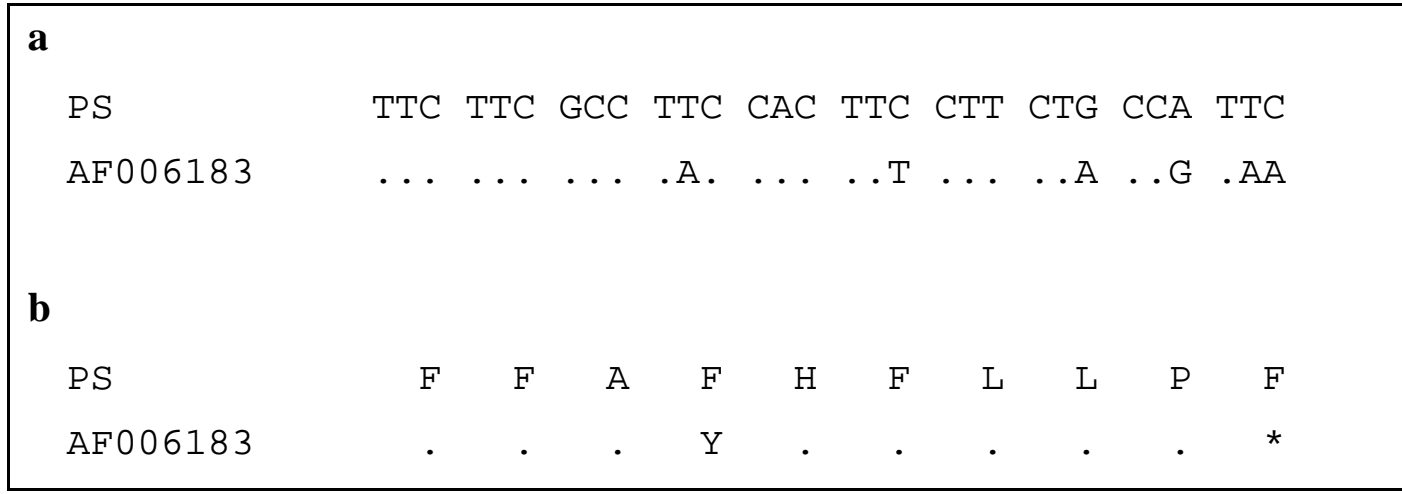

Abb. 32 Vergleich der in dieser Arbeit ermittelten Nukleotid- und deduzierten Aminosäuresequenz von $P$. spathula mit dem 3'-Terminus der in der EMBL-Datenbank erhältlichen Sequenz AF006183 dieser Spezies

a, Nukleotidsequenzvergleich; b, Vergleich der deduzierten Aminosäuresequenzen. $\mathrm{PS}=$ Sequenz des $\mathrm{mt}$ Cyt $\mathrm{b}$ von P. spathula (Nukleotidpositionen 532-561); AF006183 = Zugangsnummer der Sequenz von P. spathula in der EMBL-Datenbank; Identische Nukleotide bzw. Aminosäuren sind durch Punkte dargestellt; Aminosäuren sind im Ein-Buchstaben-Code angegeben; Der Stern symbolisiert ein Stop-Codon 
Entweder wurden von dieser Arbeitsgruppe nukleäre Pseudogene des Cytochrom b sequenziert (siehe z.B. COLLURA et al. 1996), oder die Sequenzierung wurde bei geringer Qualität der Template-DNA nur für den Plus-Strang vorgenommen. Da die partiellen Sequenzen mit maximal 247 Basen recht kurz sind, hätte die alleinige Sequenzierung des Plus-Stranges bei einer guten Qualität der Template-DNA nicht zu diesen Ergebnissen führen dürfen.

\subsection{Die Zytogenetik der Acipenseriformes}

An den ausgewerteten biochemischen Markern wiesen die Spezies A. ruthenus, A. stellatus und H. huso - diese drei Arten besitzen 120 Chromosomen - maximal zwei Banden auf. Diese Beobachtungen deuteten auf einen diploiden Status dieser Spezies hin, der von FONTANA (1994) und FONTANA et al. (1998a) für diese Arten postuliert wurde. In anderen Studien konnten dagegen duplizierte proteincodierende Loci bei acipenseriformen Spezies aus der 120 chromosomalen Gruppe detektiert werden, was für einen tetraploiden Status dieser Arten sprechen würde (Übersicht bei BIRSTEIN et al. 1997a). Im Rahmen dieser Arbeit stellte sich heraus, daß nur die PGM duplizierte Loci aufwies. Bei Salmoniden und Catostomiden, die einen tetraploiden Ursprung besitzen, konnte gezeigt werden, dass Spezies beider Familien annähernd die Hälfte ihrer ursprünglichen duplizierten Genexpression verloren (gene silencing) haben (FERRIS \& WhitT 1978, StONEKING et al. 1981). Auf der anderen Seite konnten bei den Spezies A. baerii und $A$. gueldenstaedtii, die 240 Chromosomen aufweisen, maximal vier Banden an den untersuchten biochemischen Markern detektiert werden. Unter der Annahme eines octaploiden Status der beiden Arten (BIRSTEIN et al 1997a) müsste dann auch hier das gene silencing eingetreten sein. Andernfalls sind sie funktionell tetraploid, was FONTANA (1994) und FONTANA et al. (1996) annehmen.

In vitro amplifizierte, polymorphe genomische Marker gestatten eine direkte, wenn auch nur partielle, Betrachtung des Genoms. Die auswertbaren Mikrosatelliten-Loci wiesen maximal zwei Allele bei den Individuen der Spezies A. ruthenus, A. stellatus und H. huso auf. Bei den Arten A. baerii und A. gueldenstaedtii ließen die individuellen Elektropherogramme einen tetraploiden Status an den betrachteten Mikrosatelliten-Loci 
erkennen. LS-68 hingegen deutete bei diesen beiden Spezies an, ein octaploider Locus zu sein.

Die hier untersuchten Mikrosatelliten-Loci wurden an der Spezies A. fulvescens charakterisiert (MAY et al. 1997). In einer Studie zeigte keiner dieser elf MikrosatellitenLoci bei A. fulvescens, die 240 Chromosomen besitzt, einen octaploiden Vererbungsgang (PyATSKOwIT et al. 1997). Zwei Loci wiesen sogar eine diploide Vererbung auf. Sechs Mikrosatelliten-Loci (GenBank accession numbers: AF067808-AF067813) sind für die Spezies A. oxyrinchus beschrieben, die 120 Chromosomen besitzt. Von diesen wiesen fünf einen diploiden, der sechste einen tetraploiden Erbgang auf (T. King, pers. Mitteilung).

Die hier erhaltenen Ergebnisse lassen sich mit den Beobachtungen anderer Arbeitsgruppen wie folgt zu einer Hypothese über die evolutionäre Zytogenetik der Acipenseriformes zusammenfassen. Der Urahne der Acipenseriformes enstand durch einen Tetraploidisierungsprozess und wies einen Chromosomensatz von $4 \mathrm{n} \approx 120$ auf (BIRSTEIN et al. 1997a). Vor der Diversifikation fand die Wiederherstellung des funktionell diploiden Zustandes in diesem Vorfahren statt (FonTANA 1994). Das Genom der Säuger durchlief während der Evolution einen ähnlichen Prozess und kann im Hinblick auf den Gehalt an genetischem Material und Genkopien als polyploid, funktionell jedoch als diploid bezeichnet werden (LEIPOLDT 1983). Weitere Ploidisierungsereignisse traten in der Phylogenese der Acipenseriformes erst bei der Diversifizierung innerhalb des Genus Acipenser auf (BIRSTEIN et al. 1997a, BIRSTEIN \& DESALLE 1998). Diese Gattung weist neben Arten mit 120 Chromosomen mehrere Spezies auf, die 240 Chromosomen besitzen (Übersicht bei BIRSTEIN et al. 1997a). Die in dieser Arbeit erhaltenen Ergebnisse legen nahe, dass A. ruthenus, A. stellatus und H. huso funktionell diploid sind. A. baerii und A. gueldenstaedtii scheinen daher funktionell tetraploid zu sein.

\subsection{Molekulare Phylogenese der Acipenseriformes}

Innerhalb der Ordnung der Acipenseriformes wurde die Divergenz der beiden Familien Polyodontidae und Acipenseridae in unterschiedlichen Studien bestätigt, wohingegen die Diskussion hinsichtlich der verwandtschaftlichen Beziehungen innerhalb der Acipenseridae 
kontrovers war (GRANDE \& BEMIS 1991, MAYDEN \& KUHAJDA 1996, BEMIS et al. 1997a, Findeis 1997, BIRSTEIN et al. 1997a, BIRSTEIN \& DESALLE 1998).

In dieser Arbeit wurden phylogenetische Stammbäume präsentiert, die auf zwei unterschiedlichen molekularbiologischen Methoden basieren. Während die im AFLP generierten Fragmente nukleär-genomischer Herkunft sind, wurden die Sequenzinformationen vom mitochondrialen Cytochrom b gewonnen.

\subsubsection{Dendrogramme auf der Basis der AFLP-Daten}

Es konnte keine Literaturquelle gefunden werden, die eine Rekonstruktion phylogenetischer Stammbäume auf der Basis der im AFLP generierten Fragmente für höhere Organismen mit unterschiedlichen Ploidiestati beschrieb. Daher wurde in dieser Arbeit die von WEIR (1990) für dominante Marker entwickelte Formel verwendet. DNA-Fragmente von unterschiedlicher Größe werden als separate Loci betrachtet. Mit der Gleichung kann innerhalb der betrachteten Spezies an jedem Locus (x) die Frequenz des rezessiven Allels $\left(\mathrm{q}_{\mathrm{x}}\right)$ aus der Anzahl Individuen mit nicht vorhandenem Fragment $(\mathrm{Q})$ berechnet werden. Um den unterschiedlichen Ploidiestatus der untersuchten Spezies berücksichtigen zu können, wurde die Formel entsprechend erweitert (siehe Kap. 3.2.6.2). Im Kapitel 5.2 wurden Arten mit 120 Chromosomen als funktionell diploid und solche mit 240 Chromosomen als funktionell tetraploid angesehen. Aufgrund des Gehaltes an genetischem Material können die Arten als tetra- bzw. octaploid betrachtet werden. Daher wurden zwei Datensätze aufgebaut, die auf den unterschiedlichen Annahmen hinsichtlich der Ploidielevel acipenseriformer Spezies basierten.

Verschiedene genetische Distanzmaße, die auf der Verwendung von Allelfrequenzen beruhen, sind in der Literatur beschrieben. In einer Simulationsstudie wurde die Überlegenheit des genetischen Distanzmaßes $\mathrm{D}_{\mathrm{A}}$ gegenüber anderen Distanzmaßen hinsichtlich der erzielten Stammbaum-Topologie und der linearen Beziehung zur Evolutionszeit gezeigt (TAKEZAKI \& NEI 1996). Aus diesem Grund wurde das Programm DISPAN (OTA 1993) verwendet, das phylogenetische Stammbäume auf der Basis dieses Distanzmaßes generiert. Die berechneten $\mathrm{D}_{\mathrm{A}}$-Distanzen zwischen den fünf Spezies (siehe 
Tab. 22, Kap. 4.2.5.2) waren dabei gering. Begründen lässt sich dieses durch eine zwischen den Spezies beobachtete hohe Anzahl an gemeinsamen Loci, die sehr ähnliche Allelfrequenzen aufwiesen. Unabhängig von der verwendeten Methode (UPGMA, Neighbor Joining) und der angenommenen Ploidielevel der Spezies besaßen die erstellten Stammbäume dieselbe Topologie. A. stellatus wies dabei eine basale Stellung zu den anderen vier Spezies auf. H. huso hingegen wurde innerhalb der Acipenser plaziert. Diese Beobachtung bestätigt die von BIRSTEIN \& DESALlE (1998) aufgestellte Hypothese, dass das Genus Huso keine separate taxonomische Einheit ist. In der klassischen Systematik ist H. huso dagegen in einem separaten Schwestergenus zu den Acipenser vorzufinden (FIEDLER 1991, MAYDEN \& KUHAJDA 1996). A. baerii und A. gueldenstaedtii divergierten von den untersuchten Spezies aus einem gemeinsamen Ahnen, während die beiden Spezies in der bei BIRSTEIN \& DESALLE (1998) präsentierten molekularen Phylogenie der Acipenseriformes entfernter verwandt sind.

In Abhängigkeit von dem angenommenen Ploidiestatus der einzelnen Spezies ( $z=2$ oder 4 bzw. $z=4$ oder 8) wiesen die generierten Stammbäume nach dem Bootstrap-Test in ihrer Topologie eine unterschiedliche Robustheit auf. Die Plazierung von H. huso unter den Acipenser wurde unter der Annahme, dass diese Spezies funktionell diploid ist, in dem UPGMA- sowie dem Neighbor Joining-Dendrogramm nur durch moderate Bootstrap-Werte bestätigt. Hohe Bootstrap-Werte wurden dagegen für die Stellung von $H$. huso unter der Annahme gefunden, dass diese Spezies tetraploid sei. Verschiedene Ursachen können hierfür verantwortlich sein.

Es zeigte sich, dass die an einem Locus berechnete Frequenz des rezessiven Allels in hohem Maße vom Ploidiestatus abhing. Des Weiteren könnte mit steigendem Ploidiestatus ein zunehmender Fehler in der Berechnung der Allelfrequenzen auftreten, wie aus Tabelle 26 hervorgeht. 
Tab. 26 Auswirkungen des Ploidiestatus und der Anzahl an beobachteten rezessiven Genotypen $(\mathrm{Q})^{*}$ von zehn untersuchten Individuen auf die Berechnung der rezessiven Allelfrequenz (q) an einem Locus (x)

\begin{tabular}{|c|c|c|c|c|c|c|c|c|c|c|c|}
\hline \multirow{2}{*}{$\begin{array}{l}\text { Ploidie- } \\
\text { status (z) }\end{array}$} & \multicolumn{11}{|c|}{$\mathrm{Q}$} \\
\hline & 0 & 1 & 2 & 3 & 4 & 5 & 6 & 7 & 8 & 9 & 10 \\
\hline 2 & 0,00 & 0,32 & 0,45 & 0,55 & 0,63 & 0,71 & 0,78 & 0,84 & 0,89 & 0,95 & 1,00 \\
\hline 4 & 0,00 & 0,56 & 0,67 & 0,74 & 0,80 & 0,84 & 0,88 & 0,92 & 0,95 & 0,97 & 1,00 \\
\hline 8 & 0,00 & 0,75 & 0,82 & 0,86 & 0,89 & 0,92 & 0,94 & 0,96 & 0,97 & 0,99 & 1,00 \\
\hline
\end{tabular}

*Individuen, bei denen das Fragment an dem betrachteten Locus nicht vorhanden ist

Einen weiteren Einfluss kann das Bootstrap-Verfahren selbst besitzen. In jeder der 10.000 Replikationen wurde ein neuer Datensatz erstellt, indem zufällig eine gewisse Anzahl an Loci samt deren berechneten Frequenzen entfernt und durch Duplikation anderer Loci ersetzt wurde (FELSENSTEIN 1985). Da insgesamt über die fünf betrachteten Spezies 297 Loci detektiert wurden und die Hälfte der Chromosomen der Störe Mikrochromosomen sind, können Kopplungen zwischen Loci nicht ausgeschlossen werden. Eventuelle Kopplungen werden aber im Bootstrap-Test nicht berïcksichtigt.

Beim Auftreten von Kopplungen wäre allerdings die Grundvoraussetzung für phylogenetische Studien auf der Basis dominanter Marker, nämlich dass innerhalb und zwischen den Loci das Hardy-Weinberg Gleichgewicht vorliegt, nicht erfüllt CLARK \& LANIGAN 1993).

Eine weitere Möglichkeit, phylogenetische Stammbäume auf der Basis dominanter Marker zu rekonstruieren, ist die Verwendung des Ähnlichkeitsindexes (siehe Kap. 3.2.6.2). COMINCINI et al. (1998) stellten mit dem Ähnlichkeitsindex unter Verwendung von RAPD-Daten die verwandtschaftlichen Beziehungen zwischen sechs Störarten dar. Erhebliche Unterschiede zu dem bei BIRSTEIN \& DESALLE (1998) präsentierten Stammbaum, der auf Sequenzinformationen beruhte, lassen jedoch Zweifel an dieser 
Methode aufkommen. Die Eignung von RAPD-Markern für phylogenetische Analysen wurde zudem in der Literatur kontrovers diskutiert (BOROWSKY et al. 1995, VAN DE ZANDE \& BIJLSMA 1995, MELO et al. 1998).

Da die durchschnittlichen paarweisen Ähnlichkeitsindices besonders von Individuen innerhalb der Arten A. baerii und A. gueldenstaedtii gering waren und hohe Standardabweichungen aufwiesen (siehe Tab. 21, Kap. 4.2.5.1), wurde kein phylogenetischer Stammbaum anhand dieser Daten erstellt.

Können die hier dargestellten Probleme hinsichtlich einer einheitlichen Fragmenterkennung und -auswertung gelöst werden ist anzunehmen, dass eine AFLP-basierende Rekonstruktion phylogenetischer Stammbäume dem RAPD-Verfahren überlegen ist. Eine Anwendung des AFLP zeigte z.B. bei Bakterien ein hohes evolutionäres Auflösungsvermögen sowohl zwischen verschiedenen Spezies des Genus Bacillus als auch zwischen verschiedenen Stämmen innerhalb B. anthracis (KEIM et al. 1997). Aufgrund stringenter Reaktionsbedingungen weist die AFLP-Technik zudem eine hohe intraindividuelle Wiederholbarkeit in dem generierten Fragmentmuster auf (AJMONEMARSAN et al. 1997, LIU et al. 1998). Durch die Verwendung von Sequenzierautomaten ist außerdem eine exakte Bestimmung der einzelnen Fragmentlängen möglich.

\subsubsection{Dendrogramme auf der Basis der Sequenzinformationen des mt Cyt b}

Generell hängt die Genauigkeit in der Rekonstruktion phylogenetischer Stammbäume vor allem von der betrachteten Nukleotid- und Aminosäureanzahl ab (RUSSO et al. 1996). Von den proteincodierenden mitochondrialen Genen hat sich die Verwendung der Aminosäuresequenz des vollständigen $\mathrm{mt}$ Cyt $\mathrm{b}$ als sehr zuverlässig in der molekularen Phylogenie erwiesen (RUSSO et al. 1996). Im Rahmen dieser Arbeit wurde das vollständige $\mathrm{mt}$ Cyt $\mathrm{b}$ von Individuen der Spezies A. baerii, A. gueldenstaedtii, A. naccarii, A. persicus, A. ruthenus, A. stellatus, $H$. huso und $P$. spathula sequenziert. Darüber hinaus wurden die in den Gendatenbanken (GenBank, EMBL) verfügbaren 
Sequenzen von A. transmontanus, S. albus, S. platorhynchus und S. suttkusi in die phylogenetischen Analysen einbezogen.

Der auf der Basis der Aminosäuresequenzen rekonstruierte phylogenetische Stammbaum (Abb. 29, Kap. 4.2.6.3) konnte nach dem Bootstrap-Test nur die Divergenz zwischen P. spathula und den Spezies aus der Familie der Acipenseridae absichern. Unter Einbeziehung der mt Cyt b - Sequenzen von Polypterus ornatipinnis und Salmo salar als Außengruppen wurde diese Divergenz mit einem Bootstrap-Wert von $93 \%$ bestätigt. Obwohl das vollständige mt Cyt b von P. gladius (Familie: Polyodontidae) und den drei Arten aus dem Genus Pseudoscaphirhynchus (Unterfamilie: Scaphirhynchinae) nicht bekannt ist, deutete der phylogenetische Stammbaum die Separierung der Familien Polyodontidae und Acipenseridae an. Innerhalb der Acipenseridae zeigte sich, dass sich das Genus Scaphirhynchus in der stammesgeschichtlichen Entwicklung mit einer hohen Wahrscheinlichkeit von der Unterfamilie Acipenserinae separierte. Diese Beobachtung widerlegt die aufgrund osteologischer Untersuchungen von BEMIS et al. (1997a) und FINDEIS (1997) getroffene Annahme, dass die Gattung Scaphyrhinchus der Unterfamilie Acipenserinae zuzuordnen ist. Somit besitzt die bestehende Systematik weiterhin die Gültigkeit, dass die Familie Acipenseridae die beiden Unterfamilien Acipenserinae und Scaphirhynchinae enthält (FIEDLER 1991, MAYDEN \& KUHAJDA 1996).

Die phylogenetischen Verwandtschaften innerhalb der Acipenserinae konnten demgegenüber in der molekularen Phylogenie in Abbildung 29 aufgrund sehr geringer Bootstrap-Werte nicht abgesichert werden. Begründet wird dies durch die geringe Anzahl an Aminosäuresubstitutionen zwischen den einzelnen Spezies, welche zu niedrigen Distanzwerten führten. BIRSTEIN et al. (1997a) stellten in ihrer Untersuchung eine geringe Variabilität der Acipenseriformes in partiellen Fragmenten der mitochondrialen 12S rDNA, 16S rDNA und mt Cyt b sowie der nukleären 18S rDNA fest. Ihre Annahme, dass sich ein längerer Abschnitt des $m t$ Cyt b für eine Untersuchung der verwandtschaftlichen Beziehungen innerhalb der Acipenserinae eignen könnte, hat die vorliegende Arbeit nicht bestätigt. Ein begrenztes phylogenetisches Auflösungsvermögen des mt Cyt b wurde bereits in verschiedenen Studien beobachtet (AvISE et al. 1994, NUNN \& CRACRAFT 1996). 
Gemessen an der langen evolutionären Entwicklungsgeschichte der Acipenseriformes könnte die hier beobachtete relativ geringe Sequenzdivergenz zwischen verschiedenen Störarten durch zwei unterschiedliche Faktoren bedingt sein. Zum einen konnte bei verschiedenen Fischen in proteincodierenden mitochondrialen Genen eine drei- bis achtfach langsamere Nukleotidsubstitutionsrate als bei Säugern festgestellt werden (MARTIN et al. 1992, MARTIN \& PALUMBi 1993, CANTATORE et al. 1994). Diese bedingt eine geringere Anzahl an Aminosäuresubstitutionen und könnte zumindest zum Teil für die geringen mt Cyt b-Unterschiede zwischen den Spezies verantwortlich sein. Zum anderen kann ein geringes phylogenetisches Auflösungsvermögen auftreten, wenn Arten in einem unter evolutionären Aspekten engen Zeitraum divergierten (AVISE et al. 1994, NUNN \& CRACRAFT 1996). So mutmaßten CHOUDHURY \& DicK (1998), dass die Arten der Acipenserinae in einem engen zeitlichen Rahmen divergierten.

Die Acipenseriformes konnten trotz zum Teil erheblicher morphologischer Unterschiede als engverwandte Spezies auf der Grundlage der mt Cyt b-Sequenzen betrachtet werden. Daher wurde ein zweiter phylogenetischer Stammbaum auf der Basis stiller Nukleotidsubstitutionen erstellt (Abb. 30, Kap. 4.2.6.3). Der rekonstruierte phylogenetische Stammbaum wies ein höheres Auflösungsvermögen auf, als das auf den Aminosäuresequenzen beruhende Dendrogramm. Der wesentliche Unterschied zu dem in Abb. 29 präsentierten Dendrogramm lag in der Plazierung von H. huso. Diese Spezies wies keine basale Position zum Genus Acipenser auf, sondern wurde unter den Acipenser plaziert. Diese Stellung wurde durch einen hohen Bootstrap-Wert charakterisiert. In den molekularen Phylogenien von BIRSTEIN et al. (1997a) und BIRSTEIN \& DESALLE (1998) wurde H. huso ebenfalls unter den Spezies der Gattung Acipenser gruppiert. Sollte sich diese Beobachtung auch in weiteren Untersuchungen, bei der möglichst die Schwesterspezies $H$. dauricus mit einbezogen werden sollte, bestätigen, muss die bislang angenommene evolutionäre Entwicklung innerhalb der Unterfamilie Acipenseridae angezweifelt werden. Dies hätte zur Folge, dass die Familie Acipenser entweder nicht als monophyletisches Taxon angesehen werden dürfte oder die momentan gültige Systematik abgeändert werden müsste. Die Unterfamilie Acipenserinae enthielte bei einer Umstrukturierung der Systematik nur noch die Familie Acipenser, in der beide Huso-Arten enthalten wären. H. huso müsste dann in Acipenser huso umbenannt werden, da 
LinNeAus (1758, zit. n. PIROGOVSKII et al. 1989) diesen synonymen Artnamen in der Systema Naturae in der Literatur zuerst erwähnte.

Aufgrund geringer Bootstrap-Werte an den Abzweigungen zwischen H. huso, A. stellatus und A. ruthenus könnte vermutet werden, dass diese drei Eurasischen Störarten in einem engen Zeitraum divergierten. Allerdings besitzen auch der Metabolismus, die Körpergröße, das Generationsintervall, das Alter bei der ersten Reproduktion, die Lebensdauer und Populationsgröße einen Einfluss auf die Nukleotidsubstitutionsraten von Genen innerhalb und über verschiedene Taxa (SCHLÖTTERER et al. 1991, MARTIN \& PALUMBI 1993). Da sich H. huso in der Reproduktionsbiologie, Körpergröße und Lebensdauer wesentlich von den anderen beiden Spezies unterscheidet (Übersichten bei HOLCí́ 1989, HoCHLEITHNER 1996), könnte die Distanz zu beiden anderen Arten unterschätzt sein. Die Abgrenzung von H. huso zu A. transmontanus wird demgegenüber nicht (wesentlich) überschätzt, da beide Spezies ähnliche biologische Parameter aufweisen (Übersicht bei HOCHLEITHNER 1996).

Wie schon bereits erwähnt, ließen sich die Arten des Genus Scaphirhynchus anhand biochemischer und molekulargenetischer Marker nicht unterscheiden. Diese Feststellungen spiegelte sich auch in den rekonstruierten Stammbäumen wider.

Abgesehen von dem bei A. gueldenstaedtii beobachteten Haplotyp 4 (A. g. 4) ließ der Cluster bestehend aus den Individuen der Arten A. gueldenstadtii, A. naccarii und A. persicus keine einheitliche Divergenz der Spezies erkennen.

Um die molekulare Phylogenese der Acipenseriformes und insbesondere die verwandtschaftlichen Beziehungen innerhalb der Acipenserinae eingehender betrachten zu können, sind weiterführende Untersuchungen notwendig. Da das mitochondriale Genom schneller als das nukleäre evolviert (BROWN et al. 1982), bietet es sich für phylogenetische Studien an. Die bislang untersuchten mitochondrialen Gene 12S rDNA, 16S rDNA und mt Cyt b (BIRSTEIN et al. 1997a, BIRSTEIN \& DeSAlle 1998, diese Arbeit) besaßen allerdings ein nur begrenztes phylogenetisches Auflösungsvermögen. Diese Beobachtung traf vor allem auf die verwandtschaftlichen Verhältnisse der Arten innerhalb des Genus Acipenser zu. Aus diesem Grund sollten schneller evolvierende mitochondriale Gene für phylogenetische Studien an Stören verwendet werden. Von den proteincodierenen 
mitochondrialen Genen bietet sich z.B. die zweite Untereinheit der Nikotinamid-adenindinukleotid-dehydrogenase (ND2) oder die sechste und achte Untereinheit der Adenosintriphosphatase (ATP6, ATP8) an (MEYER 1993). Bestimmte Bereiche in der Kontrollregion stellten sich für phylogenetische Studien an Finken als geeignet heraus (MARSHALl \& BAKER 1997, 1998). Zwischen Störarten ist die Evolutionsrate in der Kontrollregion im Vergleich $\mathrm{zu}$ der in dem gesamten mitochondrialen Genom allerdings unterschiedlich. Bei A. fulvescens konnte keine erhöhte Nukleotidsubstitutionsrate in der D-loop festgestellt werden (FERGUSON et al. 1993). Dagegen evolvierte bei A. transmontanus dieser Bereich vier- bis fünfmal schneller, als die gesamte mitochondriale DNA (BROWN et al. 1993).

\subsection{Schlussbetrachtung und Ausblick für die Entwicklung von artcharakteristischen Markern bei Acipenseriformes}

Idealerweise sollten Marker das Potential besitzen, sowohl Individuen als auch Störprodukte (Kaviar, Störfleisch) hinsichtlich der Artherkunft und -reinheit sicher identifizieren zu können. Molekularbiologische Marker sind hierfür das Mittel der Wahl, da sie bei jedem Probenmaterial, das DNA enthält, verwendet werden können. Zudem ist der benötigte Probenumfang bei PCR-gestützten Methoden minimal. Diese beiden Vorzüge gestatten eine schonende Probennahme am lebenden Tier.

Aufgrund der Problematik natürlich vorkommender sowie künstlich erstellter Arthybriden ist eine Identifizierung allein auf der Basis mitochondrialer DNA nicht ausreichend. So würde z.B. Kaviar vom fertilen Hybrid "Bester" (H. huso x A. ruthenus) unter Verwendung eines mitochondrialen DNA-Markers als Beluga-Kaviar (H. huso) diagnostiziert werden. Diese Marker eignen sich auf der anderen Seite wegen ihres Vererbungsgangs hervorragend für eine Überprüfung der maternalen Artabstammung. Theoretisch sind Rückkreuzungen fertiler Hybriden mit einer der Elternarten möglich. Hier stellt sich dann allerdings die Frage, wie viele über das Genom verstreute Marker für die Erkennung solcher Individuen nötig wären. Unter praktischen Gesichtspunkten reichen allerdings wenige genomische DNA-Marker für eine Spezieserkennung aus. Für eine 
Untersuchung von Störindividuen und -produkten ist eine Kombination mitochondrialer und genomischer DNA-Marker daher empfehlenswert.

Um eine korrekte Charakterisierung von Störindividuen und -produkten vornehmen zu können, müssten gerade aufgrund des internationalen Handels mit Kaviar für alle Spezies DNA-Marker zur Verfügung stehen. Aufgrund der weltweiten Verbreitung der Acipenseriformes stellt sich hier das Problem der Beschaffung von Probenmaterial der verschiedenen Spezies. Streng genommen müssten sogar Individuen verschiedener Populationen für die Entwicklung von artspezifischen Markern untersucht werden, da aufgrund der vorhandenen genetischen Variabilität innerhalb und zwischen Populationen bei zu geringer Stichprobengröße Fehlinterpretationen möglich sind (DAVIS \& NIXON 1992). Obwohl Störe teilweise in der Literatur als "lebende Fossile" bezeichnet werden, scheint die genetische Divergenz zwischen Arten nur gering ausgeprägt zu sein (KEDROVA et al. 1980, STOCK et al. 1991, MikHAILOVA et al. 1995, BIRSTEIN et al. 1997a). Dies gilt besonders für die Spezies A. baerii, A. dabryanus, A. gueldenstaedtii, A. naccarii, A. nudiventris und A. persicus (BIRSTEIN et al. 1998b). Diese Beobachtung wurde durch den Vergleich der Nukleotidsequenzen des vollständigen mt Cyt b der Arten A. baerii, A. gueldenstaedtii, A. naccarii und A. persicus in der vorliegenden Arbeit bestätigt (siehe Tab. A-1, Anhang). Die genetische Ähnlichkeit - besonders bei engverwandten Spezies stellt ein weiteres Hindernis für die Charakterisierung von artspezifischen DNA-Markern dar. Es bleibt zu überprüfen, welches Potential schnell evolvierende Bereiche im mitochondrialen und nukleären Genom hinsichtlich einer Artcharakterisierung besitzen.

KEDROVA et al. (1980) zeigten anhand molekularer Hybridisierungsstudien, dass zwischen den Spezies A. gueldenstaedtii, A. ruthenus, A. stellatus und $H$. huso nur sehr geringe Nukleotidsubstitutionsraten sowohl in codierenden (1,5-2,7 \%) als auch in repetitiven Sequenzen (0-2,6 \%) zu finden waren. Diese Arbeitsgruppe sah in der hohen Ähnlichkeit des Genoms der verschiedenen Spezies die genetische Basis für das Auftreten von lebensfähigen und fertilen Hybriden begründet. Auf der anderen Seite ist bekannt, dass einzelne nukleäre Gene unterschiedlich schnell evolvieren. In einer Studie stellten SCHMID \& TAuTZ (1997) fest, dass über ein Drittel der von der Fruchtfliegenspezies Drosophila melanogaster verwendeten cDNAs nicht mit der DNA von D. virilis kreuzhybridisierten. Die nähere Analyse von einer dieser Sequenzen ergab allerdings, dass ein extrem hoher 
Grad an deduzierten Aminosäurepolymorphismen innerhalb der Spezies auftritt. Inwiefern sich diese Methode für die Entwicklung von charakteristischen Markern für die einzelnen Störspezies eignet, kann nicht abgeschätzt werden. Andere mögliche Vorgehensweisen, artcharakterische nukleäre DNA-Marker acipenseriformer Spezies zu entwickeln, könnten z.B. auf den im Rahmen dieser Arbeit dargestellten Techniken AFLP, Inter-SSR PCR, RAPD oder SINE-PCR aufgebaut werden. Fragmente, die charakteristisch für eine Spezies sind, könnten isoliert und in Kreuzhybridisierungsstudien verwendet werden. Auf diese Weise wurden bereits speziesspezifische Sonden für Mikroorganismen entwickelt (DOBROWOLSKI \& O’BRIEN 1993, FANI et al. 1993). Nach einer Sequenzierung solcher Fragmente ist es möglich, ein Primerpaar $\mathrm{zu}$ entwickeln, mit dem eine spezifische Amplifikation dieses Fragmentes erreicht werden kann (MONNA et al. 1994, TILsALATimisjarVi \& AlATOSSAVA 1998, OLIVIER et al. 1999). Tritt hingegen ein Fragment konstant über viele Spezies hinweg auf, so kann es auf artspezifisch unterschiedlich konservierte Nukleotidsubstitutionen untersucht werden. Artunterschiedlich konservierte Nukleotidsubstitutionen in den flankierenden Bereichen von Mikrosatelliten-Motiven könnten ebenfalls für die Entwicklung artspezifischer Primerpaare Verwendung finden.

Zusammenfassend lässt sich festhalten, dass speziesspezifische DNA-Marker im Idealfall auf artunterschiedlich konservierten Nukleotidunterschieden aufbauen und in PCRgestützten Verfahren eine einfache, zweifelsfreie, schnelle und kostengünstige Diagnose von Störindividuen und -produkten gestatten. Eine Kombination artspezifischer mitochondrialer und nukleärer DNA-Marker erscheint dabei gerade für die Erkennung von Hybriden sinnvoll. 


\section{$6 \quad$ Zusammenfassung}

Eine zweifelsfreie Identifizierung von Individuen der Ordnung Acipenseriformes ist eine notwendige Voraussetzung für eine artreine Störzucht in aquakulturellen Anlagen. Die hier erzeugte Nachkommenschaft findet Verwendung in der Stützung von natürlichen und bedrohten Populationen, in der Wiedereinbürgerung in vor der Ausrottung genutzten Habitaten und in der Aquakultur selbst für eine Kaviar- und Fleischproduktion. Im Rahmen dieser Arbeit wurde daher untersucht, welches Potential verschiedene biochemische und molekulargenetische Marker besitzen, die Artherkunft von Störindividuen determinieren zu können. Für die Untersuchungen stand eine Vielzahl von Tieren der Eurasischen Arten Acipenser baerii, A. gueldenstaedtii, A. ruthenus, A. stellatus und Huso huso sowie Individuen von den vier Arthybriden A. baerii x A. ruthenus, H. huso x A. gueldenstaedtii, H. huso x A. ruthenus und (H. huso x A. ruthenus) x A. gueldenstaedtii in Form von Blutproben zur Verfügung. Des Weiteren lag Probenmaterial von je zwei Exemplaren der Spezies A. naccarii und Polyodon spathula sowie von vier Tieren der Art A. persicus für die Studie vor. Neben den hier aufgeführten Arten kommen in der Ordnung Acipenseriformes nach heutigem Kenntisstand weltweit 19 weitere Spezies vor. Jede der insgesamt 27 Störarten untergliedert sich zudem in mehrere Populationen, so dass die hier getroffenen Aussagen für bestimmte Marker hinsichtlich ihrer Speziesspezifität streng genommen nur für die untersuchten Tiere zulässig sind.

Obwohl die in dieser Studie verwendeten Methoden auf die Identifizierung von Individuen verschiedener Störarten und deren Hybriden ausgerichtet waren, ist die Übertragbarkeit der angewandten Verfahren auf unterschiedliches Probenmaterial, wie z.B. Kaviar, ebenfalls zu bedenken. So waren in der Literatur in jüngster Zeit vermehrt Hinweise darauf zu finden, dass Verbraucher, Handel und Zoll durch eine Falschdeklaration von Kaviarchargen getäuscht werden.

Von den im Blut vorkommenden, verschiedenen biochemischen Systemen wurden insgesamt 13 im Rahmen dieser Arbeit bei den Spezies A. baerii, A. gueldenstaedtii, A. ruthenus, A. stellatus und $H$. huso untersucht. Von diesen ließen sich nur die Allozymsysteme Adenylatkinase (AK), Esterase-D (EST-D), Glucosephosphatisomerase (GPI) sowie die Phosphoglucomutase (PGM) und die im Blutplasma vorhandenen 
Albumine (ALB) visuell darstellen. Trotz Variation der Methoden konnten bei den Systemen Adenosindeaminase (ADA), Alkalische Phosphatase (AKP), Carboanhydrase (CA), Diaphorase (DIA), $\quad \alpha$-Glycerophosphatdehydrogenase $\quad(\alpha$-GPDH), Laktatdehydrogenase (LDH), Transferrine (TF) und 6-Phosphogluconat-Dehydrogenase (6PGD) keine Banden detektiert werden. Daher konnten diese Systeme nicht mit in die Auswertung einbezogen werden. Lediglich die PGM-1 war innerhalb der untersuchten Individuen der in dieser Arbeit betrachteten Störarten für A. stellatus spezifisch. Diese Spezies war für das Allel c fixiert, welches bei den übrigen vier Arten nicht beobachtet werden konnte. Allerdings besitzen biochemische Marker generell den wesentlichen Nachteil, dass sie - bezogen auf das verwendbare Probenmaterial - eine beschränkte Anwendbarkeit aufweisen. Die Ergebnisse der hier untersuchten Systeme gelten lediglich für biochemische Marker im Blut und können auf keine andere Gewebeart übertragen werden.

Molekularbiologische Marker besitzen gegenüber biochemischen Systemen den Vorteil, dass sie unabhängig von der Gewebeart für eine Untersuchung an Störindividuen und -produkten verwendet werden können.

Im Rahmen dieser Arbeit wurden die Verfahren Mikrosatelliten-Analyse, AFLP, Inter-SSR PCR, RAPD, SINE-PCR angewendet sowie das mitochondriale Cytochrom b untersucht.

Von insgesamt neun untersuchten Mikrosatelliten-Loci war LS-39 für A. stellatus spezifisch. Bei sämtlichen Individuen dieser Spezies trat ein fixiertes Allel von 111 bp auf, welches bei den anderen Spezies nicht beobachtet werden konnte. Dieses Allel wurde ebenfalls im Sevruga-Kaviar, der von A. stellatus gewonnen wird, festgestellt. Die übrigen acht Mikrosatelliten-Loci LS-19, LS-34, LS-54, LS-57, LS-58, LS-62, LS-68 und LS-69 waren dagegen nicht für eine Artidentifizierung geeignet.

Die Verfahren AFLP, Inter-SSR PCR und SINE-PCR erwiesen sich unter den hier durchgeführten Versuchsbedingungen als ungeeignet für eine Identifizierung der fünf untersuchten Störspezies A. baerii, A. gueldenstaedtii, A. ruthenus, A. stellatus und H. huso. 
Dagegen führten zwei von den 40 in der RAPD-PCR getesteten Primern zu artcharakteristischen Bandenmustern bei A. baerii, A. ruthenus, A. stellatus und H. huso bzw. A. ruthenus, A. stellatus und H. huso. Störhybriden konnten jedoch mit diesem Verfahren weder unterschieden noch den Ausgangselternarten zugeordnet werden.

Das vollständige mitochondriale Cytochrom b wurde von ein bis vier Individuen der zur Verfügung stehenden acht verschiedenen Spezies sequenziert. Zusätzlich wurden die in den Sequenzdatenbanken erhältlichen Nukleotidsequenzen der Arten A.transmontanus, Scaphirhynchus albus, S. platorhynchus und S. suttkusi in die Auswertung einbezogen. Auffällige Sequenzunterschiede waren zwischen den Störarten A. ruthenus, A. stellatus, A. transmontanus, H. huso, P. spathula und den Arten des Genus Scaphirhynchus vorhanden. Von jeder Spezies standen allerdings nur Sequenzinformationen von ein bis maximal vier Individuen zur Verfügung, so dass direkte Aussagen zu intraspezifisch konservierten Nukleotidsubstitutionen nicht getroffen werden konnten. Aufgrund des mitochondrialen Vererbungsgangs kann eine Charakterisierung von Individuen wie Störprodukten (Kaviar, Fleisch) streng genommen nur maternal erfolgen. Darüber hinaus stellte sich heraus, dass innerhalb der Spezies A. gueldenstaedtii verschiedene DNAHaplotypen beobachtet wurden, welche z.T. nicht von A. baerii bzw. A. persicus differenziert werden konnten. Inwiefern die bei $A$. naccarii beobachteten Nukleotidaustausche charakteristisch für diese Störart sind, muss an einer größeren Anzahl an Individuen überprüft werden.

Hinsichtlich des Ploidiestatus zeigten die Analysen der biochemischen Marker und der Mikrosatelliten-Loci, dass die Arten A. ruthenus, A. stellatus und $H$. huso funktionell diploid waren. A. baerii und A. gueldenstaedtii besaßen dagegen einen funktionell tetraploiden Status. Somit bestätigte diese Untersuchung die Hypothese, dass Störspezies mit 120 Chromosomen diploid, Arten mit ca. 240 Chromosomen tetraploid sind.

Die phylogenetischen Untersuchungen auf der Basis des mitochondrialen Cytochrom b widerlegten Ansichten, dass das Genus Scaphirhynchus der Unterfamilie Acipenserinae zuzuordnen ist. Vielmehr bestätigten sie die Lehrmeinung, dass dieses Genus einer eigenständigen Unterfamilie, nämlich den Scaphirhynchinae, angehört. Die taxonomische Einordnung von $H$. huso konnte jedoch nicht eindeutig anhand der Sequenzinformationen 
bestimmt werden. Begründet wurde dies durch die geringen Unterschiede in den deduzierten Aminosäuresequenzen zwischen den Spezies der Gattung Acipenser und H. huso. Ein auf der Basis stiller Nukleotidsubstitutionen erstelltes Dendrogramm deutete aber die Plazierung von $H$. huso unter den Acipenser an. Die Aussagefähigkeit der Sequenzinformationen des mitochondrialen Cytochrom $b$ bezüglich verwandtschaftlichen Beziehungen der Arten aus der Gattung Acipenser zueinander war ebenfalls sehr begrenzt.

Die Rekonstruktion phylogenetischer Stammbäume unter Verwendung von AFLPDaten wurde bislang noch nicht für Arten mit unterschiedlichen Ploidiestati vorgenommen. Daher kann die Aussagefähigkeit der im Rahmen dieser Arbeit für die Arten A. baerii, A. gueldenstaedtii, A. ruthenus, A. stellatus und H. huso erstellten Dendrogramme nicht abgeschätzt werden. Festzustellen bleibt aber, dass H. huso auch mit diesem Verfahren unter den Acipenser plaziert wurde.

Die in dieser Arbeit durchgeführten molekularen Phylogenien der Acipenseriformes deuteten Zweifel an der bislang gültigen Systematik dieser Ordnung an. Diese basiert derzeit auf morphologischen Vergleichen und wurde lediglich anhand weniger untersuchter Exemplare erstellt. Der Artstatus der drei Spezies innerhalb des Genus Scaphirhynchus scheint auf der Basis des mitochondrialen Cytochrom b fraglich zu sein. Des Weiteren stellte sich die Frage, ob H. huso - wie bislang angenommen - der Gattung Huso angehört oder nicht dem Genus Acipenser zugeordnet werden sollte.

Die Ergebnisse der vorliegenden Arbeit zeigten, dass für eine Artidentifizierung von Störindividuen und -produkten weitere Marker untersucht werden müssen. Idealerweise basieren sie auf PCR gestützten Verfahren, die eine vom Probenmaterial unabhängige Charakterisierung gestatten. Um Hybriden identifizieren zu können, erscheint zudem die Kombination nukleärer und mitochondrialer Marker sinnvoll. 
A doubtless identification of individuals of the order Acipenseriformes is a neccessary prerequisite in conservation programs. Artificially hatched and reared juveniles have been used to uphold endagered natural stocks, for re-introductions into habitats where sturgeons have been extirpated, as well as in aquaculture for the production of caviar and meat. Therefore, the goal of this thesis was to explore the potential of different biochemical and molecular markers to discriminate different sturgeon species. Blood samples were collected from the Eurasian sturgeons Acipenser baerii $(\mathrm{n}=125)$, A. gueldenstaedtii $(\mathrm{n}=91)$, A. ruthenus $(\mathrm{n}=38)$, A. stellatus $(\mathrm{n}=42)$ and Huso huso $(\mathrm{n}=72)$. Additionally four samples of A. persicus as well as two samples of A. naccarii and Polyodon spathula were available Furthermore, blood samples of the hybrids A. baerii x A. ruthenus, H. huso x A. gueldenstaedtii, H. huso x A. ruthenus and (H. huso x A. ruthenus) x A. gueldenstaedtii have been at disposal. However, beside the species mentioned over 19 additional conspecifics are recognized worldwide. Each of the alltogether 27 Acipenseriformes exhibits different natural populations. Therefore, strictly speaking, the findings of this study only hold true for the specimens analysed here.

Although it was seeked for techniques to identify individuals, i.e. purebred as well as hybrid sturgeons, the possibility concerning the applicability of these techniques on different samples (blood, caviar, meat, etc.) should be considered. For instance in the recent literature it was reported that a mislabelling of highly prized caviar lots could be found on the international market. There is the need to protect consumers, wholesalers and toll against deceits.

Alltogether 13 different biochemical markers occuring in the blood were investigated at A. baerii, A. gueldenstaedtii, A. ruthenus, A. stellatus and $H$. huso. Of these solely the allozyme systems adenylate kinase (AK), esterase-D (EST-D), glucose-phosphate isomerase (GPI) as well as the phosphoglucomutase (PGM) and the blood plasma derived protein fraction albumines (ALB) could be desolved. Of these markers merely the locus PGM-1 was characteristic for stellate sturgeons. Specimens of this species were fixed at allele c not observed in individuals of the other four sturgeon taxa. Despite variations in the 
applied methods no bands at allozymes adenosine deaminase (ADA), alkaline phosphatase (AKP), carbonic anhydrase (CA), diaphorase (DIA), $\alpha$-glycerophosphate dehydrogenase $(\alpha-\mathrm{GPDH})$, lactate dehydrogenase (LDH) and glucose-6-phosphate dehydrogenase (6PGD) as well as the blood plasma protein fraction transferrins (TF) could be visualized. However, in general biochemical markers have the disadvantage of tissue-specifity. Markers established on blood samples did not work in e.g. caviar.

Opposite to this, molecular markers have the advantage to work in all tissues that contain DNA.

Several different molecular methods were investigated in this study, like AFLP, interSSR PCR, RAPD and SINE-PCR. Furthermore, microsatellite loci as well as the mitochondrial cytochrome $b$ gene have been examined.

Nine different microsatellite loci have been analyzed. Only locus LS-39 was identified as diagnostic marker for A. stellatus. All specimens as well as an analyzed caviar lot of this species were fixed at the allele of $111 \mathrm{bp}$. This allele was not observed in other sturgeons investigated. The other eight microsatellite loci - LS-19, LS-34, LS-54, LS-57, LS-58, LS-62, LS-68 and LS-69 - proved to be unsuitable in-species-identification.

With respect to the experimental conditions the techniques AFLP, inter-SSR PCR and SINE-PCR were unable to identify the investigated species A. baerii, A. gueldenstaedtii, A. ruthenus, A. stellatus and $H$. huso.

In contrast to this, two of the 40 primers used for RAPD produced species-specific banding patterns for A. baerii, A. ruthenus, A. stellatus and H. huso or A. ruthenus, A. stellatus and $H$. huso, respectively. On the other hand neither a discrimination of sturgeon hybrids nor the assignment of hybrids to parental species was possible.

The complete mitochondrial cytochrome $\mathrm{b}$ gene has been sequenced for at least one up to four individuals of the eight purebred species mentioned above. Additionally cytochrome b sequences of A. transmontanus, Scaphirhynchus albus, S. platorhynchus and $S$. suttkusi deposited in sequence databases were included in the analyses. Marked sequence differences were observed among the species A. ruthenus, A. stellatus, A. transmontanus, H. huso, P. spathula and the sisterspecies encomprised within the 
genus Scaphirhynchus. Due to the well known occurence of natural variability of nucleotide sequences among specimens within species, statements concerning interspecific conserved nucleotide substitutions could not be drawn. On the one hand different cytochrome b haplotypes were observed within A. gueldenstaedtii of which some were indistingiushable from $A$. baerii and A. persicus. On the other hand two nucleotide substitutions were observed for A. naccarii offering a possibility for a molecular discrimination of this species from the morphologically closely related A. gueldenstaedtii and $A$. persicus. However, the use of these nucleotide substititions as diagnostic features has to be proven at a larger number of specimens. The fact that mitochondrial DNA is inherited maternally has the disadvantage that hybrids could not be identified.

In the literature there was a controversial discussion concerning the ploidy level of Acipensderiformes. The data obtained from biochemical markers and from microsatellite loci led to the conclusion that the species A. ruthenus, A. stellatus and $H$. huso were functionally diploid. A. baerii and A. gueldenstaedtii exhibited a functionally tetraploid genomic status. These findings supported the hypothesis that species with $\approx 120$ chomosomes were diploid whereas species having $\approx 240$ chromosomes were tetraploid.

The reconstruction of phylogenetic trees on the basis of the mitochondrial cytochrome b gene refuted the opinion that the genus Scaphirhynchus is embedded within the subfamily Acipenserinae. The results rather corrobated the opinion that this genus belonged to the separated subfamily Scaphirhynchinae. However, a taxonomic classification of $H$. huso remained elusive which was due to observed small differences concerning the complete deduced amino acid sequences between Acipenser and $\mathrm{H}$. huso. A dendrogram generated on the basis of silent nucleotid substutions indicated the placement of $H$. huso among Acipenser. Focusing on the species of the genus Acipenser the cytochrome $b$ data yielded only limited information of their phylogenetic relationships.

Until now the reconstruction of phylogenetic trees using AFLP data has not been performed simultaneously on species with different ploidy level. Therefore, on the one hand the validity of the obtained dendrograms for A. baerii, A. gueldenstaedtii, A. ruthenus, A. stellatus and H. huso presented in this thesis could not be estimated. On the other hand, again $H$. huso was placed among the Acipenser using this procedure. 
At present the taxonomy is based solely on morphological comparisons performed on few individuals per species. Taking alltogether, the molecular phylogenies presented in this thesis shed new light on the systematics of Acipenseriformes and challenged its validity. On the basis of cytochrome $b$ data the taxanomic status of the three species within the genus Scaphirhynchus seemed to be doubtful. Furthermore the question arose, whether a seperation of $H$. huso into the genus Huso hold true or if this species should be placed into the genus Acipenser.

The results obtained in the presented study set forth that additional markers must be investigated for an identification of sturgeons as well as their products. Ideally these markers should be accomplished via the PCR to enable a doubtless, low-cost and quick characterization of different sample materials. For the identification of hybrids a combination of genomic as well as mitochondrial markers should be considered. 


\section{$8 \quad$ Literaturverzeichnis}

AdKINSON, M.A., B. BASURCO \& R.P. HEDRICK (1996). Humoral immunoglobulins of the white sturgeon Acipenser transmontanus: partial characterization of and recognition with monoclonal antibodies. Dev. Comp. Immunol. 20, 285-298.

Ajmone-Marsan, P., A. Valentini, M. Cassandro, G. Vecchiotti-Antaldi, G. BERTONI \& M. KUIPER (1997). AFLPTM markers for DNA fingerprinting in cattle. Anim. Genet. 28, 418-426.

Anderson, S., A.T. Bankier, B.G. Barrell, M.H. De Bruijn, A.R. Coulson, J. Drouin, I.C. EPERON, D.P. NIERLICH, B.A. ROE, F. SANGER, P.H. SCHREIER, A.J. SMith, R. STADEN \& I.G. YoUNG (1981). Sequence and organization of the human mitochondrial genome. Nature 290, 457-465.

ANDRESEN, E. (1970). Close linkage between the locus for phosphohexose isomerase (PHI) and the H blood group locus in pigs. Anim. Blood Grps. Biochem. Genet. 2, 119-120.

ANONYMUS (1997). California joint venture project will produce sturgeon caviar. Fish Farm. Internat. 24, 6.

ARTYUKHIN, E.N. (1995). On the biogeography and relationships within the genus Acipenser. Sturg. Quart. 3, 6-8.

AVISE, J.C. (1989). A role for molecular genetics in the recognition and conservation of endangered species. Trends Ecol. Evol. 4, 279-281.

AVISE, J.C. (1992). Molecular population structure and the biogeographic history of a regional fauna: a case history with lessons for conservation biology. OIKOS 63, 6276.

AVISE, J.C., W.S. NELSON \& C.G. SiBLEY (1994). DNA sequence support for a close phylogenetic relationship between some stork and New World vultures. Proc. Natl. Acad. Sci. U.S.A. 91, 5173-5177.

BAKER, C.S. \& S.R. PALUMBI (1994). Which whales are hunted? A molecular genetic approach to monitoring whaling. Science 265, 1538-1539.

BAKER, C.S., F. CiPRIANO \& S.R. PALUMBI (1996). Molecular genetic identification of whale and dolphin products from commercial markets in Korea and Japan. Mol. Ecol. 5, 671-685. 
BARANNIKOVA, I.A. (1987). Review of sturgeon farming in the Soviet Union. J. Ichthyol. 27, 62-71.

BARTLETT, S.E. \& W.S. DAVIDSON (1991). Identification of Thunnus tuna species by the polymerase chain reaction and direct sequence analysis of their mitochondrial cytochrome b genes. Can. J. Aquat. Sci 48, 309-317.

BAssam, B.J., G. CAETANO-AnNOLlÉS \& P.M. GRESShOFF (1991): Fast and sensitive silverstaining of DNA in polyacrylamide gels. Anal. Biochem. 196, 80-83.

BEMIS, W.E. \& B. KYNARD (1997). Sturgeon rivers: an introduction to acipenseriform biogeography and life history. Env. Biol. Fish. 48, 167-183.

BEMIS, W.E. \& E.K. FINDEIS (1994). The sturgeons' plight. Nature 370, 602.

BEMIS, W.E., E.K. FINDEIS \& L. GRANDE (1997a). An overview of Acipenseriformes. Env. Biol. Fish. 48, 25-71.

BEMIS, W.E., V.J. BIRSTEIN \& J.R. WALDMAN (1997b). Sturgeon biodiversity and conservation: an introduction. Env. Biol. Fish. 48, 13-14.

BIELAWSKI, J.P., K. NOACK \& D.E. PUMO (1995). Reproducible amplification of RAPD markers from vertebrate DNA. BioTechniques 18, 856-860.

BirSteIN, V.J. \& R. DeSAlle (1998). Molecular phylogeny of Acipenserinae. Mol. Phylogen. Evol. 9, 141-155.

BIRSTEIN, V.J. \& V.P. VASILIEV (1987). Tetraploid-octoploid relationships and karyological evolution in the order Acipenseriformes (Pisces). Karyotypes nucleoli and nucleolus-organizer regions in four acipenserid species. Genetica 72, 3-12.

BIRSTEIN, V.J. \& W.E. BEMIS (1997). How many species are there within the genus Acipenser? Env. Biol. Fish. 48, 157-163.

BIRSTEIN, V.J. (1993). Sturgeons and paddlefishes: threatened fishes in the need of conservation. Cons. Biol. 7, 773-787.

Birstein, V.J., A.I. PoletaeV \& B.F. Goncharov (1993). The DNA content in Eurasian sturgeon species determined by flow cytometry. Cytometry 14, 377-383.

BIRSTEIN, V.J., J. BETTS \& R. DESALlE (1998a). Molecular identification of Acipenser sturio specimens: a warning note for recovery plans. Biol. Conserv. 84, 97-101.

Birstein, V.J., P. DOuKaKis, B. Sorkin \& R. DeSAlle (1998b). Population aggregation analysis of three caviar-producing species of sturgeons and implications for the species identification of black caviar. Cons. Biol. 12, 766-775. 
Birstein, V.J., R. HANNER \& R. DeSAlle (1997a). Phylogeny of the Acipenseriformes: cytogenetic and molecular approaches. Env. Biol. Fish. 48, 127-155.

BIRSTEIN, V.J., W.E. BEMIS \& J.R. WALDMAN (1997b). The threatened status of acipenseriform species: a summary. Env. Biol. Fish. 48, 427-435.

BLACKLIDGE, K.H. \& C.A. BIDWELl (1993). Three ploidy levels indicated by genome quantification in Acipenseriformes of North America. J. Hered. 84, 427-430.

BOLTON, E.T. \& B.J. MCCARTHY (1962): A general method for the isolation of RNA complementary to DNA. Proc. Natl. Acad. Sci.U.S.A. 48, 1390.

BONNER, T.I., D.J. BRENNER, B.R. NEUFELD \& R.J. BRITTEN (1973). Reduction in the rate of DNA reassociation by sequence divergence. J. Mol. Biol. 81, 123-135.

Borowsky, R.L., M. MCClelland, R. CHENG \& J. Welsh (1995). Arbitrarily primed DNA fingerprinting for phylogenetic reconstruction in Vertebrates: the Xiphophorus model. Mol. Biol. Evol. 12, 1022-1032.

BowEN, B.W. \& J.C. AVISE (1990). Genetic structure of Atlantic and Gulf of Mexico populations of sea bass manhaden and sturgeon: influence of zoogeographic factors and life-history patterns. Marine Biol. 107, 371-381.

BOYER, S.H. (1961). Alkaline phosphatase in human sera and placentae. Science 134, 1002-1004.

BRANDT, H. (1998). EWERTE: Ein Programm zur Berechnung der Erwartungswerte an di- und polyploiden, kodominanten Loci. Georg-August-Universität Göttingen, Institut für Tierzucht und Haustiergenetik, Göttingen.

BRown, J.R., A.T. BECKENBACH \& M.J. SMITH (1992a). Influence of pleistocene glaciations and human intervention upon mitochondrial DNA diversity in white sturgeon (Acipenser transmontanus) populations. Can. J. Fish. Aquat. Sci. 49, 358-367.

Brown, J.R., A.T. BECKENBACH \& M.J. SMITH (1992b). Mitochondrial DNA length variation and heteroplasmy in populations of white sturgeon (Acipenser transmontanus). Genetics 132, 221-228.

BRown, J.R., A.T. BECKENBACH \& M.J. SMITH (1993). Intraspecific DNA sequence variation of the mitochondrial control region of white sturgeon (Acipenser transmontanus). Mol. Biol. Evol. 10, 326-341.

Brown, J.R., K. Beckenbach, A.T. BeckenbaCh \& M.J. Smith (1996). Length variation heteroplasmy and sequence divergence in the mitochondrial DNA of four species of sturgeon (Acipenser). Genetics 142, 525-535. 
Brown, J.R., T.L. Gilbert, D.J. Kowbel, P.J. O'Hara, N.E. BuroKer, A.T. BECKENBACH \& M.J. SMITH (1989). Nucleotide sequence of the apocytochrome B gene in white sturgeon mitochondrial DNA. Nucl. Acids Res. 17, 4389.

Brown, W.M., E.M. Prager, A. WANG \& A.C. WILSON (1982). Mitochondrial DNA sequences of primates: Tempo and mode of evolution. J. Mol. Evol. 18, 225-239.

Buroker, N.E., J.R. Brown, P.J. O'HARA, A.T BeCKENBACH, W.K. ThOMAS \& M.J. SMITH (1990). Length heteroplasmy of sturgeon mitochondrial DNA: an illegitimate elongation model. Genetics 124, 157-163.

Campton, D.E., A.I. Garcia, B.W. Bowen \& F.A. Chapman (1995). Genetic evaluation of pallid shovelnose and alabama sturgeon (Scaphirhynchus albus S. platorynchus and S. suttkusi) based on the control region (D-loop) sequences of mitochondrial DNA. Endbericht für den U.S. Fish and Wildlife Service, Bismarck North Dakota, $35 \mathrm{~S}$.

Cantatore, P., M. Roberti, G. Pesole, A. Ludovico, F. Milella, M.N. GADALETA \& C. SACCONE (1994). Evolutionary analysis of cytochrome b sequences in some Perciformes: evidence for a slower rate of evolution than in mammals. J. Mol. Evol. 39, 589-597.

Carlson, D.M., M.K. Kettler, S.E. HSher \& G.S. WhitT (1982). Low genetic variability in paddlefish populations. Copeia $3,721-725$.

Chen, I.-C., F.A. Chapman, C.I. Wei \& S.F. O'KeEFE (1996). Preliminary studies on SDS-PAGE and isoelectric focusing identification of sturgeon sources of caviar. $J$. Food Sci. 61, 533-359.

CHERFAS, J. (1989). Science gives ivory a sense of identity. Science 246, 1120-1121.

Choudhury, A. \& T.A. DICK (1998). The historical biogeography of sturgeons (Osteichthyes: Acipenseridae): a synthesis of phylogenetics, palaeontology and palaeogeography. J. Biogeogr. 25, 623-640.

Clark, A.G. \& C.M.S. LANIGAN (1993). Prospects for estimating nucleotide divergence with RAPDs. Mol. Biol. Evol. 10, 1096-1111.

ClarK, J.M. (1988). Novel non-templated nucleotide addition reactions catalyzed by procaryotic and eucaryotic DNA polymerases. Nucl. Acids. Res. 16, 9677-9686.

COHEN, A. (1997). Sturgeon poaching and black market caviar: a case study. Env. Biol. Fish. 48, 423-426. 
Collura, R.V., M.R. AuerbaCH \& C.B. STEWART (1996). A quick, direct method that can differentiate expressed mitochondrial genes from their nuclear pseudogenes. Curr. Biol. 6, 1337-1339.

COMINCINI, S., M. LANFREDI, R. Rossi \& F. FONTANA (1998). Use of RAPD markers to determine the genetic relationships among sturgeons (Acipenseridae Pisces). Fish. Sci. 64, 35-38.

DAVIS, J.I. \& K.C. NIXON (1992). Populations, genetic variation, and the determination of phylogenetic species. System. Biol. 41, 421-435.

DEBuS, L. (1995). Zur Systematik der Störe. Fischer und Teichwirt 8, 281-285.

DESALLE, R. \& V.J. BIRSTEIN (1996). PCR identification of black caviar. Nature 381, 197-198.

DINGERKUS, G. \& W.M. HOWELL (1976). Karyotypic analysis and evidence of tetraploidy in the North American paddlefish Polyodon spathula. Science 194, 842-844.

DOBROWOLSKI, M.P. \& P.A. O'BRIEN (1993). Use of RAPD-PCR to isolate a species specific DNA probe for Phytophtore cinnamomi. FEMS Microbiol. Lett. 113, 4347.

DON, R.H., P.T. COX, B.J. WAinwright, K. BAKER \& J.S. MATTICK (1991): 'Touchdown' PCR to circumvent spurious priming during gene amplification. Nucl. Acids Res. 19(14), 4008.

DORAN, J.L., X.P. WERI \& K.L. ROY (1987). Analysis of a human gene cluster coding for tRNA(GAAPhe) and tRNA(UUULys). Gene 56, 231-243.

DOROSHOV, S.I. \& F.P. BINKOWSKI (1985). Epilogue: a perspective on sturgeon culture. Env. Biol. Fish. 14, 147-151.

EgGleston-Stott, M.L., A. Delvalle, S. Dileanis, A. Wictum \& A.T. Bowling (1997). A single base transversion in the flanking region of an equine microsatellite locus affects amplification of one allele. Anim. Genet. 28, 438-440.

Fani, R., G. Damiani, C. Di Serio, E. Gallori, A. Grifoni \& M. Bazzicalupo (1993). Use of random amplified polymorphic DNA (RAPD) for generating specific DNA probes for microorganisms. Mol. Ecol. 2, 243-250.

FAO (1996). FAO aquaculture production statistics 1985-1994, Roma.

FELSENSTEIN, J. (1985). Confidence limits on phylogenies: an approach using the bootstrap. Evolution 39, 783-791 (1985) 
FERGusOn, M.M. \& G.A. DUCKWORTH (1997). The status and distribution of lake sturgeon Acipenser fulvescens in the Canadian provinces of Manitoba Ontario and Quebec: a genetic perspective. Env. Biol. Fish. 48, 299-309.

Ferguson, M.M., L. Bernatchez, M. Gatt, B.R. KonkLe, S. LeE, M.L. MalotT \& R.S. MCKINLEY (1993). Distribution of mitochondrial DNA variation in lake sturgeon (Acipenser fulvescens) from the Moose River basin Ontario Canada. J. Fish Biol. 43A, 91-101.

FERRIS, S.D. \& G.S. WHITT (1978). Phylogeny of tetraploid catastomod fishes based on the loss of duplicate gene expression. Syst. Zool. 27, 189-206.

FIEDLER, K. (1991). System des Gradus Pisces. In: Lehrbuch der speziellen Zoologie (A. Kaestner, Begr.) Bd. II - Teil 2: Fische (Strack D., Hrsg.), Gustav Fischer Verlag Jena, 212-402.

FitzSimmons, N.N., C. MoRitZ \& S.S. MoORE (1995). Conservation and dynamics of microsatellite loci over 300 million years of marine turtle evolution. Mol. Biol. Evol. 12, 432-440.

FONTANA, F. (1994). Chromosomal nuclear organizer regions in four sturgeon species as markers of karyotype evolution in Acipenseriformes (Pisces). Genome 37, 888-892.

FontanA, F. (1997). Chromosomes of the Acipenseriformes. http://dns.unife.it:/ geneweb/sturgeon.html.

Fontana, F., J. Tagliavini, L. Congiu, M. Lanfredi, M. Chicca, C. Laurente \& R. ROSSI (1998a). Karyotypic characterization of the great sturgeon Huso huso by multiple staining techniques and flourescent in situ hybridization. Marine Biol. 132, 495-501.

FontANA, F., M. LANFREDI, M. CHICCA, V. AIELlo \& R. RosSI (1998b). Localization of the repetitive telomeric sequence (TTAGGG) $)_{\mathrm{n}}$ in four sturgeon species. Chromosome Res. 6, 303-306.

Fontana, F., M. LANFredi, R. Rossi, P. BROnZI \& G. ARLATI (1996). Karyotypic characterization of Acipenser gueldenstaedti with $\mathrm{C}-\mathrm{AgNO}_{3}$ and flourescence banding techniques. Ital. J. Zool. 63, 113-118.

GAHNE, B. (1963). Genetic variation of phosphatase in cattle serum. Nature 199, 305306.

GAHNE, B., K. JUNEJA \& J. GROLMUS (1977). Horizontal polyacrylamide gradient gel electrophoresis for the simultaneous phynotyping of transferrin, post-transferrin, 
albumin and post-albumin in the blood plasma of cattle. Anim. Blood Grps. Biochem. Genet. 8, 127-137.

Garrido-Ramos, M.A., M.C. Soriguer, R. DE la Herrán, M. JAMILENA, C. RUIZ Rejón, A. DOMEZAin, J.A. HERnANDO \& M. RuIZ REJón (1997). Morphometric and genetic analysis as proof of the existence of two sturgeon species in the Guadalquivir river. Marine Biol. 129, 33-39.

GENETIC ANALYSES INC. (1994). Genetic studies of Scaphirhynchus ssp. Bericht der Genetic Analyses Inc., Smithville, Texas an das Omaha District U.S. Army Corps of Engineers Omaha NE; dem U.S. Fish and Wildlife Service, Bismarck, North Dakota und dem Mobile District U.S. Army Corps of Engineers, Mobile, AL. Smithville TX, $41 \mathrm{~S}$.

GILBERT, T.L., J.R. Brown, P.J. O'HARA, N.E. BuroKer, A.T. BeCKENBACH \& M.J. SMITH (1988). Sequence of tRNA ${ }^{T h r}$ and tRNA ${ }^{\text {Pro }}$ from white sturgeon (Acipenser transmontanus) mitochondria. Nucl. Acids Res. 16, 11825.

GomolkA, M., J. Hundrieser, P. NÜRnBerg, L. RoEwer, J.T. EPPLEN \& C. EPPlen (1994). Selected di- and tetranucleotide microsatellites from chromosomes 7, 12, 14, and $\mathrm{Y}$ in various Eurasian populations. Hum. Genet. 93, 592-596.

GÖTZ, K.U. \& G. THALLER (1998). Assignment of individuals to populations using microsatellites. J. Anim. Breed. Genet. 115, 53-61.

GRANDE, L. \& W.E. BEMIS (1991). Osteology and phylogenetic relationships of fossil and recent paddlefishes (Polyodontidae) with comments on the interrelationships of Acipenseriformes. J. Vertebr. Paleo. 11 (Suppl. 1), 1-121.

GUÉNETTE, S., R. FORTIN \& E. RASSART (1993). Mitochondrial DNA variation in lake sturgeon (Acipenser fulvescens) from the St. Lawrence river and James Bay drainage basins in Quebec Canada. Can. J. Fish. Aquat. Sci. 50, 659-664.

HJUL, P. (1996a). French farms are to market fish of kings. Seafood Internat. 5, 60-61.

HJUL, P. (1996b). French farms now ready with the fish of kings. Fish Farm. Internat. 23 (6) $32-33$.

HoCHLEITHNER, M. (1996). Störe - Verbreitung Lebensweise Aquakultur (M. Hochleithner, Hrsg.). Österreichischer Agrarverlag Klosterneuburg 202 S.

HoLCík, J. (1989). General introduction to fishes - Acipenseriformes. In: The freshwater fishes of Europe (J. Holcík, Hrsg.), Vol. 1/II. AULA-Verlag GmbH, Wiesbaden, $148-443$. 
Holcík, J., R. KINZELBACH, L.I. SOKOLOV \& V.P. VASIL'EV (1989). Acipenser sturio Linnaeus 1758. In: The freshwater fishes of Europe (Holcik J. Hrsg.) Vol. 1/II AULAVerlag GmbH Wiesbaden 367-394.

Houston, J.J. (1987). Status of the lake sturgeon Acipenser fulvescens in Canada. Canad. Field-Nat. 101, 171-185.

HU, G. (1993). DNA polymerase-catalyzed addition of nontemplated extra nucleotides to the 3' end of a DNA fragment. DNA Cell Biol. 12, 763-770.

IRWIN, D.M., T.D. KOCHER \& A.C. WILSON (1991). Evolution of the cytochrome b gene of mammals. J. Mol. Evol. 32, 128-144.

ISHIBASHI, Y., S. ABE \& M.C. YosHIDA (1995). DNA fingerprinting of animal genomes by CA-repeat primed polymerase chain reaction. Jpn. J. Genet. 70, 75-78.

JeNnECKENS, I., J.-N. MeYER, H. WEDEKIND \& G. HÖRSTGEN-SCHWARK (1998). Possible differentiation of sturgeon species (Acipenseridae) by various gene markers. Anim. Genet. 29(Suppl. 1) 22.

KedROVA, O.S., N.S. VladyChENSKAYA \& A.S. ANTONOV (1980). Divergence of unique and repetitious sequences in fish genomes. Mol. Biol. 14, 787-797.

Keim, P., A. Kalif, J. Schupp, K. Hill, S.E. Travis, K. Richmond, D.M. AdAiR, M. HUGH-JONES, C.R. KUSKE \& P. JACKSON (1997). Molecular evolution and diversity in Bacillus anthracis as detected by amplified fragment length polymorphism markers. J. Bacteriol. 179, 818-824.

Keyvanfar, A., D. Rochu \& J.M. Fine (1988). Comparative study of sturgeon oocyte soluble proteins by isoelectric focusing. Comp. Biochem. Physiol. B 90, 393-396.

Khanda, D.K., M. Tuna, M. Tal, A. NeJidat \& A. Golan-Golshirsh (1997). Variability in the pattern of random amplified polymorphic DNA. Electrophoresis 18, 2852-2856.

Kido, Y., M. Aono, T. Yamaki, K.I. Matsumoto, S. Murata, M. Saneyoshi \& N. OKADA (1991). Shaping and reshaping of salmonid genomes by amplification of tRNA-derived retroposons during evolution. Proc. Natl. Acad. Sci. U.S.A. 88, 2326-2330.

KIRCHBERG, G. \& G.G. WENDT (1970). Auftrennung von AK (EC 2.7.4.3) und ADA (EC 3.5.4.4) in einem Stärkeblock. Humangenetik 8, 361-363.

KIRPICNIKOV, V.S. (1987). Genetische Grundlagen der Fischzüchtung (W. Steffens, Hrsg.). VEB Deutscher Landwirtschaftsverlag, Berlin. 
Kloster, G., B. LARSEN \& P.B. NiELSEN (1970). Carbonic anhydrase polymorphism in cattle and swine. Acta vet. scand. 11, 318-321.

Kumar, S., K. TAMura \& M. Nei (1993). MEGA: Molecular Evolutionary Genetics Analysis, V. 1.0.2. The Pennsylvania State University, University Park, PA 16802, U.S.A..

KUZ'MIN, E.V. (1994). Comparative analysis of the fractional composition of sacroplasmic muscle proteins of different representatives of sturgeons (Acipenseridae). J. Ichthyol. 34, 111-124.

KUZ'MIN, E.V. (1996). Blood serum albumin system in Acipenseriformes during the river period of life. Vopr. Ikhtiol. 36, 101-108.

LE, H.L.V., G. LECOINTRE \& R. PERASSO (1993). A 28S rRNA based phylogeny of the gnathostomes: first steps in the analysis of conflict and congruence with morphological based cladograms. Mol. Phylogen. Evol. 2, 31-51.

LEIPOLDT, M. (1983). Towards an understanding of the molecular mechanisms regulating gene expression during diploidization in phylogenetically polyploid lower vertebrates. Hum. Genet. 65,11-18.

LISCUM, M. \& P. OELLER (1995). AFLP: not only for fingerprinting, but for positional cloning. http://carnegiedpb.stanford.edu/methods/aflp.html.

LIU, Z., A. NiCHOLS, P. LI \& R.A. DUNHAM (1998). Inheritance and usefulness of AFLP markers in channel catfish (Ictalurus punctatus), blue catfish (I. furcatus) and theit F1, F2, and backcross hybrids. Mol. Gen. Genet. 258, 260-268.

LOGAN, S.H., W.E. JOHNSTON \& S.I. DOROSHOV (1995). Economics joint production of sturgeon (Acipenser transmontanus Richardson) and roe for caviar. Aquaculture 130, 299-316.

LuDWIG, A. \& F. KIRSCHBAUM (1998). Comparison of mitochondrial DNA sequences between the European and Adriatic sturgeon. J. Fish Biol. 52, 1289-1291.

MARSHALL, H.D. \& A.J. BAKER (1997). Structural conservation and variation in the mitochondrial control region of fringilline finches (Fringilla spp.) and the greenfinch (Carduelis chloris). Mol. Biol. Evol. 14, 173-184.

MARSHALL, H.D. \& A.J. BAKER (1998). Rates and patterns of mitochondrial DNA sequence evolution in fringilline finches (Fringilla spp.) and the greenfinch (Carduelis chloris). Mol. Biol. Evol. 15, 638-646. 
MARTIN, A.P. \& S.R. PALumbi (1993). Body size, metabolic rate, generation time and the molecular clock. Proc. Natl. Acad. Sci. U.S.A. 90, 4087-4091.

Martin, A.P., NAYlor, G.J. \& S.R. PAlumbi (1992). Rates of mitochondrial DNA evolution in sharks are slow compared with mammals. Nature 357, 153-155.

MAtsou, M., Y. ABE, Y. SARUTA \& N. OKADA (1995). Mullusk genes encoding lysine tRNA (UUU) contain introns. Gene 165, 249-253.

MAY, B., C.C. KRUEGER \& H.L. KINCAID (1997). Genetic variation at microsatellite loci in sturgeon: Primer sequence homology in Acipenser and Scaphirhynchus. Can. J. Fish. Aquat. Sci. 54, 1542-1547.

MAYDEN, R.L. \& B.R. KUHAJDA (1996). Systematics taxonomy and conservation status of the endagered Alabama sturgeon Scaphirhynchus suttkusi Williams and Clemmer (Actinopterygii, Acipenseridae). Copeia 2, 241-273.

MCDOWALL, R.M. (1993). A recent marine ancestry for diadromous fishes? Sometimes yes but mostly no! Env. Biol. Fish. 37, 329-335.

Melo, A.S., L.P. DE AlmediA, A.L. COlOMBO \& M.R. BrioneS (1998). Evolutionary distances and identification of Candida species in clinical isolates by randomly amplified polymorphic DNA (RAPD). Mycopathologia 142, 57-66.

MEYER, A. (1993). Evolution of mitochondrial DNA in fishes. In: The biochemistry and molecular biology of fishes (Hochachka, P.W. \& T.P. Mommsen, Hrsg.), Vol. 2, Elsevier, Amsterdam. 1-38.

MeYer, A., T.D. Kocher, P. BasasibWaki \& A.C. Wilson (1990). Monophyletic origin of Victoria cichlid fishes suggested by mitochondrial DNA sequences. Nature 347, 550-553.

Mikhailova, N.A., I.B. Lobov, O.I. PodgORNAYA \& V.J. BirSTEIN (1995). Restriction analysis of the nuclear DNA of three species of Acipenser. Sturg. Quart. 3, 8-9.

MirAClE, A.L. \& D.E. CAMPTON (1995). Tandem repeat sequence variation and length heteroplasmy in the mitochondrial DNA D-loop of the threatened Gulf of Mexico sturgeon Acipenser oxyrhynchus desotoi. J. Hered. 86, 22-27.

Möller, E.M., G. Bahnweg, H. SAndermann, \& H.H. GeIGER (1992): A simple and efficient protocol for the isolation of high molecular weight DNA from filamentous fungi, fruit bodies, and infected plant tissues. Nucl. Acids Res. 20, 6115-6116. 
Monna, L., A. Miyao, T. Inoue, S. Fukuoka, M. Yamazaki, H.S. Zhong, T. SASAKI \& Y. MINOBE (1994). Determination of RAPD markers in rice and their conversion into sequence tagged sites (STSs) and STS-specific primers. DNA Res. 1, 139-148.

MoOre, S.S., L.L. SARgeAnt, T.J. King, J.S. MAtTick, M. GeORGES \& D.J.S. HeTZEL (1991). The conservation of dinucleotide microsatellites among mammalian genomes allows the use of heterologous primer pairs in closely related species. Genomics $\mathbf{1 0}$, 654-660.

Murata, S., N. TAKasaki, M. Saitoh \& N. OKADA (1993). Determination of the phylogenetic relationships among Pacific salmonids by using short interspersed elements (SINEs) as temporal landmarks of evolution. Proc. Natl. Acad. Sci. U.S.A. 90, 6995-6999.

Murray, V., C. Mbnchawin \& P.R. England (1993). The determination of the sequences present in the shadow bands of a dinucleotide repeat PCR. Nucl. Acids Res. 21, 2395-2398.

Negroni, G. (1999). Caviar set to boom - stock scarcity sees price rocket. Fish Farm. Internat. 26, 20.

NEI, M. \& W.H. LI (1979). Mathematical model for studying genetic variation in terms of restriction endonucleases. Proc. Natl. Acad. Sci. U.S.A. 76, 5269- 5273.

Nei, M., F. TAJima \& Y. TATENo (1983). Accuracy of estimated phylogenetic trees from molecular data. J. Mol. Evol. 19, 153-170.

NGuyen, T.M., T.P. MOMMSEN, S.M. MiMs \& J.M. ConLON (1994). Characterization of insulins and proglucagon-derived peptides from a phylogenetically ancient fish, the paddlefish (Polyodon spathula). Biochem. J. 300, 339-345.

NIKOLJUKIN, N.I. (1966). Some questions of cytogenetics, hybridization and systematics of the Acipenseridae. Genetika 5, 25-27.

NikONOROV, S.I. G.D. RyABOVA, I.G. KuTERginA \& M.V. Ofitserov (1986). Electrophoretic analysis of genetic variability of the starred sturgeon Acipenser stellatus. Dokl. Biol. Sci. 284, 570-572.

NOACK, K., R. ZARDOYA \& A. MEYER (1996). The complete mitochondrial sequence of the bichir (Polypterus ornatipinnis), a basal ray-finned fish: ancient establishment of the consensus vertebrate gene order. Genetics 144: 1165-1180. 
NunN, G.B. \& J CRACRAFT (1996). Phylogenetic relationships among the major lineages of the birds-of-paradise (Paradisaeidae) using mitochondrial DNA gene sequences. Mol. Phylogenet. Evol. 5, 445-459.

O’BRIEN, S.J. \& E. MAYR (1991). Bureaucratic mischief: recognizing endagered species and subspecies. Science 251, 1187-1188.

Ohno, S., J. Muramoto, C. Stenius, L. Christian, W.A. Kittrell \& N.B. AtKin (1969). Microchromosomes in holocephalian chondrostean and holostean fishes. Chromosoma 26, 35-40.

OHSHIMA, K., R. KOISHI, M. MATSUO \& N. OKADA (1993). Several short interspersed repetititve elements (SINEs) in distant species may have originated from a common ancestral retrovirus: Characterization of a squid SINE and a possible mechanism for generation of tRNA-derived retroposons. Proc. Natl. Acad. Sci.U.S.A. 90: 62606264.

OKADA, N. (1991). SINEs. Curr. Opin. Genet. Dev. 1, 498-504.

OLIVIER, M., M.A. MEEHL \& G. LUST (1999). Random amplified polymorphic DNA (RAPD) sequences as markers for canine genetic studies. J. Hered. 90, 78-82.

Ong, T.-L., J. Stabile, I. Wirgin \& J.R. WALdman (1996). Genetic divergence between Acipenser oxyrinchus oxyrinchus and A. o. desotoi as assessed by mitochondrial DNA sequencing analysis. Copeia 2, 464-469.

ORITA, M., Y. SUZUKI, T. SEKIYA \& K. HAYASHI (1989): Rapid and sensitive detection of point mutations and DNA polymorphisms using the polymerase chain reaction. Genomics 5, 874-879.

OTA, T. (1993). DISPAN: Genetic distance and phylogenetic analysis. The Pennsylvania State University. University Park, PA 16802, U.S.A..

PATTERSON, C. (1982). Morphology and interrelationships of primitive actinopterygian fishes. Am. Zool. 22, 241-259.

Penner, G.A., A. Bush, R. Wise, W. Kim, L. Domier, K. Kasha, A. Laroche, G. SCOLES, S.J. MOLNAR \& G. FEDAK (1993). Reproducibility of random amplified polymorphic DNA (RAPD) analysis among laboratories. PCR Methods Appl. 2, 341-345.

PereZ, T., J. ALBORNOZ \& A. DOMINGUEZ (1998). An evaluation of RAPD fragment reproducibility and nature. Mol. Ecol. 7, 1347-1357. 
PHELPS, S.R. \& F.W. AllENDORF (1983). Genetic identity of pallid and shovelnose sturgeon (Scaphirhynchus albus and S. platorhynchus). Copeia 1983, 969-700.

PIROGOVSKII, M.I., L.I. SOKOLOV \& V.P. VASIL'EV (1989). Huso huso (Linnaeus 1758). In: The freshwater fishes of Europe (Holcík J. Hrsg.), Vol. 1/II. AULA-Verlag GmbH, Wiesbaden, 156-200.

Pyatskowit, J., H.C. KincAid, C.C. KRUEGER \& B. MAY (1997). Inheritance of microsatellite loci in lake sturgeon. Posterbeitrag zu dem 6th International Symposium on Genetics in Aquaculture. Stirling, Schottland, 24-28.06.1997.

REHBEIN, H. (1985). Caviare: proximate composition amino acid content and identification of fish species. Z. Lebensm. Unters. Forsch. 180, 457-462.

REHBEIN, H. (1997). Fischartbestimmung von Caviar durch Protein- und DNA-Analyse. Inf. Fischwirtsch. 44, 27-30.

REICHLE, G. \& H. BERGLER (1998). Störe in der Teichwirtschaft. Fischer und Teichwirt 4, 133-136.

REICHLE, G. (1997a). Der Stör (Reichle G. Hrsg.). Verlag Lassleben, Kallmünz, $80 \mathrm{~S}$.

REICHLE, G. (1997b). Die Störe vom Wöllershof. Fischer \& Teichwirt 12,506-507.

RICO, C., I. RICO \& G. HEWITT (1996). 470 million years of conservation of microsatellite loci among fish species. Proc. R. Soc. Lond. B 263, 549-557.

Rochard, E., G. Castelnaud \& M. Lepage (1990). Sturgeons (Pisces: Acipenseridae); threats and prospects. J. Fish Biol. 37A, 123-132.

RONYAI, A. \& L. VARADI (1995). The sturgeons. In: Production of aquatic animals (Nash C.E. \& A.J. Novotny, Hrsg.). Elsevier, New York, 95-108.

RuBAN, G.I. (1996). The Siberian sturgeon, Acipenser baerii, population status in the $\mathrm{Ob}$ river. Sturg. Quart. 4, 8-10.

RUBAN, G.I. (1997). Species structure contemporary distribution and status of the Siberian sturgeon, Acipenser baerii. Env. Biol. Fish. 48, 221-230.

RÜMMLER, F. \& M. PFEIFFER (1998). Aufzuchtversuche von Stören in verschiedenen Anlagetypen. Fischer und Teichwirt 6, 231-234.

RuSSO, C.M., N. TAKEZAKI \& M. NEI (1996). Efficiencies of different genes and different tree-building methods in recovering a known vertebrate phylogeny. Mol. Biol. Evol. 13, 525-536. 
SAiki, R.K., S. Scharf, F. FAlOONA, K.B. Mullis, G.T. Horn, H.A. EHRlich \& N. ARNHEIM (1985): Enzymatic amplification of $\beta$-globin genomic sequences and restriction site analysis for diagnosis of sickle cell anemia. Science 230, 1350-1354.

SAITOU, N. \& M. NeI (1987). The neighbour-joining method: A new method for reconstructing phylogenetic trees. Mol. Biol. Evol. 4, 406-425.

SAKAR, G., J. CASSADY, C.D. BotTema \& S.S. SOMMER (1990). Characterization of polymerase chain reaction amplification of specific alleles. Anal. Biochem. 186, 6468.

SAMBROOK, J., E.F. FRITSCH \& T. MANIATIS (1989): Molecular cloning: A laboratory manual. Cold Spring Harbor Laboratory Press, New York.

SCHLÖTtERER, C., B. AMOS \& D. TAUTZ (1991). Conservation of polymorphic simple sequence loci in cetacean species. Nature 354, 63-65.

SCHMID, K.J. \& D. TAUTZ (1997). A screen for fast evolving genes from Drosophila. Proc. Natl. Acad. Sci. U.S.A. 94, 9746-9750.

Sharma, P.C., B. Huttel, P. Winter, G. Kahl, R.C. Gardner \& K. Weising (1995). The potential of microsatellites for hybridization- and polymerase chain reaction-based DNA fingerprinting of chickpea (Cicer arietinum L.) and related species. Electrophoresis 16, 1755-1761.

SHAW, C.R. \& R. PRASAD (1970). Starch gel electrophoresis of enzymes - a compilation of recipes. Biochem. Genet. 4, 297-320.

ShubINA, T.N., A.A. PoPOVA \& V.P. VASIL'EV (1989). Acipenser stellatus Pallas 1771. In: The freshwater fishes of Europe (Holcík J. Hrsg.), Vol. 1/II. AULA-Verlag GmbH, Wiesbaden, 395-443.

SINGER, M.F. (1982). Highly repeated sequences in mammalian genomes. Int. Rev. Cytol. 76, 76-112.

SLYN'KO, V.I. (1976). Multiple molecular forms of malate dehydrogenase and lactate dehydrogenase in Russian sturgeon (Acipenser güldenstädti Br.) and geat sturgeon (Huso huso L.). Dokl. Biol. Sci. 228, 201-204.

SMITH, M.F. \& J.L. PATTON (1991). Variation in mitochondrial cytochrome b sequence in natural populations of South American akodontine rodents (Muridae: Sigmodontinae). Mol. Biol. Evol. 8, 85-103.

SNEATH, P.H.A. \& R.R. SOKAL (1973). Numerical Taxonomy. W.H. Freeman, San Francisco. 
SOKOLOV, L.I. \& L.S. BERDICHEVSKII (1989a). Acipenseridae Bonaparte 1831. In: The freshwater fishes of Europe (Holcík J. Hrsg.), Vol. 1/II. AULA-Verlag GmbH, Wiesbaden, 150-153.

SOKOLOV, L.I. \& L.S. BeRDICHEVSKII (1989b). Acipenseriformes Berg 1940. In: The freshwater fishes of Europe (Holcík J. Hrsg.), Vol. 1/II. AULA-Verlag GmbH, Wiesbaden ,148-149.

SOKOLOV, L.I. \& V.P. VASIL'EV (1989a). Acipenser baeri Brandt 1869. In: The freshwater fishes of Europe (Holcík J. Hrsg.), Vol. 1/II. AULA-Verlag GmbH, Wiesbaden, 263-284.

SOKOLOV, L.I. \& V.P. VASIL'EV (1989b). Acipenser nudiventris Lovetsky 1828. In: The freshwater fishes of Europe (Holcík J. Hrsg.), Vol. 1/II. AULA-Verlag GmbH, Wiesbaden, 206-226.

SOKOLOV, L.I. (1989). Acipenser Linnaeus 1758. In: The freshwater fishes of Europe (Holcík J., Hrsg.), Vol. 1/II. AULA-Verlag GmbH, Wiesbaden, 201-205.

SPENCER, N., D.A. HOPKINSON \& H. HARRIS (1964). Phosphoglucomutase polymorphism in man. Nature 204, 742-745.

Stabile, J., J.R. Waldman, F. Parauka \& I. Wirgin (1996). Stock structure and homing fidelity in Gulf of Mexico sturgeon (Acipenser oxyrinchus desotoi) based on restriction fragment length polymorphism and sequence analyses of mitochondrial DNA. Genetics 144, 767-775.

Stock, D.W., J.K. GiBbons \& G.S. WhitT (1991). Strengths and limitations of molecular sequence comparisons for inferring the phylogeny of the major groups of fishes. J. Fish Bio. 39A, 225-236.

STONEKING, M., B. MAY \& J.E. WRIGHT (1981). Loss of duplicate gene expression in Salmonids: Evidence for a null allele polymorphism at the duplicate aspartate aminotransferase loci in brook trout (Salvelinus fontinalis). Biochem. Genet. 19, 1063-1077.

SubBotKin, M.F. \& T.A. SUbBOtKINA (1998). Immunochemical analysis of antigens of serum albumins of Acipenser persicus. J. Ichthyol. 38, 527-533.

Takasaki, N., S. Murata, M. Saitoh, T. Kobayashi, L. Park \& N. Okada (1994). Species-specific amplification of tRNA-derived short interspersed repetitive elements (SINEs) by retroposition: A process of parasitization of entire genomes during the evolution of salmonids. Proc. Natl. Acad. Sci. U.S.A. 91, 10153-10157. 
TAKAsaki, N., T. YAmaki, M. HAMAda, L. PARK \& N. OKAdA (1997). The salmon SmaI family of short interspersed repetitive elements (SINEs): Interspecific and intraspecific variation of the insertion of SINEs in the genomes of chum and pink salmon. Genetics 146, 369-380.

TAKEZAKI, N. \& M. NEI (1996). Genetic distances and reconstruction of phylogenetic trees from microsatellite DNA. Genetics 144, 389-399.

TARIVERDiAN, G., H. RitTER \& G.G. WENDT (1970). Genetisch kontrollierte Varianten der NADH-Diaphorase. Humangenetik 11, 75-77.

TARIVERDiAN, G., H. RITTER \& J. SCHMITT (1971). Zur transspezifischen Variabilität der 6-Phosphogluconatdehydrogenase (E.C. 1.1.1.44) der Primaten. Humangenetik 11, 323-327.

Tilsala-Timisjarvi, A. \& T. Altossava (1998). Strain-specific identification of probiotic Lactobacillus rhamnosus with randomly amplified polymorphic DNAderived PCR primers. Appl. Environ. Microbiol. 64, 4816-4819.

TORTONESE, E. (1989). Acipenser naccarii Bonaparte 1836. In: The freshwater fishes of Europe (Holcík J. Hrsg.), Vol. 1/II. AULA-Verlag GmbH, Wiesbaden, 285-293.

VAN DE ZANDE, L. \& R. BIJLSMA (1995). Limitations of the RAPD technique in phylogeny reconstruction in Drosophila. J. Evol. Biol. 8, 645-656.

VAN EENENNAAM, A.L., J.D. MuRRAY \& J.F. MEDRANO (1998). Synaptonemal complex analysis in spermatocytes of white sturgeon Acipenser transmontanus Richardson (Pisces, Acipenseridae) a fish with a very high chromosome number. Genome 41, 51-61.

van Zeveren, A., L. Peelman, A. Van de Weghe \& Y Bouquet (1995). A genetic study of four Belgian pig populations by means of seven microsatellite loci. J. Anim. Breed. Genet. 112, 191-204.

VECSEI, P. (1997). Portraits of juvenile Acipenser gueldenstaedtii from the Black Sea stock. Env. Biol. Fish. 48, 436.

VlasenKO, A.D., A.V. PAVLOV \& V.P VASIL'EV (1989a). Acipenser persicus Borodin 1897. In: The freshwater fishes of Europe (Holcík J. Hrsg.), Vol. 1/II. AULA-Verlag GmbH, Wiesbaden, 345-366.

VlasenKo, A.D., A.V. PAVlov, L.I. SOKOlov \& V.P. VASIL'EV (1989b). Acipenser gueldenstaedti Brandt 1833. In: The freshwater fishes of Europe (Holcik J. Hrsg.), Vol. 1/II. AULA-Verlag GmbH, Wiesbaden, 294-344. 
Vos, P., R. Hogers, M. Bleeker, M. Reilans, T. Van De Lee, M. Hornes, A. FriJters, J. Pto, J. Peleman, M. KuiPer \& M. ZABeAu (1995): AFLP: A new technique for DNA fingerprinting. Nucl. Acids Res. 23(21), 4407-4414.

WADE, E.M. \& J.G. FADEL (1997). Optimization of caviar and meat production from white sturgeon (Acipenser transmontanus). Agricult. Syst. 54, 1-21.

Waldman, J.R., K. NOlan, J. HART \& I.I. Wirgin (1996). Genetic differentiation of three key anadromous fish populations of the Hudson river. Estuaries 19, 759-768.

WALSH, P.S., D.A. METZGER \& R. HiguCHI (1991): Chelex ${ }^{\circledR} 100$ as a medium for simple extraction of DNA for PCR-based typing from forensic material. BioTechniques 10(4), 506-513.

WALSH, P.S., H.A. ERLICH \& R. HIGUCHI (1992). Preferential PCR amplification of alleles: mechanisms and solutions. PCR Methods Appl. 1, 241-250.

WALSH, P.S., N.J. FILDES \& R. REYNOLDS (1996). Sequence analysis and characterization of stutter products at the tetranucleotide repeat locus vWA. Nucl. Acids Res. 24, 2807-2812.

WAYNE, R.K. (1992). On the use of morphologic and molecular genetic characters to inverstigate species status. Conserv. Biol. 6, 590-592.

WEIR, B.S. (1990). Methods for discrete population genetic data. In: Genetic data analysis. Sinauer Associates Inc., Sunderland, Massachusetts.

WELSH, J. \& M. MCCLELLAND (1990): Fingerprinting genomes using PCR with arbitrary primers. Nucl. Acids Res. 19, 303-306.

Williams, J.G.K., A.R. KubeliK, K.J. LivaK, J.A. RAFALSKI \& S.V. TingEY (1990): DNA polymorphisms amplified by arbitrary primers are useful as genetik markers. Nucl. Acids Res. 18, 6531-6535.

Willot, P., E. Rochard, G. Castelnaud, T. Rouault, R. Brun, M. Lepage \& P. ELIE (1997). Biological characteristics of European Atlantic sturgeon, Acipenser sturio, as the basis for a restoration program in France. Env. Biol. Fish 48, 359-370.

WinK, M. \& H. WeHRLE (1994). DNA-Isolierung. In: PCR im medizinischen und biologischen Labor - ein Handbuch für den Praktiker (Wink M. \& H. Wehrle, Hrsg.). GIT Verlag GmbH, Darmstadt, 16-20.

WiRgin, I., J.E. StABILE \& J.R. WALDMAN (1997). Molecular analysis in the conservation of sturgeons and paddlefish. Env. Biol. Fish. 48, 385-398. 
YU, X., T. ZHOU, K. L \& M. ZHOU (1987). On the karyosystematics of cyprinid fishes and a summary of fish chromosome studies in China. Genetica 72, 225-236.

Zholdasova, I. (1997). Sturgeons and the Aral Sea ecological catastrophe. Env. Biol. Fish. 48, 373-380.

ZIETKIEWICZ, E., A. RAFALSKI \& D. LABUDA (1994): Genome fingerprinting by simple sequence repeat (SSR)-anchored polymerase chain reaction. Genomics 20: 176-183. 


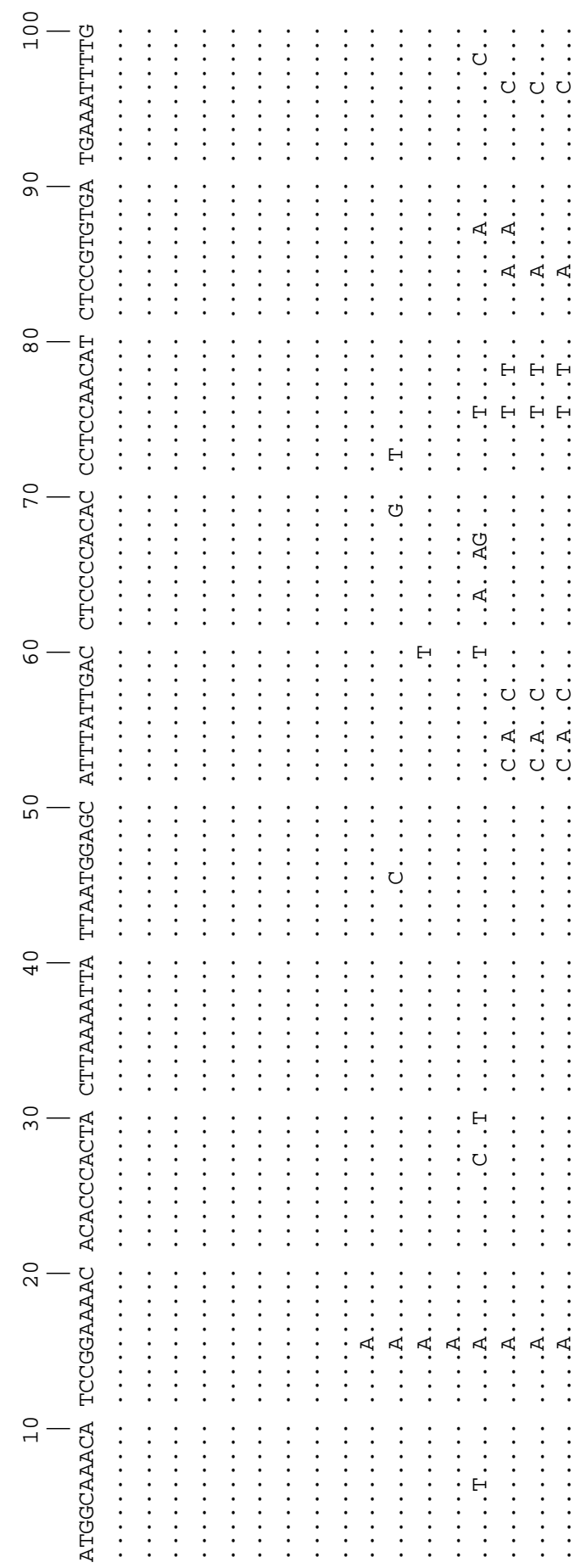

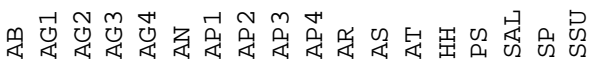

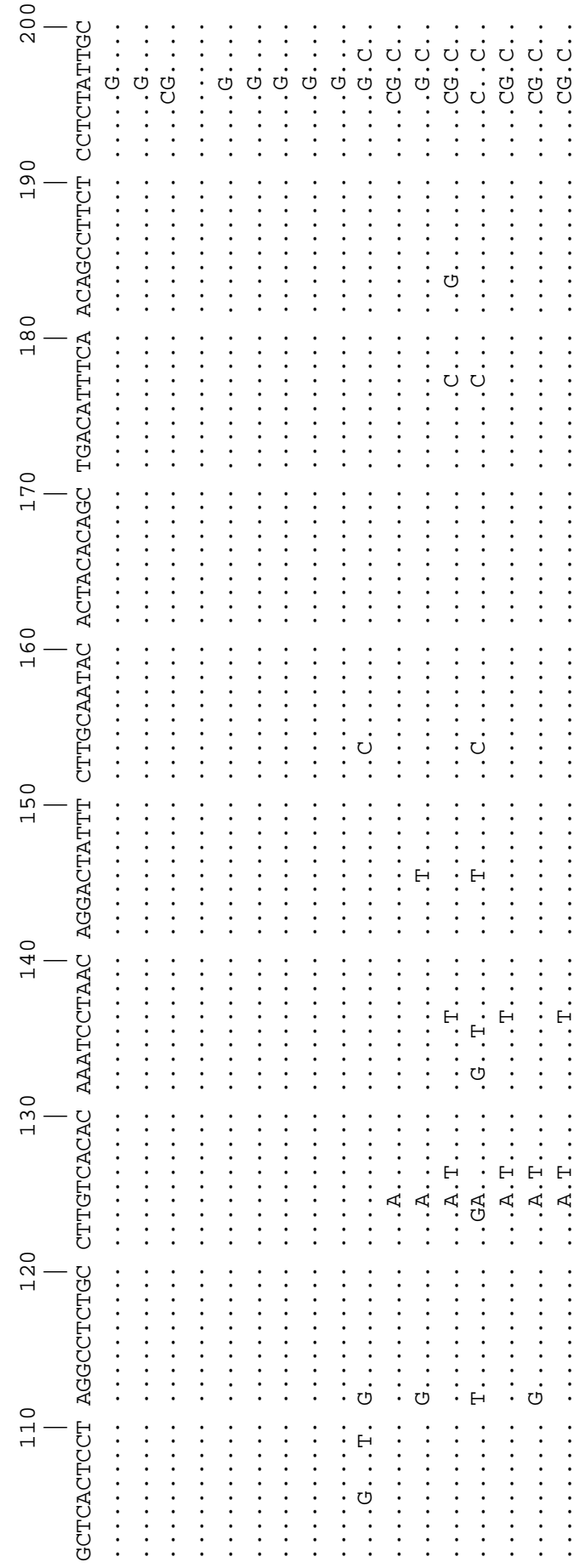

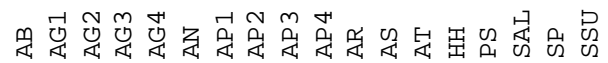




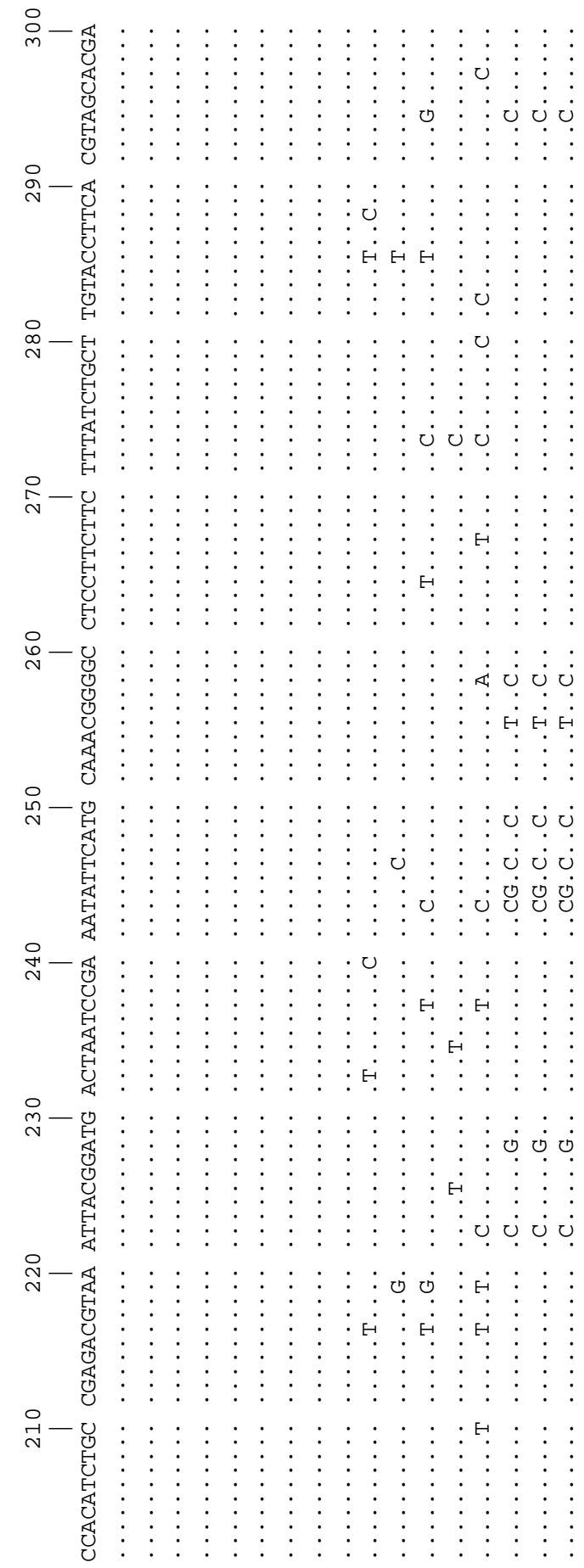

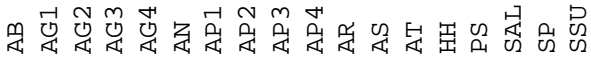

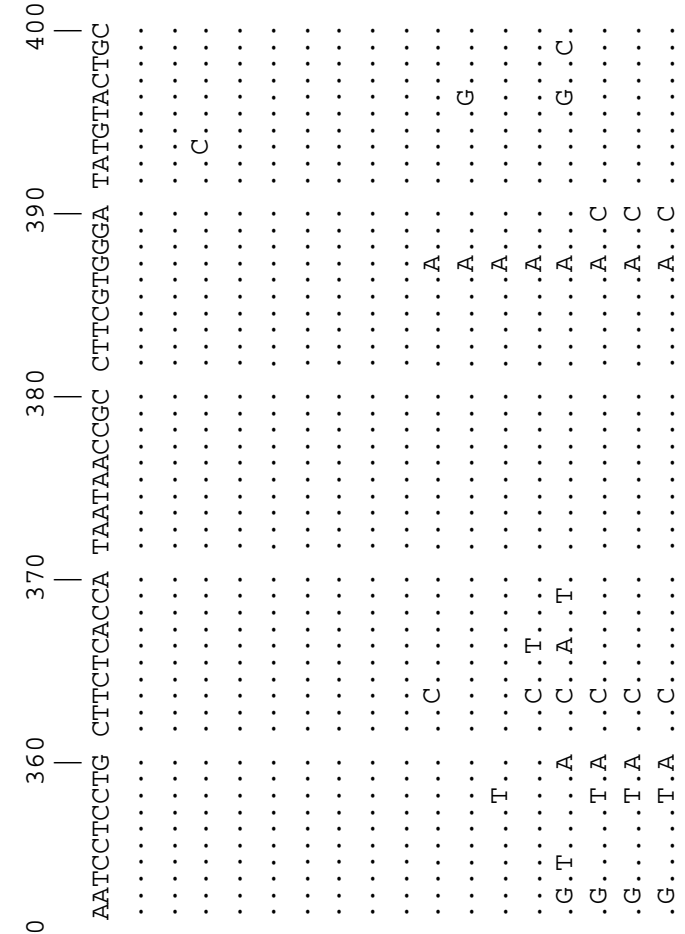

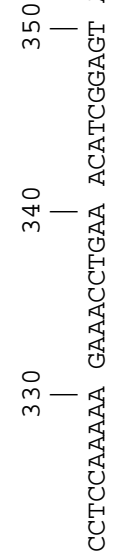

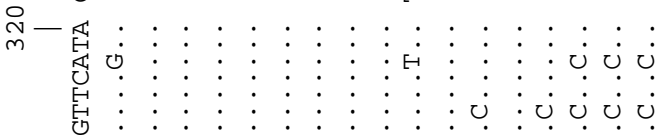
罗:

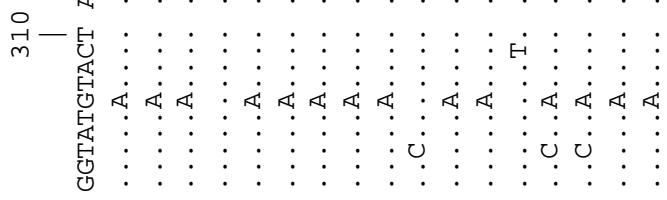

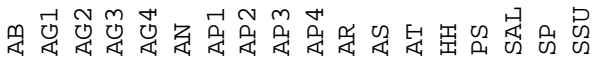




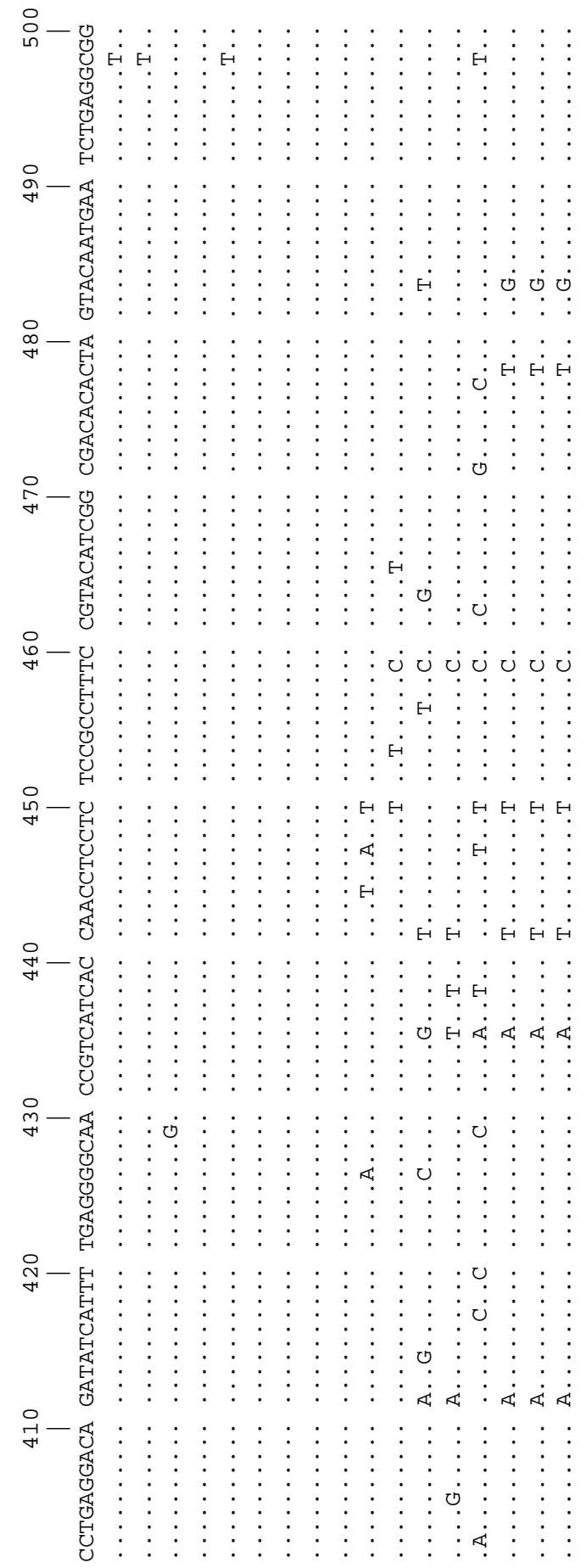

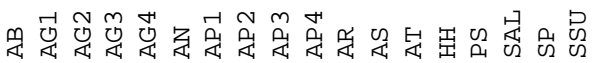

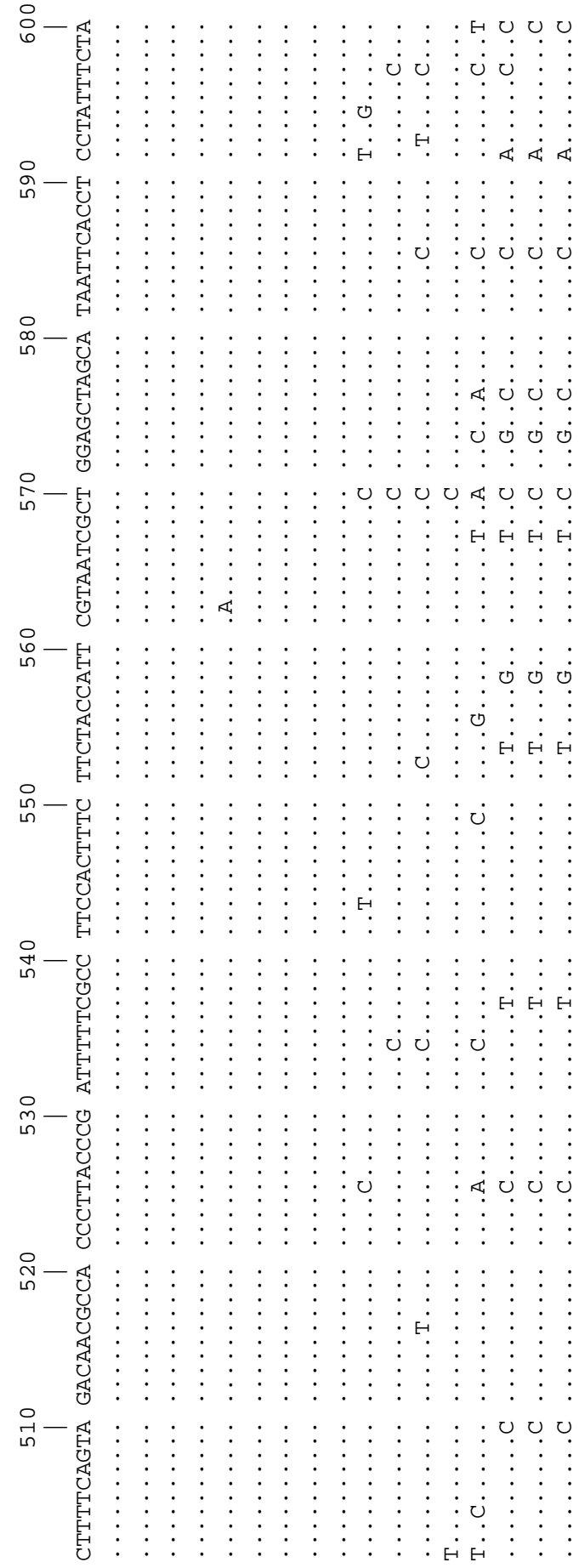

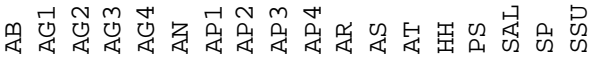




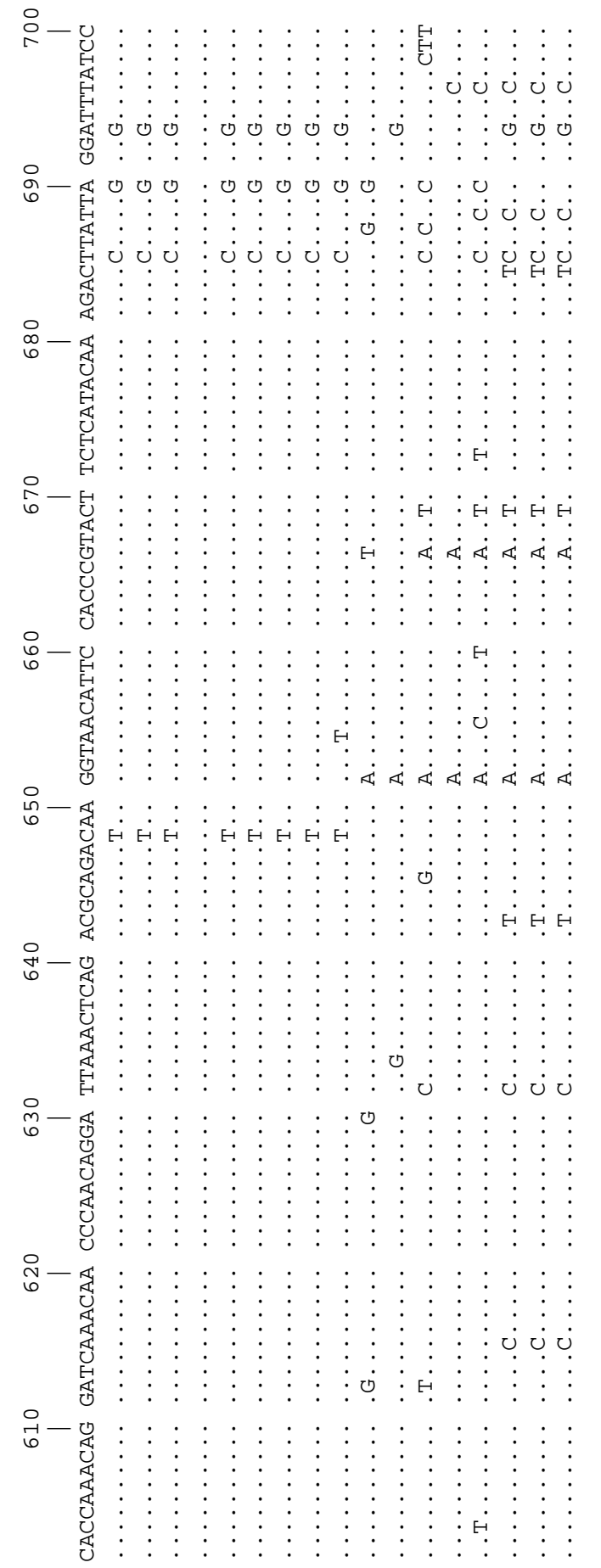

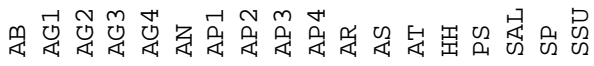

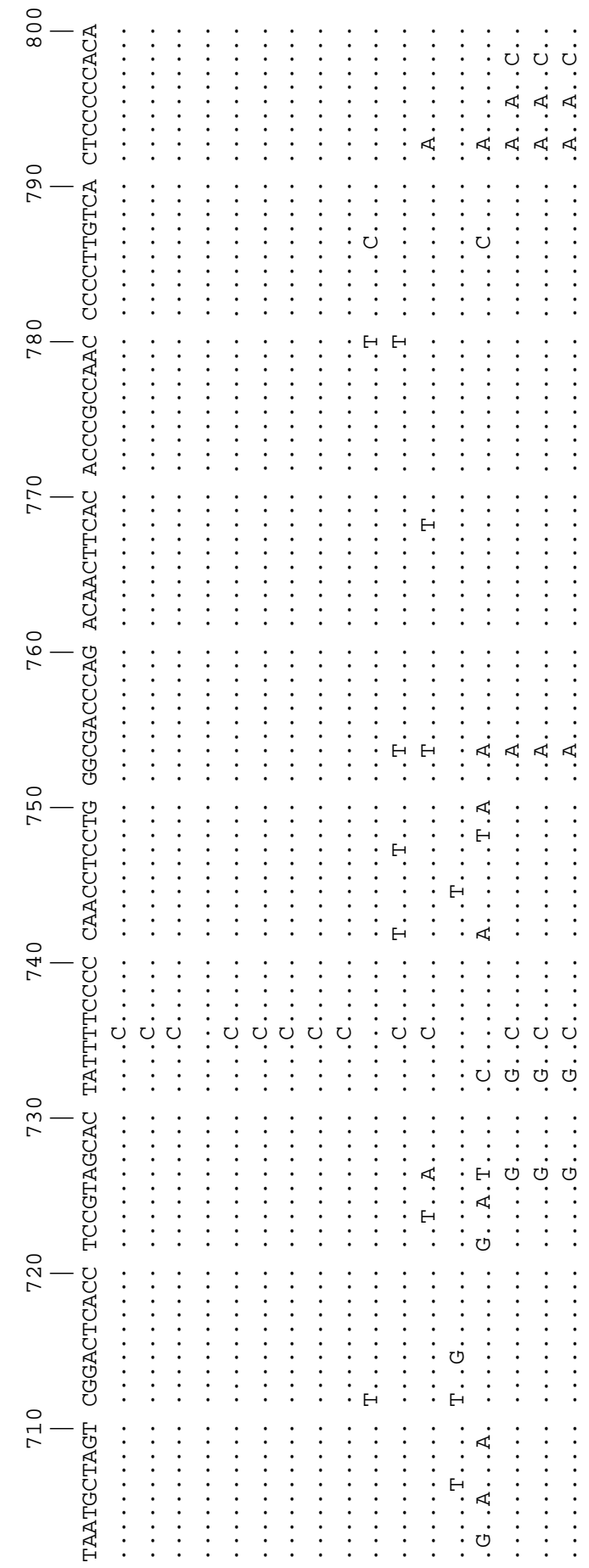

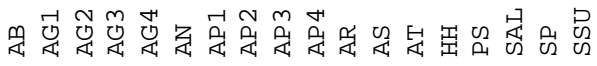




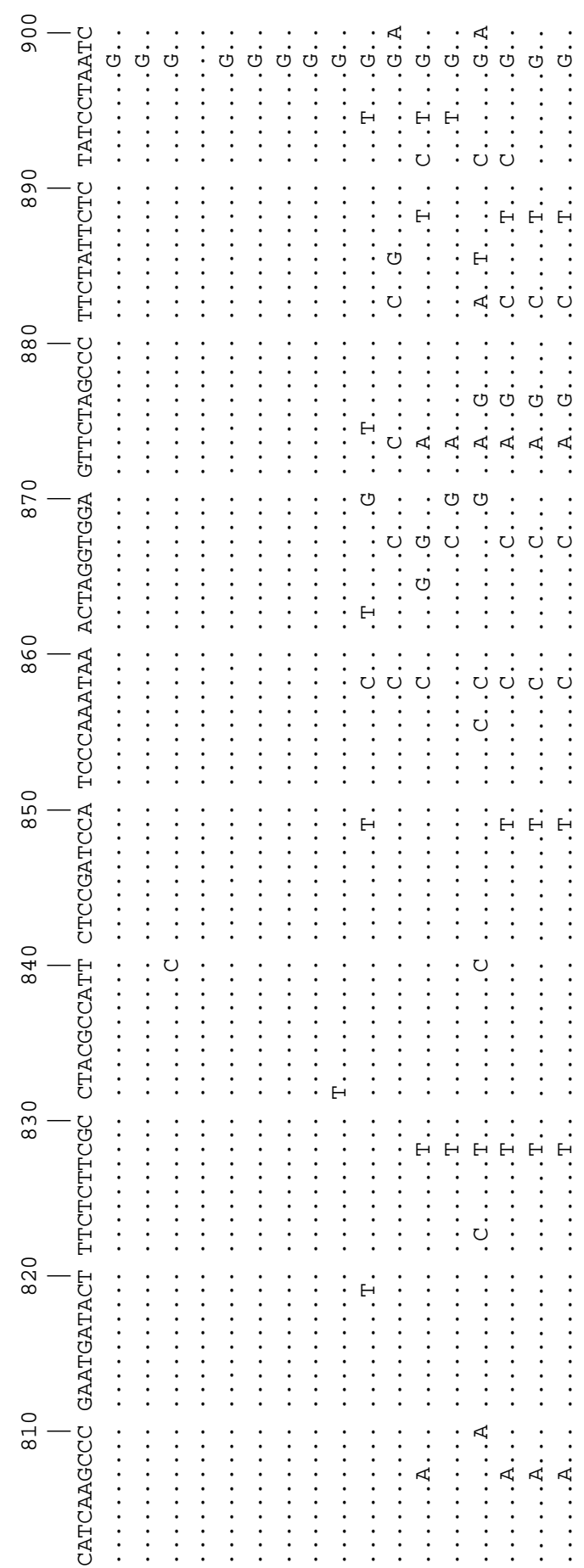

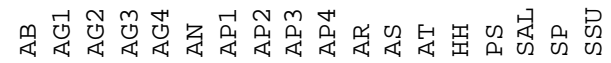

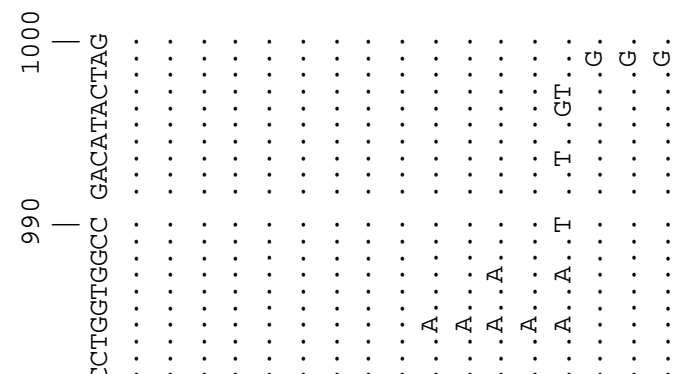

$\stackrel{\infty}{\infty}-$

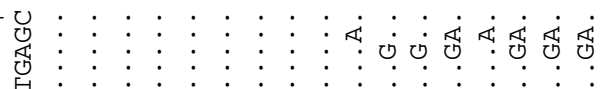

葛:

号-

0

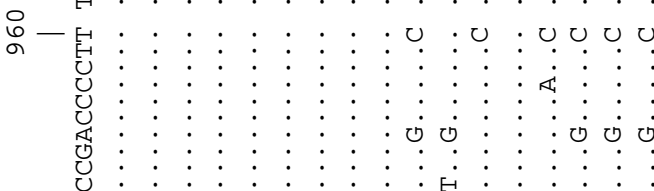

员一皆

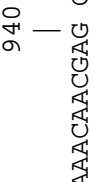

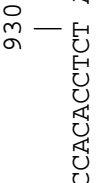

\%ิ-

U: : : : : : : : : :

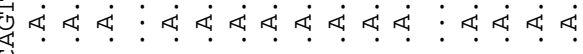

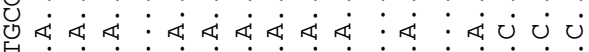
ने-0

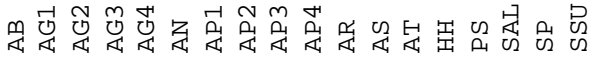




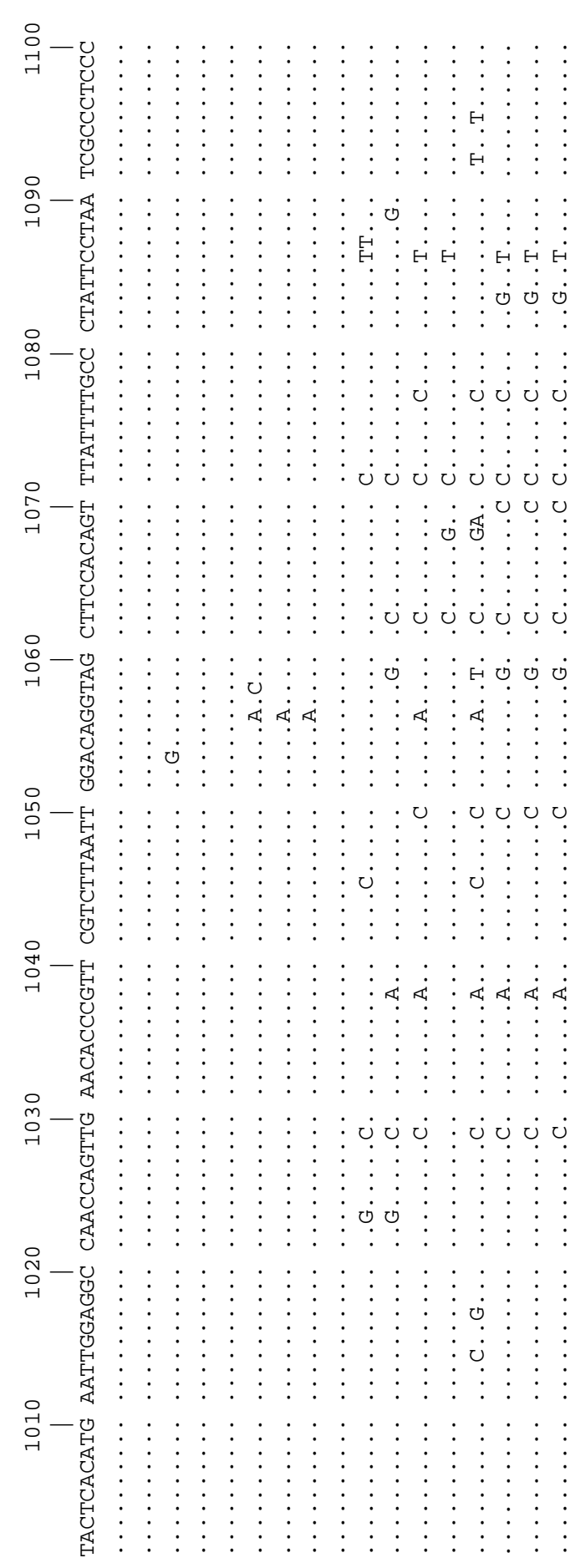

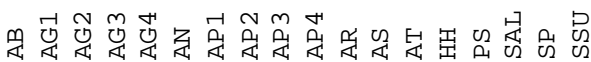
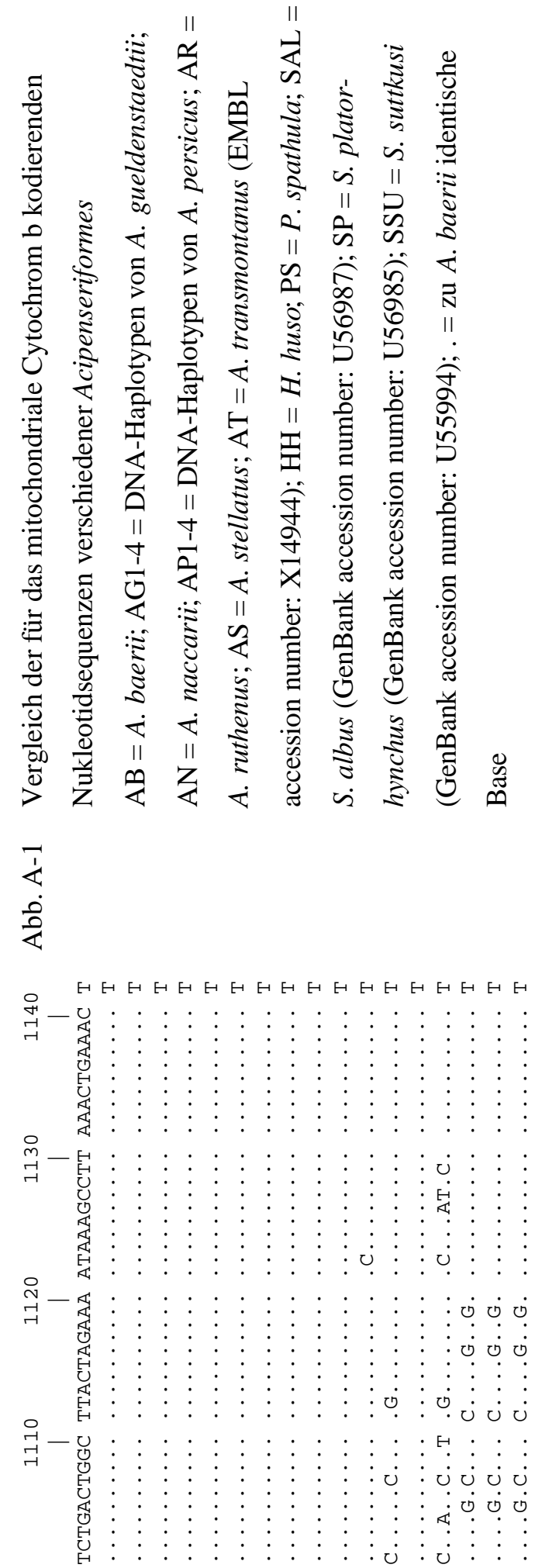

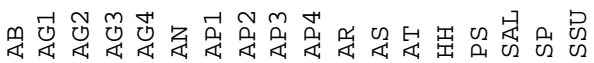




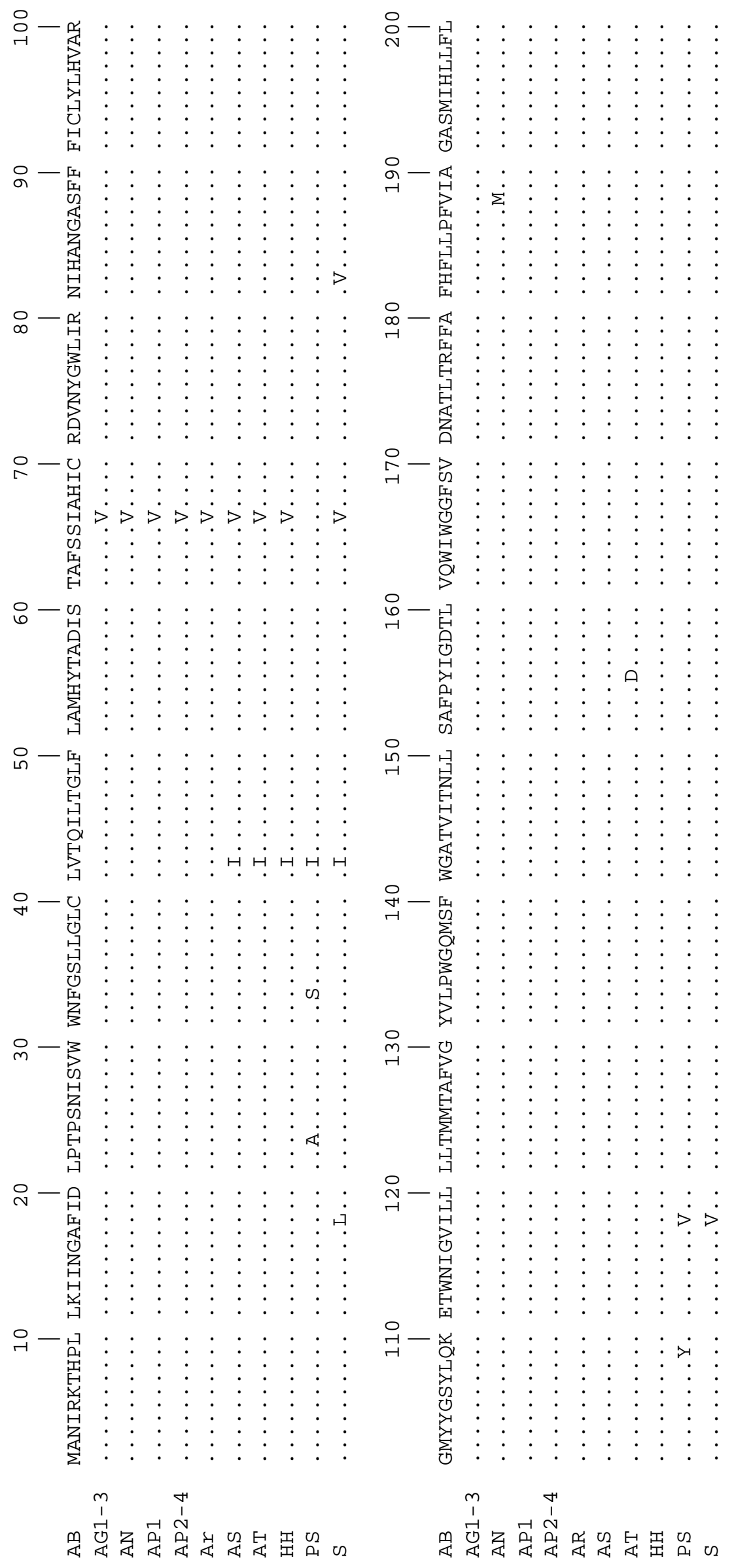




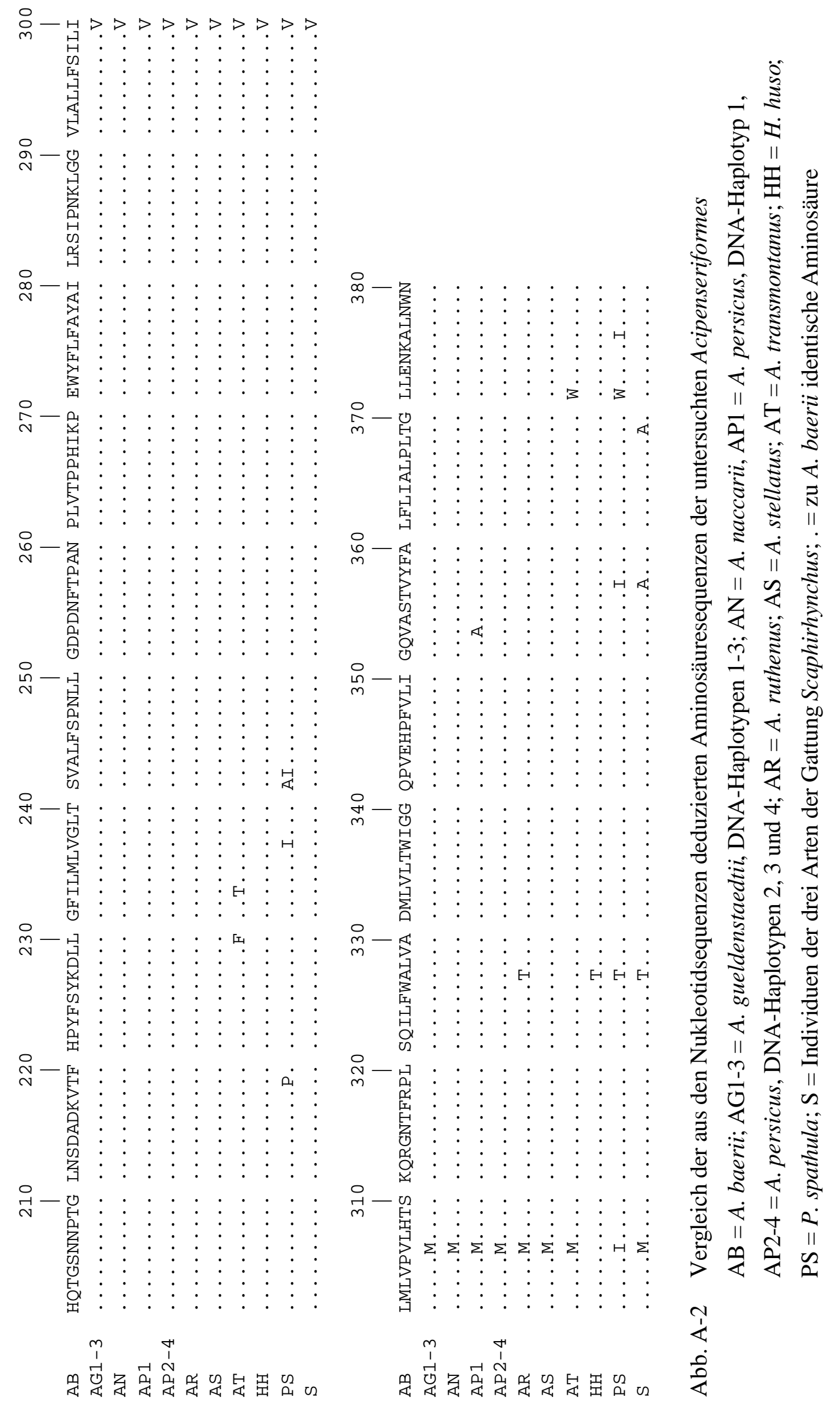





\section{Danksagung}

Mein herzlicher Dank gilt Frau Prof. Dr. G. Hörstgen-Schwark, Herrn Dr. J.-N. Meyer und Herrn Dr. H. Wedekind für die Überlassung des Themas und die jederzeit gewährte Unterstützung und Diskussionsbereitschaft während der Anfertigung dieser Arbeit.

Herrn Prof. Dr. Dr. B. Brenig danke ich für die Übernahme des Korreferates, für seine wertvollen Beiträge und für die großzügig zur Verfügung gestellten Materialien für die Durchführung des AFLPs.

Für die Beschaffung des Tiermaterials möchte ich mich bei Frau Prof. Dr. G. HörstgenSchwark, Herrn Dr. H. Wedekind, Herrn P. Ludewig, Herrn C. Müller und insbesonders Herrn Dr. J.-N. Meyer bedanken. Ferner gilt mein Dank Herrn Dr. L. Debus für die Zusendung von Probenmaterial aus dem Astrachaner Gebiet sowie den Zucht- und Haltungsbetrieben, die mir die Blutentnahme aus ihren wertvollen Störbeständen gestatteten.

Mein besonderer Dank gilt Frau Claudia „Cesare“ Kaltwasser, die durch ihre engagierte und tatkräftige Hilfe im molekularbiologischen Labor sowie ihre seelische und moralische Unterstützung während der gesamten Dauer einen wesentlichen Anteil zum Gelingen der Arbeit beigetragen hat. Des Weiteren danke ich ihr für das stets freundschaftliche Verhältnis.

Besonders bedanken möchte ich mich weiterhin bei Frau Rosemarie „Rosi“ Clemens nicht nur für ihre sehr große Hilfe bei den biochemischen Untersuchungen und Auswertungen der Ergebnisse, sondern auch für die freundschaftliche Atmosphäre.

Ebenfalls danken möchte ich Frau Kolle für ihre tatkräftige Unterstützung im Elektrophoreselabor.

Meinem Freund Bernd „Bepho“ Kriegesmann und Frau Dr. Ina Pfeiffer möchte ich für ihre stetige Diskussionsbereitschaft und für die Hilfe bei der Durchführung des AFLP danken.

Herrn PD Dr. H. Brandt danke ich für die Programmierung der Software EWERTE. 
Bei dem „Störgenetiker“ Dr. A. Ludwig möchte ich mich ebenfalls für seine Kooperationsbereitschaft und seine wertvollen Beiträge herzlich bedanken.

Herrn Dr. M.C. „Mardos“ Voß danke ich für seine Freundschaft und seine Hilfe bei der Summary.

Bei Herrn Dr. J. Rameckers möchte ich mich für die Unterstützung zu jeder Tages- und Nachtzeit rund um den ABI Prism 310 bedanken.

Allen Mitdoktoranden, speziell Annette „Pepita“ Bünger, Nina „wildes Hainchen“ Wildenhayn und Eckart „Giovanni“ Grünhagen, danke ich für ein fröhliches und abwechslungsreiches Doktorandenleben.

Den Angestellten und Mitarbeitern aus der „Baracke“ des Instituts für Tierzucht und Haustiergenetik danke ich für das ausgesprochen nette Arbeitsklima.

Der Deutschen Forschungsgemeinschaft danke ich für die finanzielle Unterstïtzung meiner Arbeit.

Ich möchte besonders und herzlich meiner lieben Freundin Antje und meiner Familie danken, die mich in jeglicher Hinsicht immer unterstützt und gefördert haben. 


\section{Lebenslauf}

\section{Persönliche Daten}

Name:

Geburtsdatum, -ort:

Familienstand:

Eltern:

\section{Schulbildung}

Aug. 1975 - Jun. 1979:

Aug. 1979 - Mai 1988:

\section{Praktikum}

Okt. 1988 - Okt. 1989: landwirtschaftliches Praktikum auf dem Betrieb H.-T. Wille, Beverungen

Abschluss: Praktikantenprüfung

\section{Studium}

Okt. 1989 - Dez. 1995: $\quad$ Studium der Agrarwissenschaften, Fachrichtung Tierproduktion, an der Georg-August-Universität Göttingen Abschluß: Diplom

\section{$\underline{\text { Promotion }}$}

März 1996 - Jul. 1999: Doktorand im Institut für Tierzucht und Haustiergenetik der Universität Göttingen 